\title{
Ammonia Absorption Technologies Development for Air Conditioning, Heat Pumping and Refrigeration
}

\author{
Final Report
}

June 2010

Prepared by:

Rocky Research

1598 Foothill Drive

Boulder City, NV 89005

for

U.S. Department of Energy

National Energy Technology Laboratory

P.O. Box 10940

Pittsburg, PA 15236

Cooperative Agreement DE-FC26-05NT42404 


\section{DISCLAIMER}

This report was prepared as an account of work sponsored by an agency of the United States Government. Neither the United States Government nor any agency thereof, nor any of their employees, makes any warranty, expressed or implied, or assumes any legal liability or responsibility for the accuracy, completeness, or usefulness of any information, apparatus, product, or process disclosed, or represents that its use would not infringe privately owned rights. Reference herein to any specific commercial product, process, or service by trade name, trademark, manufacturer, or otherwise does not necessarily constitute or imply its endorsement, recommendation, or favoring by the United States Government or any agency thereof. The views and opinions of authors expressed herein do not necessarily state or reflect those of the United States Government or any agency thereof.

\section{ACKNOWLEDGMENTS}

This material is based upon work supported by the U.S. Department of Energy, National Energy Technology Laboratory (NETL) under Award Number DE-FC26-05NT42404. Mr. Paul Giles, the NETL Project Officer provided oversight and guidance for the project, for with the authors are especially grateful. 


\section{AMMONIA ABSORPTION TECHNOLOGIES DEVELOPMENT FOR AIR CONDITIONING, HEAT PUMPING AND REFRIGERATION}

\section{FINAL REPORT}

\section{Table of Contents}

Task 1. Project Management

Task 2. Equipment Cost Reduction and Robust Operation Issues (Aqua-Ammonia Absorption Technology

Task 3. Seasonal Energy Efficiency Improvement (Aqua-Ammonia Absorption Technology

Task 4. Heat Pump Refinement (Aqua-Ammonia Absorption Technology)

Task 5. DFM Packaged Prototype Fabrication/Field Testing (Complex Compound Absorption Technology)

Task 6. Cost Effective Absorber Heat Transfer Surfaces (Aqua-Ammonia Absorption Technology)

Task 7. Generator Firetube Life Testing (Aqua-Ammonia Absorption Technology)

Task 8. Controls Optimization (Aqua-Ammonia Absorption Technology)

105

Task 9. Dual Temperature Use of Absorption System Design (Aqua-Ammonia Absorption Technology)

Task 10. OEM Manufacturing (Aqua-Ammonia Absorption Technology)

Task 11. Application to Reciprocating Engines (Aqua-Ammonia Absorption Technology)

Task 12. Sorber Manufacturing Process Development and Reliability Testing (Complex Compound Absorption Technology) 
Task 13. Evaluation of Energy Storage Systems Including Heat Activated Thermal Energy Storage Systems (Aqua-Ammonia Absorption and Complex Compound Absorption Technology)

References 


\section{Task 1. Project Management}

The project management task under the project was completed and related to the development of a plan for the implementation of the project and is thus not relevant to final report. For this reason it is not included.

\section{Task 2. Equipment Cost Reduction and Robust Operation Issues (Aqua-Ammonia}

\section{Absorption Technology}

\section{$\underline{\text { Subtask 2.1 Generator Metrics }}$}

The generator metrics effort focused on the following efforts related to the critical dimensions and tolerances of the generator subcomponents:

1. The identification of critical dimensions for a high efficiency, manufacturable firetube and the identification of production tolerances required for this.

2. The development of a casting design and layout that allowed for the elimination of porosity concerns for reliable casting production and the specification of tolerances, draft angle and other issues relevant to this design..

3. The sizing of a generator GHX/adiabatic section interface fluid storage tank that would allow the proper volume of fluid in the generator for all relevant operating conditions.

4. Establishment of operational tolerances for the Generator Heat Exchanger (GHX).

5. The tolerance and dimensional specifications for a generator adiabatic section fluid distributor.

6. Identification of flue parameters that could be useful in determining out-ofspecification generators when in production.

7. Corrosion testing to identify the applicability of a non-chromate based corrosion inhibitor that is environmentally and toxicologically superior to the corrosion inhibitor used by present manufacturers of aqua-ammonia chiller and to determine the applicable concentrations of these.

\section{Firetube}

Initial efforts in the metrics evaluation of the firetube task focused on the original corrugated fin firetube. However, as the information derived revealed that this design was not viable from a manufacturing standpoint due primarily to metrics issues, this design was changed to a more robust longitudinal fin firetube design. Finally as manufacturing problems with this design were realized, the design of a robust firetube 
with C-shaped fins was arrived at and critical tolerances and dimensions for this were arrived at.

\section{Corrugated Fin Firetube}

The original firetube design, which was provided to Rocky by a consultant, utilized a corrugated stainless steel material that was nickel brazed to the inside of the cylindrically shaped firetube shell. The design offered good heat transfer capability because of the large amount of effective surface area, and low pressure drop because of essentially laminar flow.

However, Rocky had observed some instances of separation of the extended surface from the firetube shell after long term testing of these generators in chillers that had been made under an earlier effort. Nevertheless, initially it was decided to proceed with this design to better understand the tolerances and other limitations in the manufacture of this type of firetube and to see if this effect could be eliminated.

Corrugated material for the firetubes was procured as well as nickel brazing material. Firetube material was purchased and sized for this application.

Attention then focused on the assembly procedures required for production of this type of firetube. One difficult aspect of assembling the fire-tube with the two layers of the nickel alloy required was securing the layers to the tube so that they would not shift when the corrugated fin was inserted. During the assembly process the nickel alloy is first spot welded in place to the ID of the tube. The corrugated fin is then secured to the inner mandrel with wire and then inserted into the tube to the desired location. Because of the tight fit necessary during brazing, the initial insertion of the tube lightly drags against the ID. This slight frictional force can sometimes cause the alloy to break free at the spot weld locations and then shift as a result. This problem was further enhanced when the alloy was doubled and contact between the inner alloy layer and the ID of the tube was obstructed by the outer layer of alloy. This problem was alleviated somewhat with a redesign of the electrode used in the spot welder. All of the commercially available electrodes utilize a spot type configuration that limits the strength of the joint. The newly designed electrode was configured using a line type configuration oriented in the direction of the shear frictional forces that were applied. Figure 1 shows this electrode. 


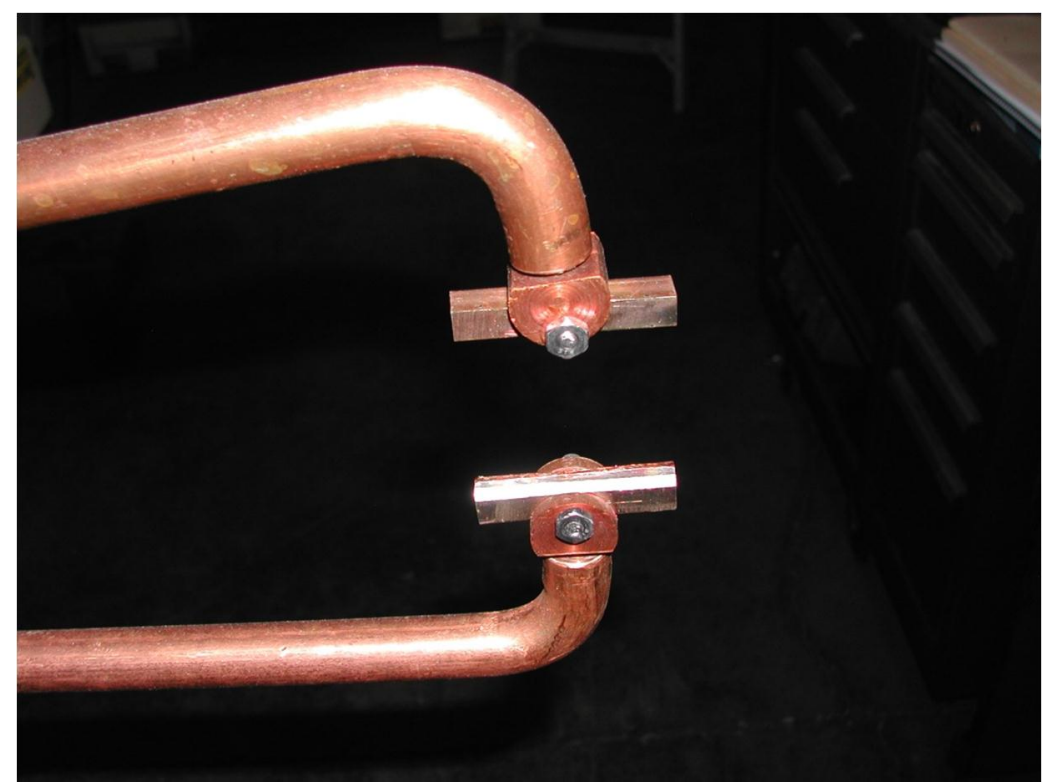

Figure 1. New Electrode Design

As a result the newly designed electrode held both layers of the alloy to the ID of the tube better than the original electrode held just one layer previously.

Two sample fire tubes were then built and sent out to be vacuum brazed. Both of the tubes were brazed in the horizontal position with the oven cycle previously used on prior samples. Figure 2 is a picture of one of the sample tubes prior to brazing.

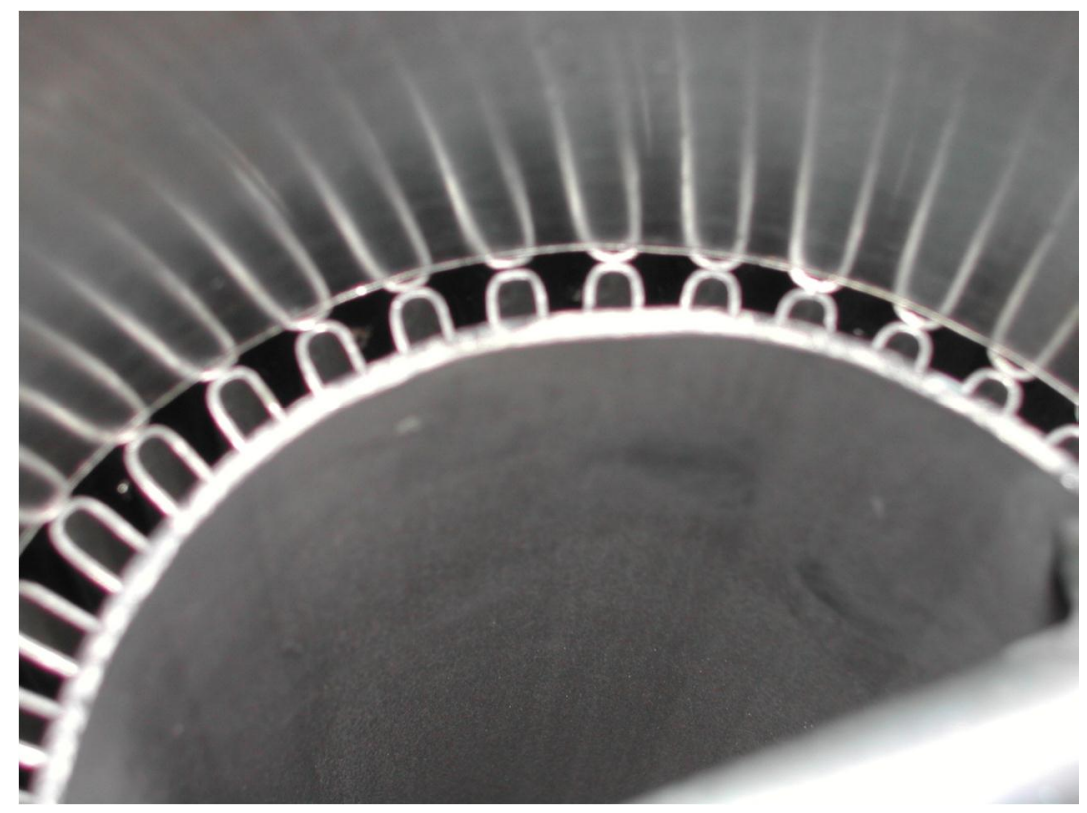

Figure 2. Firetube Core Prior to Brazing 
The sample tubes were received after brazing was complete. Both firetubes exhibited an issue in the seam where the two edges of the corrugated material meet. One of the samples was cross sectioned to inspect the braze quality down the length of the tube. After inspecting every one of the cross sections it was observed that the fillets between the corrugations and the ID of the tube were in fact more pronounced in these samples than in the samples with only one layer of the alloy. Figure 3 is a picture of one of the cross sections.

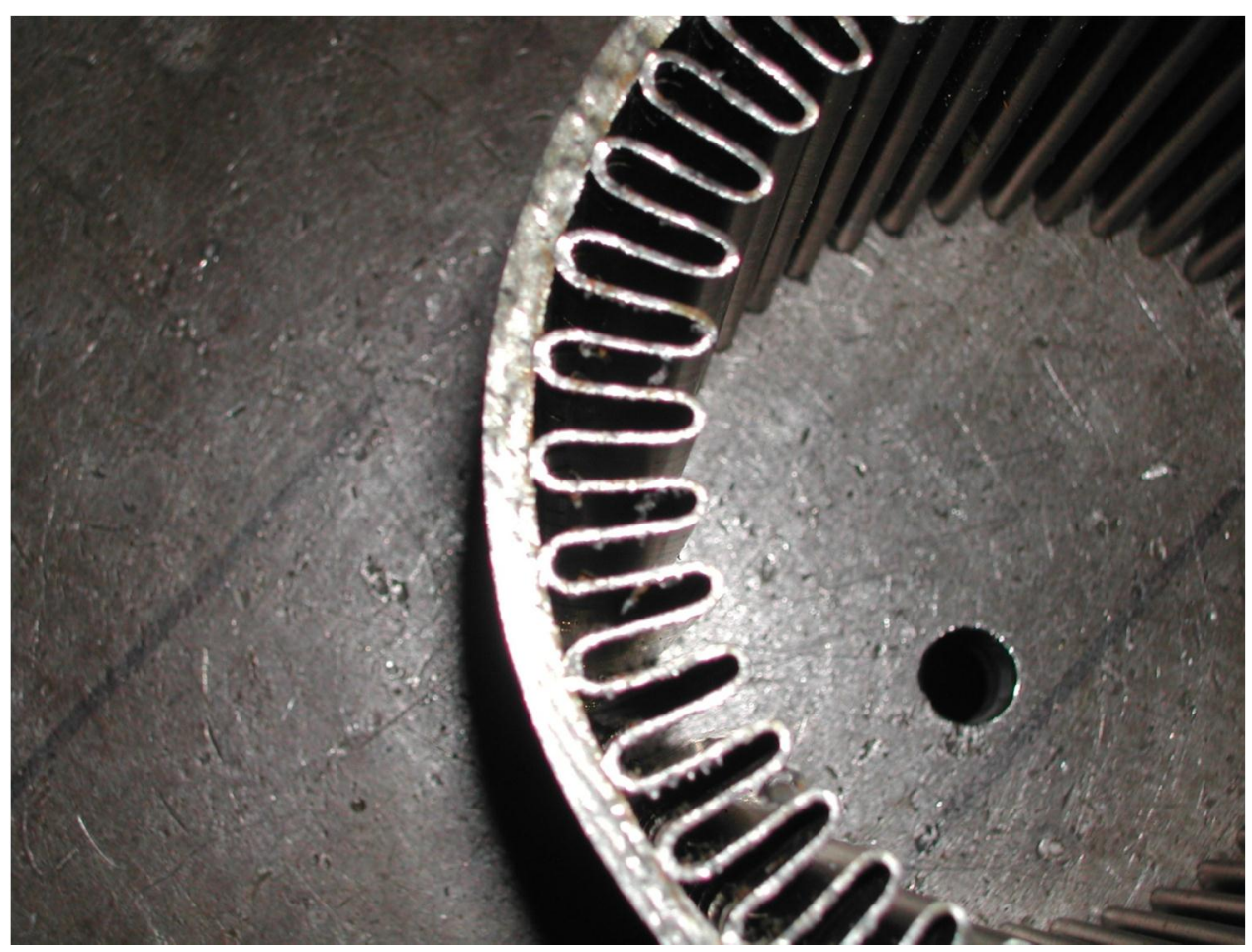

Figure 3. Firetube Cross Section Post Brazing

Another issue found was the inconsistency in the gap of the corrugated fin seam that is wrapped around the inner mandrel. There is a difference in the compression of each corrugation from part to part, and thus the seam varies accordingly. A test was performed that once the corrugated material was wrapped around the mandrel the seam was mechanically pulled together and then tack welded.

However, fixturing of the inner mandrel proved to be very difficult and not suitable for high volume manufacturing due partly to the ovalilty tolerance associated with the tubing. With evidence of a high possibility of failure and a difficulties in fixturing, it was decided to finally abandon this design for a more promising firetube design. 


\section{Full Length Welded Longitudinal Fin Firetube}

The alternative to the original generator firetube design proved to be a firetube with longitudinal fins. An early analytical design was done for fins that ran the entire length of the firetube, and such a firetube, shown in Figure 4 and Figure 5 was built.

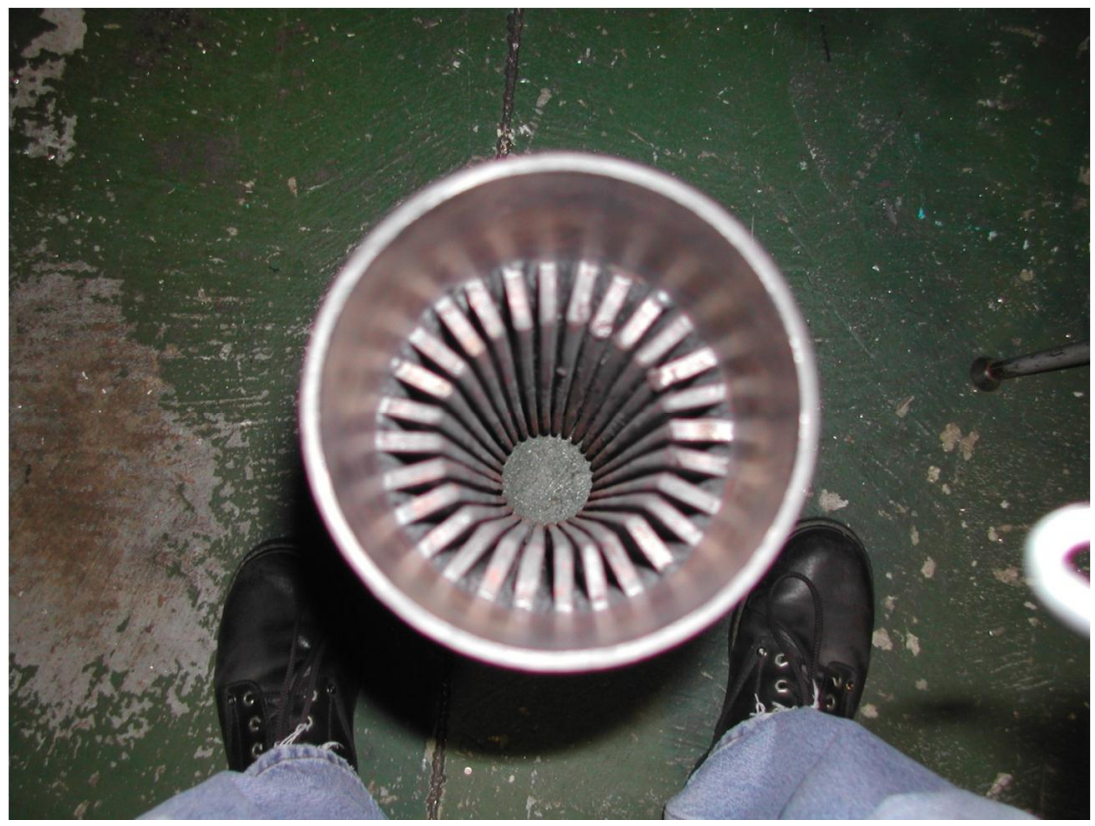

Figure 4. Longitudinal Fin Firetube

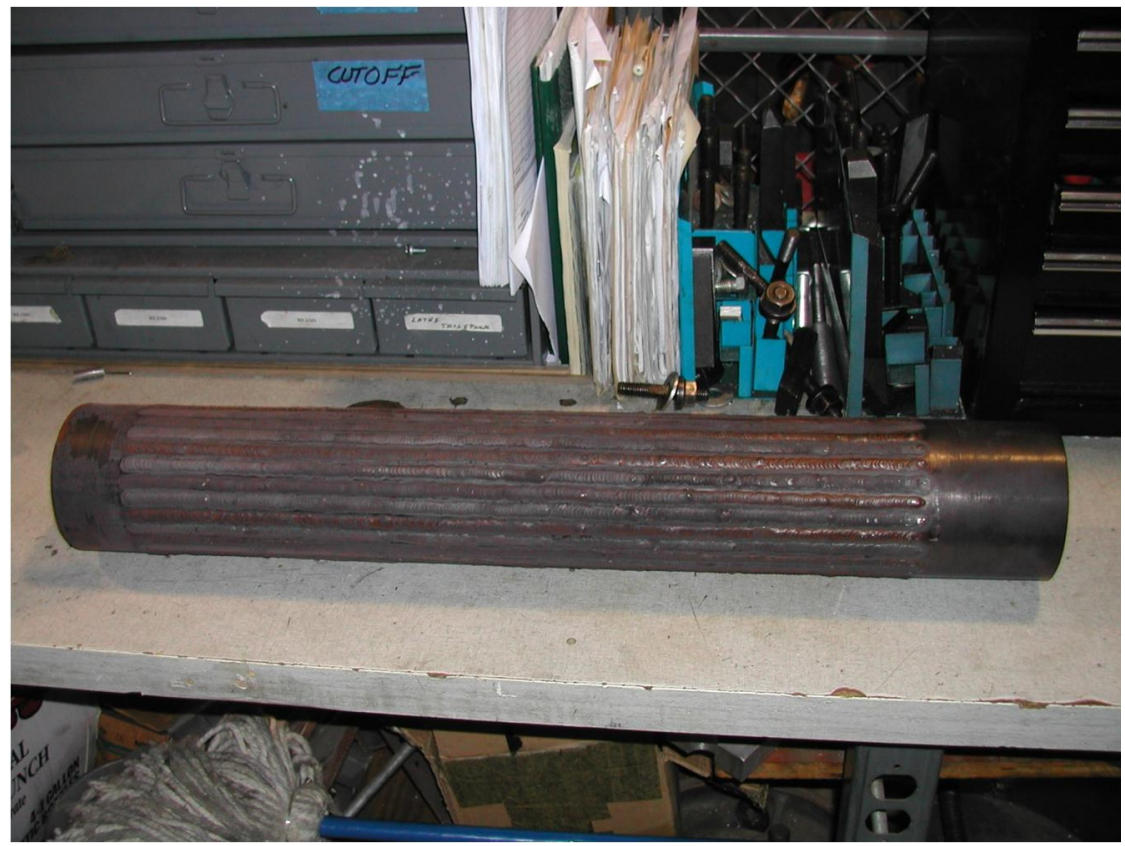

Figure 5. Outside View of Longitudinal Fin Firetube 
While this firetube was promising because it did not require extremely difficult fixturing, fabrication of this firetube was impractical because it required and excessive amount of time for slotting and then welding. With long welds, the possibility of leakage was very high, and therefore this design was abandoned after performance testing.

A generator with this firetube was tested in a chiller test bed. Figure 6 is an example results from one of these tests. The figure shows a flue temperature of $384^{\circ} \mathrm{F}$, which is below that of the original firetubes, which typically were in the range of $405-425^{\circ} \mathrm{F}$. This results in an improvement in flue efficiency. Combustion analysis showed very low NOx at $3 \mathrm{ppm}$ and the $\mathrm{CO}$ was acceptable at $70 \mathrm{ppm}$, but higher than that of the original firetube which typically has less than $20 \mathrm{ppm}$. The fin tip temperature was $1238^{\circ} \mathrm{F}$ $\left(670^{\circ} \mathrm{C}\right)$, which is hundreds of degrees less than that of the original firetube design provided to Rocky from a subcontractor on an earlier project.

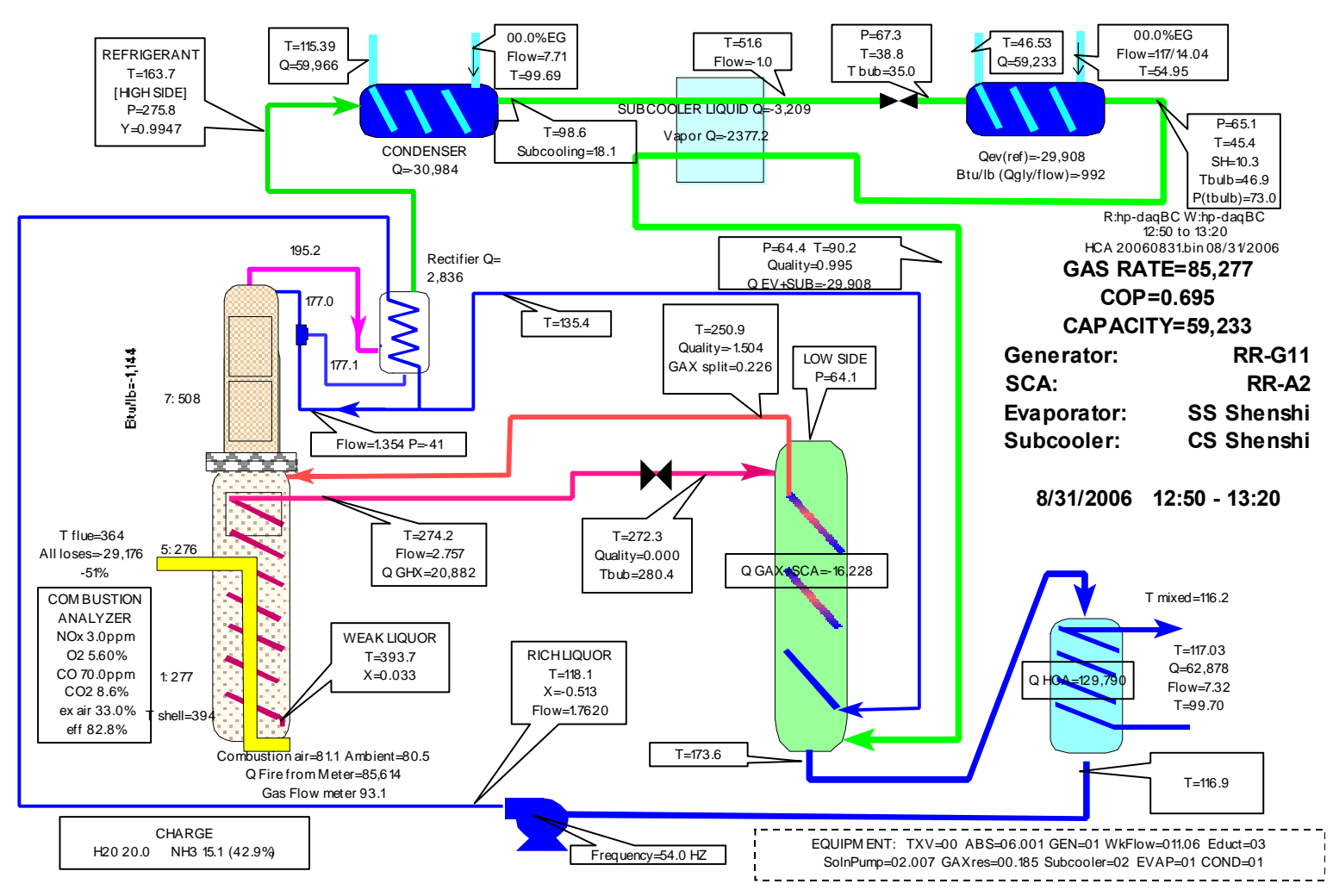

Figure 6. Test Results with Longitudinal Design Generator

Improved Longitudinal Fin Firetube 
An improved design for the longitudinal design firetube was then evaluated. For this design, vacuum brazing was chosen as the process for joining the fin to the inside of the firetube. The concept chosen was to copper plate the fin material and then tack-weld the fin to the shell to secure it for brazing. Initially for prototypes the concept utilized a hole drilled into the shell to give access to the fin for tack-welding. Samples were made using cut sections of fire tube shell material. The fins were plated by two different vendors with three different plating thickness ranges. $1^{\text {st }}$ set $(.0002-.00040) ; 2^{\text {nd }}$ set $(.0004-.00060$ ) and finally the $3^{\text {rd }}$ set $(.0006-.00080)$. Figure 7 is a drawing of the samples that were fabricated and sent to the vacuum brazer.

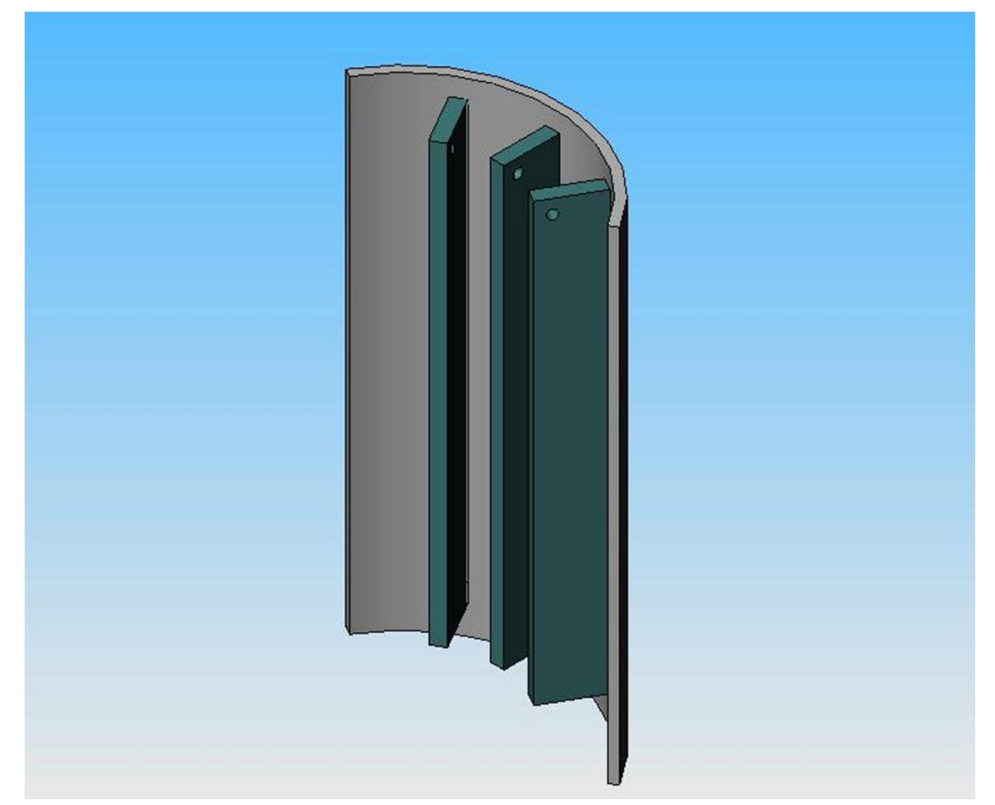

Figure 7. Sample of Plated Fins and Shell Section

The next step for the new fire tube concept was to build a full scale firetube to be vacuum brazed and then assembled into a generator for performance and life testing. In order to properly secure the fins to the inside of the shell, a fixture was developed to properly clamp the fin to the ID of the shell. Figures 8 and 9 are model pictures of the device with the throw extended and retracted, respectively. 


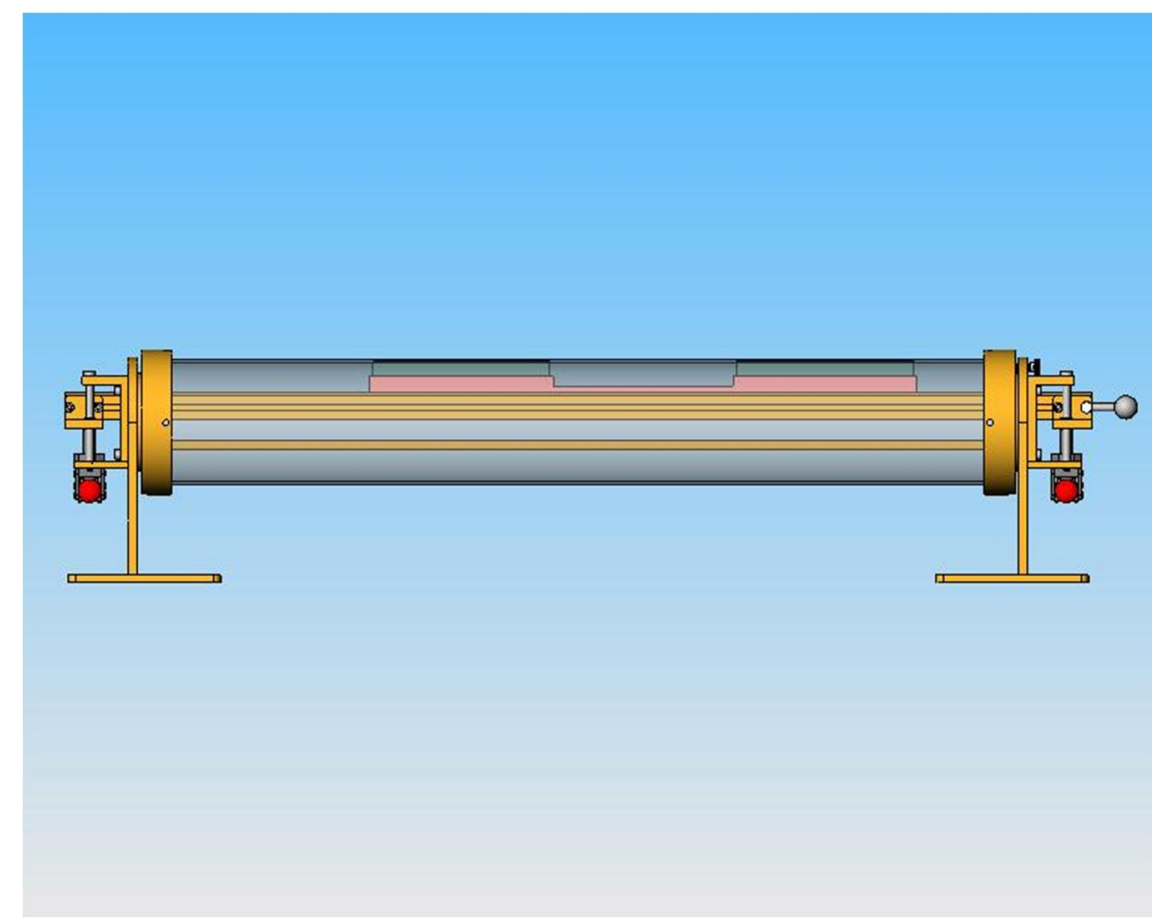

Figure 8. Clamping Fixture Ï Extended

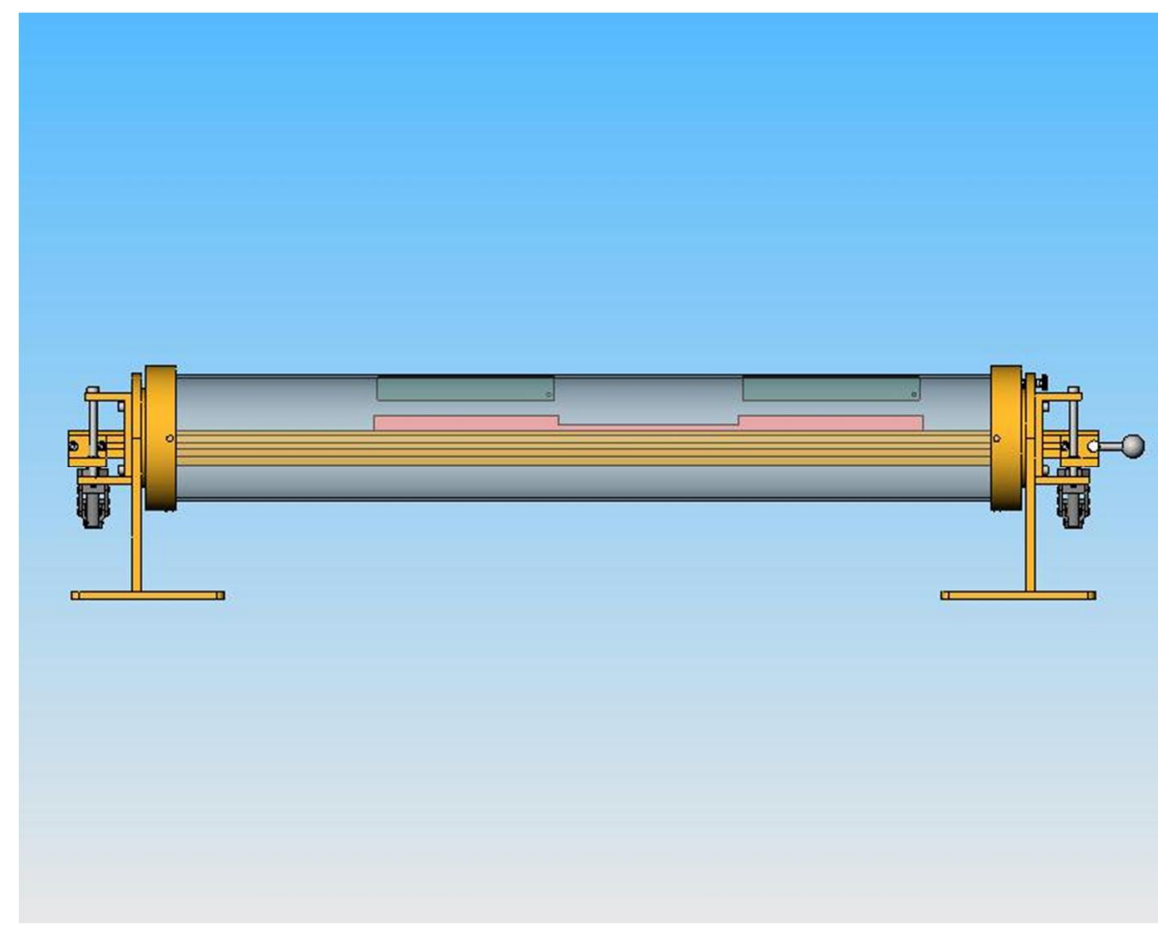

Figure 9. Clamping Fixture $̈$ Retracted 
Out of the six samples that were sent for brazing, only one showed partial signs of proper bridging between the base metals and the alloy. This sample was the higher plating thickness of .0006 - .0008. Figures 10 and 11 are pictures of these samples.

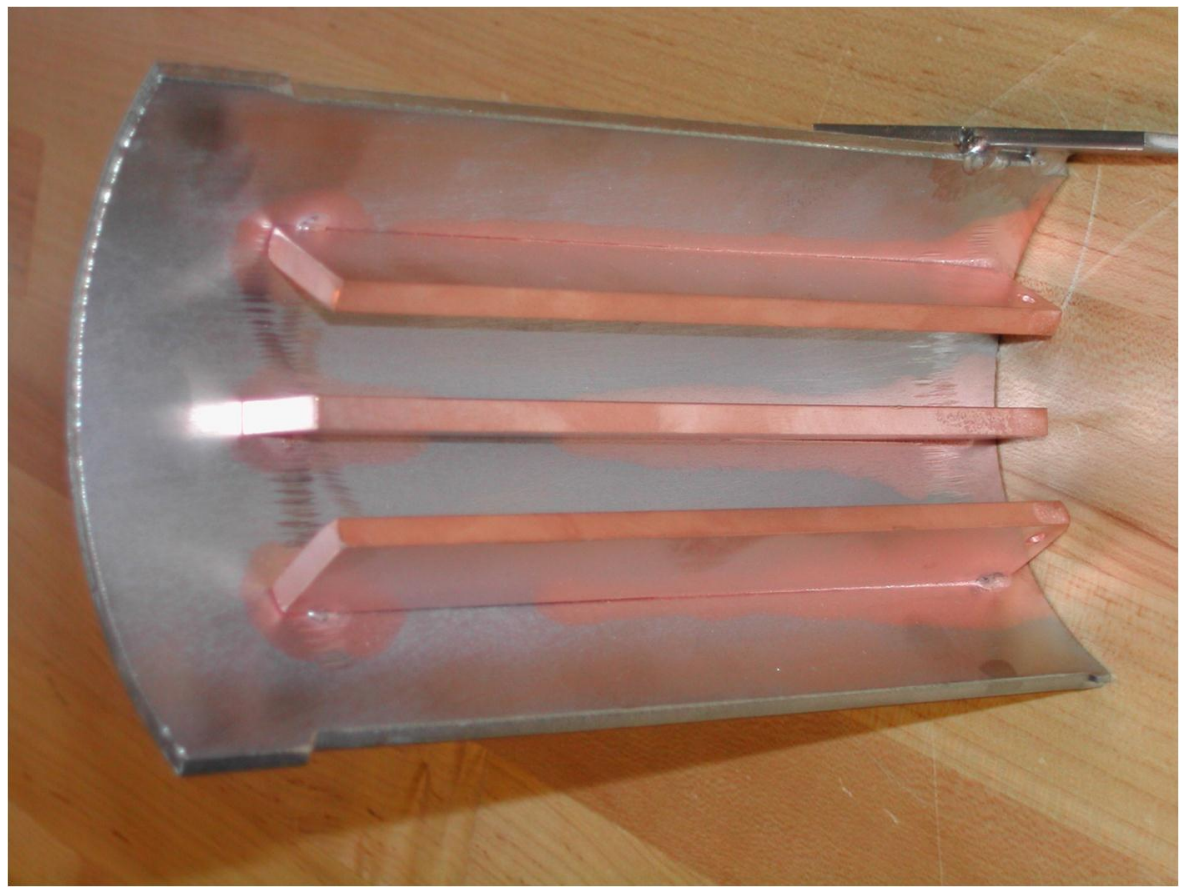

Figure 10. Braze Samples

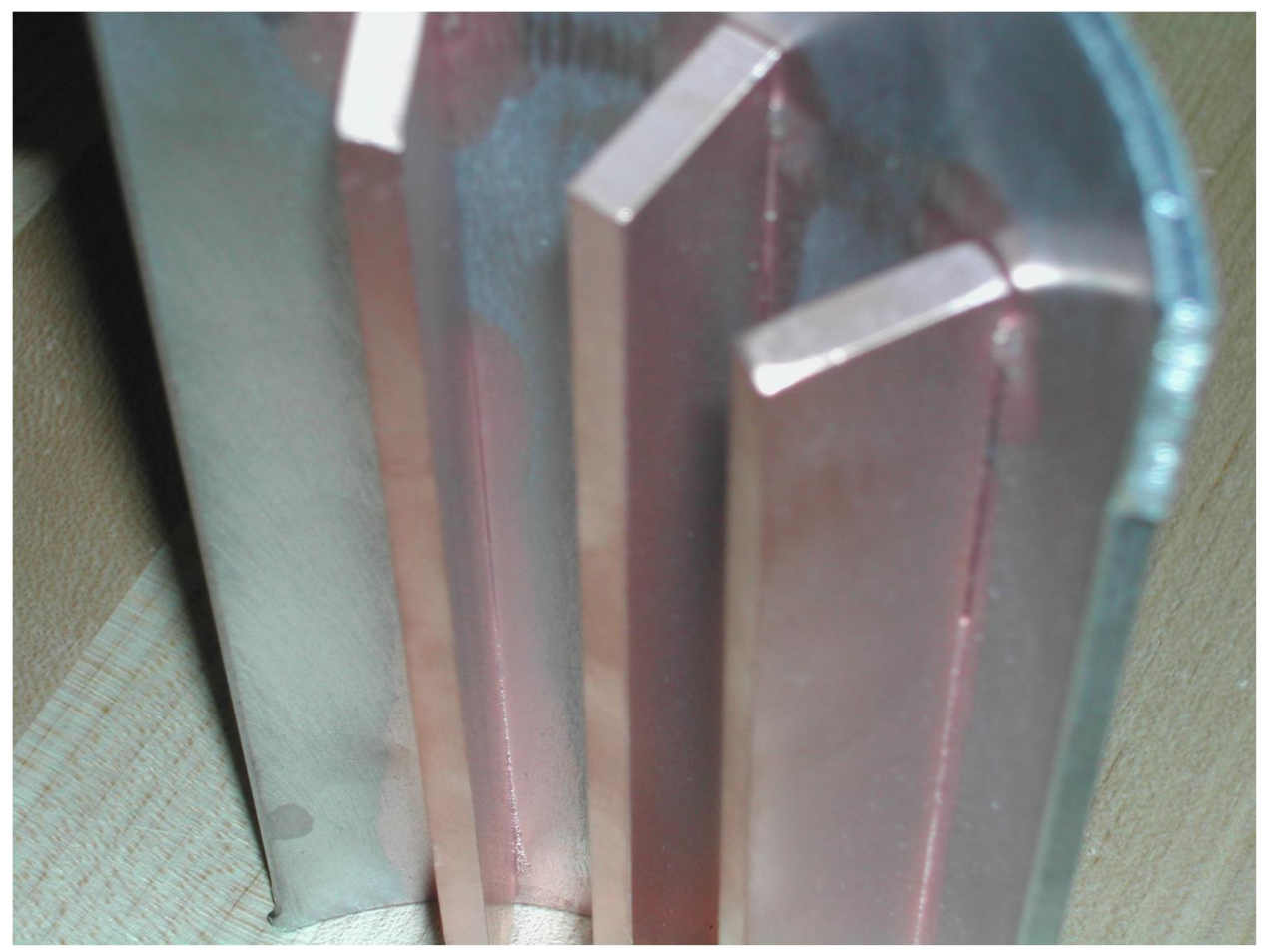

Figure 11. Braze Samples 
From this testing it was concluded that the plating thicknesses chosen were too thin and another set of samples were needed with higher plating thickness. Material was then sent to the plating company to plate 3 more sets with (.0009 - .0011ò), (.0014 - .0016ò) and (.0019- .0021ò).

Brazing of these fins was much more successful. See Figures 12 and 13 below for pictures of the samples.

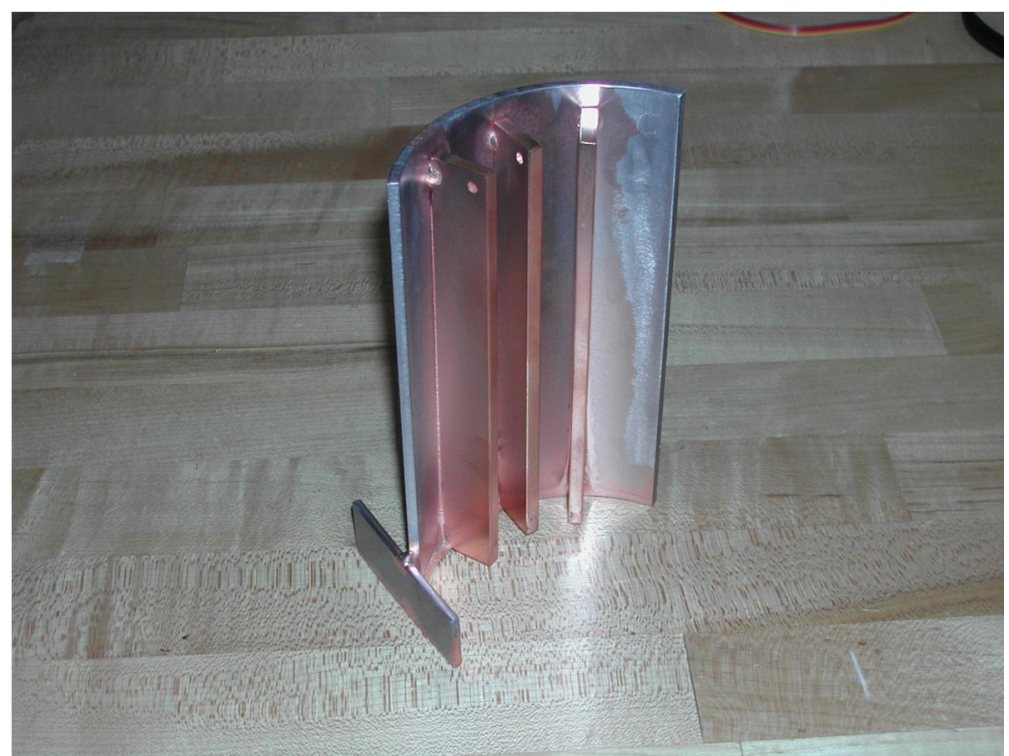

Figure 12. Full Sample

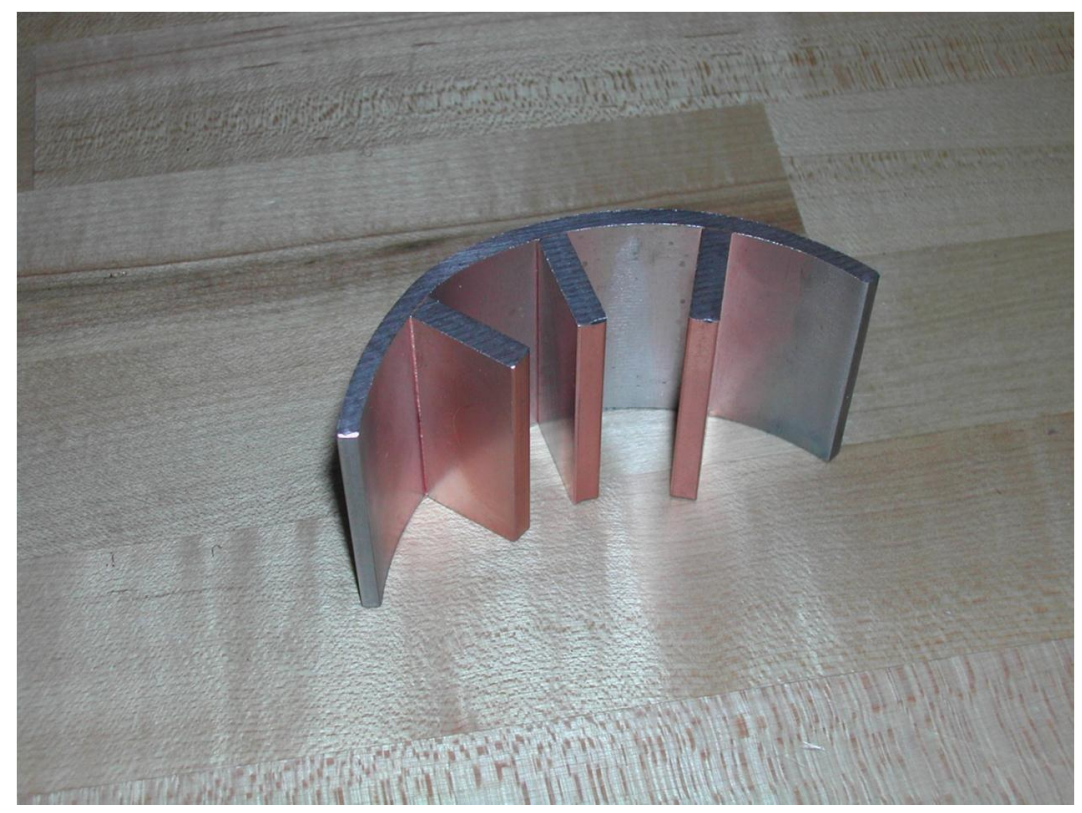

Figure 13. Sectioned Sample 
After careful examination it appeared that the 1 mil thick plating yielded the best results, showing good braze flow down the entire length of the joint and minimal excess build up at the end of the fin. Based on the success of these samples, the next step for the firetube is to build a full scale firetube to be vacuum brazed and then assembled into a generator for testing.

The assembly was built and brazed and returned to Rocky with less than promising results. There were several issues that possibly contributed to this result. First, the fins used were made from hot rolled steel that had a rounded edge that was then secured to the ID of the tube, shown in Figure 14. The samples that were tested successfully earlier used this same material but were machined prior to assembly and therefore did not have the rounded edge. Secondly the copper plating thickness causes the joint gap to be .002ò more than the minimum recommended dimension. This did however work in the earlier samples that were tested so the rounded edge, resulting in a compromised joint design, appears to be the main reason the brazing failed. Minimizing the joint gap is preferred for better quality control. Figure 14 shows a view of a cut section of full fire tube assembly after brazing.

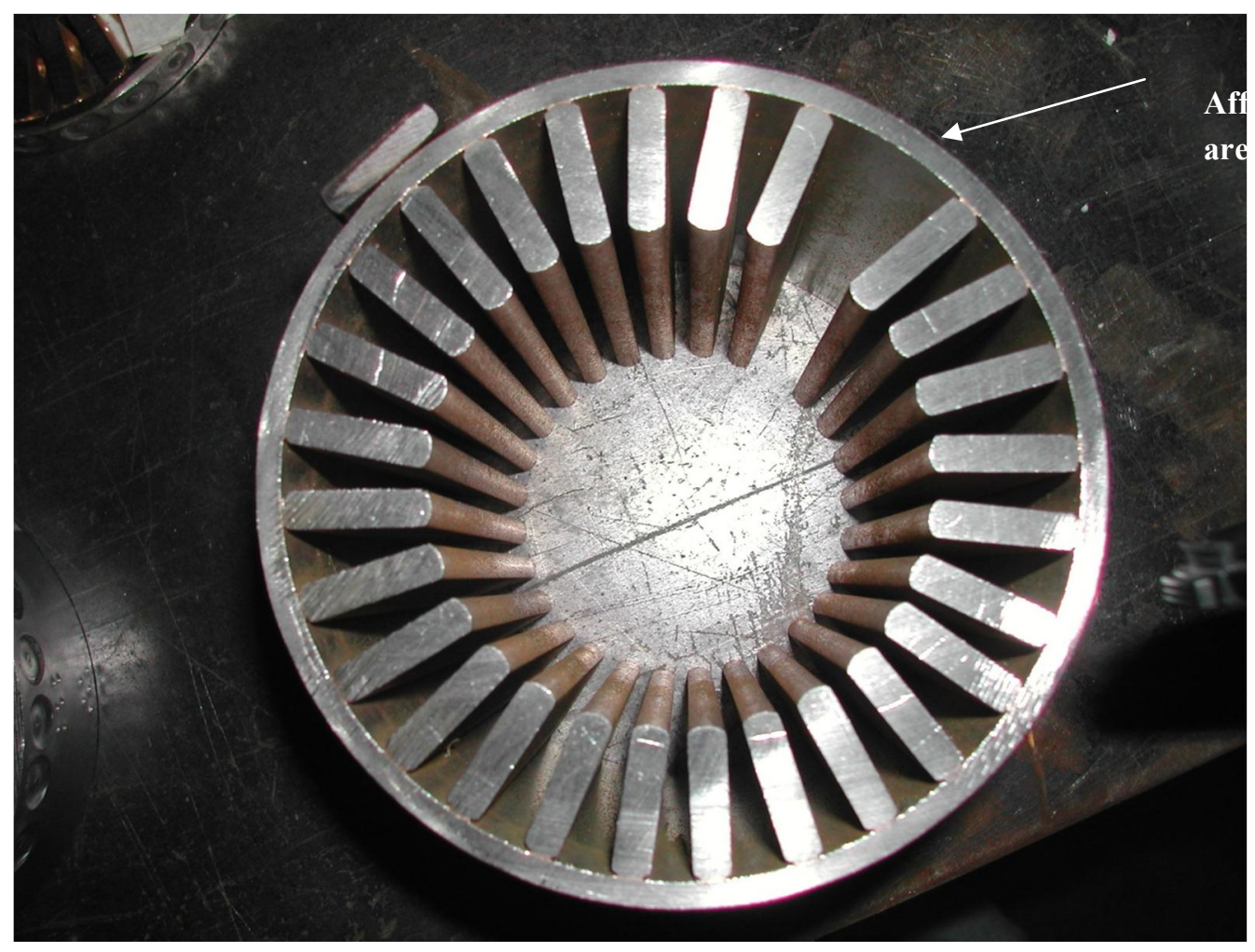

Figure 14. Sectioned Sample 
After a conference call with the brazer, a new concept for applying braze was devised by Rocky and to be tested. The concept was to tack weld the un-plated fins to the shell and then add a copper ring to the top of the fin row. This should create a tighter and more preferred joint gap for brazing. Due to the capillary flow of the copper in the furnace the new tighter joint design should hold the copper in the joint and create the desired result. Figure 15 shows this assembly before brazing..

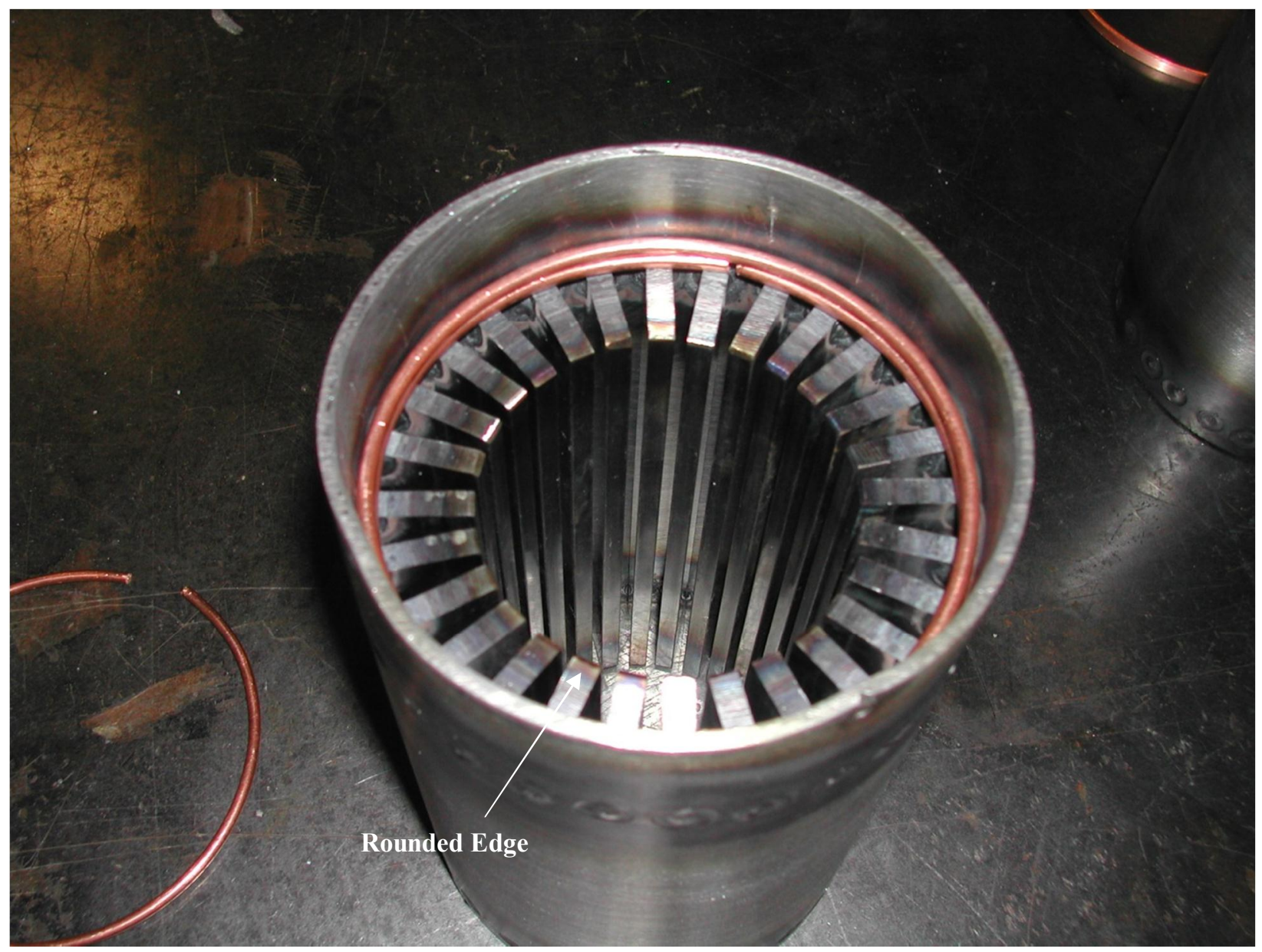

Figure 15. Fire Tube Braze Sample

The samples were made by welding a full length fire tube using the designed clamping fixture and then cut in to sections where the fin patterns were staggered. The samples were then sent out for brazing and returned to Rocky Research. The method showed tremendous promise, however there were several areas where braze did not adhere well in the joint gap, as shown in Figure 16. 


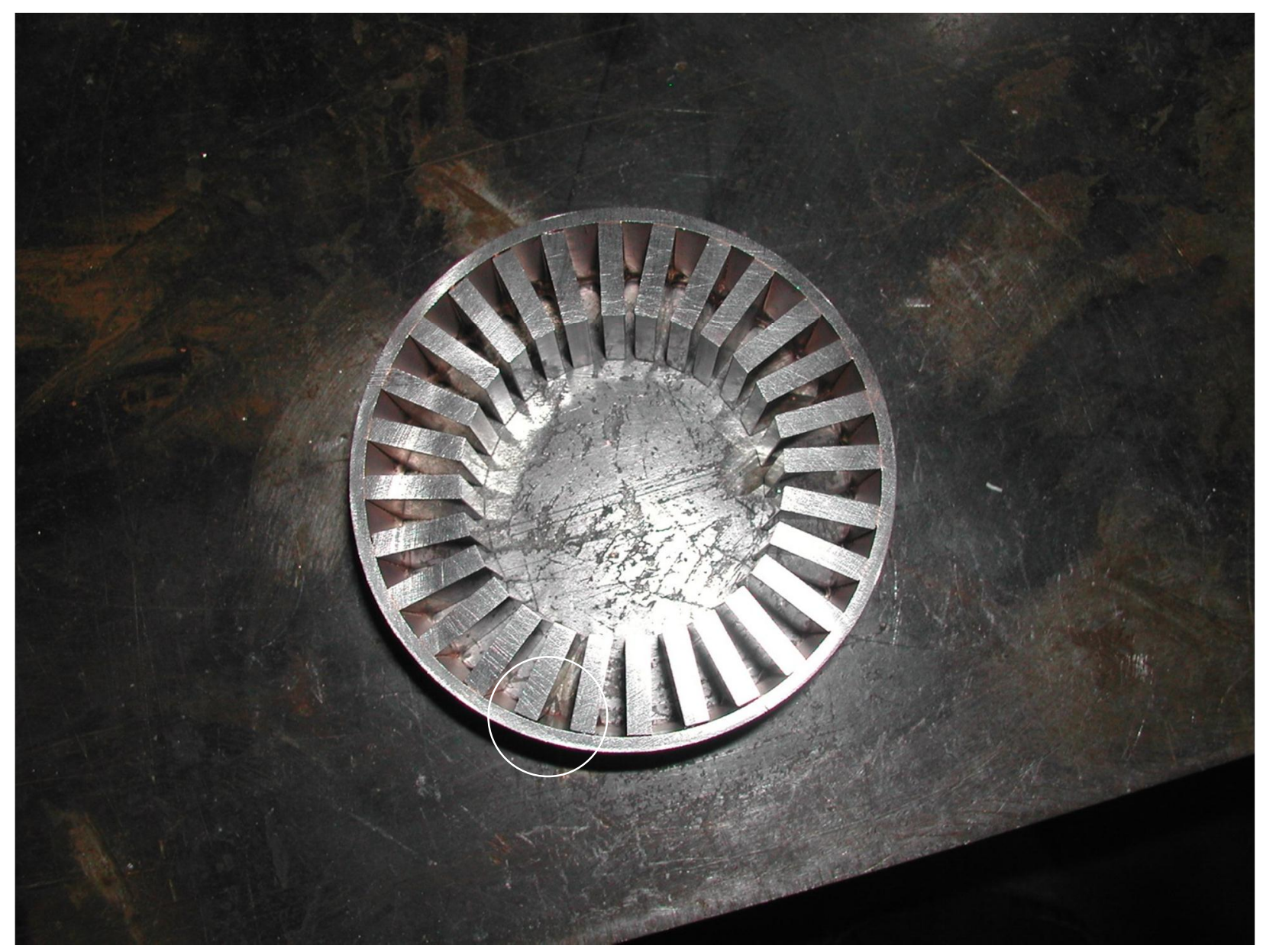

Figure 16. Fire Tube Cut Section

The gaps highlighted in Figure 16 show the inadequate clamping forces from the fixture. It was decided to run another set of samples only this time instead of using the clamping fixture the samples were pre-cut to a 6.25ò length and the fins were then clamped on each end with a C-Clamp to ensure a tight fit.

The last batch of samples was pre-cut to a 6.25ò length and the fins were secured at each end with c-clamps for welding. This was done to test whether the inconsistency down the length of the braze joint was due to inadequate forces generated by the fin fixture. The samples were sectioned just after the plug weld for inspection. Although these samples were better than the last run, there were still locations where the braze alloy did not properly adhere down the length of the gap. This typically takes place at the top of the joint and gets better towards the bottom. The following figures show this effect. Figure 17 is a cross sectioned sample at the top of the fin. The white circles indicate areas where braze is void. 


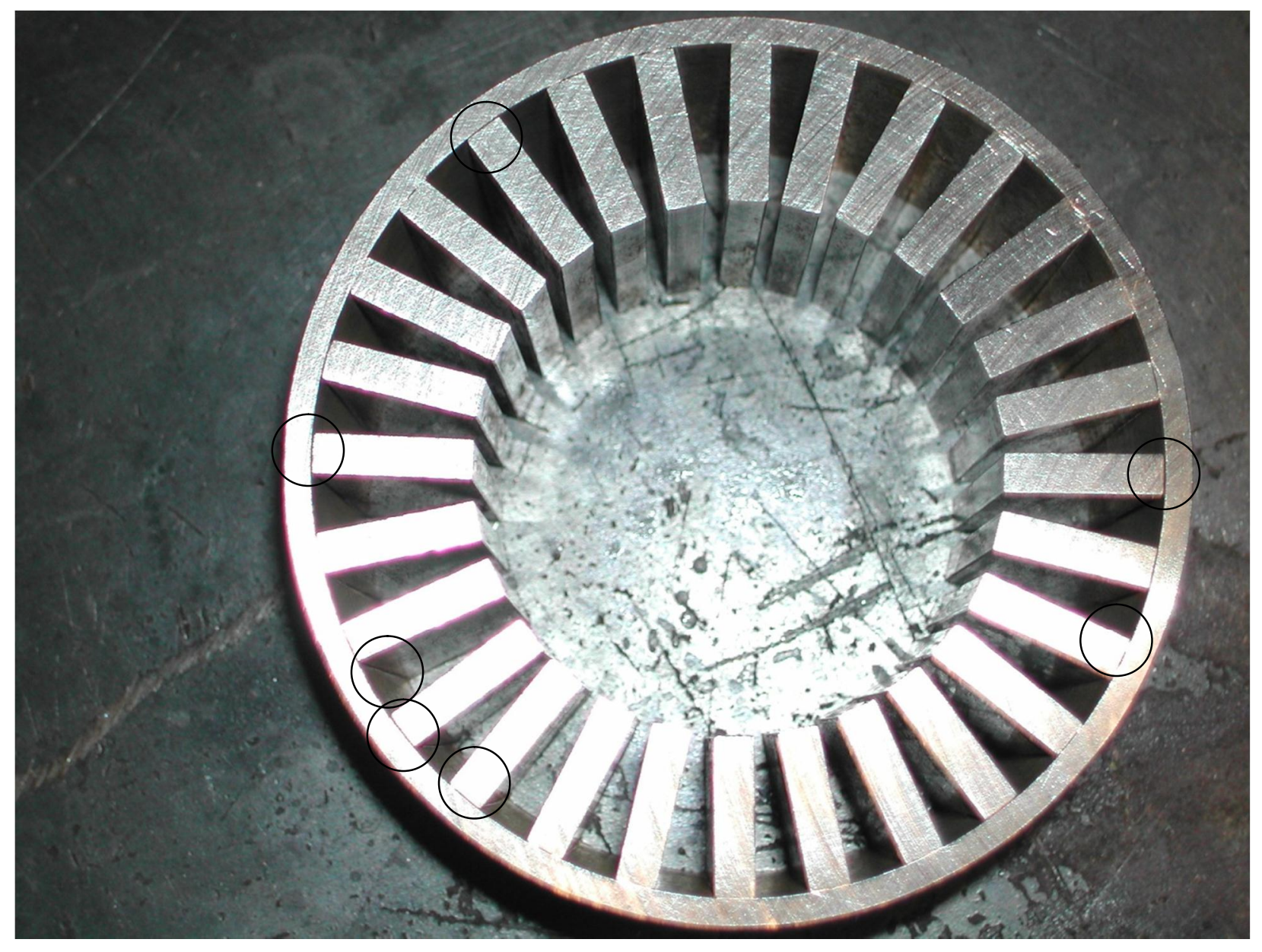

Figure 17. Fire Tube Braze Sample

Figure 18 shows the same sample flipped over and cross sectioned at the bottom of the fin. This figures shows the same fin joints where braze did not adhere at the top but did adhere towards the bottom. 


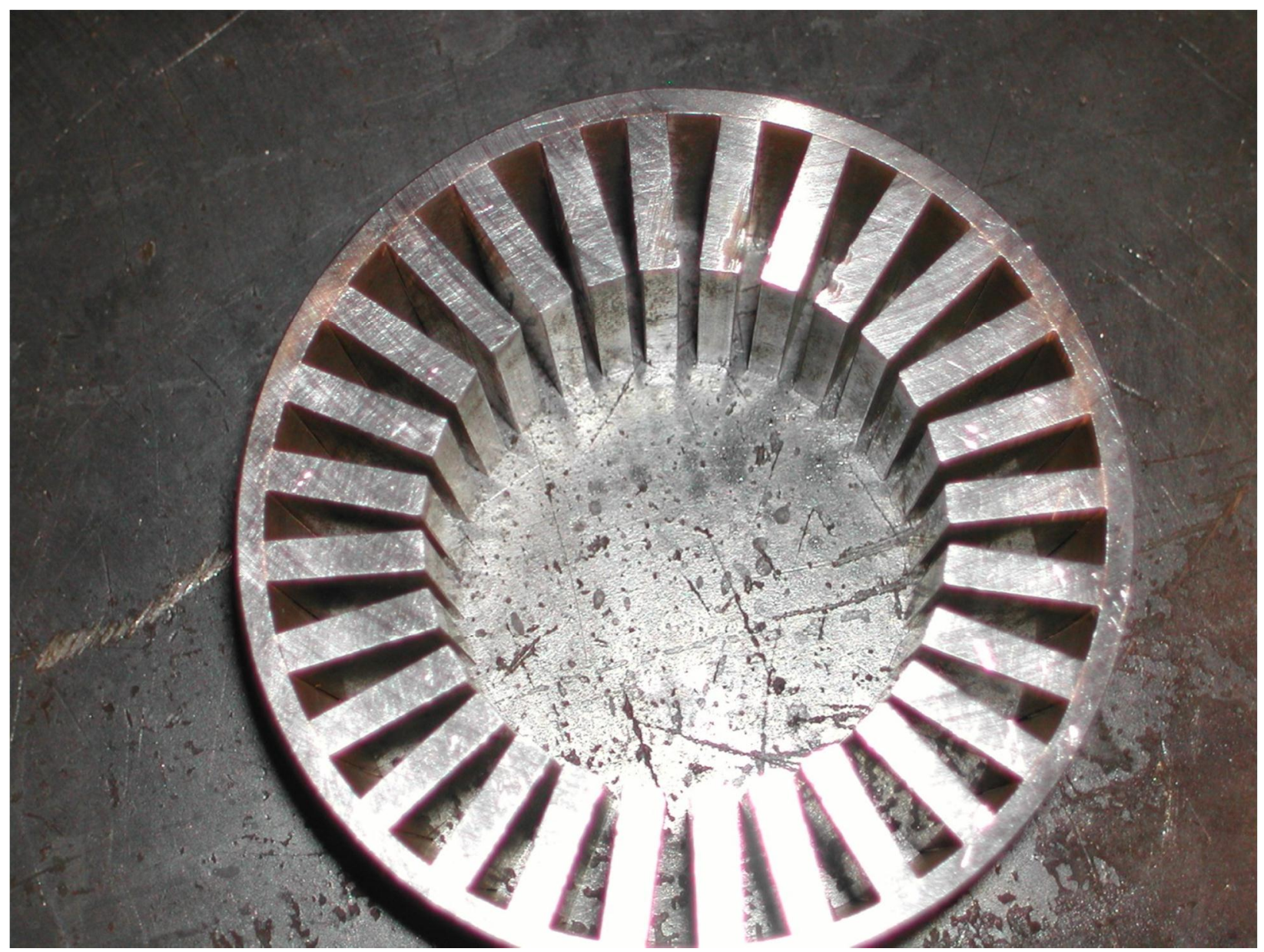

Figure 18. Fire Tube Cut Section Ï Reverse Side

This again appears to be an issue with a poor joint gap. It was decided to cut a small chamfer down the length of each fin that fits against the tube ID. This chamfer will allow an even tighter gap and will hopefully alleviate the problem that has been occurring. However, during this time, an improved fin design was arrived at, one that would easy attachment of the fin to the inside of the firetube before brazing.

\section{C-Shaped Fin Design for Firetube}

This concept uses similar fin geometry (rectangular fins) however instead of being a rectangular bar shape for the fin it uses a channel with a web between the two fins at the root. See the Figure 19 for graphic representation. 


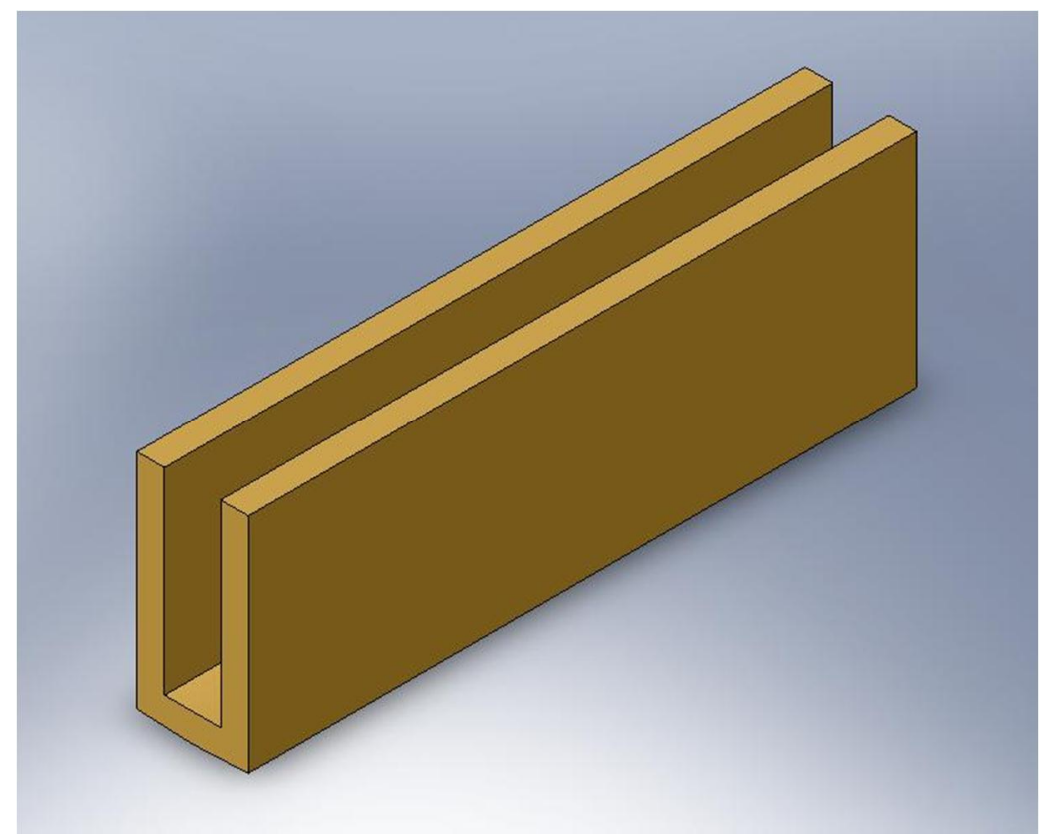

Figure 19. New Concept fin

There are several advantages with this design. First the shape allows for a conventional spot welding technique to be used as opposed to the laser spot welding which tends to be more expensive. The second advantage is that the root of the fin is contoured to match the tube ID and therefore allows for nearly a zero gap tolerance for brazing. For prototyping, the fin is being machined but for production can either be stamped or roll formed to make it a cost effective solution. Figure 20 is a picture of a machined fin.

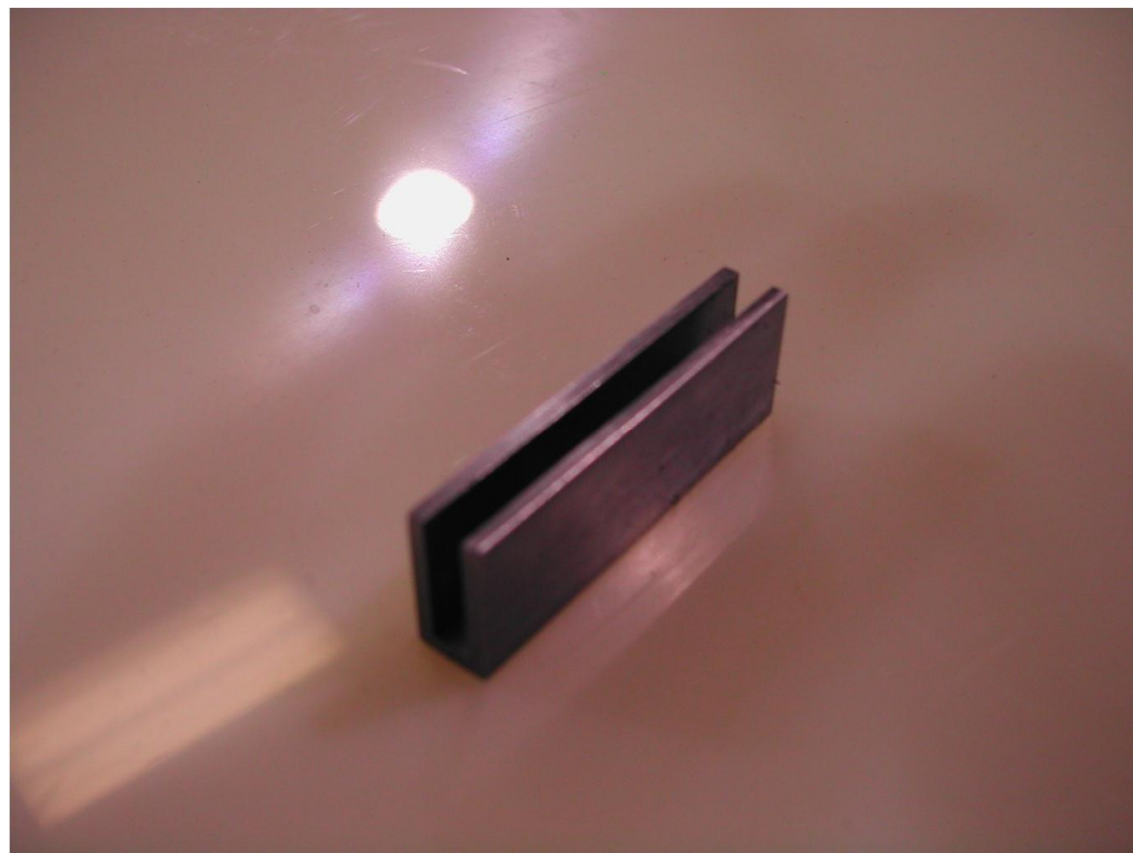

Figure 20. Machined Fin 
A sample part was assembled using conventional spot welding to hold the fins in place. This

new sample was provided to the brazer. During shipment and prior to brazing, several of the spot welds, which tack the fins to the shell before brazing, broke free, resulting in the loss of some fins. It was decided to continue with the brazing to determine the integrity of the new concept on the remaining good joints. Figure 21 is a picture of the brazed sample.

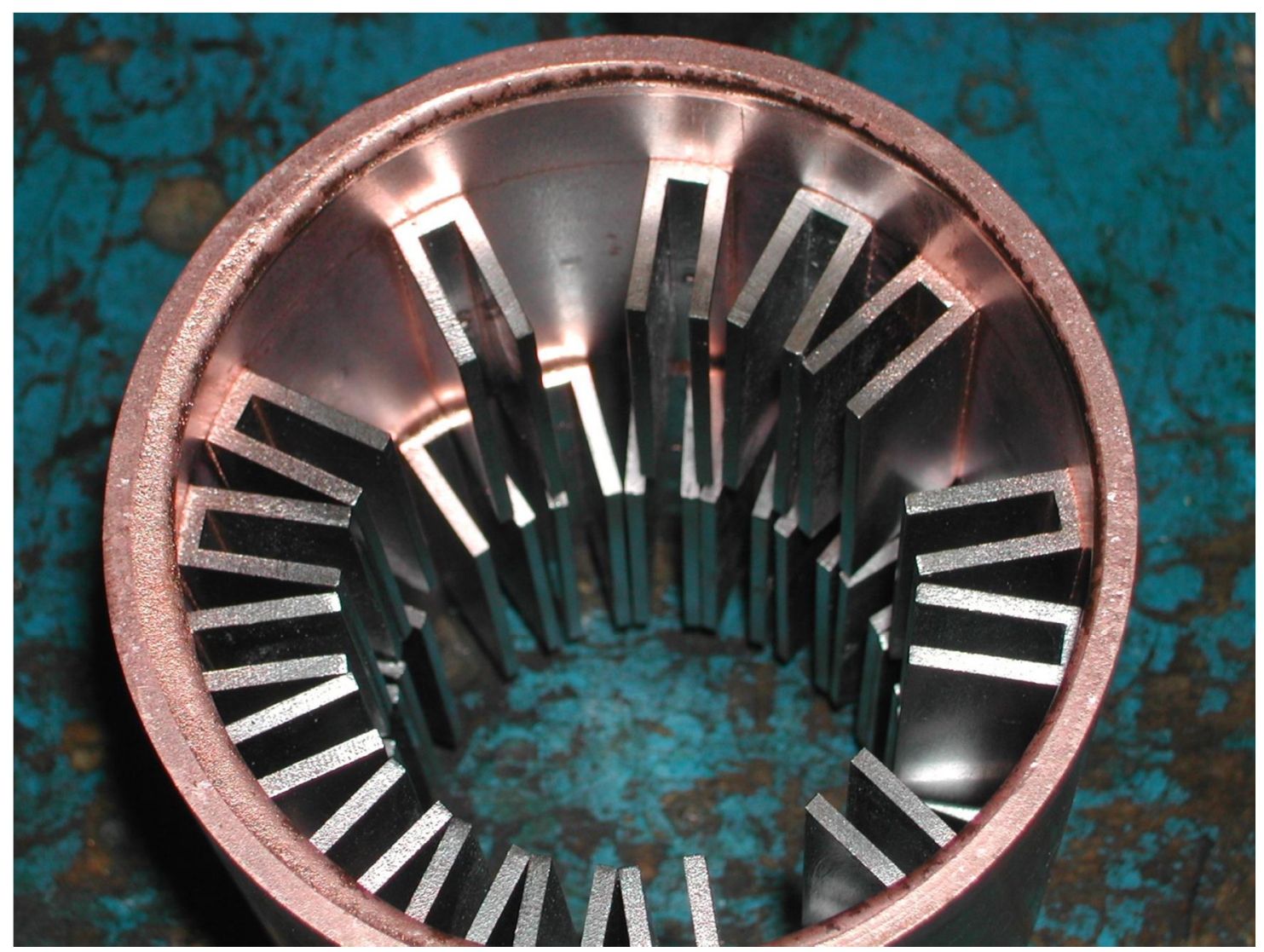

Figure 21. Fire Tube Braze Sample

On the fins that remained the joints looked very good. The copper alloy appeared to flow more uniformly with the new design and adhered properly in the joint gap. Figure 22 is a cross sectioned piece of the sample. Although not well visible in the photo, the joint between the fin and the wall consists of a thin layer of copper that had excelled flow, the result of a well performing braze joint. 


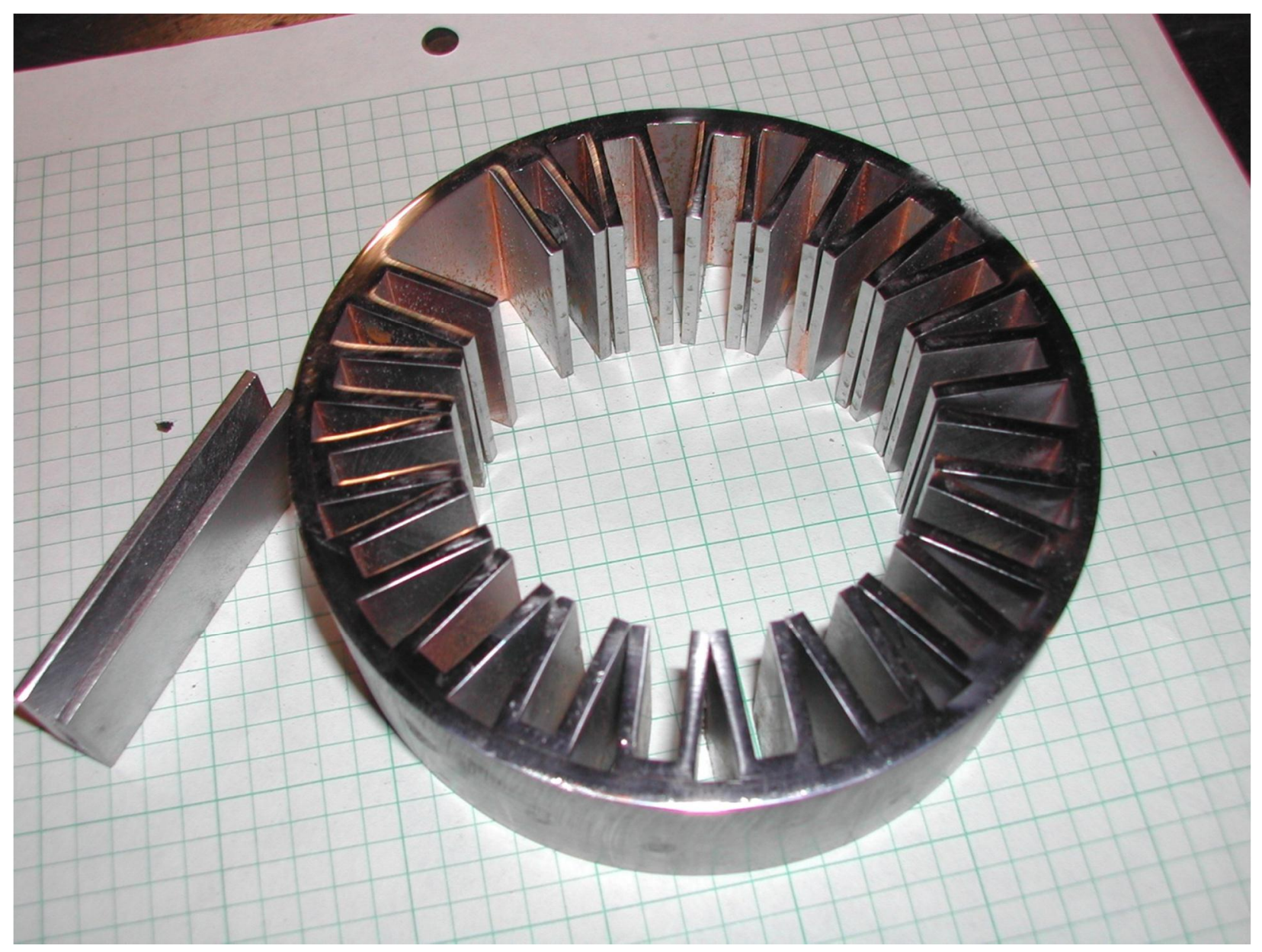

Figure 22. Cross Sectioned Sample

The issue that still remains is the spot welding technique for initially securing the fin to the ID of the fire tube. The new fin was designed to allow for a conventional spot welder to be used as the primary process for attaching the fin. The difficulty initially was in controlling the process well enough to consistently weld the fin without it breaking loose.

A welder with a special arm and electrode for our application was rented. In tandem, the effort continued on building sections of fire tube with the old spot welder and TIG welding them together to make full length samples. Figure 23 is a picture of the two completed firetubes. 


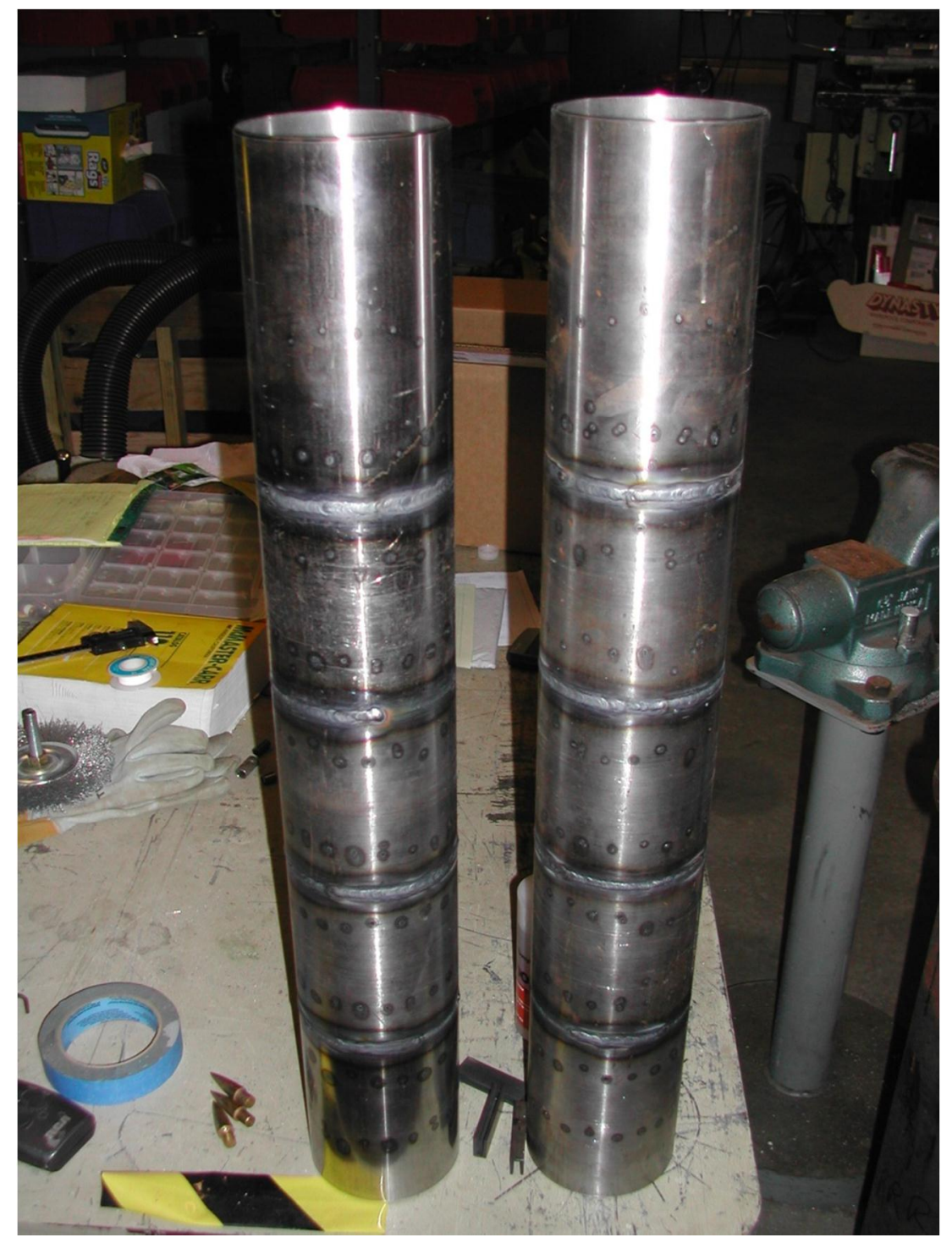

Figure 23. Full Length Pre-Brazed Firetubes

One of the more difficult tasks was machining of the fins. This is a multi step procedure and also requires heat treating afterwards for stress relief. Several different processes were looked at as an alternative and for the short run prototyping it appears that fabricating the fins in a press brake appears to be the best solution. This is done simply by putting a piece of straight stock into the press brake and bending the u-shape channel. A local sheet metal company was identified as and an order and supplied these parts. Figures 24 and 25 are two pictures of a sample they have fabricated 


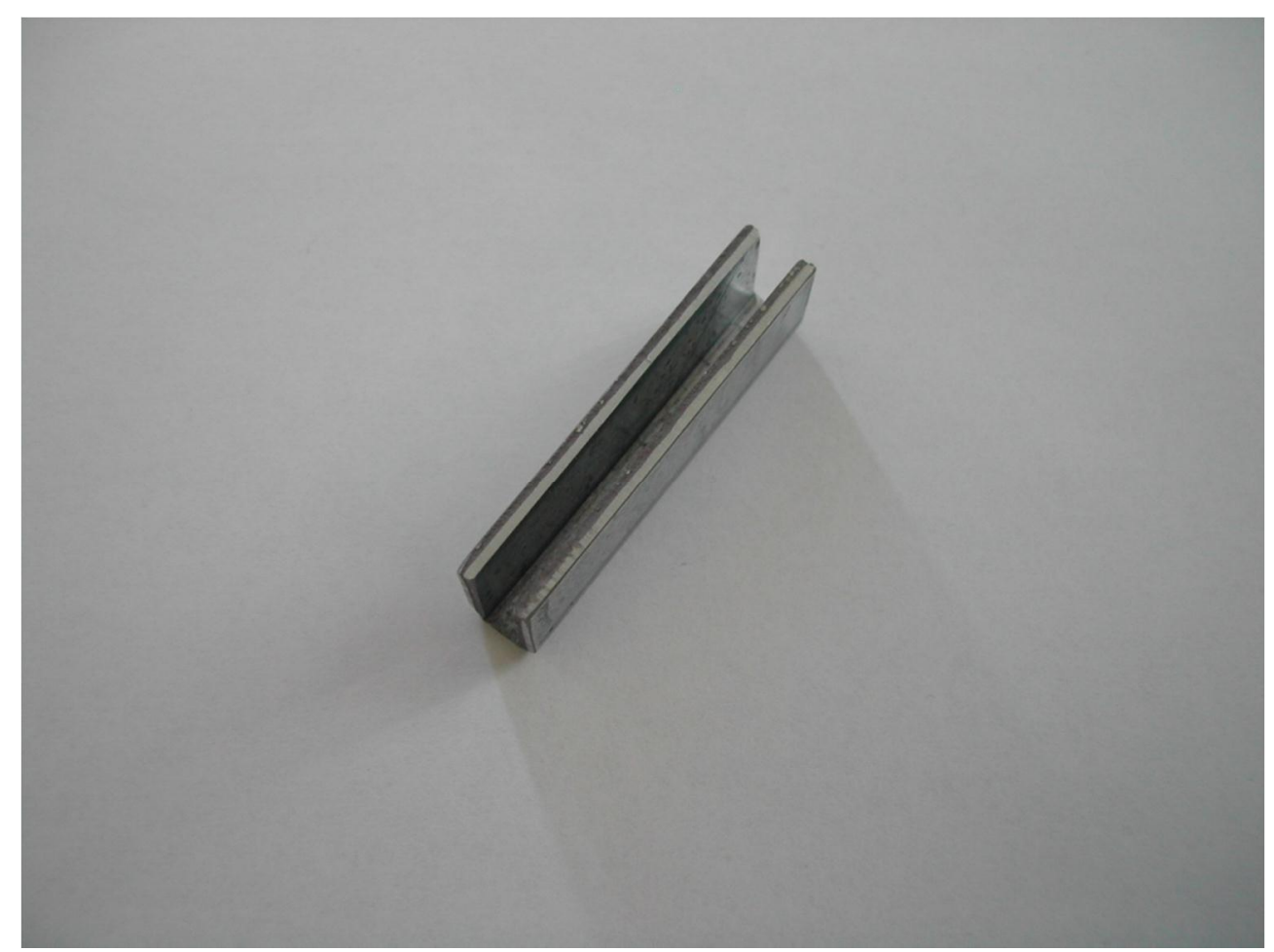

Figure 24. Iso view of formed fin

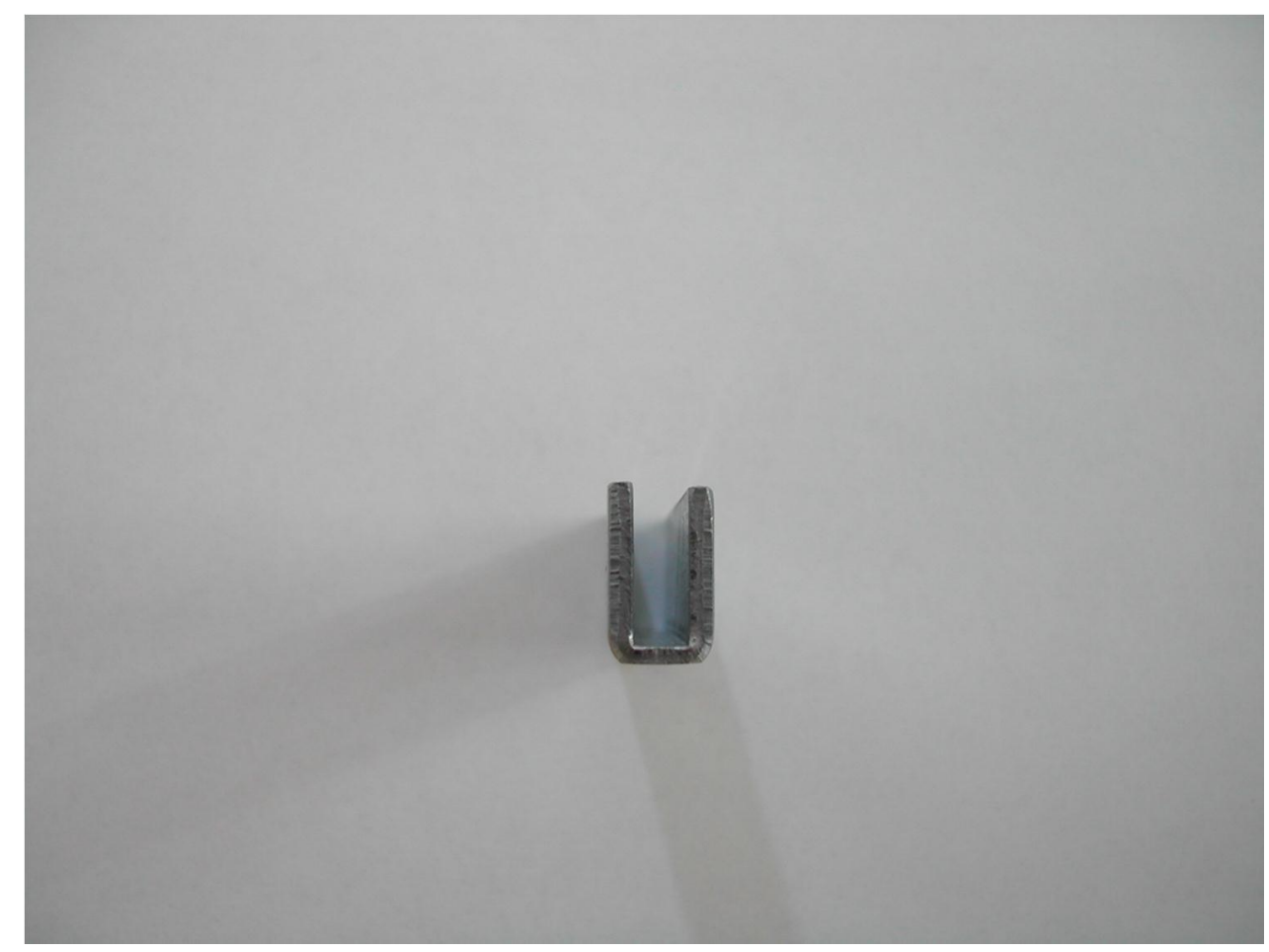

Figure 25. End view of formed fin 
The custom spot welder rented from the manufacturer for these fins is shown on Figure 26. The welder was qualified at the manufacturerôs facility by Rocky Research prior to shipment to ensure spot welds were yielding the desired result.

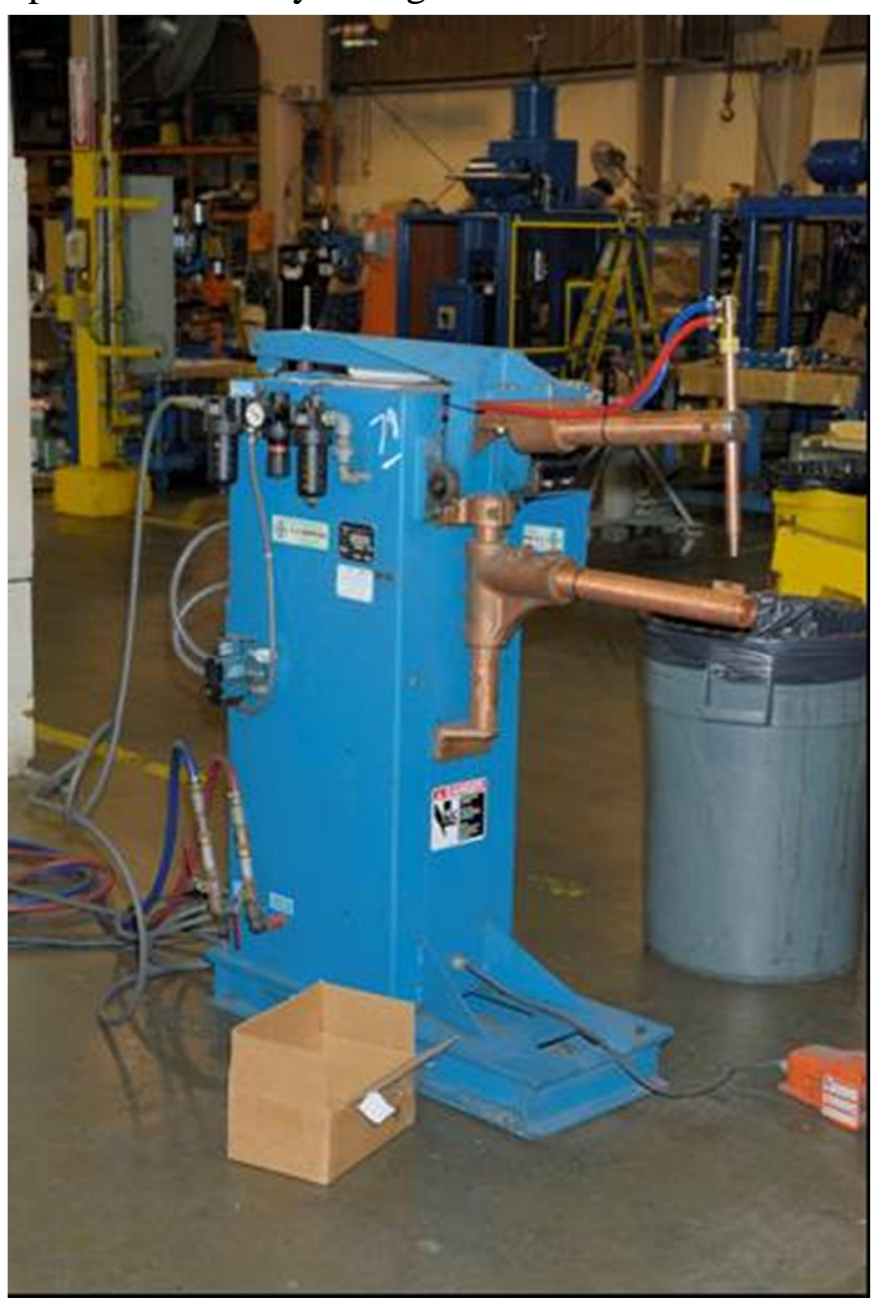

Figure 26. Custom Spot Welder

The electrode was similar in some aspects to electrodes fabricated at Rocky Research however a special insulator was chosen to prevent undesirable contact in the fin. The upper electrode was contoured to fit the outer diameter of the shell and provide better contact for the weld.

Two different style fins were tested during the qualification process. The first was the machined fins which were stress relieved after machining to prevent warping. The second was the fins that were formed in the press brake. The fins that were formed in the press brake showed the best results for welding with less arcing and better adherence. This may be attributed to the stress relieving process in the machined fins as the stress relieving can 
leave an oxidized surface on the inner surface of the fin, possibly creating a poor surface for contact. Figures 27 and 28 are pictures of the sample pieces.

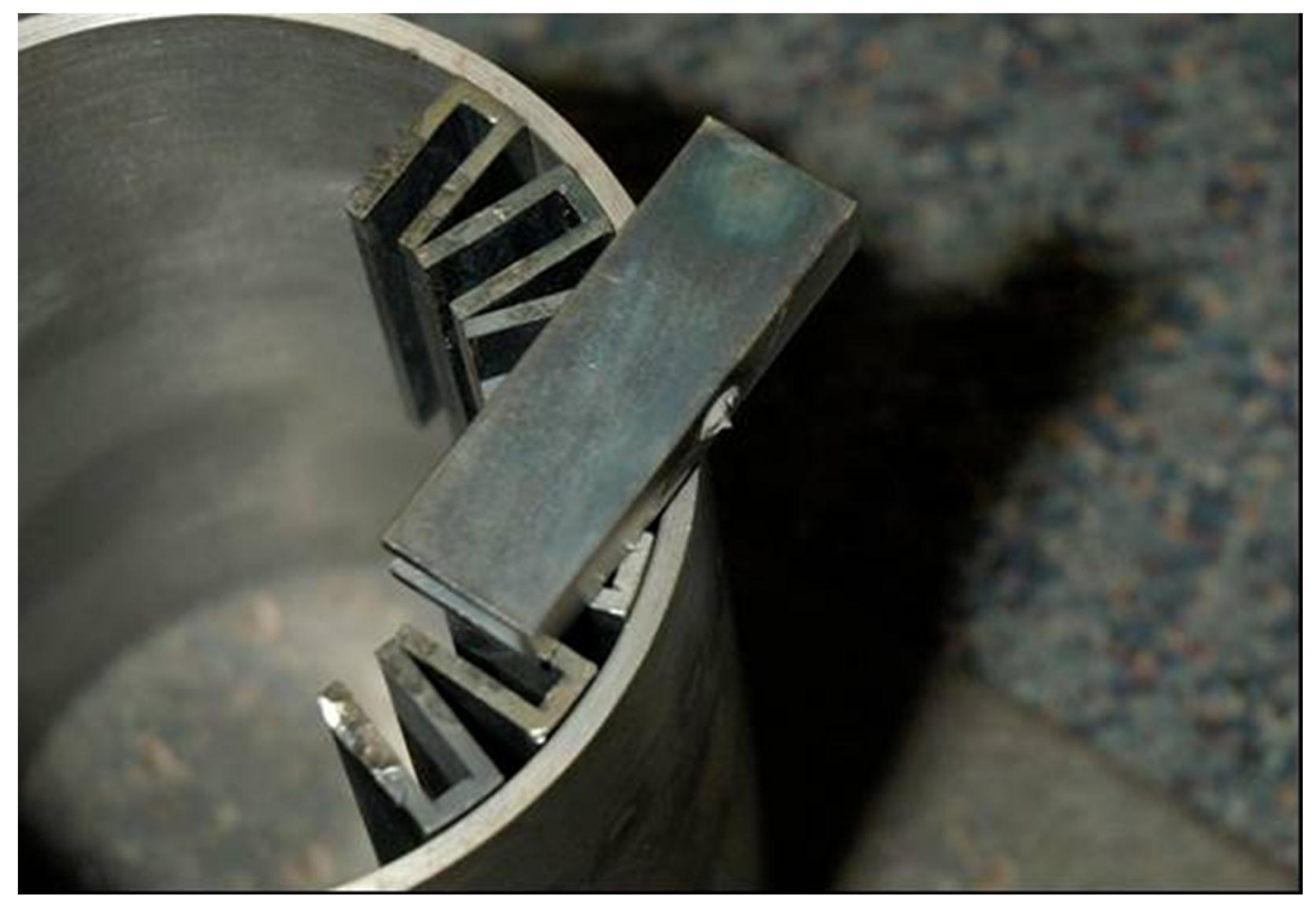

Figure 27. Weld bead of welded fin

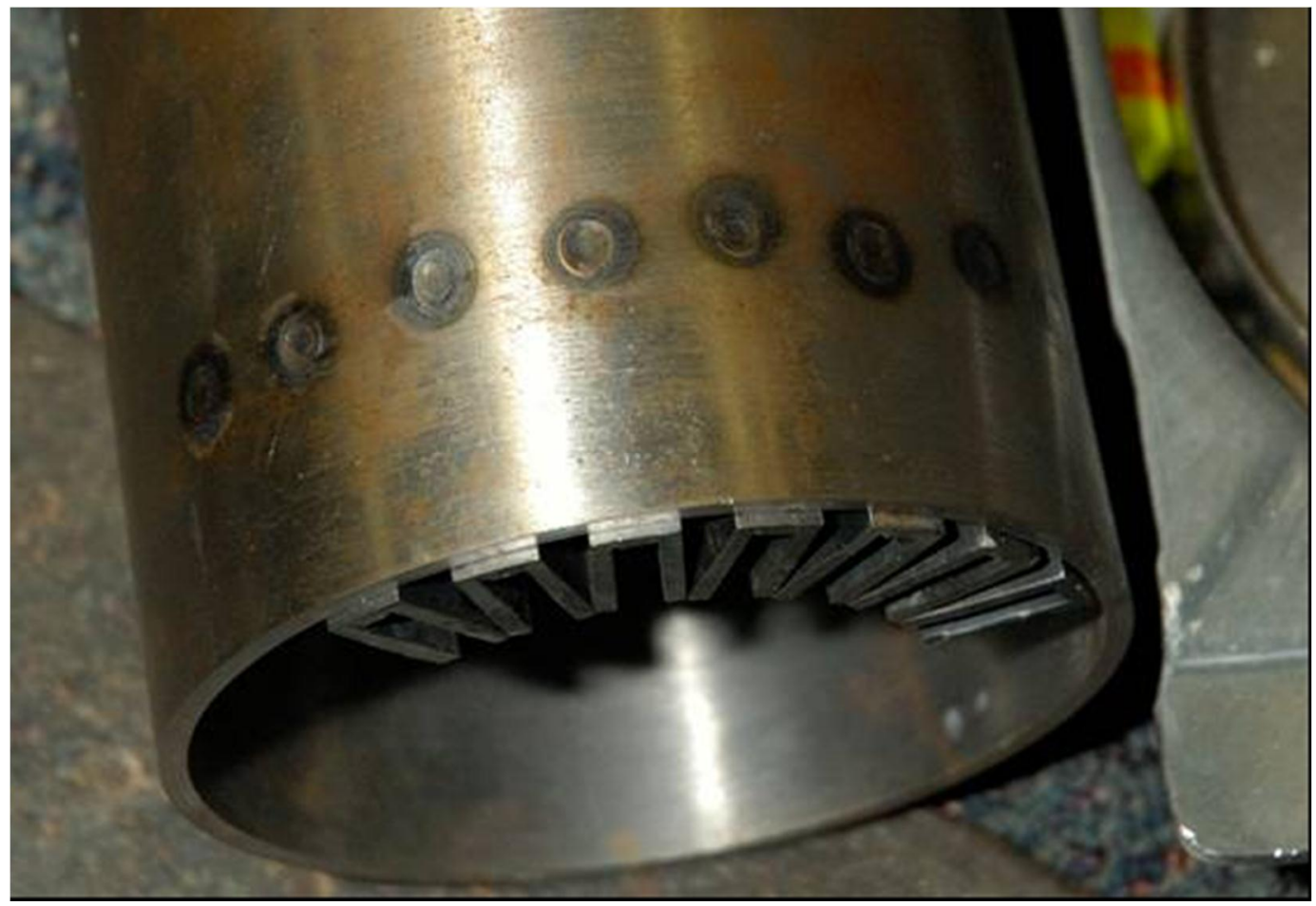

Figure 28. Spot weld on outside of shell 
The apparatus for spot welding firetube fins within design tolerances in terms of location and strength for testing was completed. This apparatus is shown in Figure 29. The apparatus is shown connected to Rockyôs spot welder. The apparatus consists of an indexing head, positioning carriage and a steady, leveling support. With the use of this apparatus, test firetubes were made with a continuous shell rather than being segmented and then welded together. This reduced the possibility of leaks.

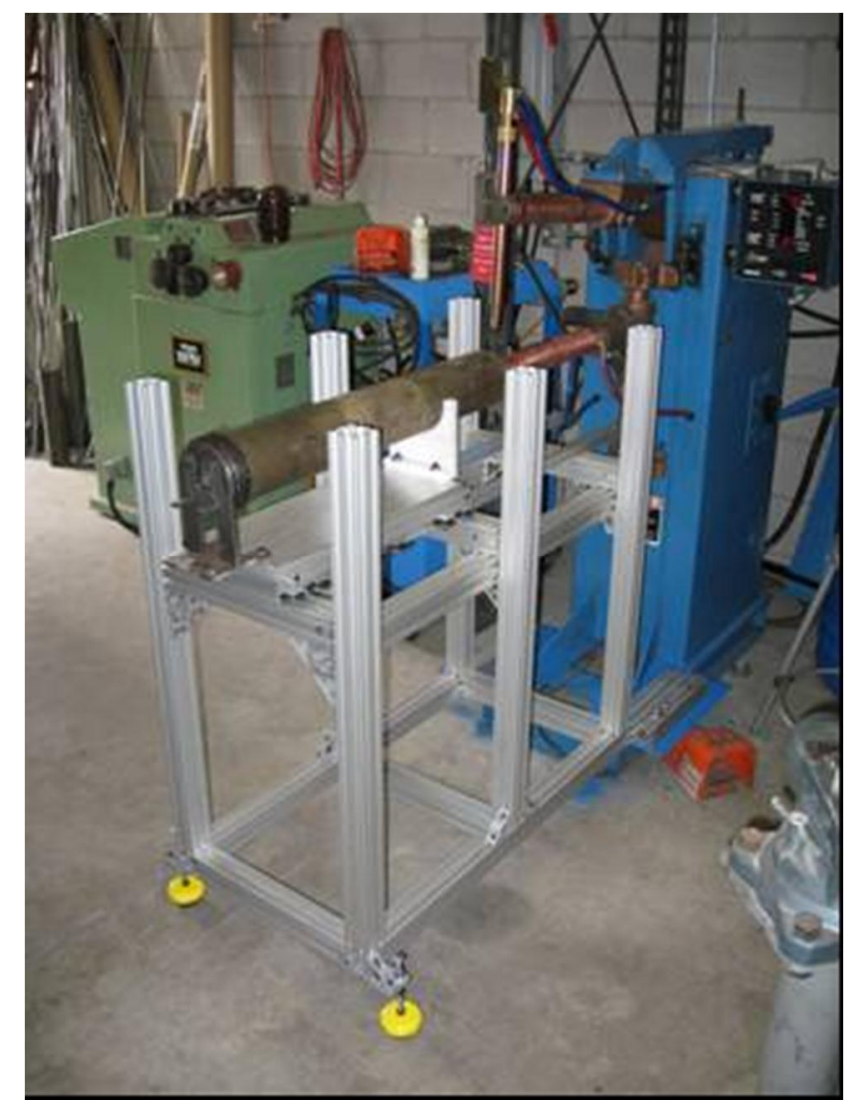

Figure 29. Firetube Spot Welding Apparatus

The fabrication of five firetubes was completed. These were made to finalize the braze ring orientation and type required as well as to determine the efficacy of fin attachment with the low cost bent fins.

A photo of a representative firetube is shown in Figure 30. This photo was taken from the top end of the firetube, which would correspond to the exhaust end. As can be seen from the photo, while the fins are attached and have copper braze material between them and the firetube, the root section between each radial fin and the firetube does not quite have sufficient coverage to maximize fin efficiency. 


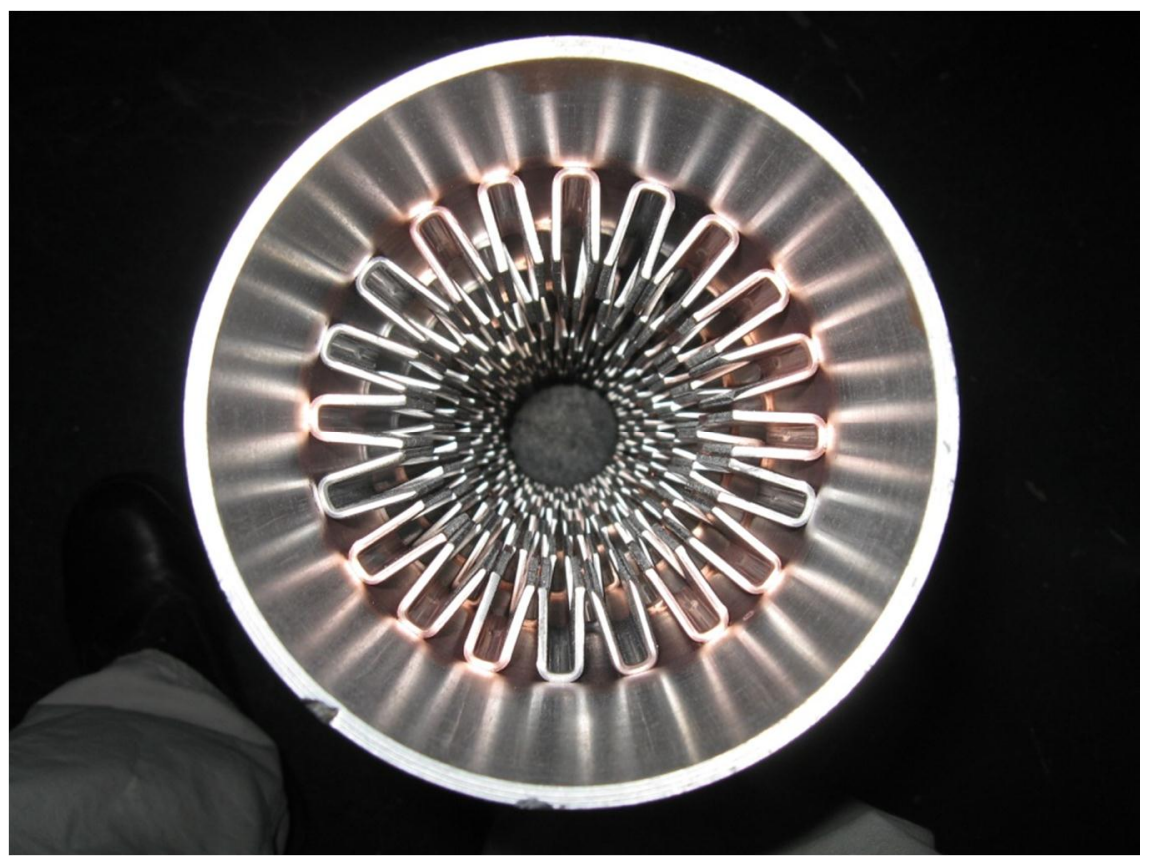

Figure 30. Firetube, top

A view of the opposite end of the same firetube, shown in Figure 31, shows much different circumstances. Here, the copper has collected better at the fin roots making the fins more effective. It should be noted that the excess copper is easily removed using hand tools so that the firetube can be welded to the casting.

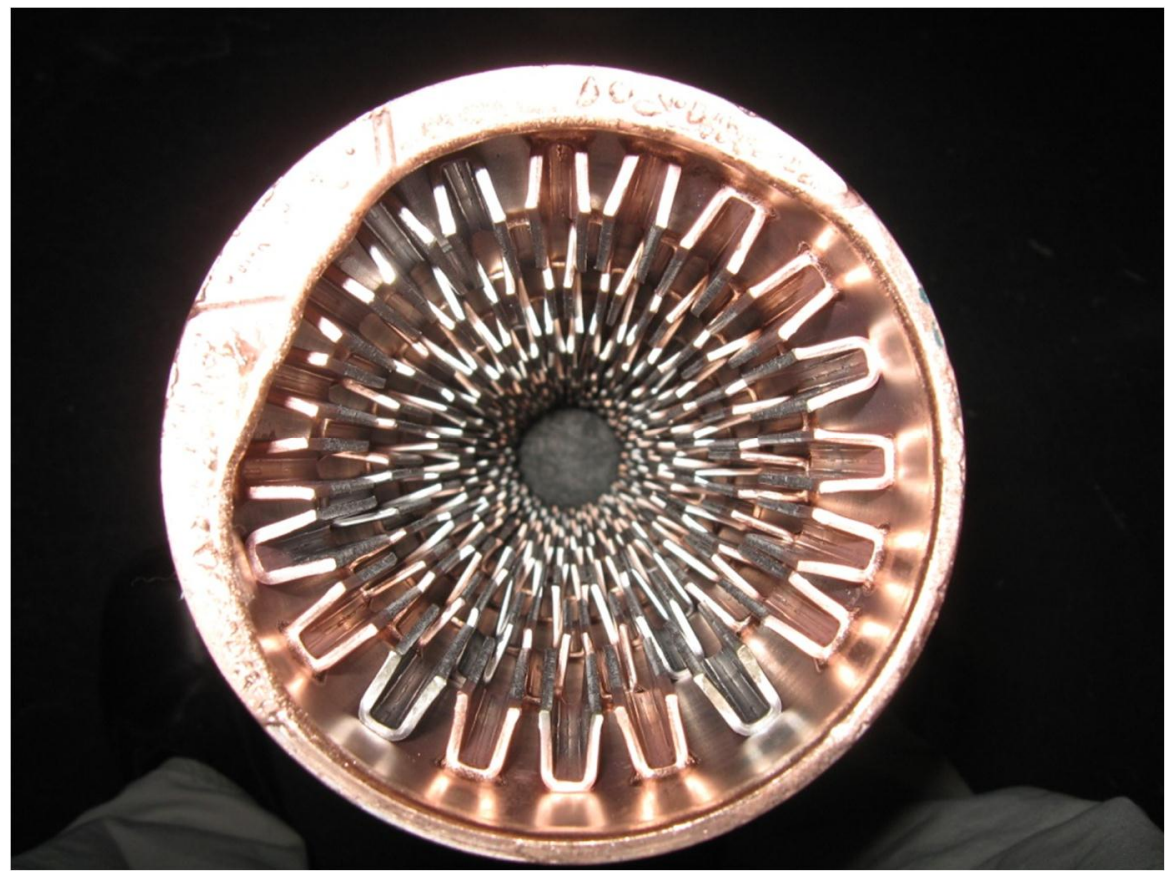

Figure 31. Firetube, bottom 
Based on the results of these tests, the braze ring cross section and spacing to best produce the joints has was determined.

Three firetubes were then spot welded in preparation for brazing. The firetubes are shown on Figure 32. The ends of the firetube, on both the inside and outside, were prepared to keep the braze material from sticking to a surface. This is the light green material that is shown at the base of the firetube. This eliminates the need for machining off the excess copper. The removal of the excess copper is necessary to allow welding of the firetube into the generator casting.

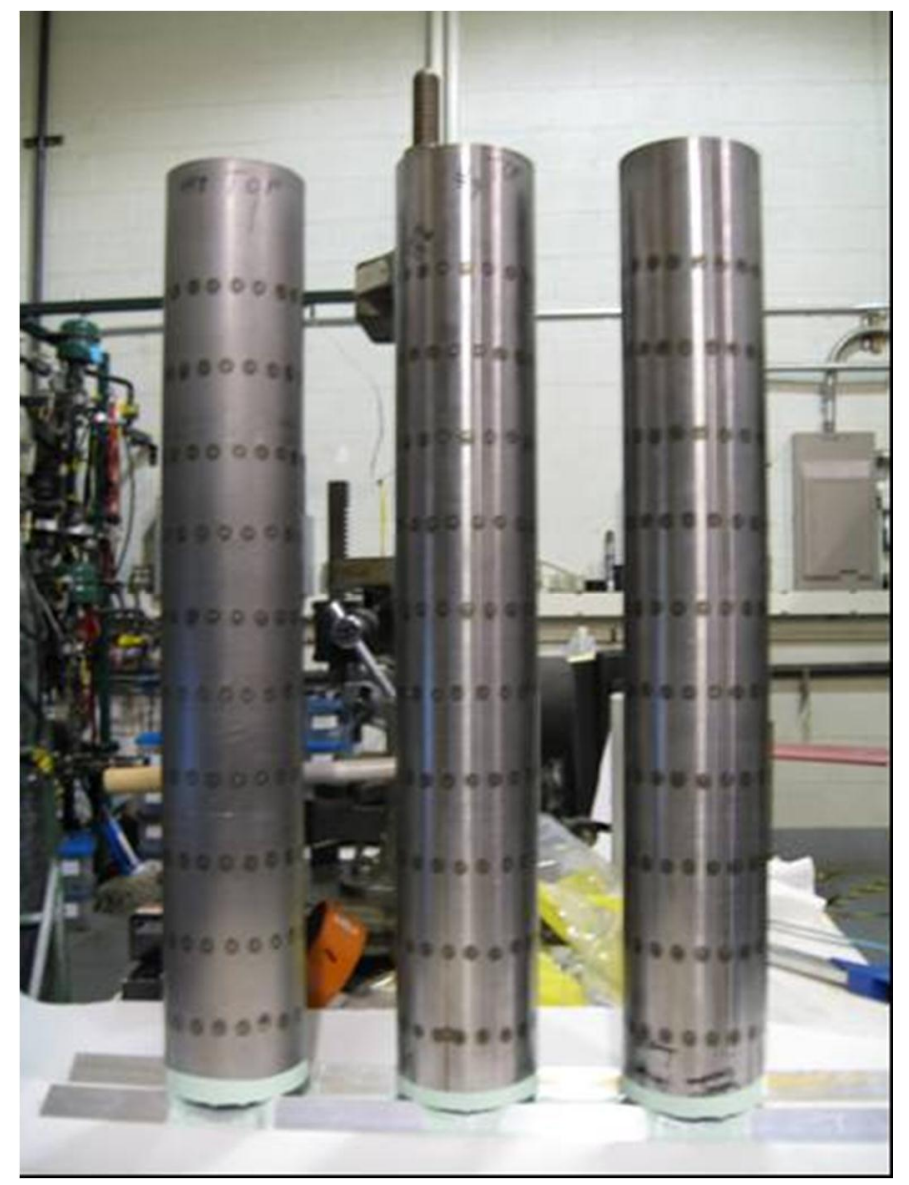

Figure 32. Photograph of Three Firetubes Prepared for Brazing

Three firetubes brazed firetubes are shown on Figure 33. The in Figure 34, these firetubes are arranged in progressively higher brazing temperatures to show the effect on brazing quality. They all have been brazed for a similar amount of time, approximately 5 minutes. 
The firetube on the left, \#9, which was brazed at between $1990^{\circ} \mathrm{F}$ and $2010^{\circ} \mathrm{F}$, was by far the worst of the three, with the copper flowing by gravity and balling up at the bottom in a tight formation. The middle firetube, $\# 10$, brazed at $2010^{\circ} \mathrm{F}+-15^{\circ} \mathrm{F}$, was a bit better. The flow of the copper does not seem to be dominated by gravity only, capillary forces are more at work, allowing braze to flow circumferentially. As a result of this there is less balling up of braze at the bottom. The firetube on the right, $\# 8$, brazed at $2020^{\circ} \mathrm{F}$ shows very good flow of copper circumferentially and almost no balling up of the copper at the bottom. While \#8 was done in a vacuum brazing oven, the same trend towards better wetting of the surface would have occurred in the hydrogen oven also.

Based on these, it was decided that the next samples would be brazed in the vacuum oven at a higher temperature, $2030^{\circ} \mathrm{F}$. To this end, three additional firetubes were spot welded and prepared for brazing.

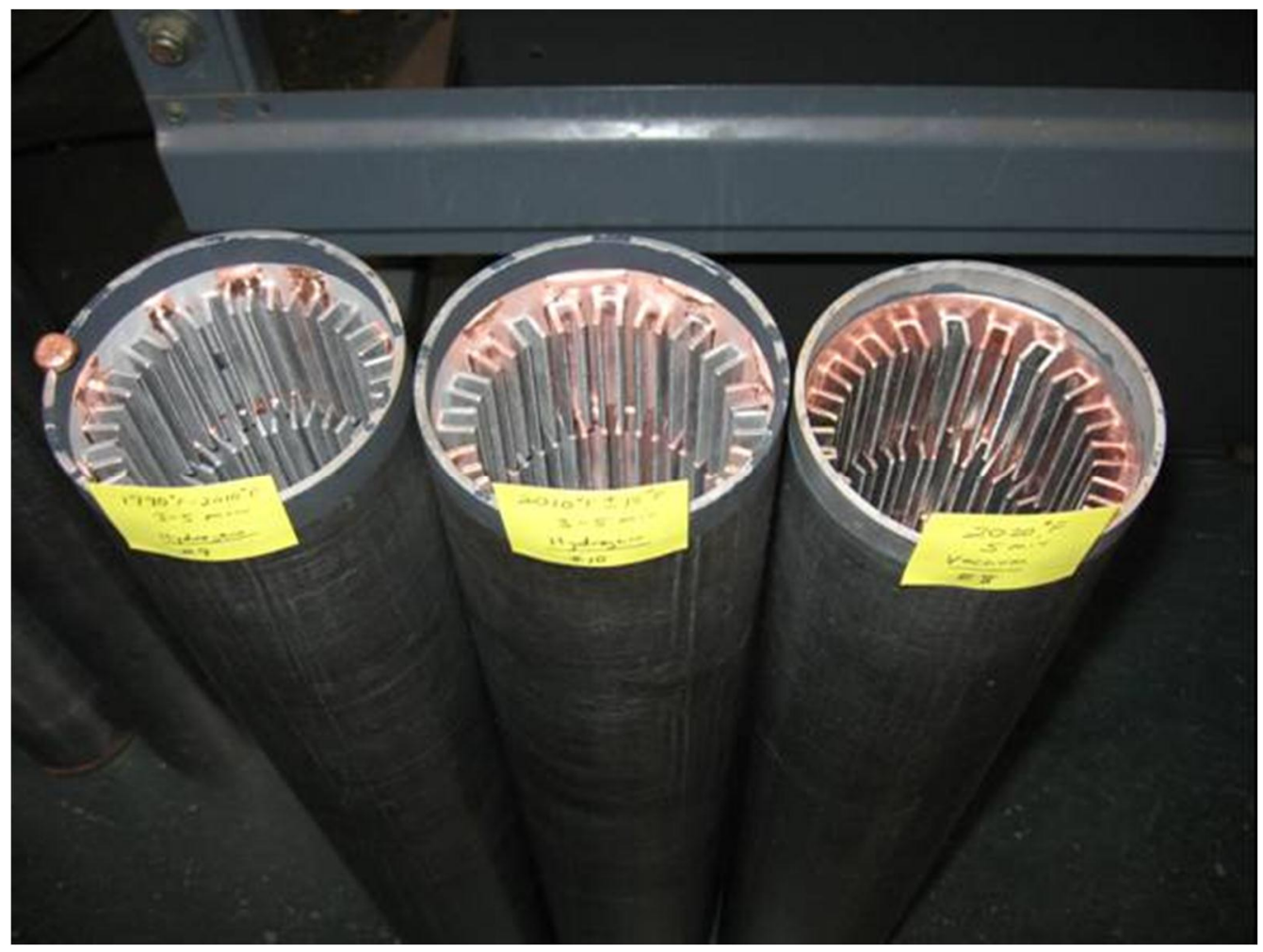

Figure 33. Three Firetubes Brazed at Successively Higher Temperatures

For these tests a vacuum oven was used and braze temperatures were increased over those used previously and braze times were 8 minutes (at braze temperature) for firetubes 11 and 12 and 4 minutes for firetube 13. The firetubes, shown in Figure 34, showed excellent results and revealed little benefit in increasing braze times. As such, brazing times in this range will be deemed as adequate for future firetubes. 


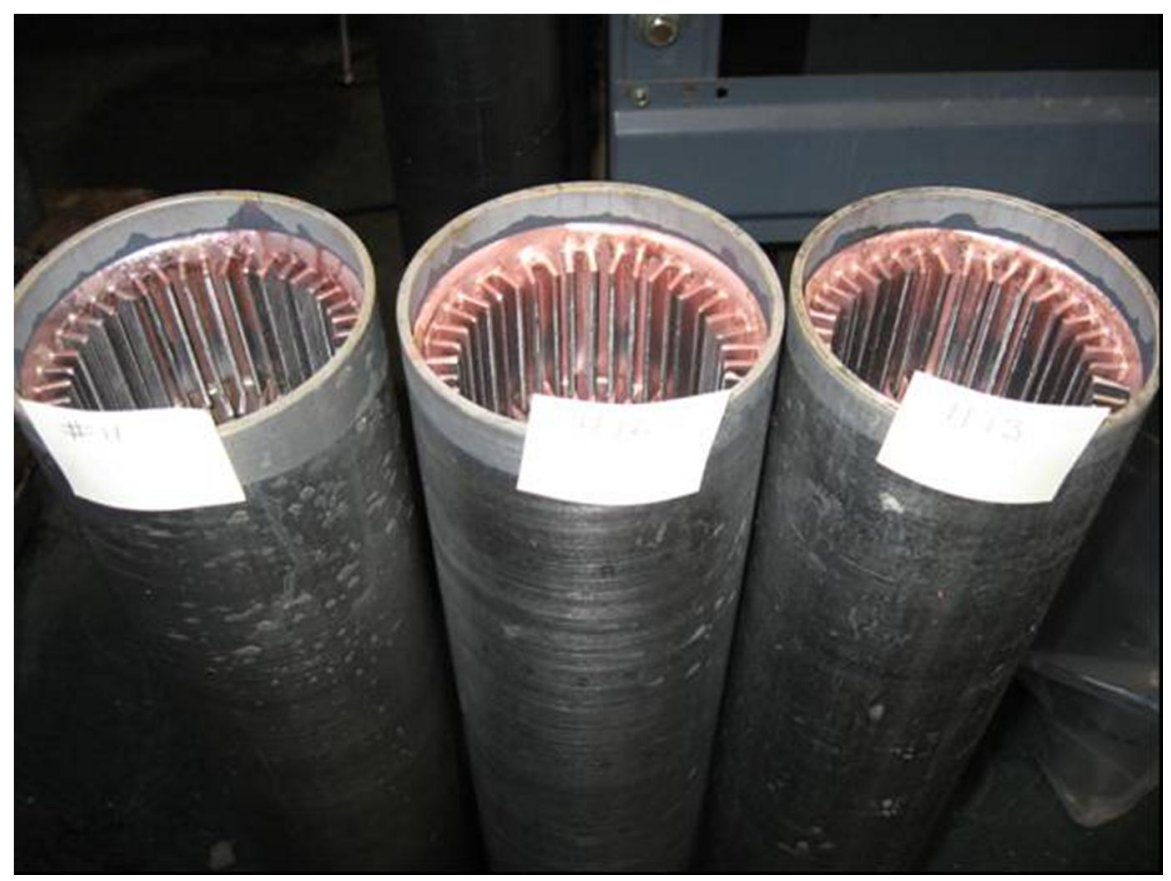

Figure 34. Firetubes 11, 12 and 13 showing excellent braze joints

Based on the excellent results obtained, it is believed that the specification for brazing the firetube fins was written.

Two additional firetubes were then brazed to verify the accuracy of the brazing specification and the ability of the vacuum brazer to perform the process. Both of these firetubes proved to have excellent brazing. Subsequent to this operation, the brazer asked Rocky to consider the use of less brazing material as a cost cutting measure.

Rocky revisited the braze material issue and worked with vendors in developing more cost efficient brazing. Rocky originally used twelve 1/8òthick braze rings in the firetube that are made of CDA 101. This copper is $99.99 \%$ pure and is oxygen free. In conversations with the vendor and brazer, it was determined that we could use CDA 102 copper as a replacement. This copper specification is $99.95 \%$ pure and is also oxygen free and costs approximately $39 \%$ less than CDA 101. In addition to this, our analysis showed that decreasing the braze ring thickness to 3/32ò would reduce the amount of braze material used by $43 \%$. For these reasons, CDA 102 copper braze rings were purchased. These were used in brazing tests for two additional firetubes. These two changes are expected to reduce the cost of the braze material by $65 \%$. 
Photos of the leading edge end of these two firetubes are shown as Figures 35 and 36. As the photos show, excellent brazing occurred using these new braze rings. Also, because of the reduction of braze material, there is less excess braze material collecting at the end of the firetube.

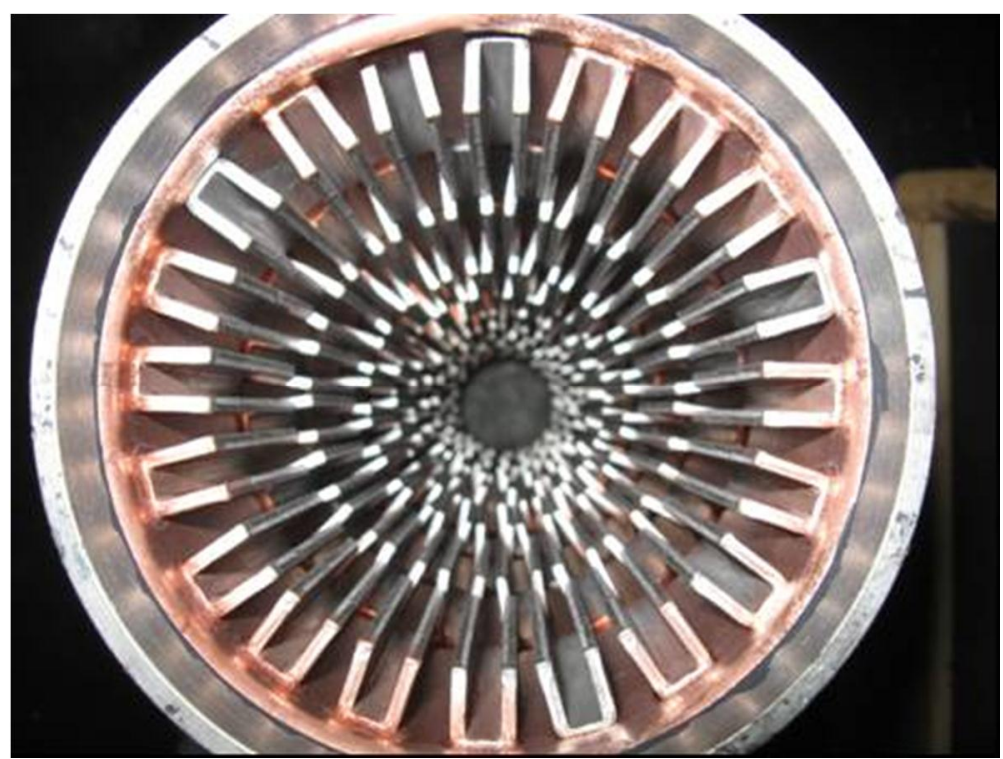

Figure 35. First of Two Firetubes Brazed in December

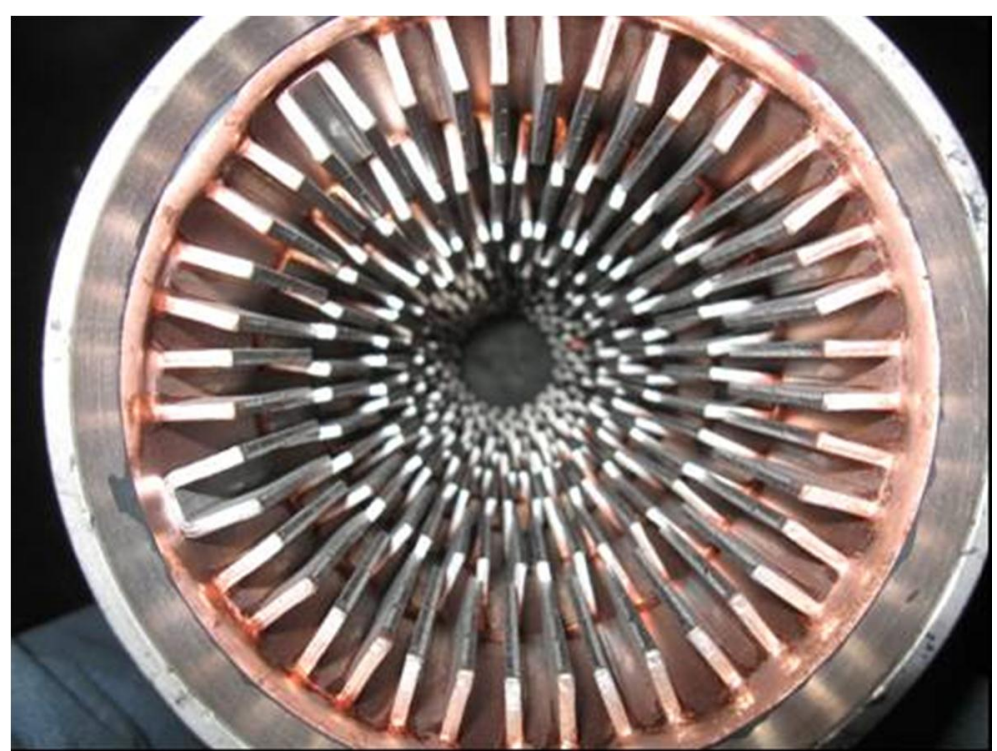

Figure 36. Second of Two Firetubes Brazed in December

Three firetubes were then brazed to determine the repeatability of the new brazing specification. Photos of the leading edge of these three heat exchangers are shown in Figure 37 to 39. As with the earlier firetubes using CDA 102 copper and 3/32ò braze 
rings, the amount of excess copper slag shown is very little. This means that no subsequent manufacturing step is now required to remove this slag.

The figures show good wetting between the fins and the shell with excess braze material forming a wetting angle between the two. However, each of the firetubes appears to have a couple of fins where this wetting angle does not appear. While this may have no effect on performance because of adequate braze material underneath the fin root (as has been observed in the past.

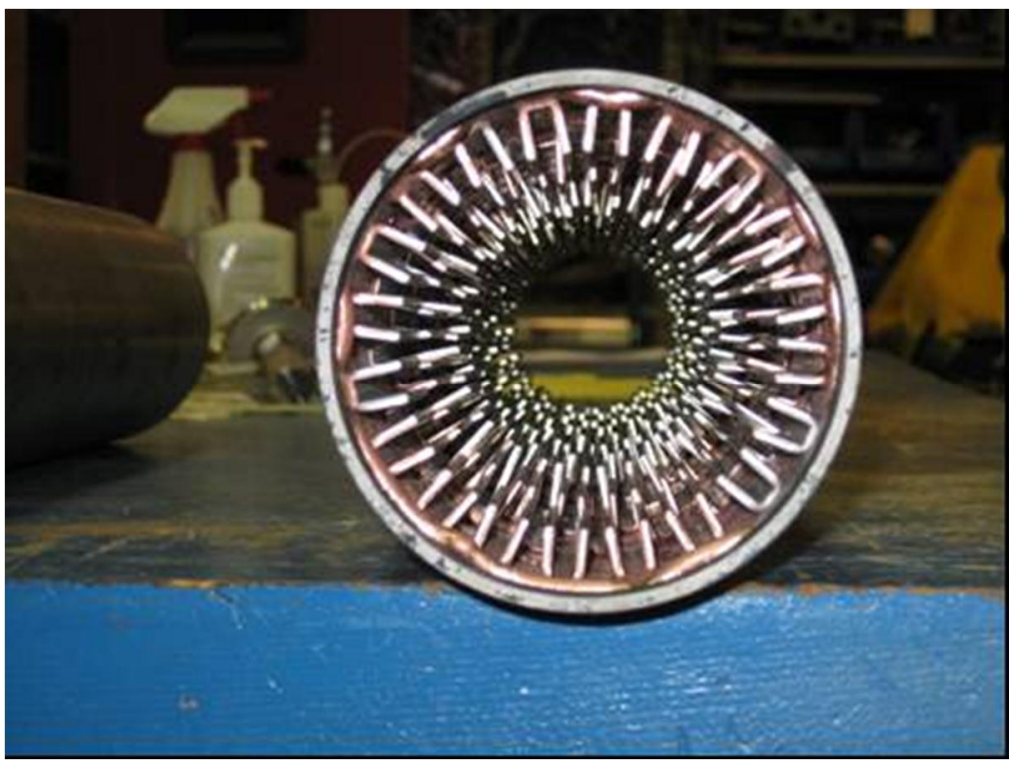

Figure 37. First of three firetubes

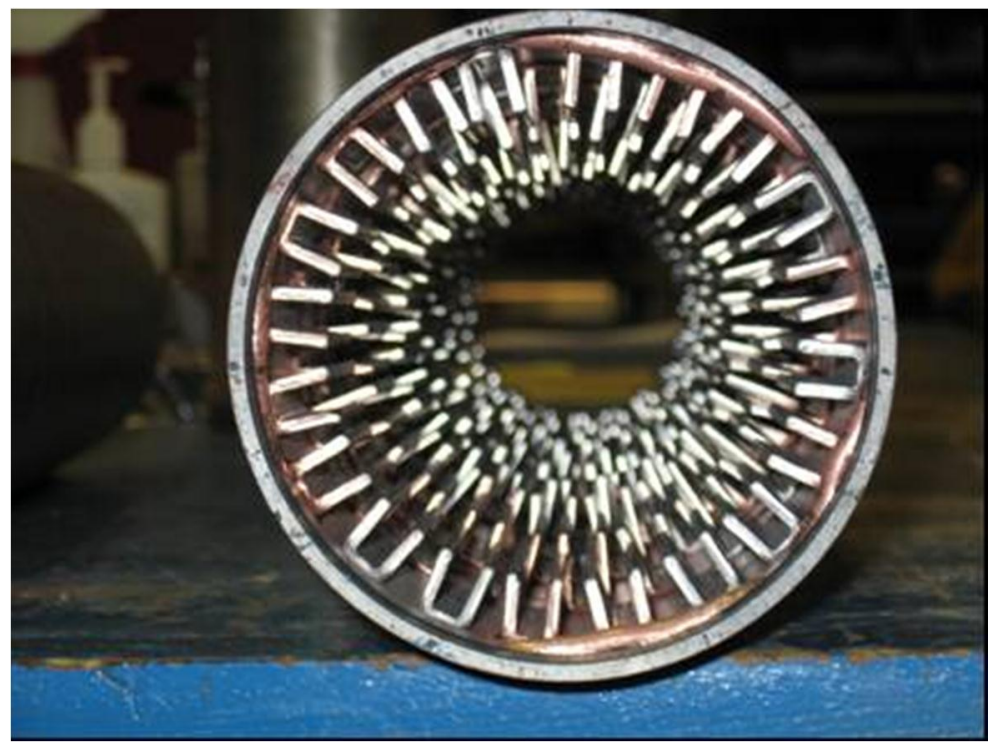

Figure 38. Second of three firetubes 


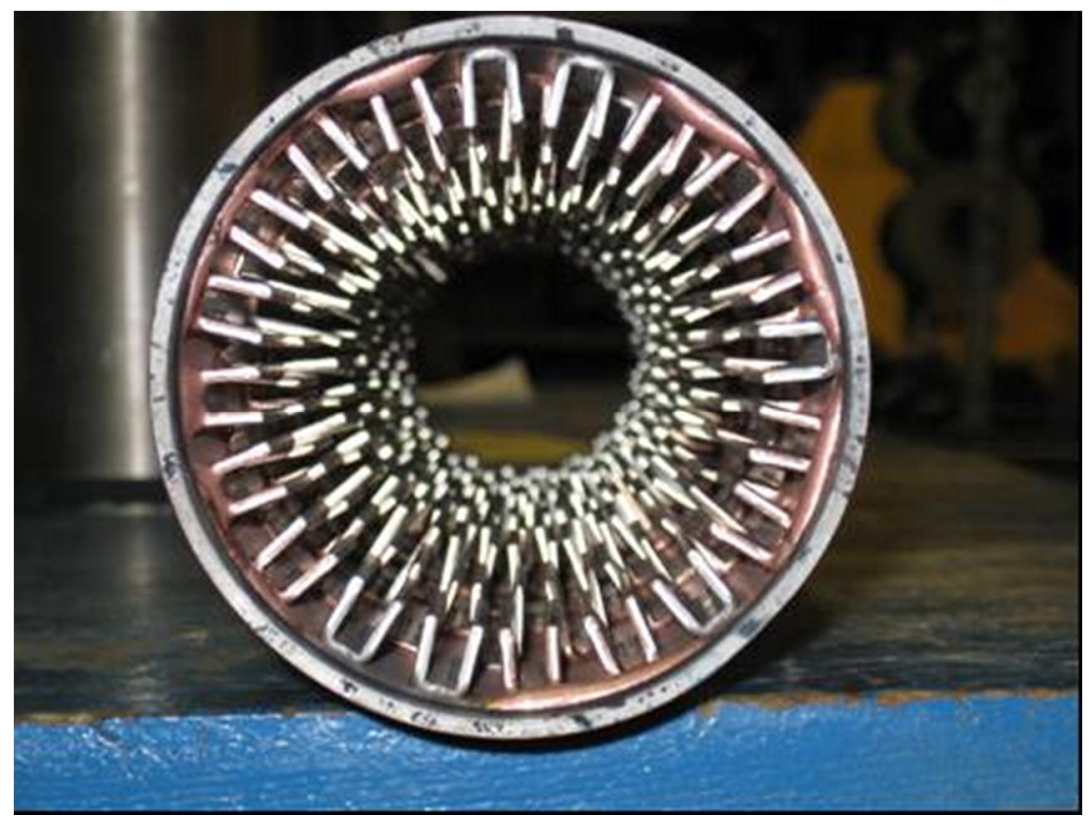

Figure 39. Third of three firetubes

\section{Generator Castings}

Early testing showed that some generators could develop small leaks at the casting. One such casting was dissected found to be porous in the region between the igniter hole and the burner hole. In this region of the casting there is little distance between the two and the flow of casting material can be compromised during the casting process. For this reason, a change to the casting design was investigated.

Inspection of new generator castings also revealed that a potential porosity issue may still exist on the internal boss of the igniter flange. This was an issue with the first castings received during earlier efforts where leaks were detected in one of the tapped holes. After careful inspection it was concluded that the proximity of the igniter boss and the burner boss are such that metal flow in the mold may be not be distributing properly, causing this defect. Figure 40 shows the igniter and burner bosses while Figure 41 shows the location of the area of greatest porosity potential with respect to these. 


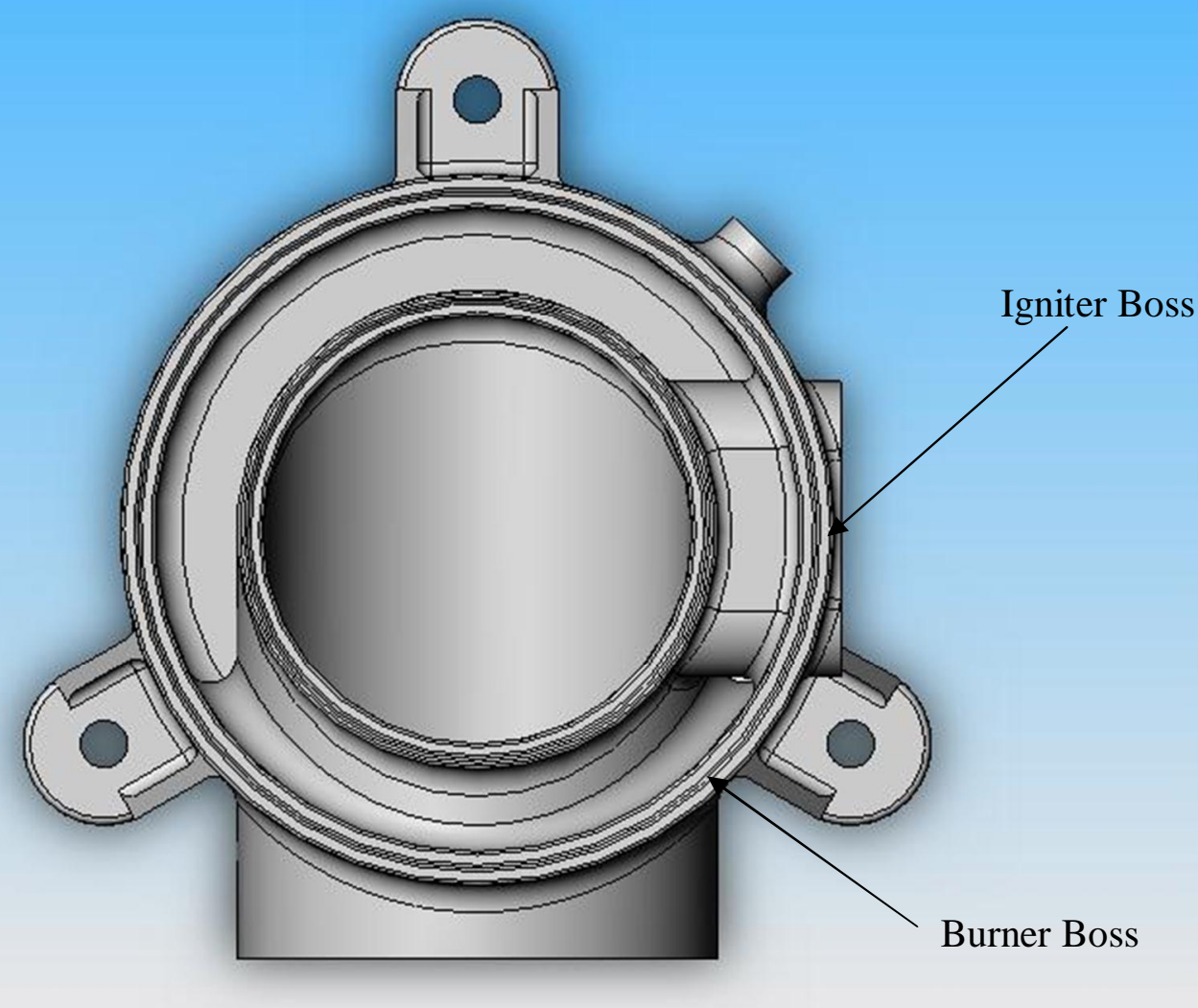

Figure 40. Casting solid model showing bosses

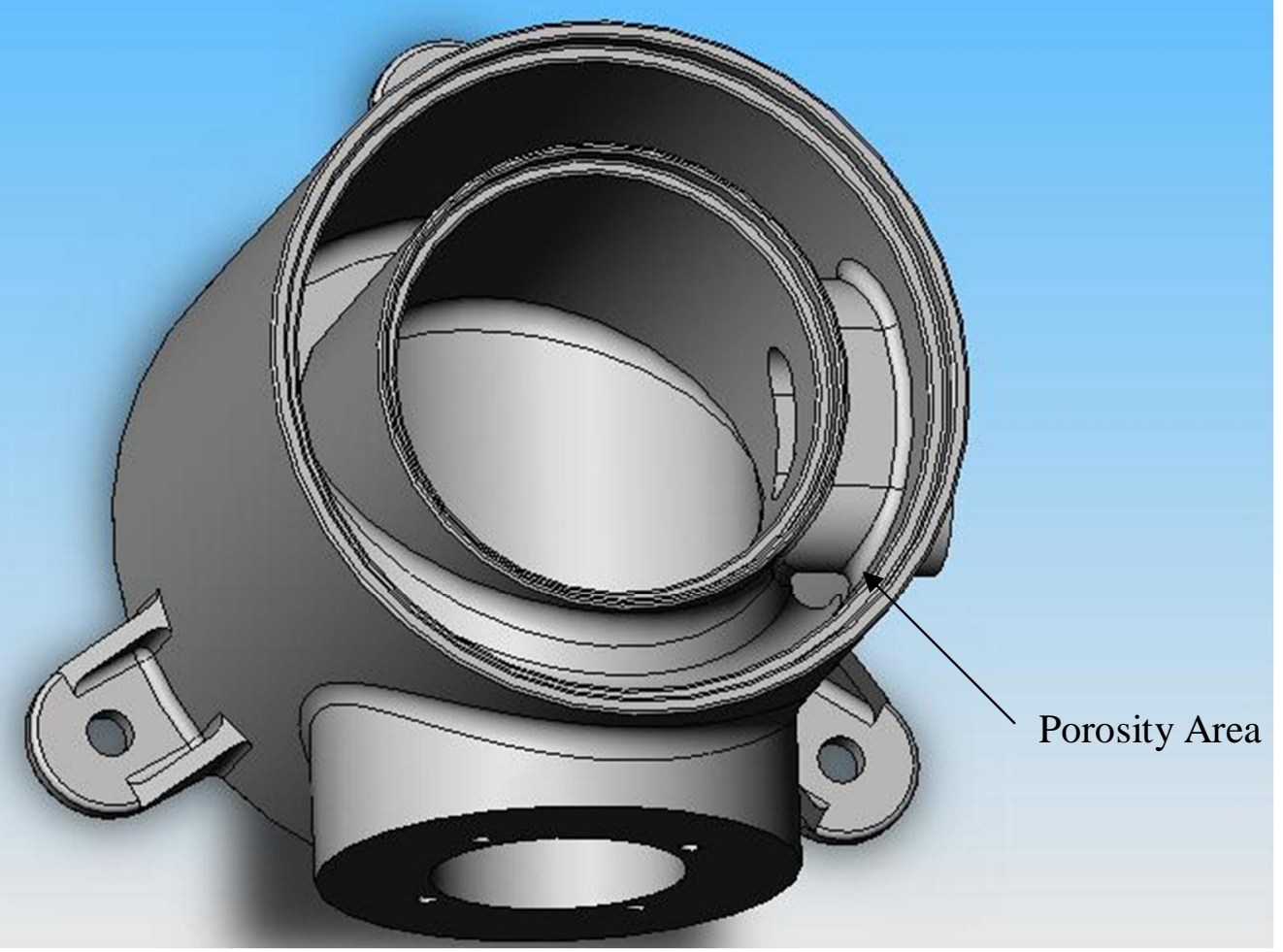


Figure 41. Solid model of casting showing porosity area

To alleviate this problem the generator casting was redesigned to re-orient the igniter boss 120 degrees from the burner flange instead of the original 90 degrees. In order to do this however the lower NPT boss used as a drain was also reoriented as well. Detailed drawings for this new configuration were completed with the necessary specification of tolerances, draft angle and other issues relevant to this new design were made. Figure 42 is a solid model of the newly designed casting.

No leaks were observed upon testing after this change to the casting design was made.

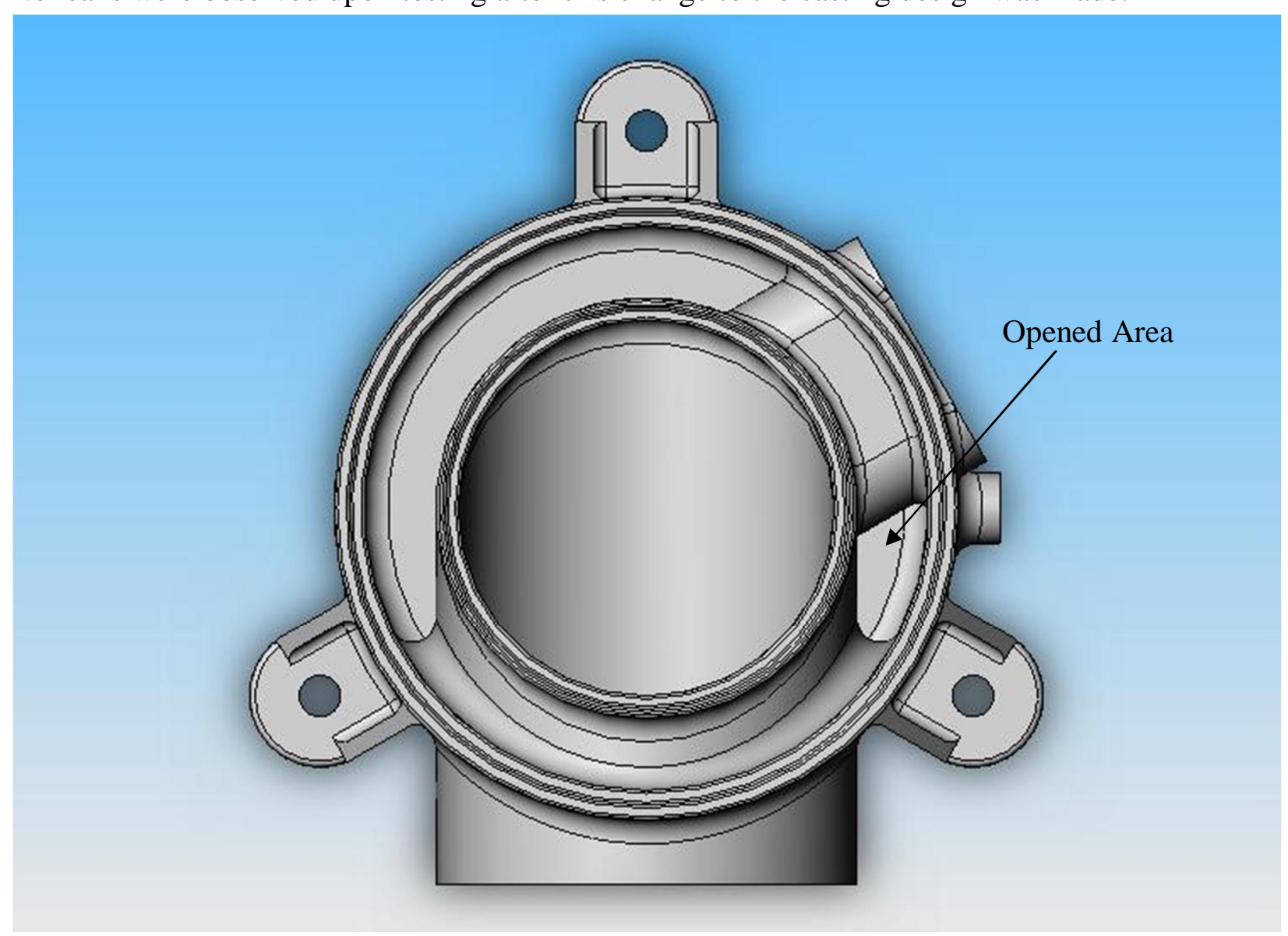

Figure 42. Solid model of newly designed casting with larger open area

\section{Generator Surge Tank}

A generator was modified to increase the solution tank size to determine the effect on system performance. One performance shortcoming with the original design is that as 
high side pressure varies, the volume liquid level in the generator can either be too high, leading to flooding of the adiabatic section, or too low, leading to loss of liquid level and resultant firing delay. Because of this shortcoming, high side pressure is controlled to a minimum of approximately 220 psia when on high fire and approximately 200 psia when on low fire using fan speed control. This affects the cycle thermodynamically, since at lower ambient temperatures if the unit were allowed to operate at lower high side pressure, the COP would improve.

To alleviate this, a generator was refitted with a larger surge tank, which, like the original unit is mounted on the side of the generator vessel centered at the liquid level sensor. Replacement of the tank required cutting off the original tank and welding the new tank with the associated end cap and connection transition. The unit was then pressure tested to 400 psi to ensure that it was leak tight.

The generator was installed in an absorption system assembly for testing. Tests were conducted over a range of ambient temperatures and the absorption system assembly was able to operate at a high side pressure of 169.1 during low fire at an ambient temperature of $64^{\circ} \mathrm{F}$. Figure 43 , showing the operation of the apparatus under this condition follows.
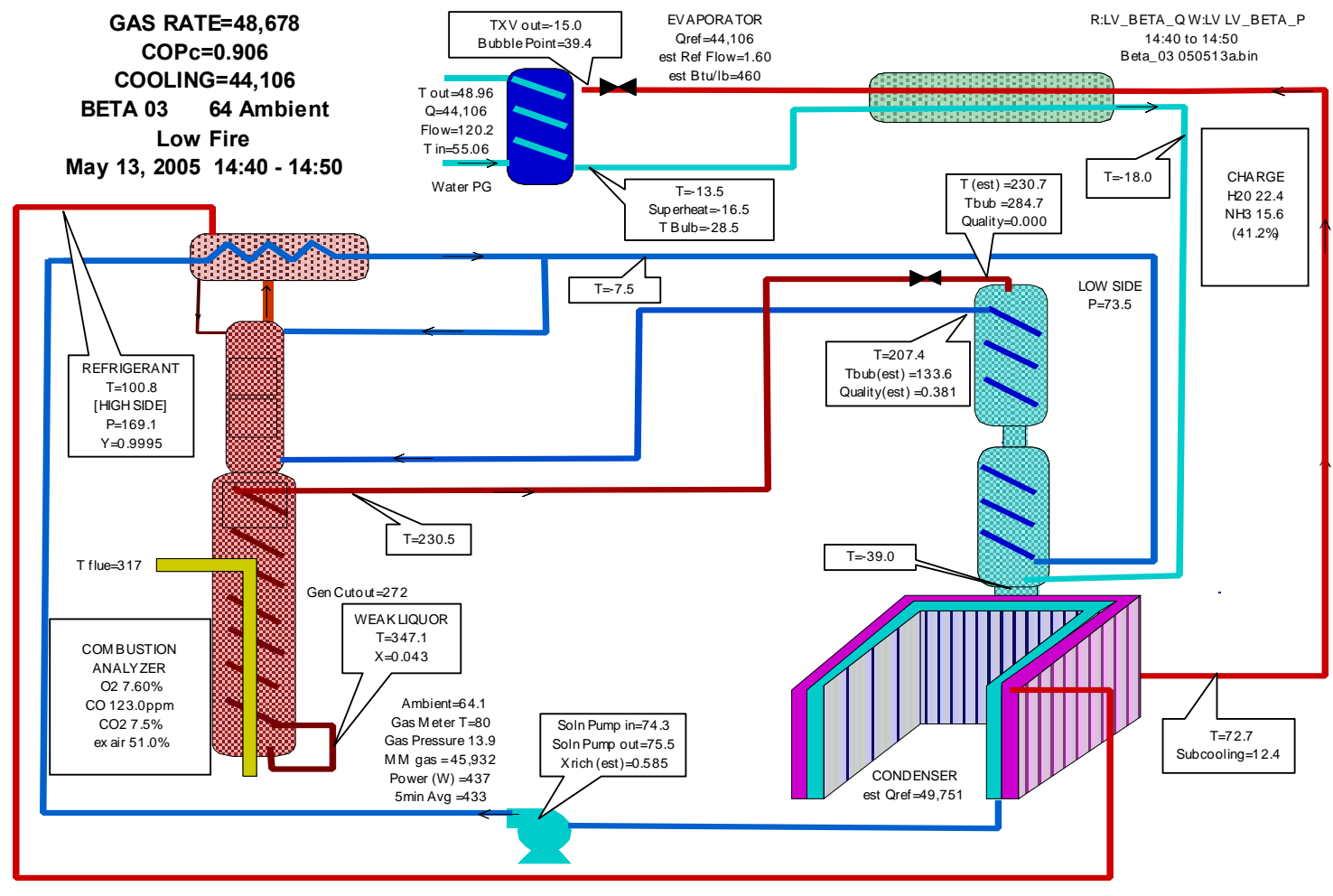

Figure 43. Test Data for Absorption Test Apparatus with Generator with Large Surge Tank 


\section{Generator Heat Exchanger (GHX) and Firetube Testing}

A method for testing the operational tolerances for the Generator Heat Exchanger (GHX) portion of the generator as well as the firetube was established. A test station that consolidates two post assembly tests of the generator was completed and tests of four fabricated generators were performed. Figure 44 shows a picture of the test station with a generator installed. The test station is capable of testing both the combustion side pressure drop as a function of nitrogen flow rate as well as the GHX pickup tube pressure drop as a function of nitrogen flow rate. The test station includes two rotometer type flow meters and two pressure gauges, one set for each test. Also included are thermocouples for the measurement of the nitrogen temperature.

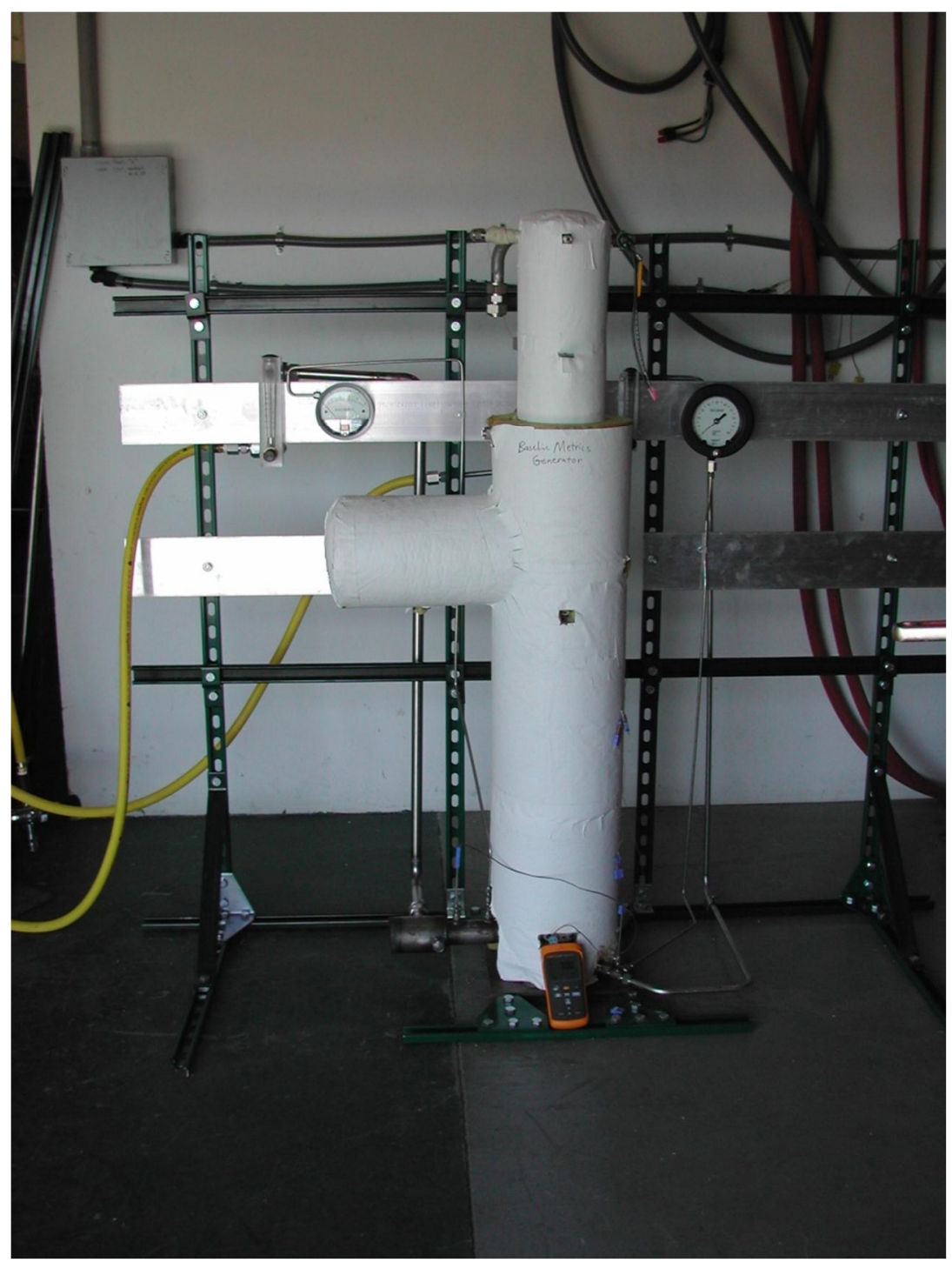

Figure 44. Generator Post Fabrication Test Station 
Results of these tests are shown on Figure 45 and Figure 46. Figure 45 shows the test results for the firetube and flue of the first four generators as well as the generator casting only, with exhaust into the open air. This is shown so that the pressure drop of the firetube and flue only can be determined as the difference between the generator curves and the casting only curve. The tests show reasonable consistency (within 10\%) in pressure drop, which has little effect on combustion performance.

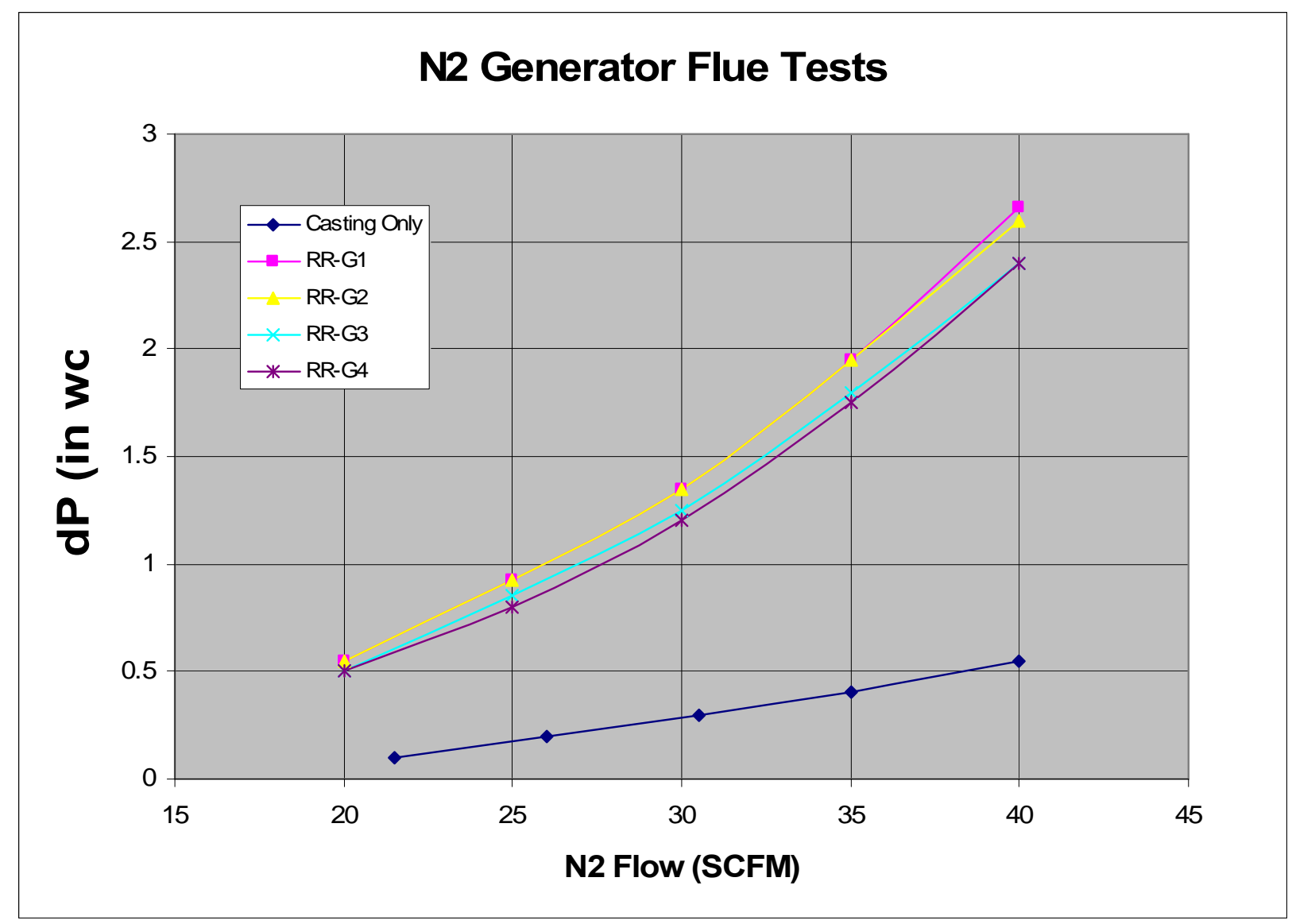

Figure 45. Generator Firetube and Flue Pressure Drop Tests

Figure 44 shows the generator GHX tube test results. These tests also show a maximum differential at the maximum flow rate tested of $8.3 \%$, and up to $25.3 \%$ at the lowest flow rate (which is the most inaccurate). If the worst case difference is applied to the design liquid pressure drop of 6.35 psi for the GHX tube during operation, it results in a pressure drop differential of 1.58 psi. Since the design pressure drop between the high and low pressures of the chiller is $200 \mathrm{psi}$, a 1.58 psi perturbation would only result in a flow rate change of $0.4 \%$, which is trivial. Therefore, the differentials shown in Figure 46 alone will not have an effect on chiller performance. 


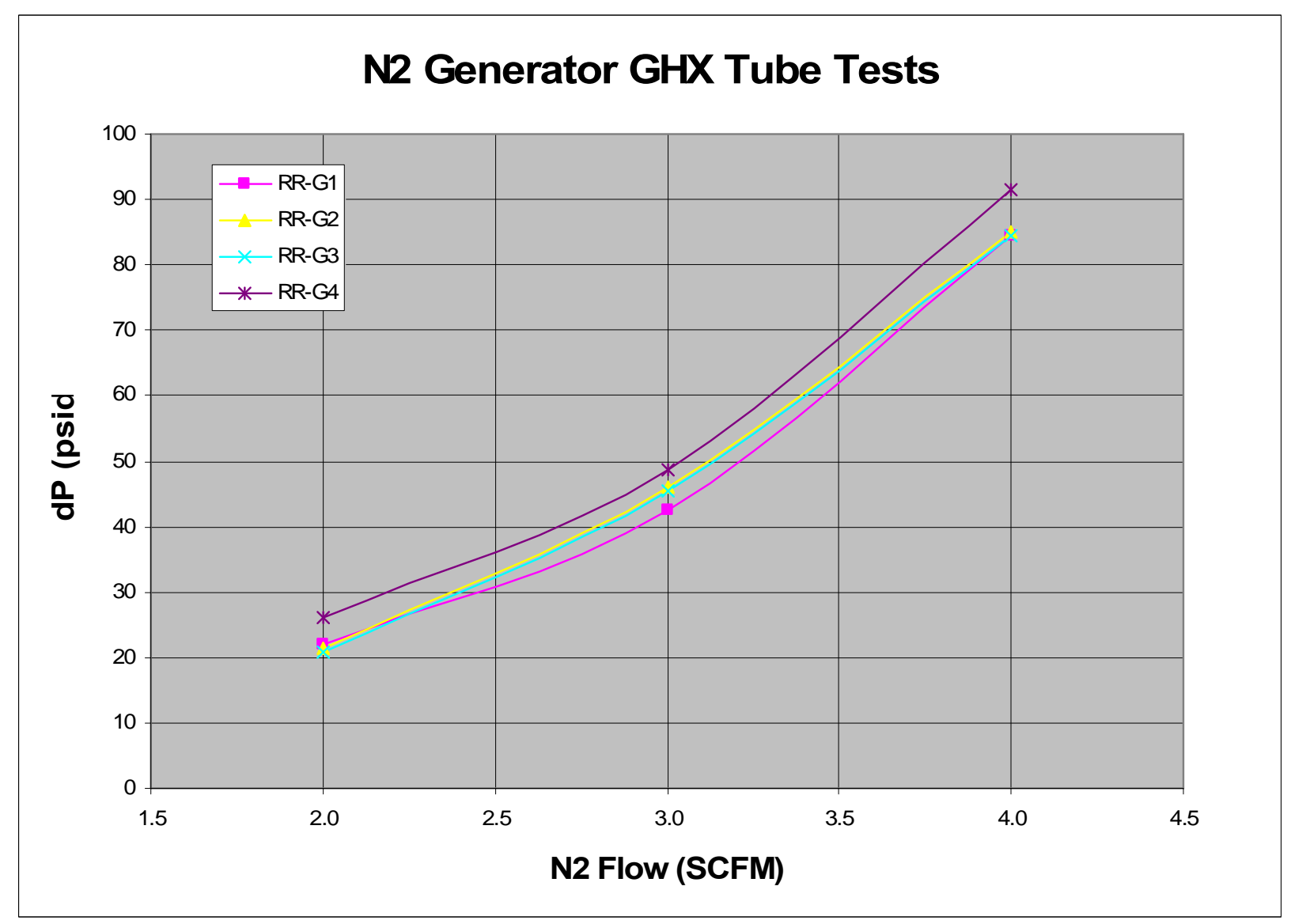

Figure 46. Generator GHX Tube Pressure Drop Tests

\section{Baseline Metrics Generator Testing}

Based on the design tolerances arrived at, the design and fabrication of the first metrics generator was completed. Figure 47 is a picture of the completed generator. 


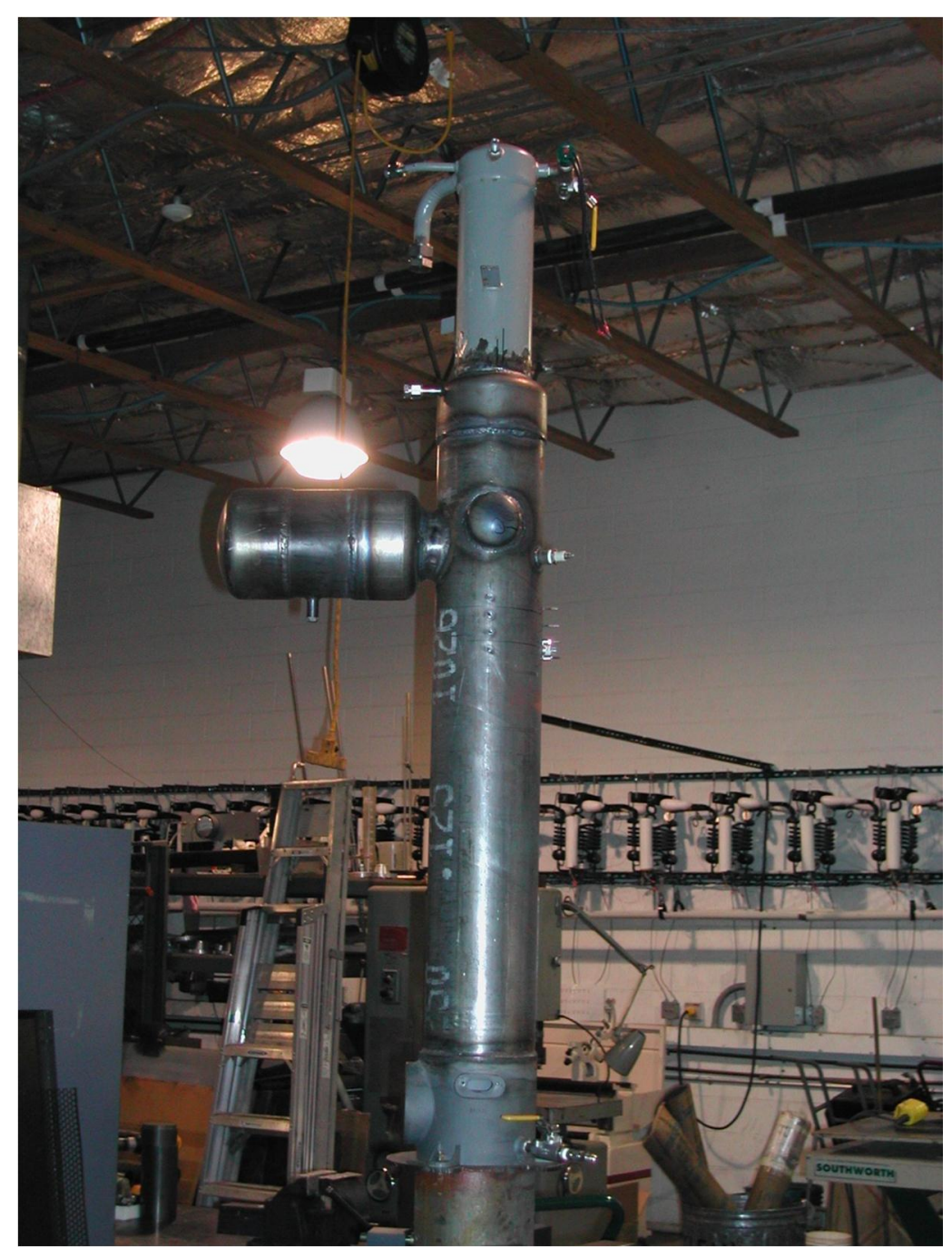

Figure 47. Photograph of the first metrics generator

The baseline generator was tested in an absorption system assembly. Figure 48 shows the result of this testing. As the figure shows, operation resulted in a weak solution concentration of $4.9 \%$ with a GHX outlet temperature of $287.8^{\circ} \mathrm{F}$ generator. These temperatures, as well as a GHX heat transfer rate of $18,473 \mathrm{Btu} / \mathrm{hr}$ are nominal for the design. Also, the flue temperature of $406^{\circ} \mathrm{F}$ results in heat output from the gas burner that is nominal. 


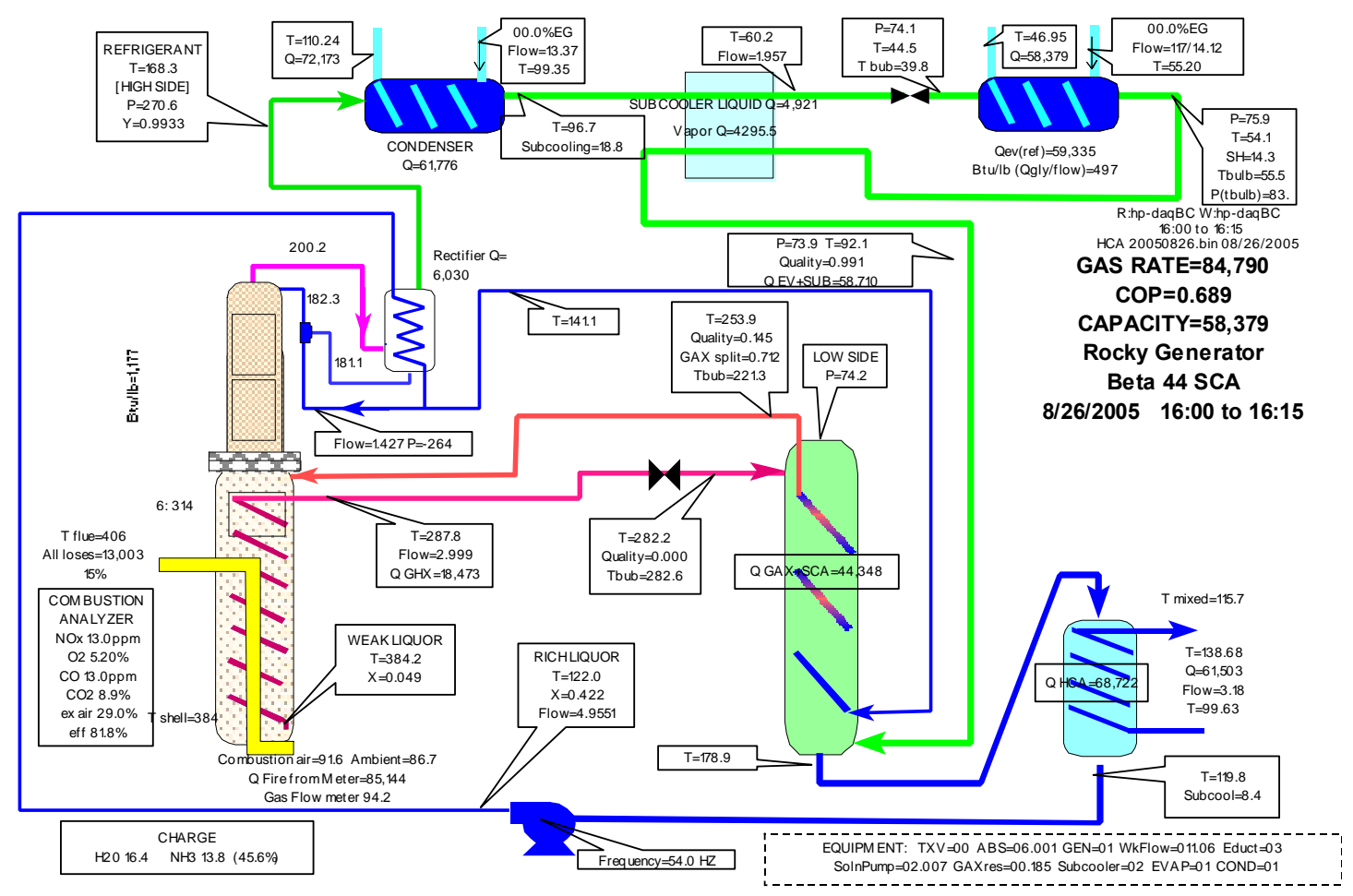

Figure 48. Test of Baseline Metrics Generator

Tests of a series of five additional baseline metrics generators were then completed. Table 1 shows a list of these tests. The generators are numbered RR-G1 to RR-G5. These generators included five firetubes that were assembled at Rocky Research and brazed by our supplier. The goal of these tests was to determine the variability in performance for a series of generators that were assembled identically.

As Table 1 shows, there was some variability in performance with COPôs ranging from 0.658 to 0.695 and capacities between 56,704 and 59,016 Btu/hr. However, the lowest performing test (RR-G4) may have been somewhat erroneous because of the discovery later that the performance could be improved with successive cleaning of the system by dumping the systemôs aqua-ammonia charge and then recharging. This operation was found to clean the generator surfaces and improve capacity and COP. Nevertheless, these results show that the variability in COP with ñdenticalò generators will likely be approximately 0.03 . This is an important result to note since with dimensional or tolerance metrics changes to the baseline generator design, only differences in COP greater than this can be considered truly significant. 


$\begin{array}{cccccc}\text { TEST DATE } & \begin{array}{c}\text { ABSORBER } \\ \#\end{array} & \begin{array}{c}\text { GENERATOR } \\ \#\end{array} & \begin{array}{c}\text { EVAP/SUB } \\ \text { TYPE }\end{array} & \text { CAPACITY } & \text { COP } \\ \text { 9/22/2005 } & \text { Beta \#16 } & \text { RR-G1 } & \text { Alpha } & 59016 & 0.695 \\ 10 / 3 / 2005 & \text { Beta \#16 } & \text { RR-G3 } & \text { Alpha } & 57252 & 0.664 \\ 10 / 4 / 2005 & \text { Beta \#16 } & \text { RR-G3 } & \text { Alpha } & 59008 & 0.688 \\ 10 / 5 / 2005 & \text { Beta \#16 } & \text { RR-G2 } & \text { Alpha } & 57532 & 0.669 \\ 10 / 7 / 2005 & \text { Beta \#16 } & \text { RR-G4 } & \text { Alpha } & 56704 & 0.658 \\ 10 / 12 / 2005 & \text { Beta \#16 } & \text { RR-G5 } & \text { Alpha } & 57956 & 0.677 \\ 10 / 12 / 2005 & \text { Beta \#16 } & \text { RR-G5 } & \text { Alpha } & 57740 & 0.666\end{array}$

Table 1. Baseline Generator Test Results

\section{Subtask 2.2 Absorber Metrics}

Efforts under this task included:

1. The determination of the viability of the surface enhancement method and tooling.

2. Then determination as to the dimensional tolerances required for the production of the helically would absorber core.

3. The determination as to whether special processes, such as oxidation, are required for the production of the absorber core.

4. The evaluation of the possibility of surface oxidation to enhance heat and mass transfer by improved wetting.

5. Testing of absorbers

\section{Surface Enhancement Tolerances}

Tube threading for the absorber has begun using a thread rolling process for extruding the 32 FPI thread onto the 5/80̀ OD tube. The commercially made thread roller uses a three die head that spins in the lathe as the tube is inserted. Once the tube is inserted the thread rolling die then self feeds the rest of the tube through the dies. Figure 49 is a picture of a completed tube. 


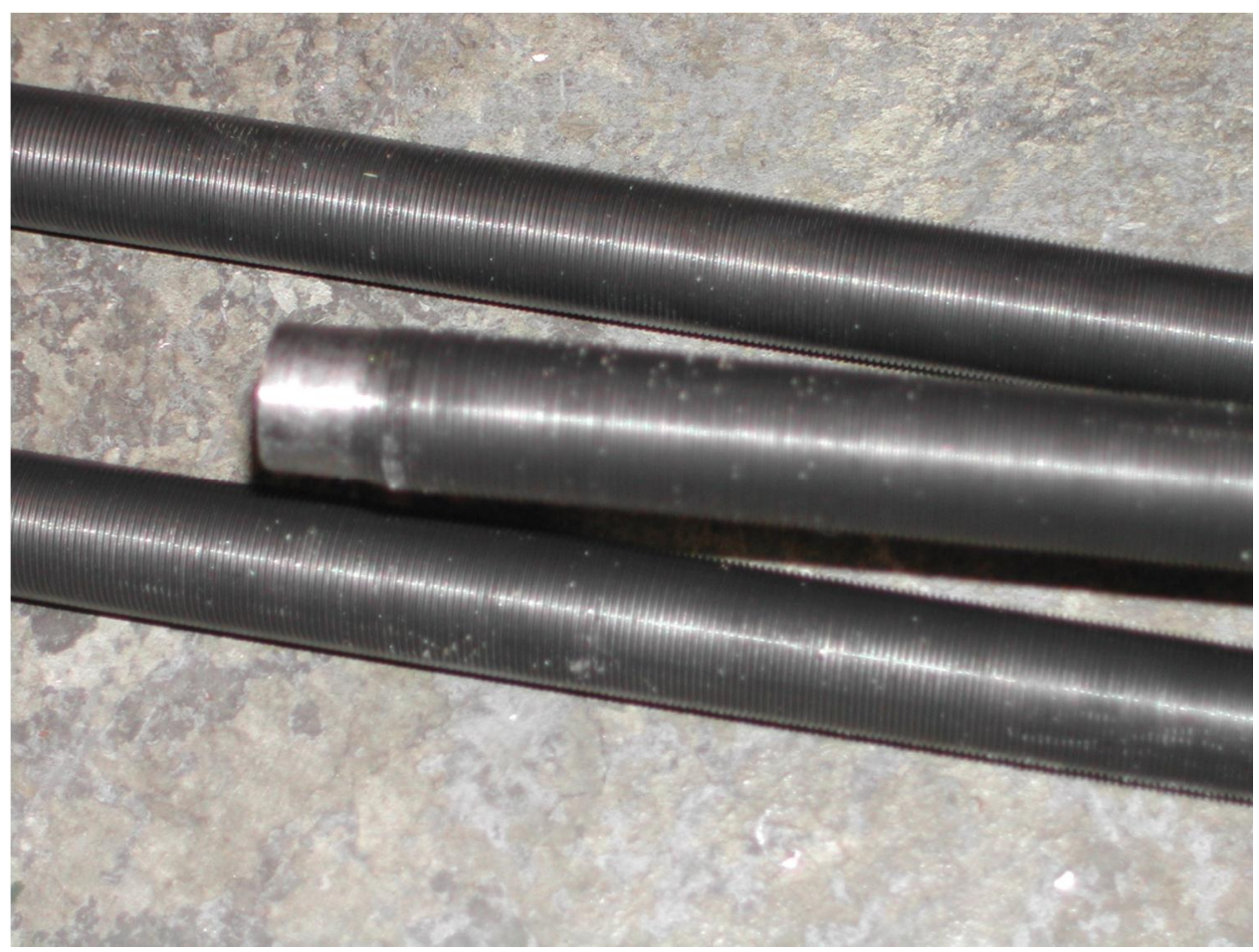

Figure 49. Threaded Absorber Surface

These studies used 4 different tube samples that were produced using the proscribed threading speed and measured both pitch to pitch and thread height. Dimensions were measured using an optical comparator, see Figure 50. Table 2 below shows the results of the study and the associated tolerance that was developed.

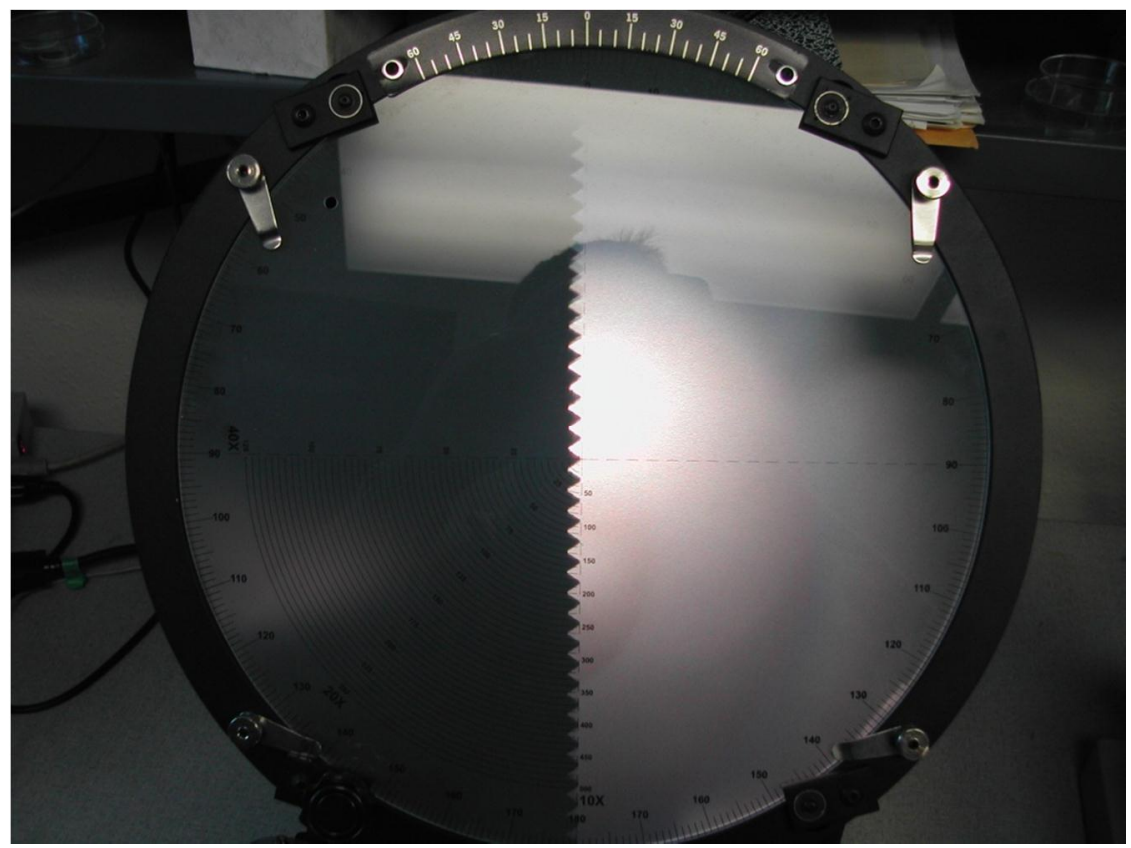

Figure 50. Thread profile on Optical Comparator 


\begin{tabular}{|c|c|c|}
\hline Sample & Pitch & Height \\
\hline \multirow[t]{5}{*}{$\begin{array}{l}\text { RR-A2 ï Inner } \\
\text { Tube }\end{array}$} & .0310 & .0190 \\
\hline & .0310 & .0185 \\
\hline & .0310 & .0180 \\
\hline & .0315 & .0185 \\
\hline & .0315 & .0185 \\
\hline Average & .0312 & .0185 \\
\hline \multirow[t]{5}{*}{$\begin{array}{l}\text { RR-A2 Ï Outer } \\
\text { Tube }\end{array}$} & .0310 & .0190 \\
\hline & .0315 & .0180 \\
\hline & .0310 & .0185 \\
\hline & .0315 & .0185 \\
\hline & .0310 & .0190 \\
\hline Average & .0312 & .0186 \\
\hline \multirow[t]{5}{*}{$\begin{array}{l}\text { RR-A3 ï Inner } \\
\text { Tube }\end{array}$} & .0320 & .0195 \\
\hline & .0310 & .0190 \\
\hline & .0310 & .0190 \\
\hline & .0315 & .0195 \\
\hline & .0310 & .0195 \\
\hline Average & .0313 & .0193 \\
\hline \multirow[t]{5}{*}{$\begin{array}{l}\text { RR-A3 Ï Outer } \\
\text { Tube }\end{array}$} & .0315 & .0200 \\
\hline & .0305 & .0190 \\
\hline & .0315 & .0195 \\
\hline & .0320 & .0190 \\
\hline & .0315 & .0190 \\
\hline Average & .0314 & .0193 \\
\hline
\end{tabular}

Table 2. Tube Pitch and Height Data

The results showed that a thread pitch can be held to a very good tolerance (within 0.00020 ), but the pitch height had a wider tolerance, (within 0.0008ò). 
These tolerances would not themselves hinder the assembly and operation of a finished absorber. For this reason, it was determined that the tooling used for tube enhancement is adequate for absorber use.

\section{Helix Dimensional Tolerances}

Sample coils that were fabricated are part of the metrics study to determine pitch tolerances during winding and, as will be described if the testing section, if different pitch configurations will have an impact on absorber performance. The winder was designed for this purpose and yielded very good quality samples from a manufacturing standpoint. Figure 51 is an example of a coiled bundles that were fabricated on the winder.

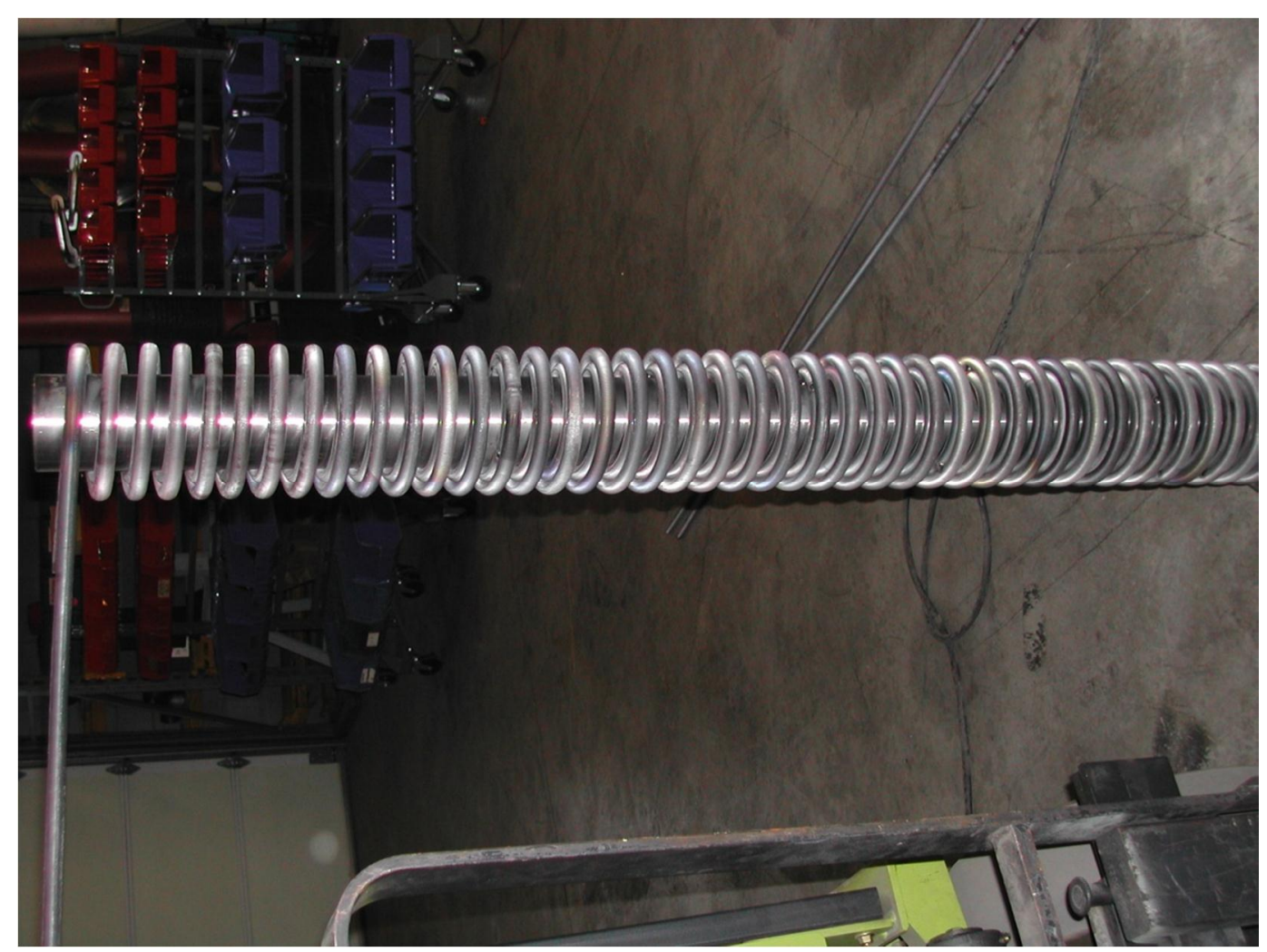

Figure 51. Coiled bundle ï 1.375ò pitch

These studies considered samples that were produced on the coiling machine using current specification of 1.250ò pitch for the absorber bundle. Multiple samples were run prior to the actual coiling to make the necessary adjustments for obtaining this pitch. Once the winder was set for the desired pitch, both samples were run with just the inner tube first to assure the die position would not change. Pitch was measured from the inside 
edge of the tube to the next corresponding inside edge along the same plane. See Figure 52 below for illustration of measuring technique.

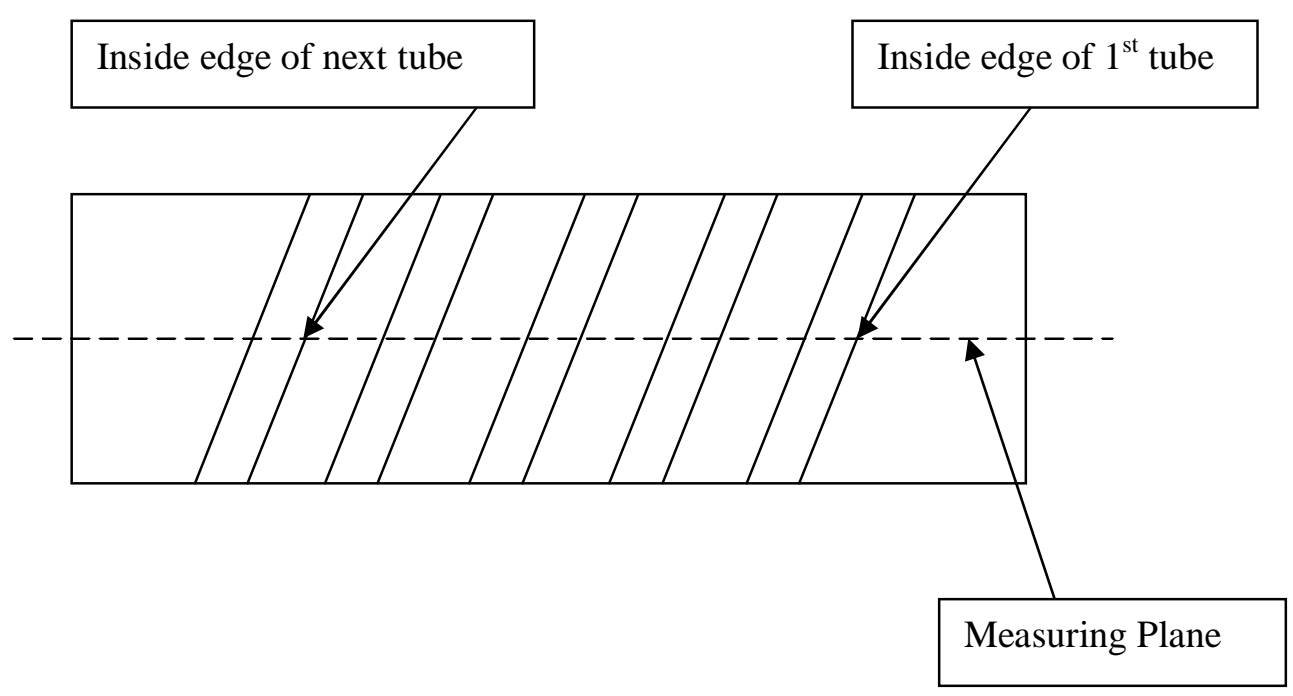

Figure 52. Measuring Technique

The pitch was measured over a total of 9 wraps and then averaged. This was done in four different locations down the length of the bundle. A total length measurement was also taken as a reference dimension. These results are shown below in Tables 3 and 4 for absorbers RR-A2 and RR-A3. 


\begin{tabular}{|c|c|}
\hline Trial & Average Measurement \\
\hline $1^{\text {st }}, 9$ wraps & 1.277 ò \\
\hline $2^{\text {nd }}, 9$ wraps & 1.300 ò \\
\hline $3^{\text {rd }}, 9$ wraps & 1.263 ò \\
\hline $4^{\text {th }}, 9$ wraps & 1.277 ò \\
\hline Total Ave & 1.297 ò \\
\hline 40 wraps $=51.875$ ò & 1.297 ò \\
\hline
\end{tabular}

Table 3. RR-A2

\begin{tabular}{|c|c|}
\hline Trial & Average Measurement \\
\hline $1^{\text {st }}, 9$ wraps & 1.277 ò \\
\hline $2^{\text {nd }}, 9$ wraps & 1.277 ò \\
\hline $3^{\text {rd }}, 9$ wraps & 1.263 ò \\
\hline $4^{\text {th }}, 9$ wraps & 1.277 ò \\
\hline Total Ave & 1.274 ò \\
\hline 42 wraps $=53.9375$ ò & 1.284 ò \\
\hline
\end{tabular}

Table 4. RR-A3

Coil Winding Tolerance

Tolerance on Pitch $($ RR-A2) $=1.300$ òï 1.263 ò $=0.037$ ò

Tolerance on Pitch $($ RR-A3) $=1.277$ òï 1.263 ò $=0.014$ ò

Average Tolerance $\quad=\quad \pm .0255$

For manufacturing purposes tolerance should be rounded up to $\pm .032 \grave{o}$

\section{Heat Treatment}

\section{Annealing}

As a result of the work hardening of the tube that occurs during the threading process, an annealing procedure is needed previous to winding. The new apparatus for continuously annealing both the absorber tube was built and tested.

The need for an improved annealing process was determined when, during the winding process of absorber coils it was observed that flaking of the threaded tube occurred. This 
is a result of tube being exposed to the atmosphere while still at an annealing temperature. To prevent this flaking from happening, the new extended section for cooling the annealed tube with inert gas after the annealing process was added. The secondary section is using a lower pressure of nitrogen to cool the tube and ensure that back flow will not enter the annealing oven. Figures 52 and 53 are photos of an annealed tube without cooling with inert gas and with cooling with inert gas, respectively. As the photos show, the tube with gas cooling shows no flaking.

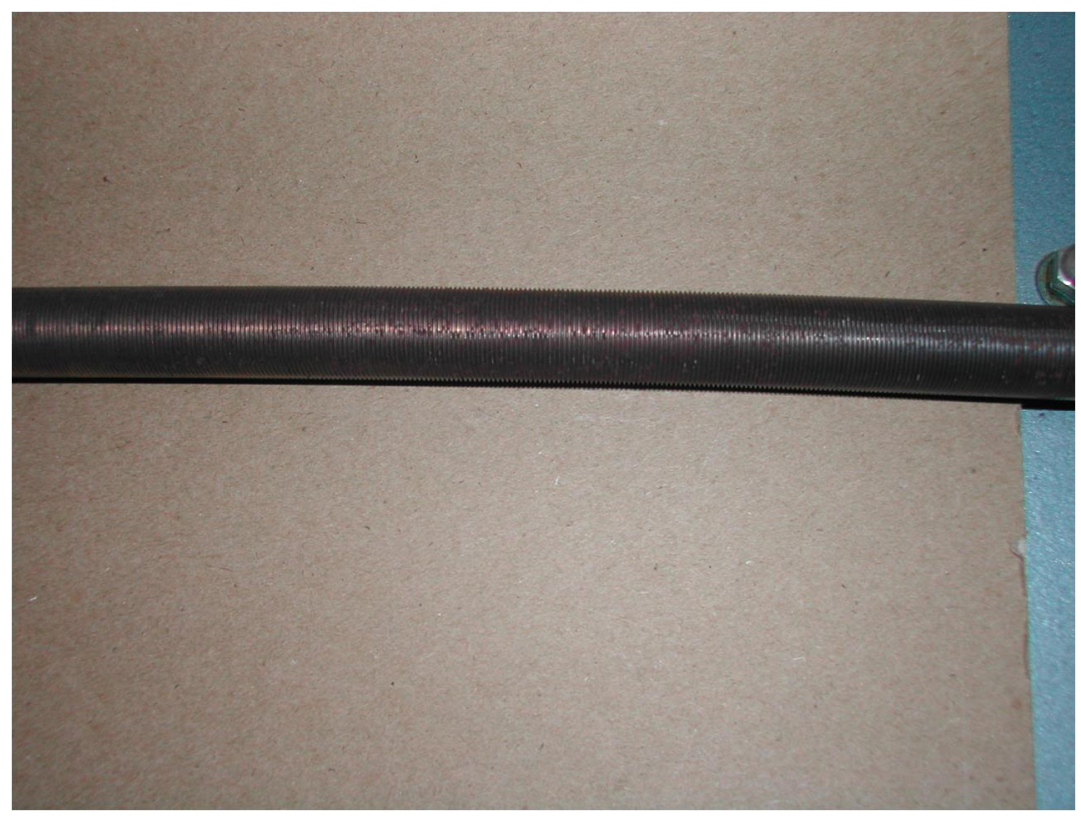

Figure 52. Annealed tubing without inert gas cooling

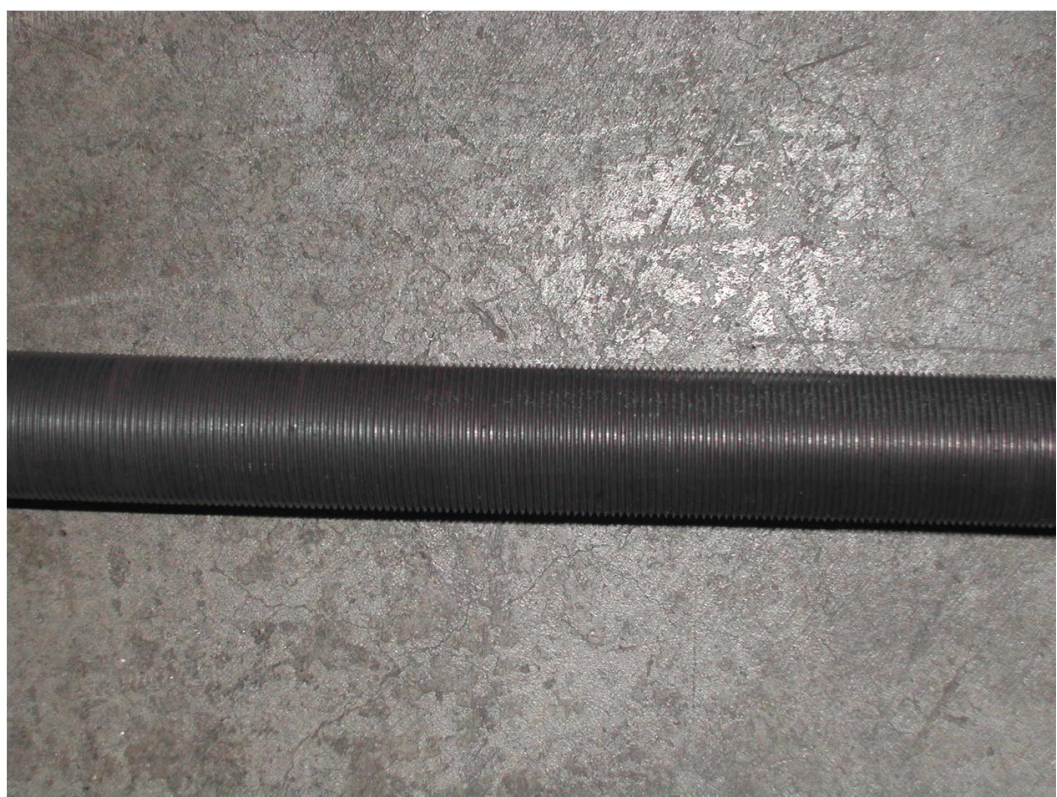

Figure 53. Annealed tubing with inert gas cooling 
Two sample coils were then fabricated on the winder machine and exhibited very minimal amounts of flaking, indicating that the secondary cooling section of the annealing oven is working. Figure 54 is a close up of a coiled bundle and the condition of the outer tube.

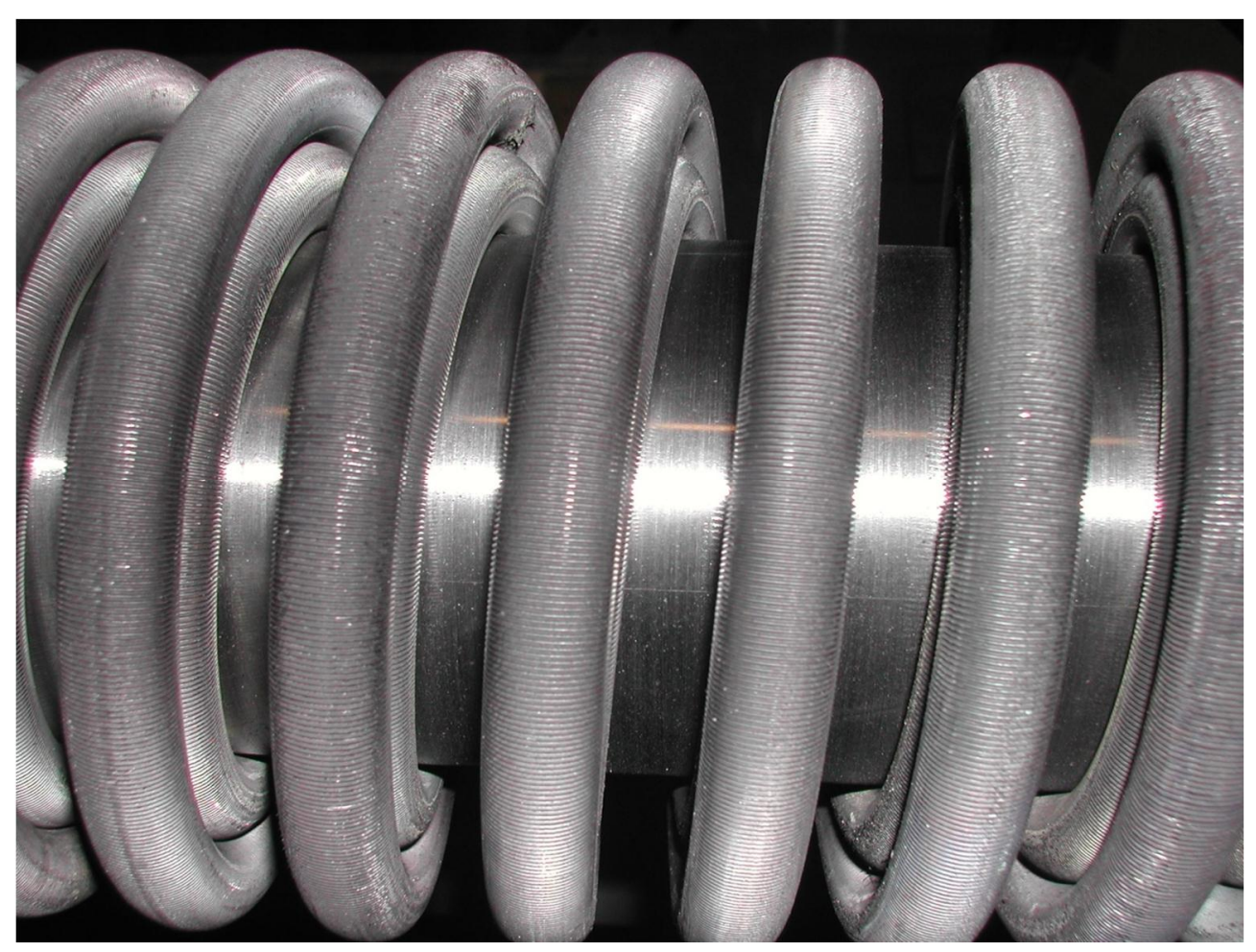

Figure 54. Close up of coiled bundle

\section{Conclusion}

This effort has concluded with the identification of the correct tubing pitch and the associated manufacturing tolerances using the assembly apparatus. It also established a means of annealing the tubing before helically bending.

\section{Subtask 2.3 Robust Flow Components Performance Issues}

1. Improvements in the design of the solution pump for reliability and minimization of the production of particulates for extremely long life operation.

2. Orifice pack with reliable solenoid valve for weak solution flow control.

3. Improvements in thermal expansion valve design for long life and improved reliability. 
4. Evaporator and subcooler redesign to more conventional designs for low cost production.

5. Development of a reversing valve suited for aqua-ammonia applications.

\section{Solution Pump}

Rocky Research began the solution pump efforts with an early design of a balanced diaphragm positive displacement pump. A solid model of the solution pump is shown as Figure 55. The major focus of these efforts was to develop the metrics, in terms of component designs and tolerances, required for extremely long (15 years operation) life of the solution pump. The addressing of issues related to this and long term testing of these pumps were pursued. Over the course of the project, long term testing of prototype solution pumps built with improved components were added to a life test rack and operated in a cyclical (on/off cycles) manner.

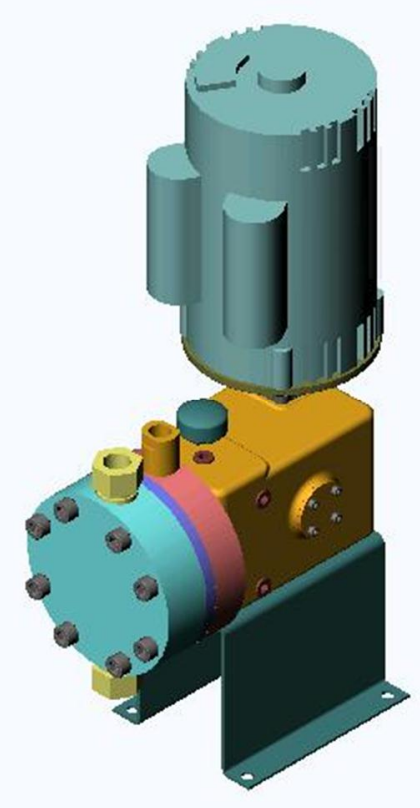

Figure 55. Solid Model of Solution Pump

Pump Stroke Issues

One of the major issues to be addressed was the generation of particulate matter in the oil, especially during the first few hundred break-in hours. The reason that this is 
important is that for an air conditioning or heat pump consumer product for residential or light commercial applications, very little service is allowed, and usually this occurs during a failure. For this reason, an oil change and filter requirement after a short period would not be practical.

Fortunately, the cause of virtually all of the breaking particulate matter was the eccentric. Inherent in the pump design is the fact that the plunger is not pressed on center by the ring/eccentric assembly. The contact line moves above and below center during each stroke. It was believed that this may be the cause of the plunger getting cocked in the cylinder and causing wear. To test this theory and possibly solve the problem we are built a new pump with a flat eccentric section that met the back of the plunger. This changed the line of contact to a plane and prevented the plunger from getting cocked in the cylinder. A picture of the eccentric is seen in Figure 56.

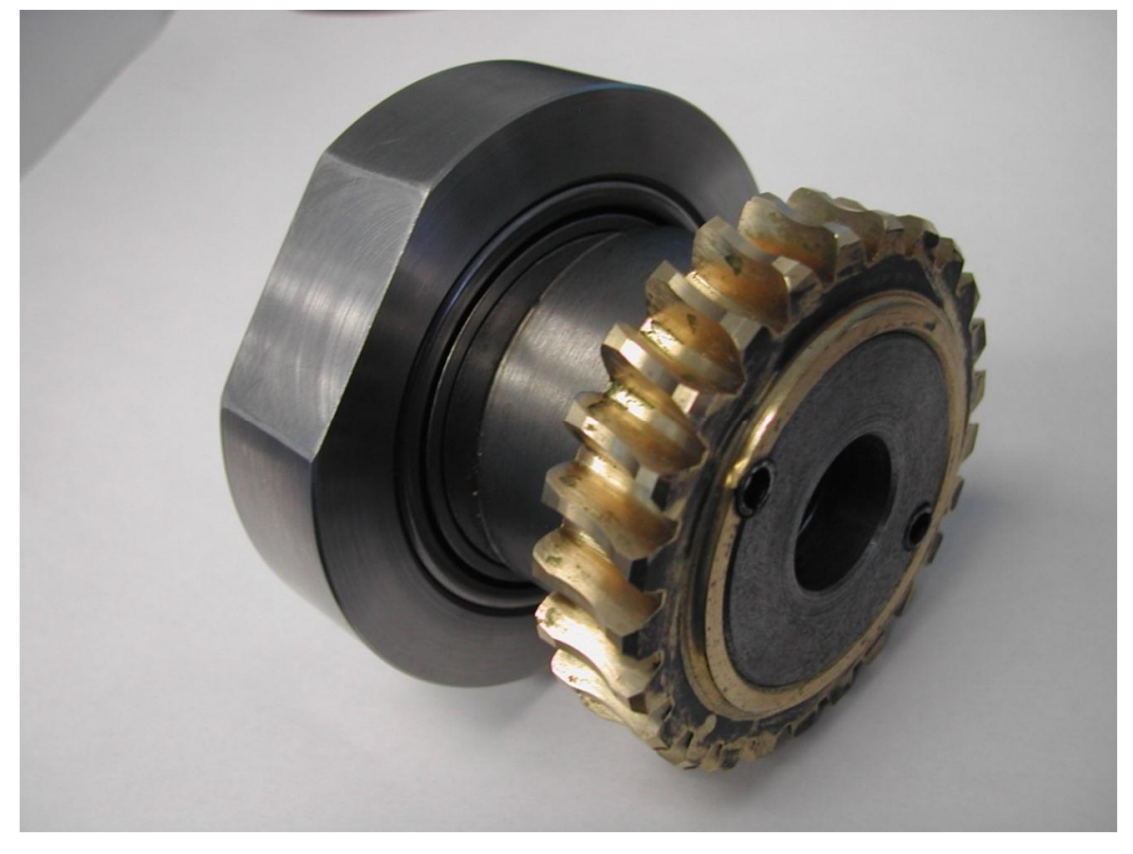

Figure 56. Flattened section on prototype eccentric

Our modification to the plunger helped because it decreased the rocking motion of the plunger, but it did not eliminate it because even if the plunger and eccentric remain perfectly connected on the flat face, the plunger can still get offset because it is only supported at one point (the T-seal) and there is still play in the plunger to cylinder fit. However, this had a dramatic effect on particulate matter generation. The oil in the pump with this first new eccentric (pump \#58) remained cleaner than any other pump built up 
until then. The typical high particle counts during early break-in were simply not present. Since there still was some cylinder wear in this pump, it is an indication that the dirty oil normally experienced during pump break-in is not from wear of the cylinder wall.

Figure 57 is a typical curve showing how pump oil initially starts with high particle counts during the break-in period. The particle count gradually decreases as the filter system eventually overtakes the particle generation rate and cleans the oil. Figure 10 is a plot of the oil particulate for pump \#58. Note that in the early stages, when all previous pumps would normally show high break-in wear, this pump has only about $1 / 10^{\text {th }}$ the amount of particulate and it remains clean through the whole normal break-in period.

\section{Pump \#53-2 Particle Counts}

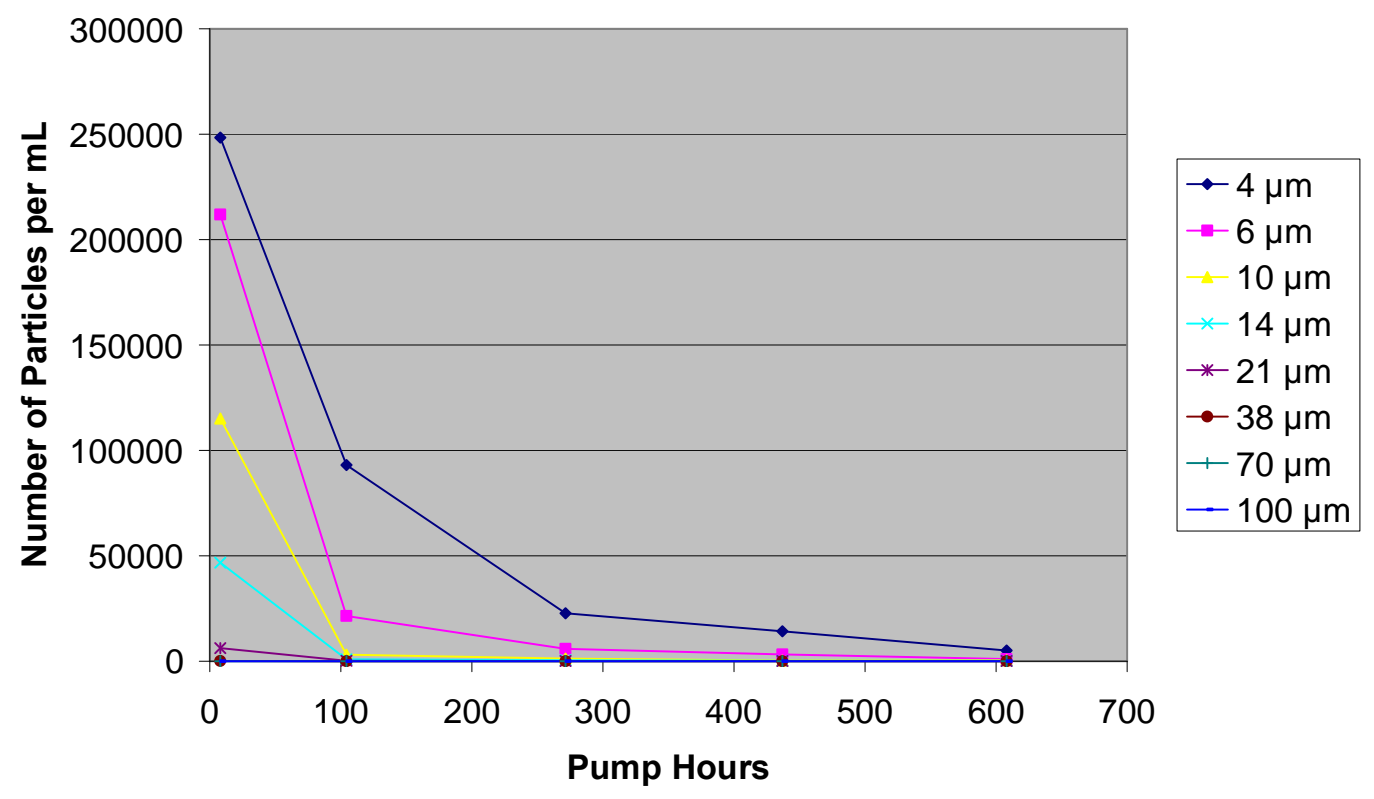

Figure 57. Normal decrease in particle count after break-in period 


\section{Pump \#58 Particle Counts}

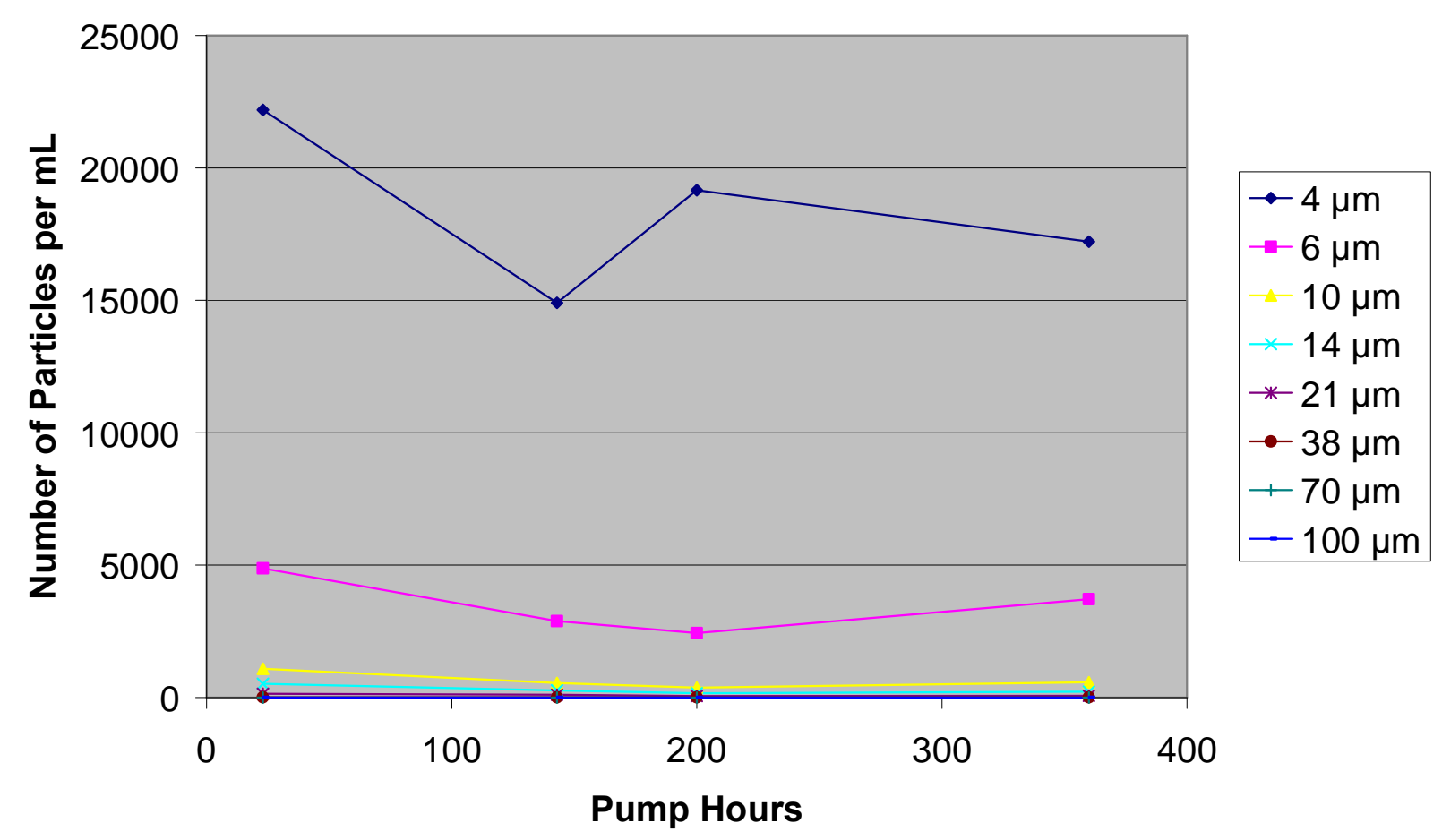

Figure 58. Pump \#58 partical counts indicating very little break-in wear.

The redesigned eccentric to plunger connection in prototype pump resulted in a dramatic reduction in matriculate matter. This reduction in particulates was found to be so promising, that based on extended testing, Rocky believes that the solution pump will now be able to be operated for its entire 15 year life without an oil change or filter change.

\section{Other Significant Pump Design Issues}

Other issues addressed during the project included check valve springs, check valve ball cage and pump replenishment system issues.

A number of attempts were made to utilize different spring types in the check valve assemblies. However, no springs were found that were capable of truly infinite life in the ammonia/water environment with the high number of cycles used. To alleviate this problem, a new check valve design for the suction and discharge of the pump was arrived at which eliminated the need for the spring assembly. Another part of this new design was the ball cage for the check valve. Two different types of this assembly were tried 
before arriving at a final design. The design and tolerances for this new ball cage were added to the solid model of the pump.

The replenishment system for the pump is required to ensure that the oil side of the diaphragm is completely full. Some interesting results were obtained using the pressure ports installed on all pumps to view performance of the pump. One pump that was examined had evidence of being a very tight pump in terms of its replenishment system. Figure 59. is a photo of the oscilloscope screen showing the pressure trace during a pump stroke. The two horizontal lines represent the high discharge pressure and low suction pressure. The oscillations just after the switching of pressure are due to the check balls bouncing on their seats.

The dip in pressure at the end of the suction stroke is the area of interest in terms of the replenishment system performance. This dip in pressure occurs due to a loss of a small amount of oil in the forward pressure stroke. Since the hydraulic end is not then completely full of oil, at the very end of the back stroke a vacuum is created. This vacuum is the driving force for the replenishment system. It pulls fresh oil from the crankcase into the hydraulic end to make up for leakage losses in the forward stroke. It is this induced flow that we are using to cycle the oil through our filter system.

The length of the dip is a measurement of leakage losses in the pressure stroke, longer dips mean more oil was lost. The depth of vacuum that occurs in the dip is a measure of how well the replenishment system is able to replace the lost oil.

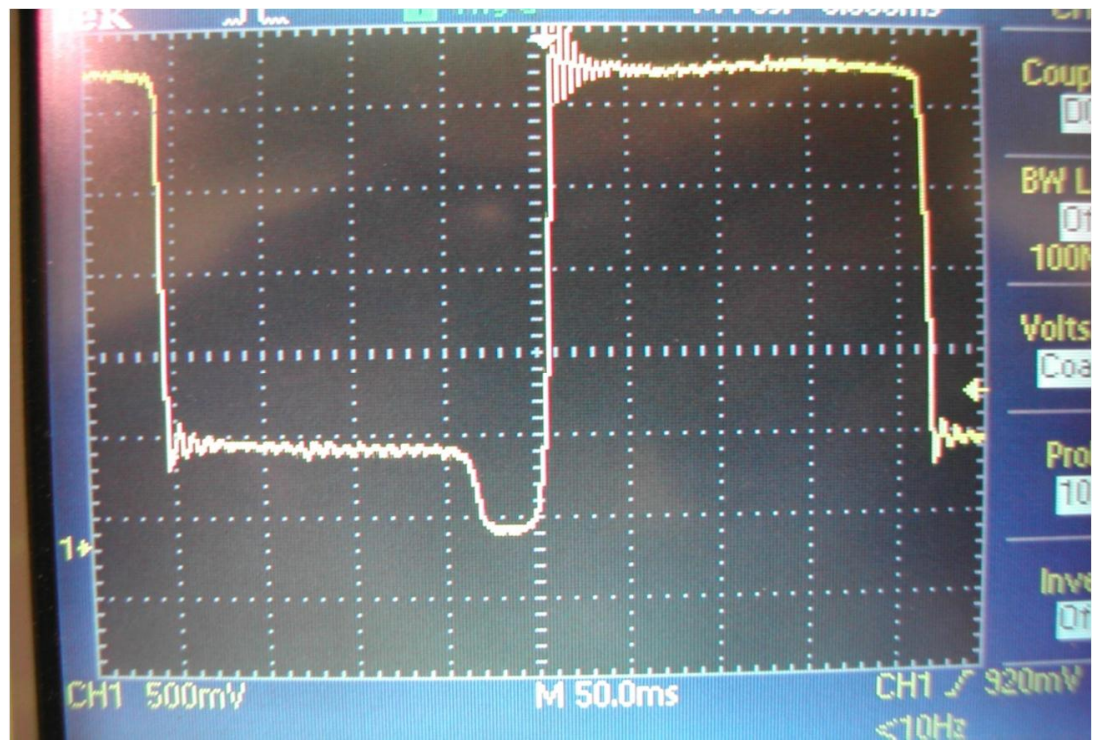

Figure 59. Pressure trace of a pump stroke in pump \#48 


\section{Long Term Testing of Solution Pumps}

A test stand was built to allow for the long term testing of the solution pump. A photograph of this test stand is shown as Figure 60. The test rack was capable of testing up to 20 pumps at a time. The pumps are mounted at individual stations and were subjected to the same inlet and outlet pressures that would occur in a chiller. The individual stations are run with the pumps cycling on/off to maximize the stress encountered. The pumps were cycled continuously, unless the pump stand required servicing.

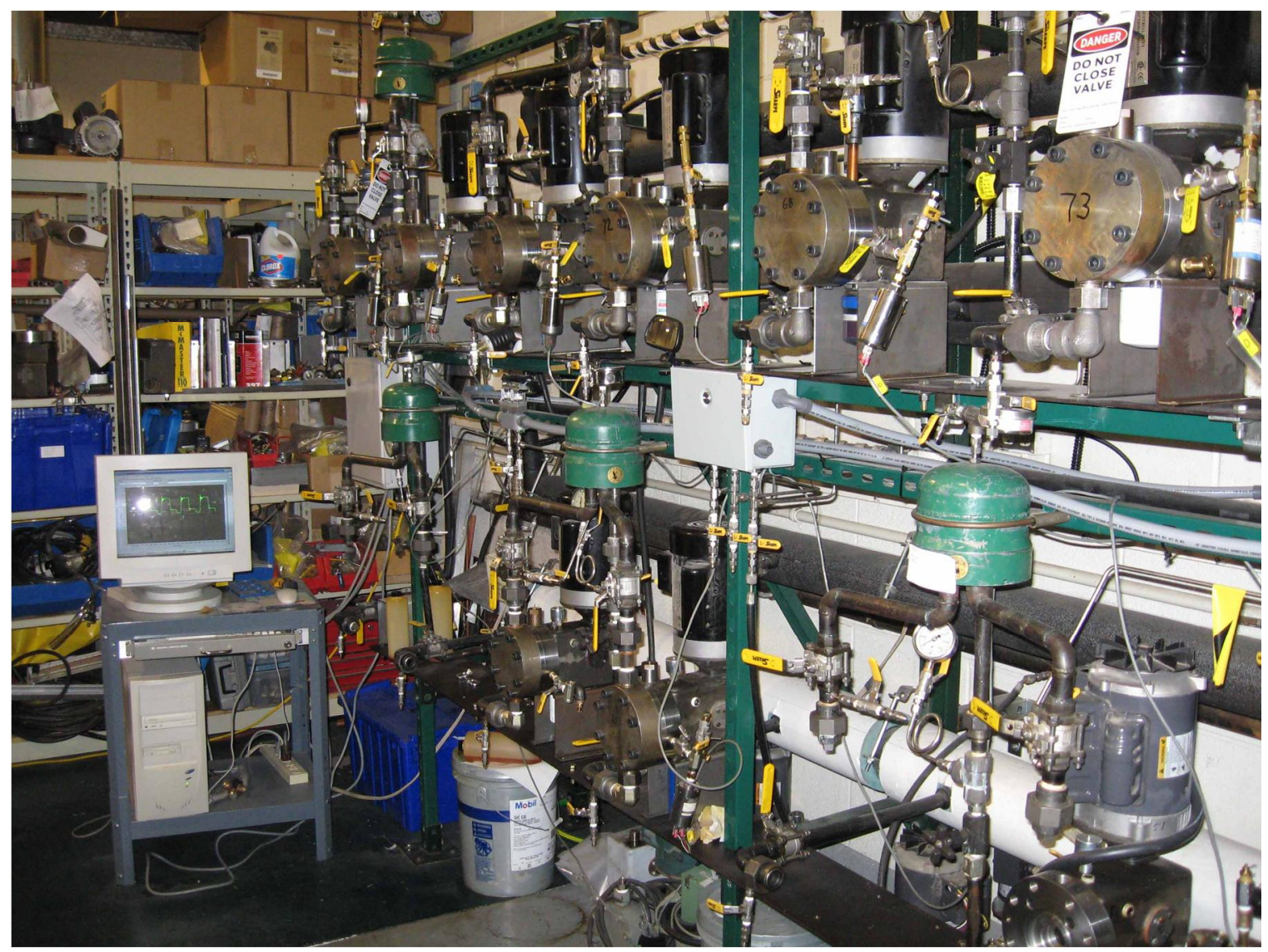

Figure 60. Solution Pump Test Stand

Over the course of the project, many pumps were exposed to this long term testing. The following Table 5 shows the operating hours for the pumps to date. We presently have a pump with over 40,000 hours, another with over 35,000 hours and three with over 20,000 operating hours. 


$\begin{array}{cc}\begin{array}{c}\text { Pump } \\ \#\end{array} & \text { Hours } \\ 53-2 & \\ 58 & 42670 \\ 59 & 39866 \\ 60 & 24122 \\ 68 & 22828 \\ 73-2 & 20209 \\ 75 & 12823 \\ 76 & 13286 \\ 77 & 9102 \\ 78 & 9605 \\ 79 & 4716 \\ 80 & 3497 \\ & 3783\end{array}$

Table 5. Long Term Testing Solution Pump Operating Hours

Based on these results, Rocky Research believes that it has developed the most reliable, low maintenance solution pump for aqua-ammonia applications ever. The solution pump reliability should rival compressors for vapor compression applications.

\section{Orifice Pack and Solenoid Valve Control}

The original orifice pack used included 11 orifices with a 0.065 ò hole to create the pressure drop required for proper flow of weak solution from the generator to the absorber. During this project rocky developed a sealing method using Locktite sealant during the pressing process that eliminates the bypass potential that can occur when the orifice cups are pressed into the tubing shell. This ensured that all of the flow went through the orifices. The manufacturing tolerance for the orifices themselves was established and included in the drawing package.

The orifice pack required that the solenoid valve stay open $100 \%$ of the time. Based on this requirement, manufacturers were contacted to supply a small solenoid valve that would operate with hot ammonia/water solution at temperatures of up to $300^{\circ} \mathrm{F}$. 
G.W. Lisk Company, Inc. a commercial manufacturer of solenoid coils, developed a design for the coil for the weak solution solenoid valve based on Rocky Researchôs specifications. A prototype coil to this design was received. The prototype coil was mounted on a valve and tested. Oven tests and system tests were conducted.

The oven test consisted of heating the valve and coil to $300^{\circ} \mathrm{F}$ in an oven and verifying that the valve would open against 300 psi pressure differential while hot. Operating voltage was $24 \mathrm{vdc}$, which is the voltage used in the GAX appliances to energize the weak solution valve.

System tests were conducted on the hydronic breadboard. First the valve was proven to work at nominal $95^{\circ} \mathrm{F}$ chiller conditions. Then an extreme temperature test was conducted to verify that the valve would work in all anticipated conditions. To maximize coil temperature and pressure differential, system conditions were adjusted as follows:

1. Cooling water temperature to the condenser and $\mathrm{HCA}$ was increased to $117^{\circ} \mathrm{F}$, to give high-side pressure of 343 psia.

2. Duty cycle of the valve was set to $90 \%$ to maximize $I^{2} R$ heating of the coil.

3. Weak flow was reduced to increase generator temperature to $409^{\circ} \mathrm{F}$.

These conditions resulted in a coil temperature of $302^{\circ} \mathrm{F}$ and pressure differential across the valve of 270 psi. A process diagram for this test is shown in Figure 12.

All tests with the prototype coil were successful. This solenoid valve is capable of use with the specified orifice pack.

\section{Thermal Expansion Valve}

Over the course of the project, modifications to Rocky Researchô original thermal expansion valve were made to alleviate problems that had arisen. There changes are as follows:

- The bottom adjustment cap of the TXV was remachined so that the compression of the contained spring is limited and cannot go beyond the recommended compression. In earlier operation of some TXVô, this over compression of the spring may earlier have resulted in bending of the TXV shaft. After the 
modification, the TXV was installed in the hydronic test chamber, where it was successfully tested and used on all new TXVôs ever since.

- The TXV diaphragm assembly tightening to the TXV body was done using hand tools to tighten the two assemblies until the two mating pieces were ñmetal-tometalòtight. This method, although adequate for prototypes, does not lend itself for commercial production. Thus it was refined by finding the torque required for sealing and correct operation of the valve. The torque was calculated to be 150 in-lbs. Torque tools were purchased and two sample valves were then assembled and tested several times to ensure that the method was correct and repeatable.

- The plunger cup design was changed from an o-ring to a Teflon seal to eliminate swelling

- The plunger shaft was changed from a 4-40 thread to an e-clip to better secure the plunger cup

- The inside volume of the TXV was enlarged to eliminate noise propagation due to water hammering

- The charge volume and composition of the constituent refrigerants were established and has been noted in the manufacturing procedure for the TXV

These changes resulted in a reliable and manufacturable TXV design with all dimensional and tolerance specifications.

\section{Evaporator and Subcooler Redesign}

As a part of the metrics study a newly configured evaporator and sub-cooler combination was investigated. The major benefit of this evaporator and subcooler is that it can be produced using available tooling from an OEM manufacturer. The first trial yielded promising results with the sub-cooler performing very well and the evaporator needing some improvement. A newly configured design was drafted and sent to the fabricator. After reviewing our design the fabricator forwarded a revised print for consideration. Figure 61 is a three dimensional model of the newly configured evaporator and the layout of the sub-cooler/evaporator combination in the package is shown as Figure 62. 


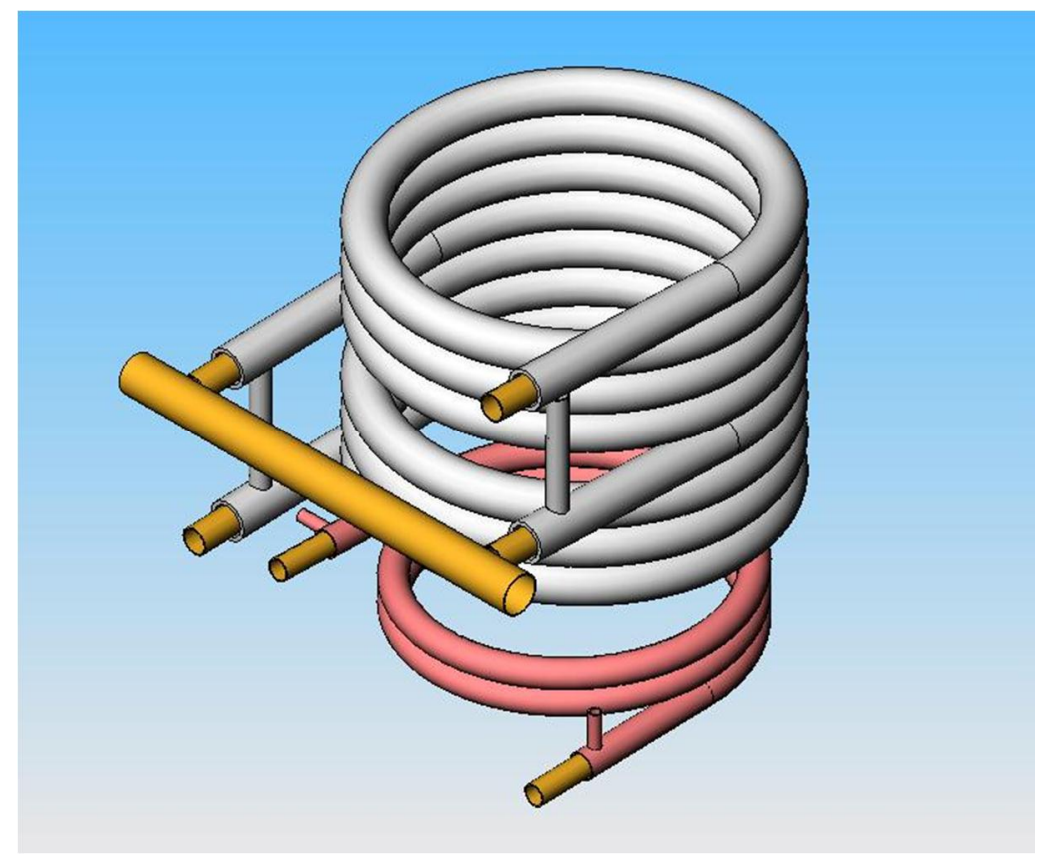

Figure 61. Model of evaporator and subcooler

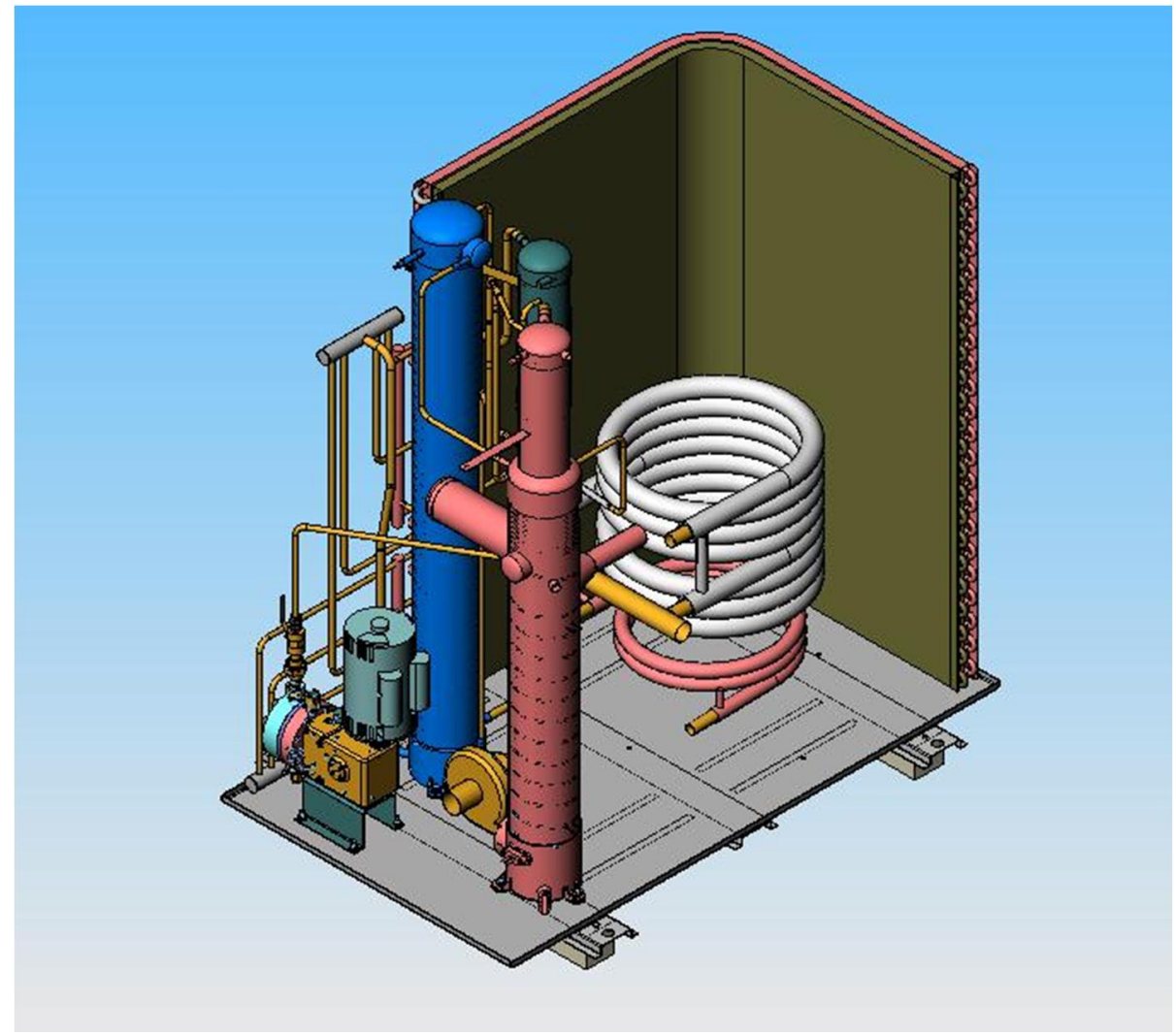

Figure 62. Layout of package showing location of the evaporator and subcooler 
Tests were conducted using the OEM supplied evaporator installed in the hydronic test loop. The evaporator consisted of two tube-in-tube heat exchanger coils that were circuited in series with respect to the refrigerant (to increase the velocity) and in parallel with respect to the water (to reduce pressure drop). Tests were conducted over a range of water flow rates with a controlled return temperature of $55^{\circ} \mathrm{F}$ to determine performance. The results of these tests are below:

$\begin{array}{lll}\begin{array}{l}\text { Flow Rate } \\ \text { GPM }\end{array} & \begin{array}{l}\text { Capacity } \\ \text { Btu/hr }\end{array} & \text { COP } \\ & & \\ 14.08 & 54,600 & 0.634 \\ 15.12 & 55,262 & 0.649 \\ 16.03 & 56,739 & 0.659 \\ 14.07 & 55,330 & 0.645\end{array}$

As the table indicates, the performance of this evaporator was below the desired capacity of $60,000 \mathrm{Btu} / \mathrm{hr}$ and $0.70 \mathrm{COP}$.

Because the manufacturerôs circuiting could allow uneven water flow to each of the two portions of the heat exchanger, the evaporator was removed and recircuited, still in a parallel arrangement, but with reverse return headers. The evaporator was then reinstalled into the hydronic test apparatus.

When retest at $14.23 \mathrm{gpm}$ water flow, the evaporator exhibited a capacity of 55,235 $\mathrm{Btu} / \mathrm{hr}$ and a COP of 0.647 . Therefore, little if any improvement was made with this modification.

An evaporator of alternate design was then received from the OEM manufacturer. Based on the results of earlier testing of the OEM supplied evaporator, it was believed that if circuited in parallel on both the water and refrigerant side, with each running in counterflow, two of the OEMôs subcoolers should perform better than the evaporator, and at a lower cost.

An evaporator based on this design was constructed at Rocky Research. Results for this arrangement showed the following performance over a range of adjustments of the GAX cycle operation: 


$\begin{array}{clc}\begin{array}{c}\text { Evap. Water Flow Rate } \\ \text { GPM }\end{array} & \begin{array}{l}\text { Capacity } \\ \text { Btu/hr }\end{array} & \text { COP } \\ 14.15 & 56,563 & 0.656 \\ 14.15 & 58,511 & 0.682 \\ 14.12 & 57,341 & 0.668\end{array}$

These results show an average improvement in capacity of 1,989 Btu/hr and a COP increase of 0.022 over the original OEM supplied evaporator, with a much smaller and more cost effective implementation.

Unfortunately, this performance was still too low to meet the target $60,000 \mathrm{Btu} / \mathrm{hr}$ capacity and $0.70 \mathrm{COP}$. For this reason, the surface area of the next new evaporator was increased to arrive at a configuration that meets the performance goals. Using the test data generated, heat transfer calculations reveled that a 0.42 turn increase in the each of the two $2 \frac{1}{2}$ turn coils would result in the desired heat transfer. Based on these results, the coil was modified to include an additional $1 \frac{1}{2}$ turn for each coil.

Tests were conducted at two different weak solution concentration levels to determine the capacity and COP of the system with this modified evaporator. The results of these tests are shown below:

\section{Evaporator}

Water Flow Rate

GPM

13.97

13.95
Wk. Conc.

$3.5 \%$

4.1
Capacity

$\mathrm{Btu} / \mathrm{hr}$

59,565

61,531
COP

0.695

0.714

These results were in line with the desired nominal capacity of $60,000 \mathrm{Btu} / \mathrm{hr}$ with a COP of 0.70 and are much better than those with the smaller coil. The results prove that the twisted tube evaporator is a viable approach from a thermal standpoint.

A final, larger sized alternative tube-in-tube evaporator from a low cost supplier was received and tested. Because of the difficulty in obtaining the proper grade of carbon steel tubing, the evaporators were fabricated and delivered with $316 \mathrm{~L}$ stainless tubing. The effect of the lower conductivity of the stainless inner tube vs. carbon steel was calculated to result in a loss of 1,000 to $1,500 \mathrm{Btu} / \mathrm{hr}$ cooling capacity because of the higher thermal resistance of the stainless vs. carbon steel heat transfer surface. 
This evaporator was been installed in an absorption test apparatus and tested. The results from this testing are shown on Table 6.

\begin{tabular}{|c|c|c|c|c|c|}
\hline & $\begin{array}{l}\underline{\text { QFIRE }} \\
\underline{\underline{\text { Btu/hr }}}\end{array}$ & $\begin{array}{c}\underline{\text { Cooling }} \\
\underline{\underline{B t u / h r}}\end{array}$ & $\underline{\mathrm{COP}}$ & $\frac{\underline{\mathrm{P} \underline{\mathrm{HI}}}}{\underline{\text { psia }}}$ & $\frac{\underline{\text { P Low }}}{\underline{\text { psia }}}$ \\
\hline High Fire & 85742 & 59378 & 0.693 & 274.4 & 66.3 \\
\hline High Fire & 86462 & 60247 & 0.697 & 275.2 & 60.6 \\
\hline High Fire & 85783 & 58934 & 0.687 & 275.1 & 61.1 \\
\hline High Fire & 85429 & 60687 & 0.710 & 276.1 & 63.8 \\
\hline High Fire & 86598 & 59452 & 0.687 & 277.0 & 64.2 \\
\hline High Fire & 86051 & 59700 & 0.694 & 275.6 & 65.7 \\
\hline Low Fire & 40642 & 40475 & 0.996 & 209.8 & 72.3 \\
\hline
\end{tabular}

Table 6. Test data for evaporator design

The table information includes firing rate, cooling capacity, COP and high and low side pressure. As the table shows, the cooling capacity obtained was approximately the desired $60,000 \mathrm{Btu} / \mathrm{hr}$. Based on these results, it is expected that a production evaporator with carbon steel tubing will more than meet the capacity requirement.

\section{Reversing Valve}

A preliminary design for a reversing valve was developed that utilized a cylinder and plunger concept. The design worked at low pressures but the diameter necessary for maintaining flow rates and low pressure drop were such that at the higher pressures leakage occurred. Figure 63 shows this original design. 


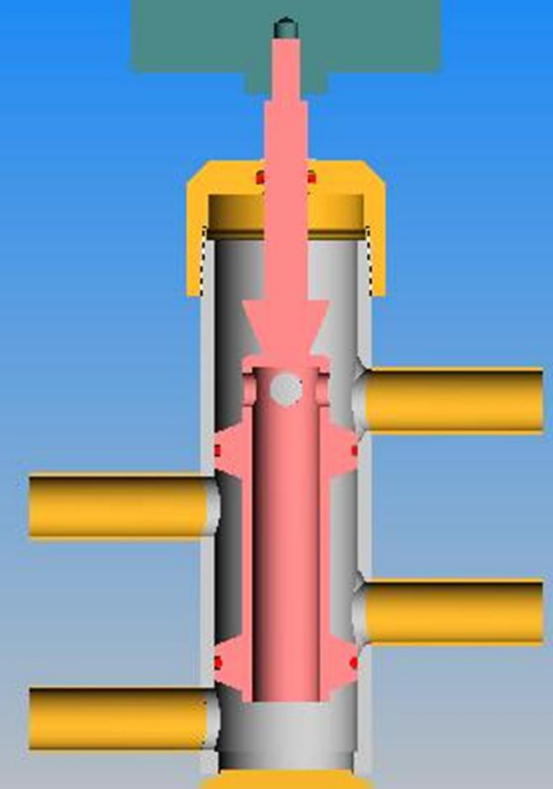

Figure 63. Original Reversing Valve Design

It was decided to redesign the valve using a rotating disk instead of the plunger. The advantage being that the intermittent unconfined o-ring diameters will be much smaller and less likely to fail during valve position switching. Figures 64 and 65 show a 3-D pictures of the design.

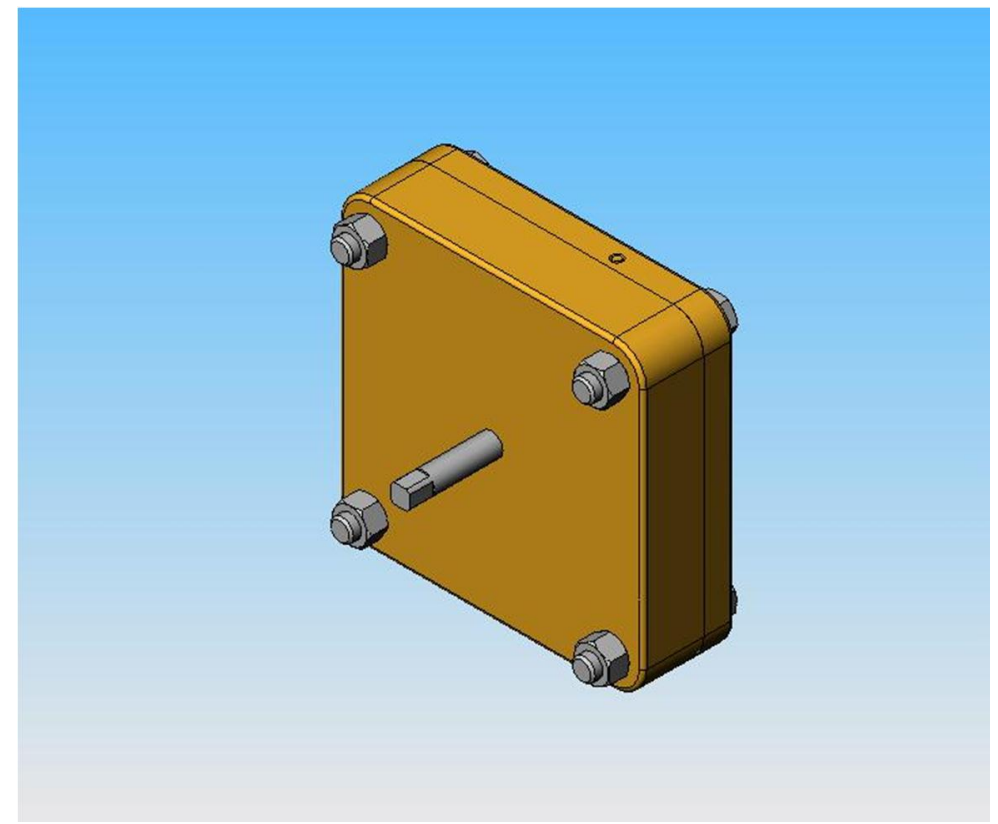

Figure 64. New Reversing Valve Design Concept 


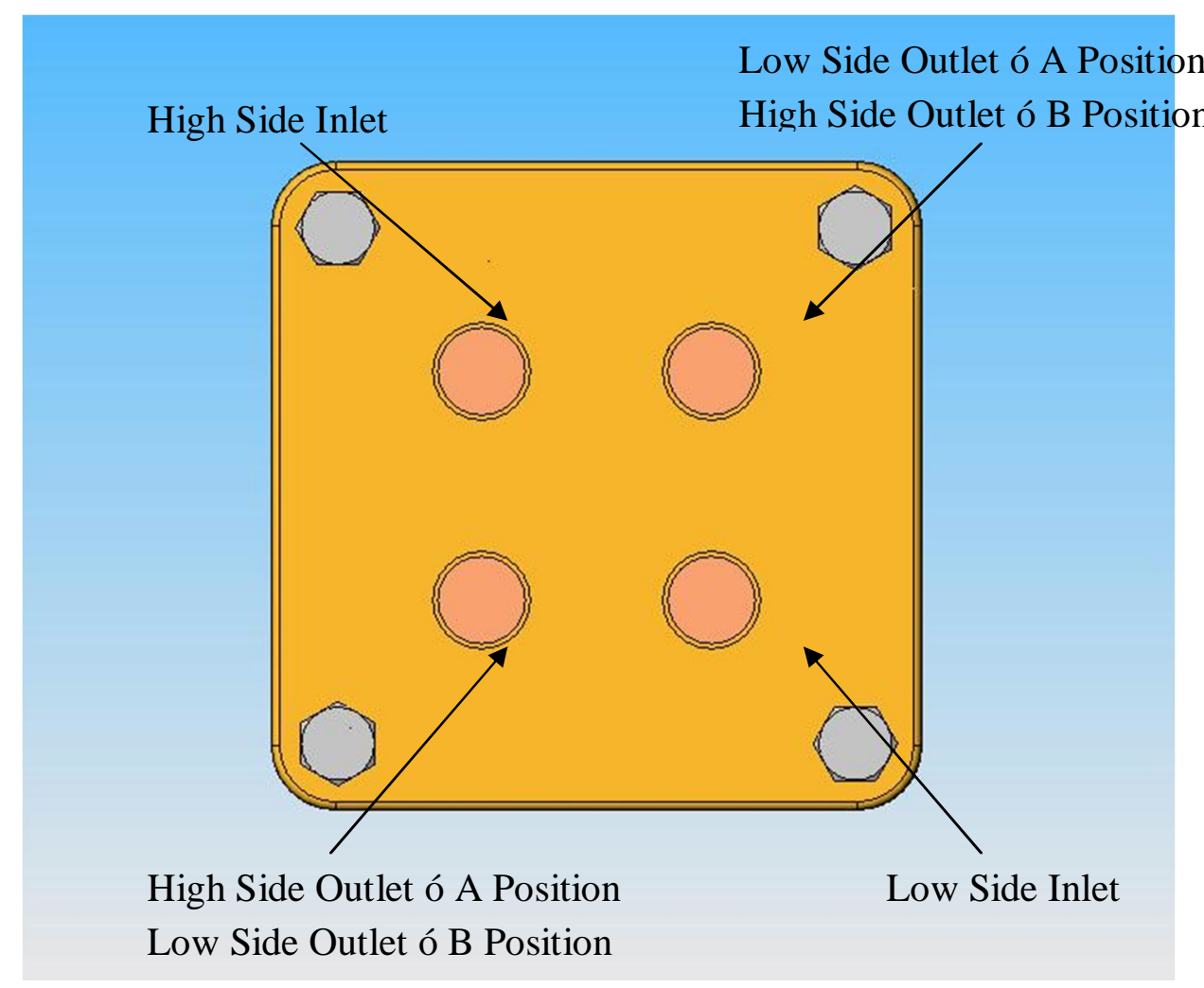

Figure 65. Reversing Valve Flow

Parts for the improved reversing valve were purchased and assembled. Figures 66 and 67 are pictures of the machined parts that make up the valve. 


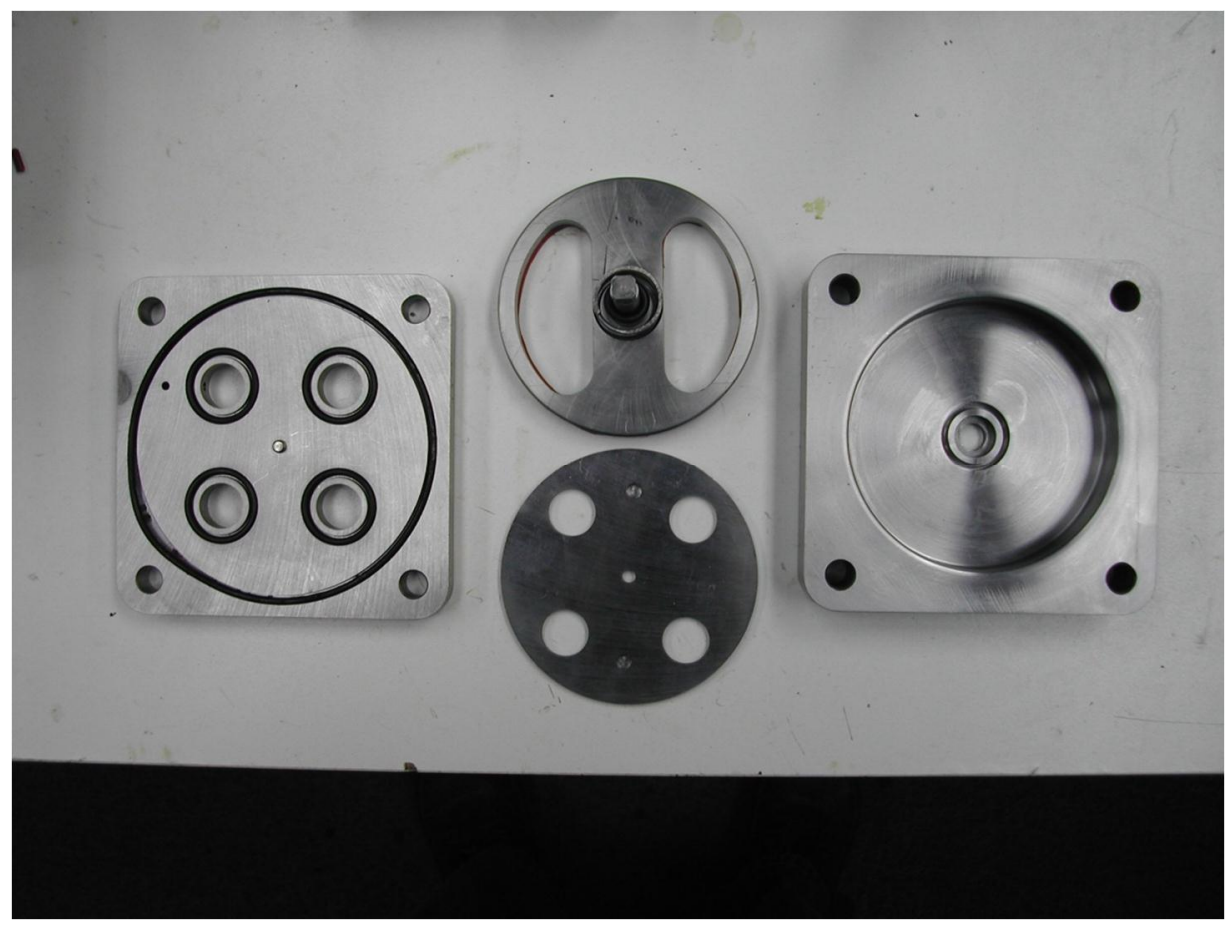

Figure 66. Reversing Valve Parts

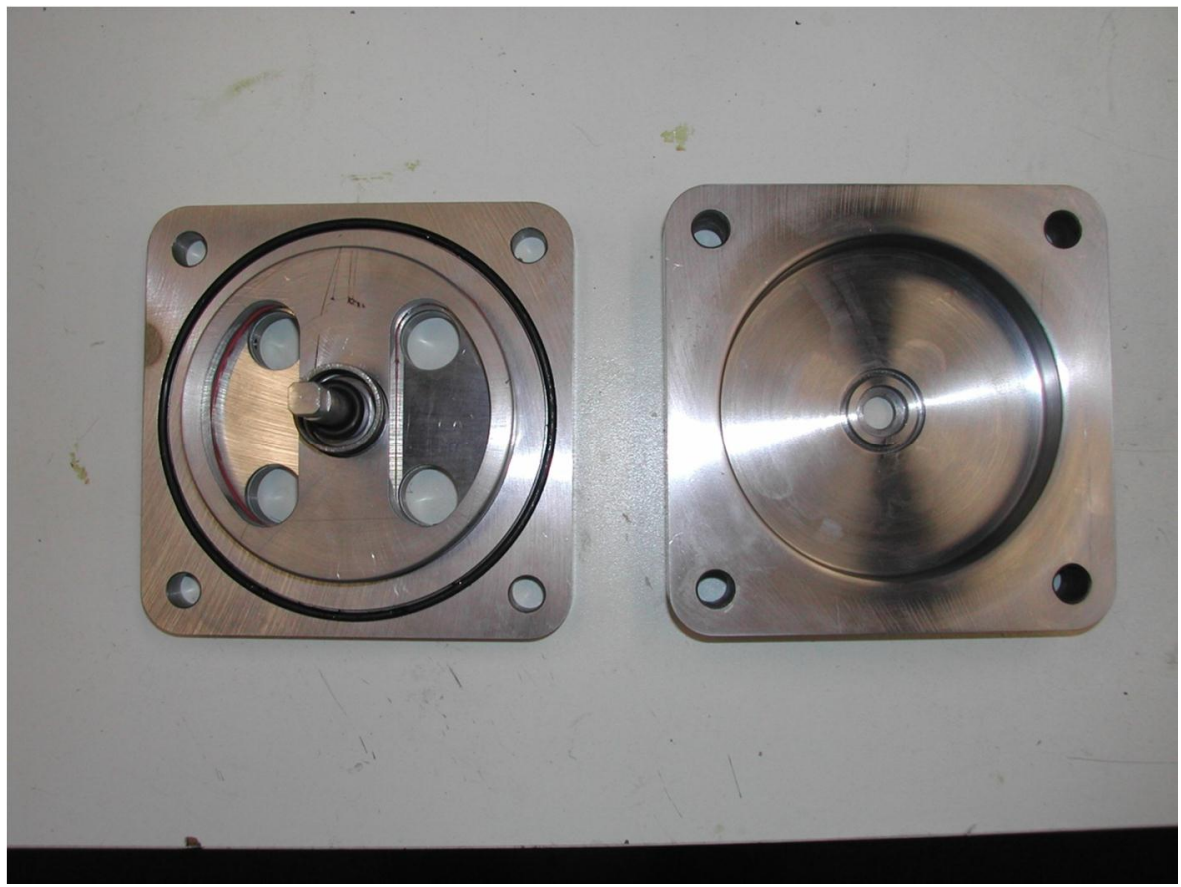

Figure 67. Close up of parts

Testing was done on this new reversing valve design. Initial testing showed that the forces on the o-ring were too excessive and causing failures once the valve is actuated. 
The idea was to then place a thin sheet of Teflon between the steel face plate and the orings. This change had little to no effect and o-ring failure still occurred.

Testing continued on the new reversing valve design. However, after much iteration it has been decided that as a parallel path, an investigation would be made into commercially available four-way ball valves to see if they perform properly, or can be modified to perform as needed.

To operate as a reversing valve, a number of commercially available 4-way valves were acquired and tested under operating system pressure differentials. The vast majority of valves leaked, not to atmosphere but between flow streams. These included 3 models of hydraulic type valves and one ball valve.

For the ball valve, increasing bolt torque did not cure the seat sealing issue. Dissection of the valve indicated valve manufacturing quality, including quality of the Teflon seat itself, may have been the cause. This manufacturer had delayed shipment of samples once already because the valves they were about to send us did not meet their own quality standards.

Another manufacturer sent ball valve samples that were tested under pressure and passed without leakage, either across seats or out to atmosphere. Pressure seals held even through repeated operation cycles of the valve.

The sample Sigma 4-way valve was pressure tested successfully with no leakage at design differential pressures. Torque to actuate the valve was measured at the worst case conditions. This torque value was used (x2) to size a single actuator to operate both heat pump 4-way valves simultaneously. A supplier was found and a sample was received and initial evaluation indicated a good fit for the application. The actuator has excellent footprint dimensions as compared to most others on the market, plenty of power and ease of linkage layout for actuating the 2 valves.

The sample was successfully tested in the heat pump under Task 4 . 


\section{Testing in Absorption System Assemblies}

The successful modifications in pumps, orifices and solenoid valves, thermal expansion valves, evaporator, subcoolers and reversing valves were incorporated into all (more than the 5 required) of the multiple absorption system assemblies that are described in the coming sections.

\section{Task 3. Seasonal Energy Efficiency Improvement (Aqua-Ammonia Absorption Technology}

\section{$\underline{\text { Subtask 3.1 Assembly of Chiller Test Bed with Metrics Improved Components }}$}

A chiller test bed was developed as a means to incorporate the metrics improved components into the chiller design and to test the overall system with the metrics improved components. The chiller test bed also required that the control be modified for improved chilled water temperature control to minimize cycling and maximize seasonal COP.

A three dimensional model of the internal components of the chiller test bed with metrics improved components was made. The model included all components improved during the metrics efforts. The model developed, shown on Figure 68, allows for the positioning of components and the interconnecting tubing runs to be defined and checked for interference and viability of the assembly process. Also from this drawing, Autocad style drawings of the positioning of components as well as dimensions for all tubing sections are produced. The tubing dimensions were converted into programming for Rockyô $\mathrm{CNC}$ bender, facilitating the rapid production of these parts. 


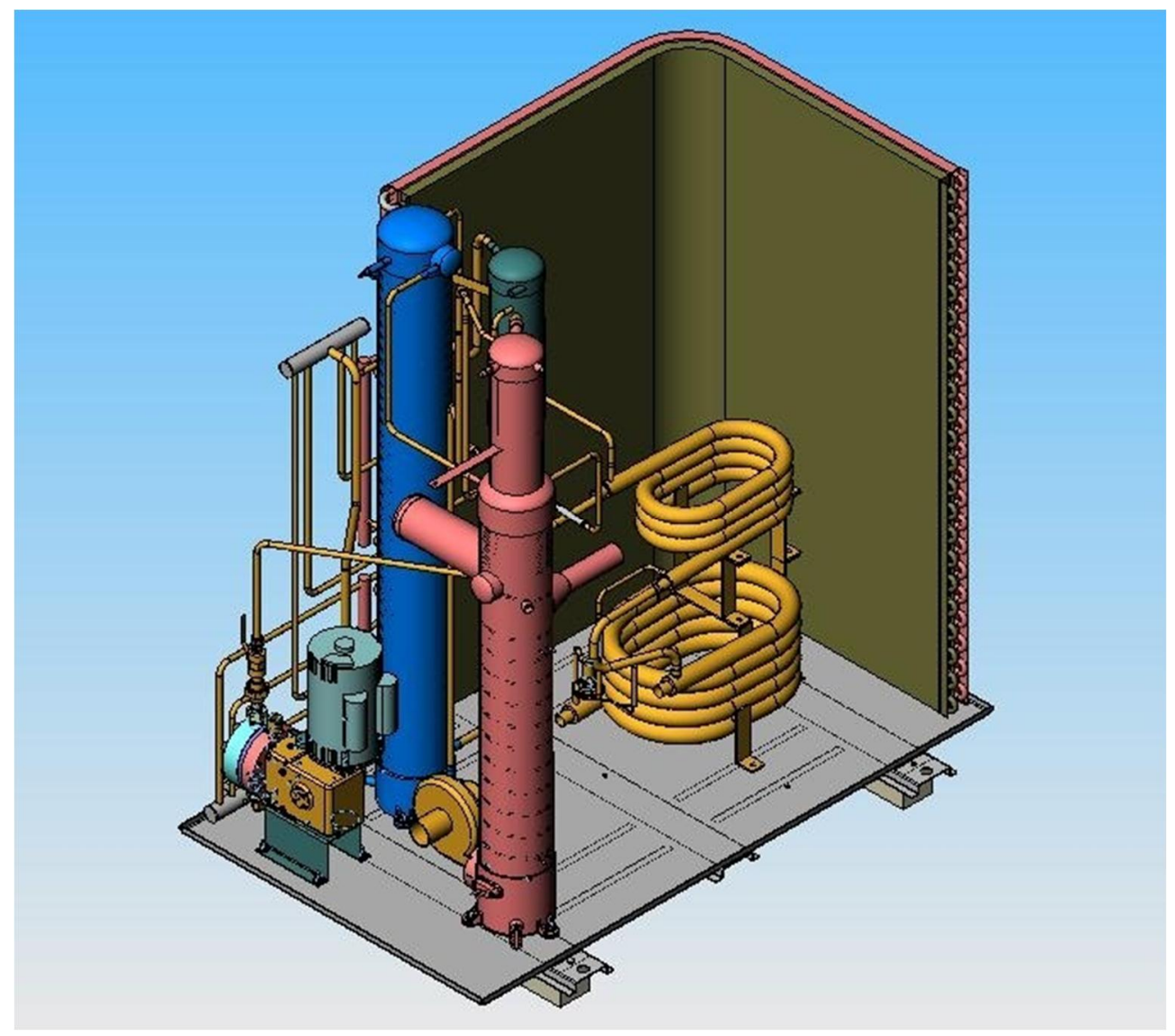

Figure 68. Chiller Test Bed with Metrics Improved Components

To facilitate the assembly process and to ensure high performance of the metrics chiller, it was decided to assemble two subassemblies of grouped metrics components and to test these. Finally, these grouped subassemblies would be installed in the air cooled metrics chiller.

The first of these grouped metrics component assemblies consisted of the generator, rectifier and the absorber. Also included in this were the eductor and the associated tubing. The second assembly consisted of the evaporator and subcooler.

After the testing of these subassemblies in the hydronic absorption test apparatus, (described below), the subassemblies were mounted in the metrics chiller. Figure 69 is a photograph showing this step in the assembly process. The subcooler/evaporator assembly has black insulation, while the generator and absorber section have white insulation. Also shown in the photograph is the air coil. Subsequent to this, the solution pump was installed and all piping connections were made. The burner, gas and water piping were then installed. Controls were installed next, along with instrumentation for testing. Finally, the sheet metal parts, fan motor and fan blade were installed. 
The unit was then placed in the test chamber for testing. A photograph of the chiller in the test chamber is shown as Figure 70. The instrumentation was connected to the data acquisition and testing of the chiller was initiated.

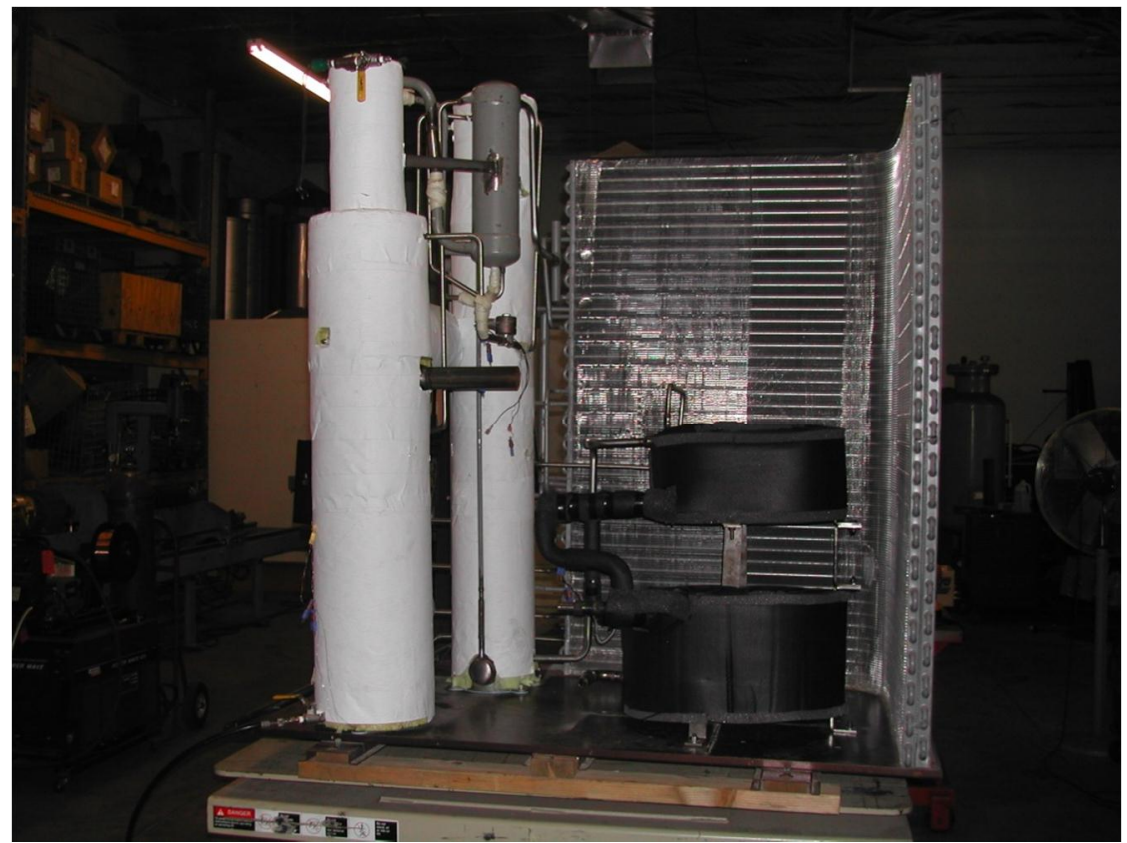

Figure 60. Metrics Chiller During Construction Showing Installed Subassemblies

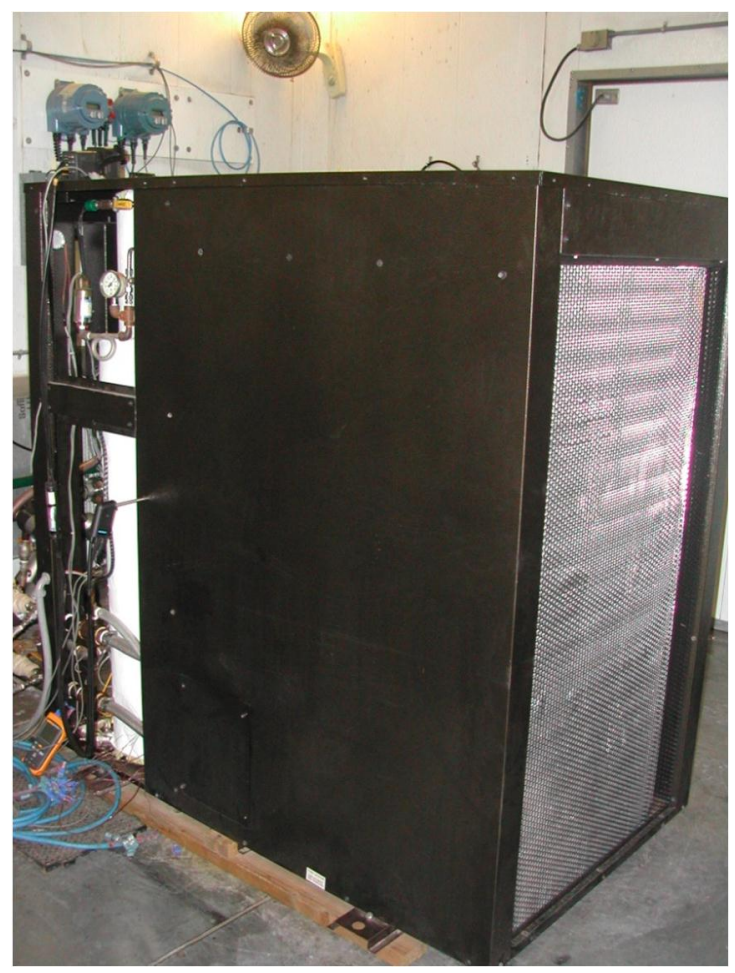

Figure 70. Completed Metric Chiller (two side panels removed) 


\section{$\underline{\text { Subtask 3.2 Chiller Test Bed Operation with Metrics Improved Components }}$}

Tests of the two subassemblies of grouped metrics components were conducted in the hydronic test apparatus to ensure performance prior to assembly of the metrics chiller. Figure 71 shows a representative test of these subsystems. As the figure shows, the components operate extremely well, with a capacity of $62,409 \mathrm{Btu} / \mathrm{hr}$ and a COP of 0.727. This performance is far in excess of our target of $60,000 \mathrm{Btu} / \mathrm{hr}( \pm 5 \%)$ and 0.70 $( \pm 5 \%)$.

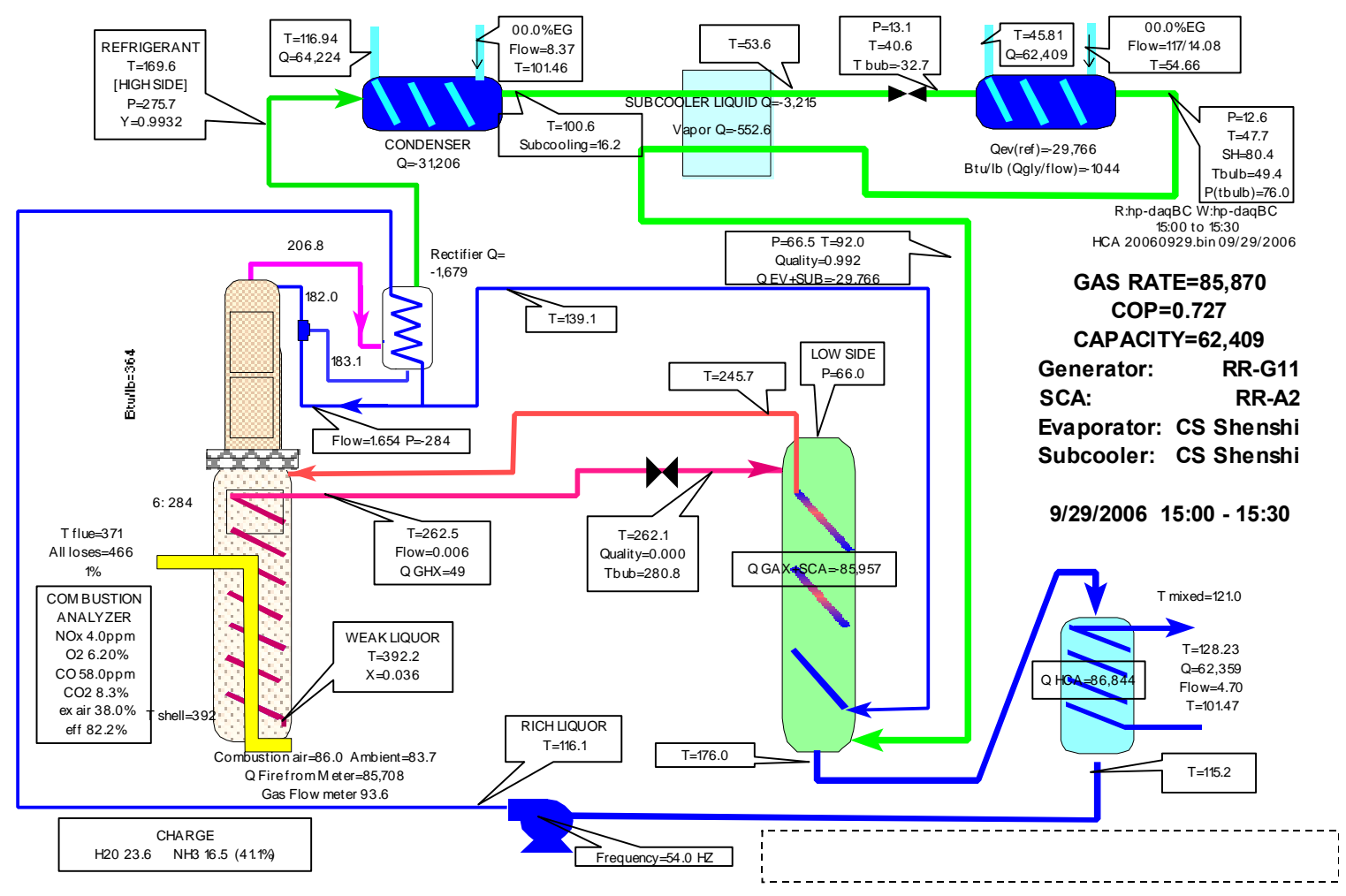

Figure 71. Test of Subassemblies with Metrics Components

After these tests were completed, the metrics chiller was assembled, as mentioned earlier. Tests were conducted of the chiller test bed with metrics improved components, also known as the ñMetrics Chillerò, over a variety of ambient temperatures. The cooling capacity results from all tests are shown on Figure 72, while the COP results are shown on Figure 73. 
At the ARI rating point condition of $95^{\circ} \mathrm{F}$ with $55^{\circ} \mathrm{F}$ return water temperature and a nominal 14 gpm flow rate, most of the capacity data taken showed capacity of approximately $60,000 \mathrm{Btu} / \mathrm{hr}$ (5 tons), with only one set of data even close to the $5 \%$ tolerance level on this value.

The COPÂs observed at the ARI point were also, for the most part, in line with the design specification of 0.70. Again, only one test datum approached the 5\% tolerance value on this important performance barometer.

At high operating conditions, the capacity decrease with ambient temperature increase was below the Rocky Research target of $600 \mathrm{Btu} / \mathrm{hr}{ }^{\circ} \mathrm{F}$, and was actually closer to 360 $\mathrm{Btu} / \mathrm{hr}{ }^{\circ} \mathrm{F}$ for a regression over the temperature range between $95^{\circ} \mathrm{F}$ and $116^{\circ} \mathrm{F}$. If the lowest capacity value at $95^{\circ} \mathrm{F}$ is eliminated as a flyer, this value becomes $379 \mathrm{Btu} / \mathrm{hr}{ }^{\circ} \mathrm{F}$.

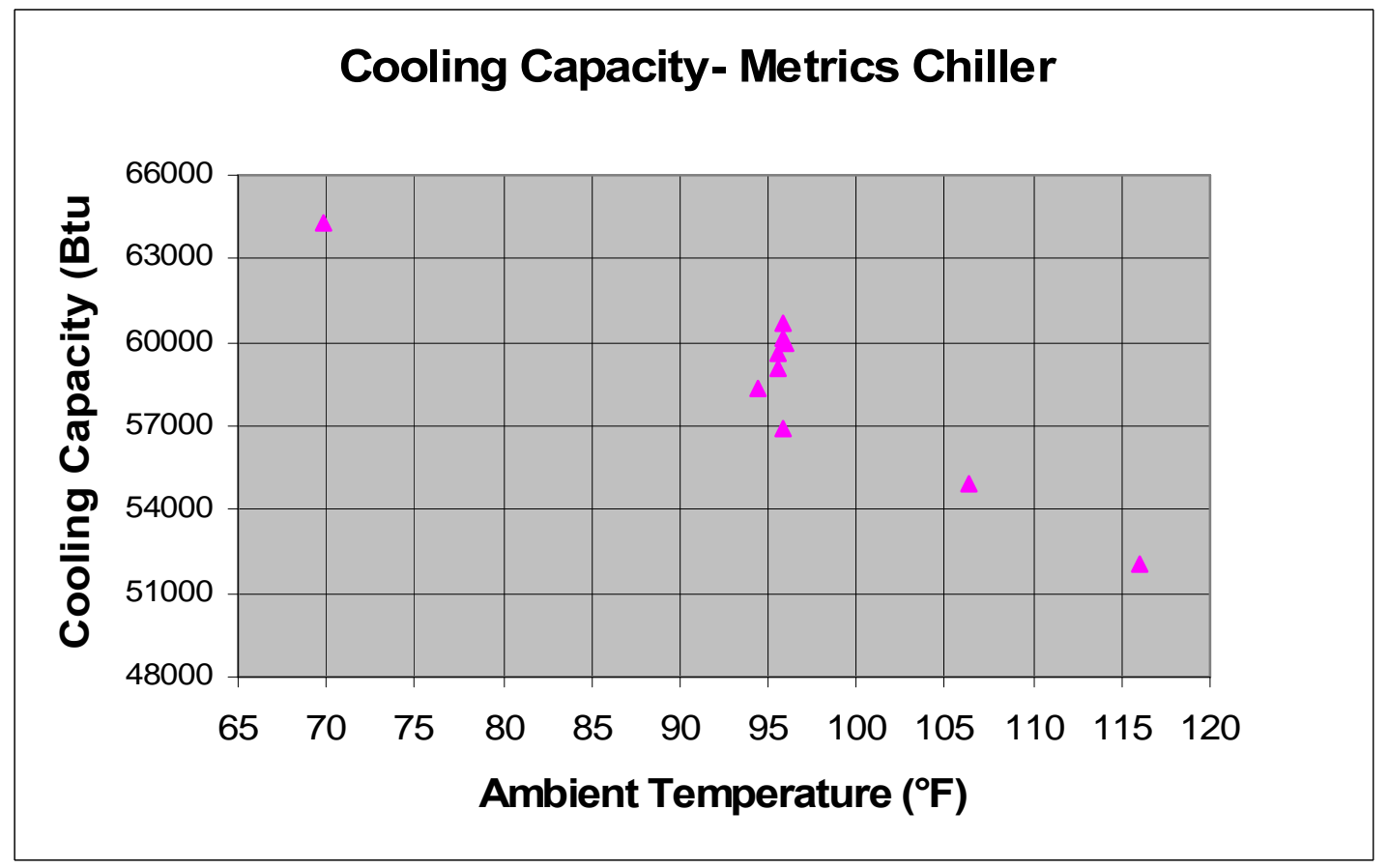

Figure 72. Metrics Chiller Cooling Capacity 


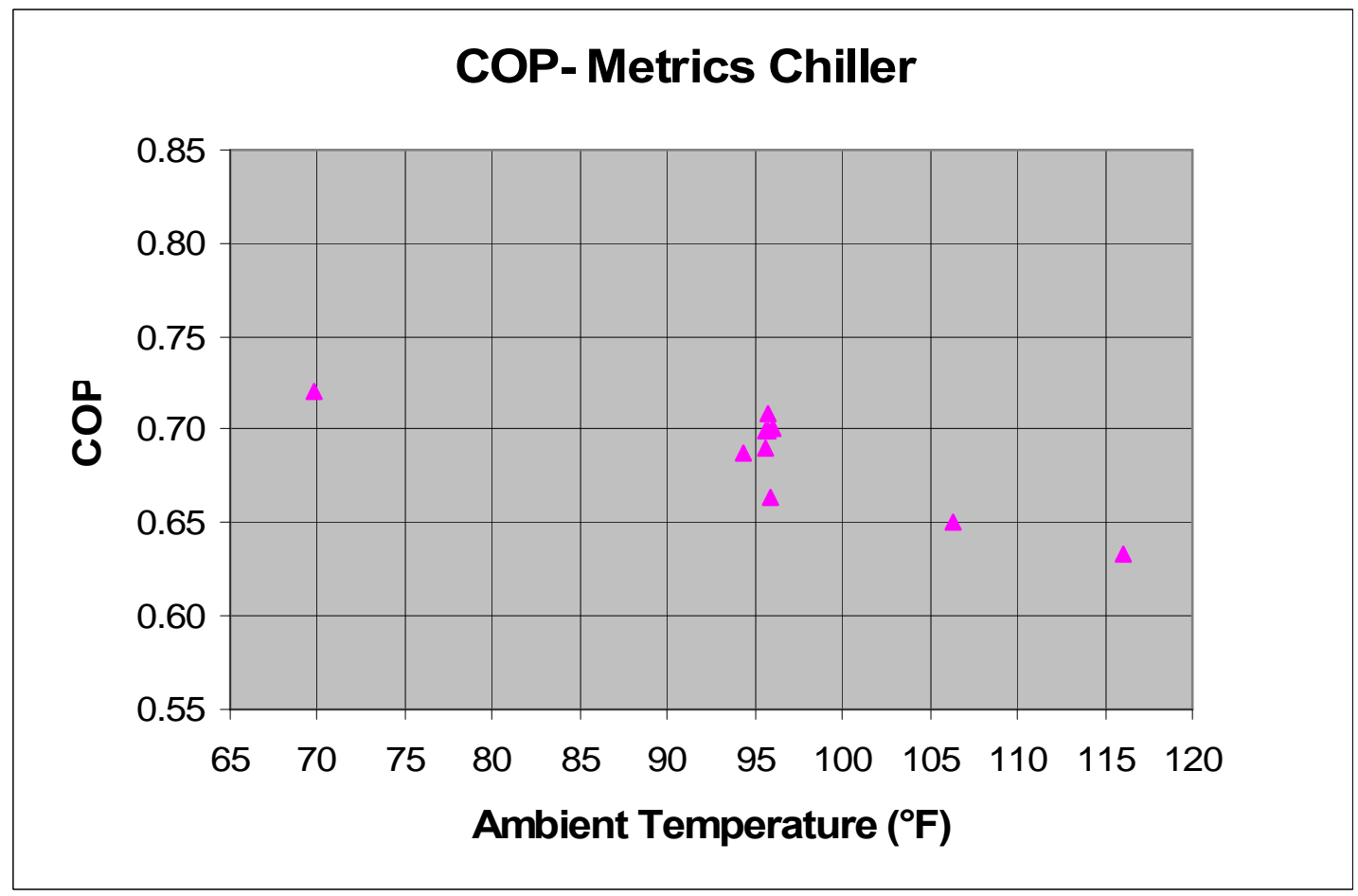

Figure 73. Metrics Chiller COP

\section{Task 4. Heat Pump Refinement (Aqua-Ammonia Absorption Technology)}

\section{$\underline{\text { Subtask 4.1 Heat Pump Test Bed Fabrication with Metrics Improved Components }}$}

A heat pump test bed was developed that incorporated the metrics improved components from Task 2 into the heat pump design and functional unit.

One of the critical and unique components in the heat pump is the reversing valve. Initial efforts focused the implementation of this subsystem as a step in the heat pump fabrication. The reversing valve actuator passed initial tests for operation in terms of pressure rating and leakage. Linkages for connecting the actuator to two valves simultaneously were designed and constructed and tested successfully under full pressure load. The low cost actuator was shown to have plenty of torque for this application.

Heat pump design with metrics improved components was completed. Due to the complexity of the tubing connections, placement of the valves with the actuator linkage tested is proving to be a difficult task. Figure 74 shows the metrics components in place in the solid model of the heat pump. 


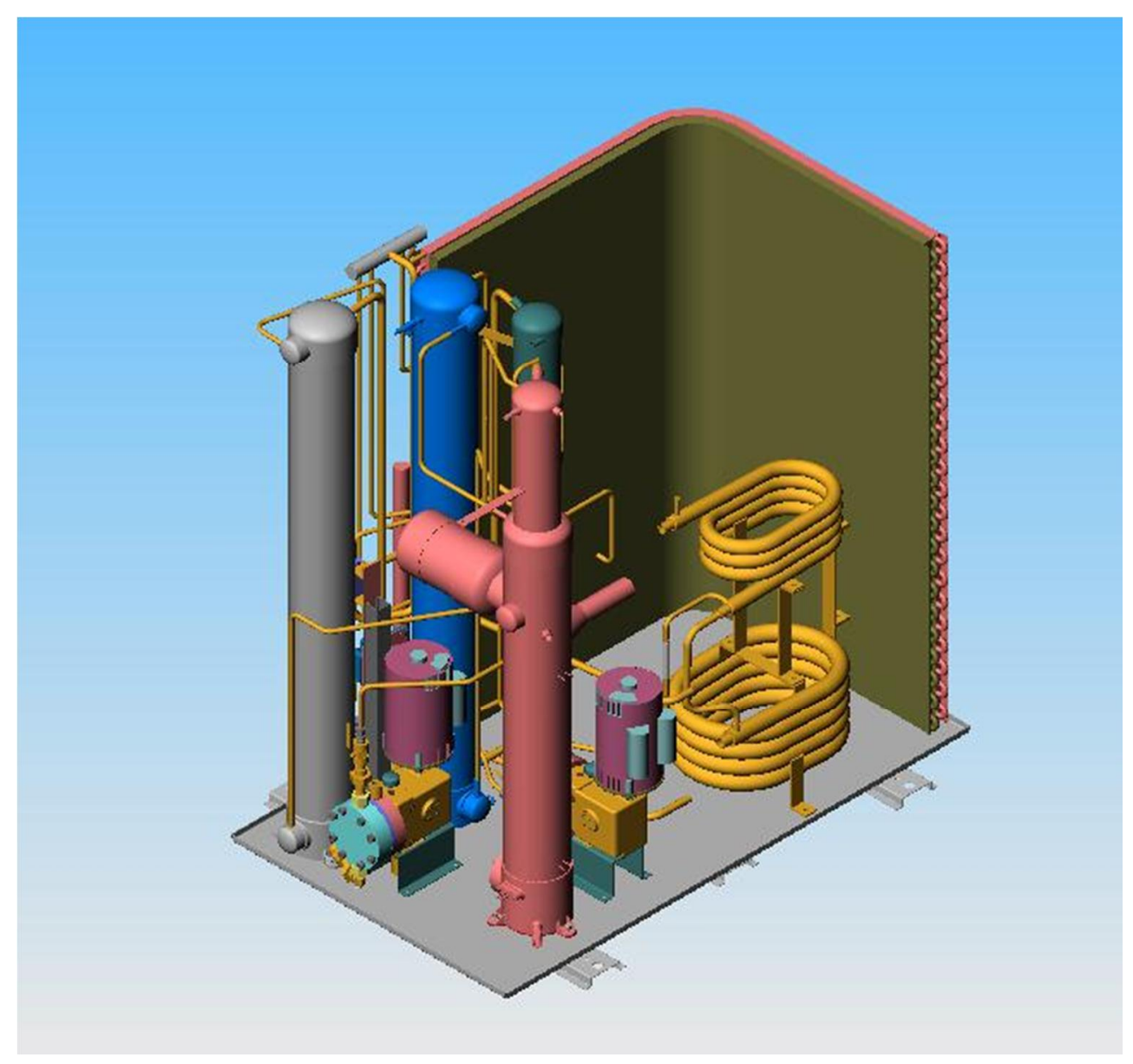

Figure 74. Heat Pump Solid Model

Assembly of the heat pump was completed. Figures 75 and 76 show the assembly of the chiller when it was nearing completion, with the valves and valve actuator, generator, absorbers and the pumps having been assembled. The reversing valve assembly was first bench assembled and tested to make sure valve properly actuated and were free from obstruction. The assembly was installed onto the heat pump skid and was then fitted with all the respective connections. In order to assure the welding process will not damage the internal seals of the valve it was disassembled. The connections were then welded to the connecting plates of the valve and will then be re-assembled in the heat pump. 


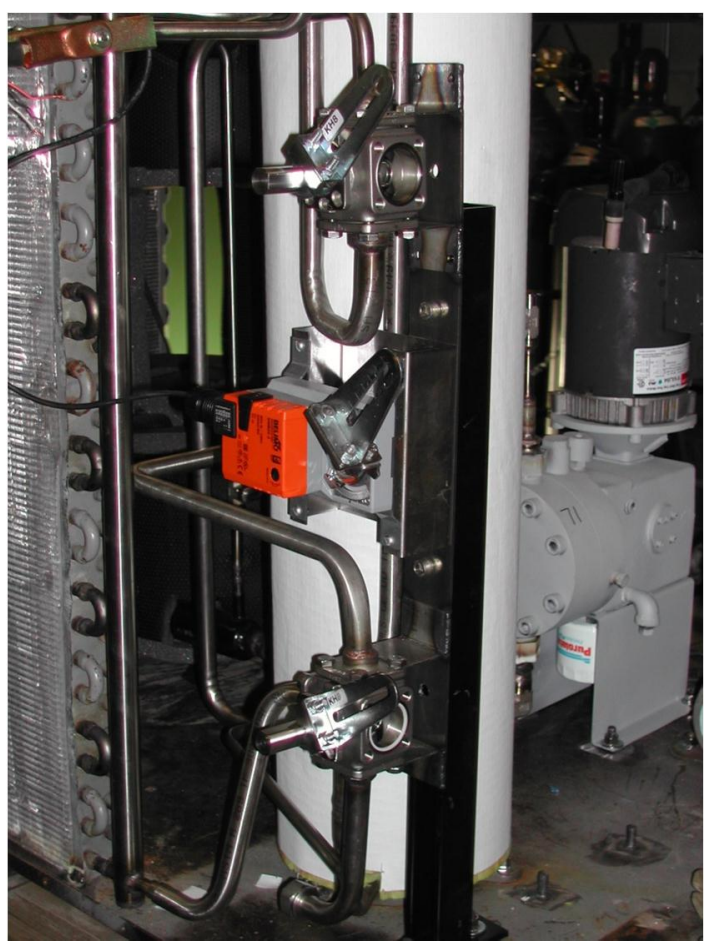

Figure 75. Reversing Valve Assembly on Heat Pump

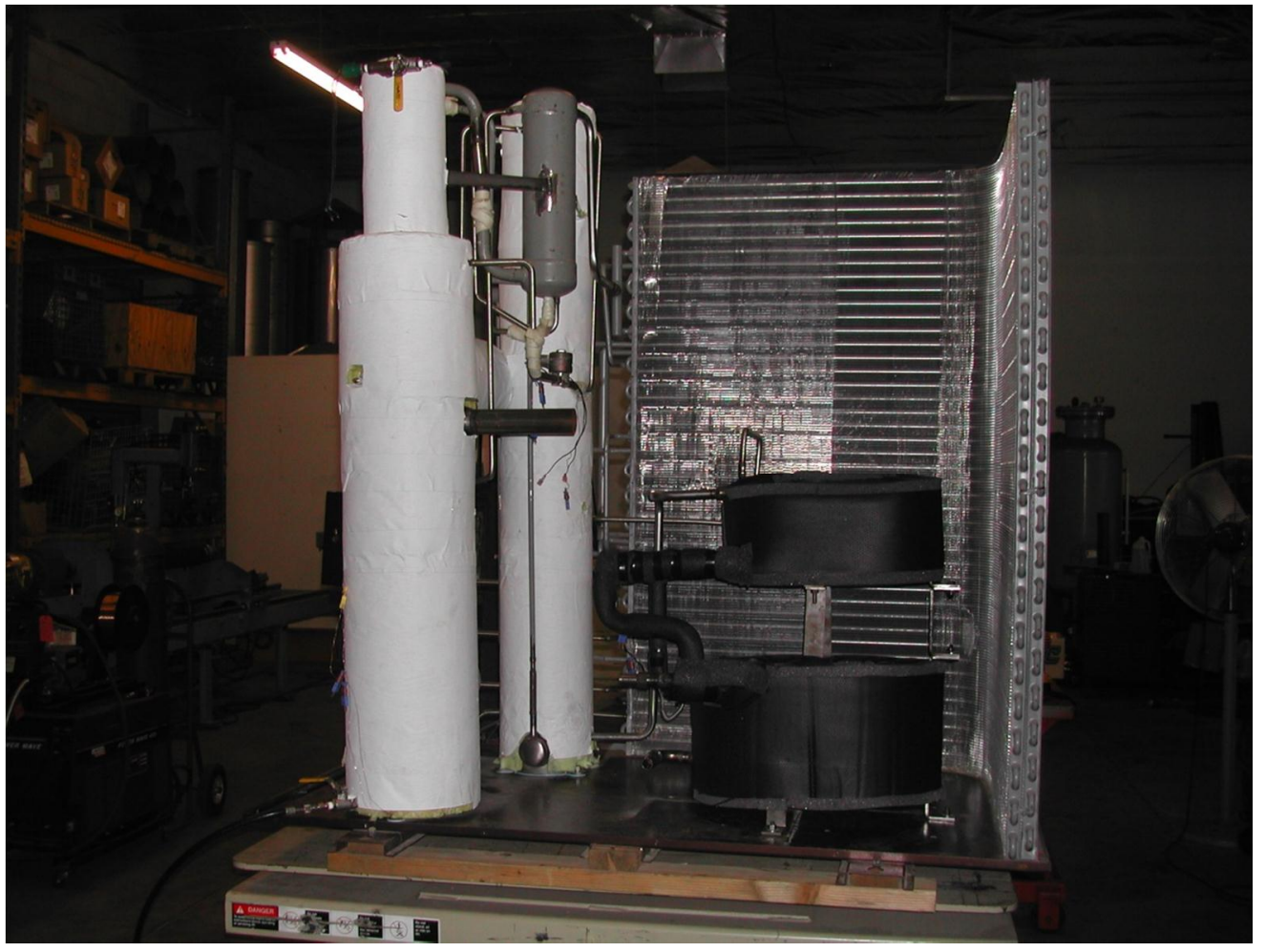

Figure 76. Photograph of Heat Pump Assembly 
The final heat pump test bed assembly is shown as Figure 1. The photo shows the assembly with the front access door removed.

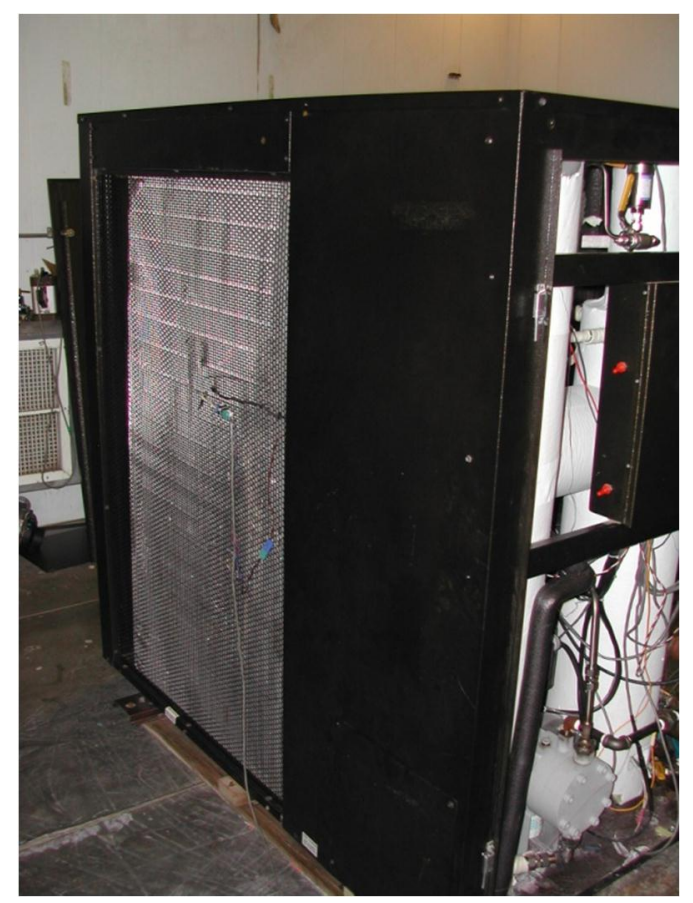

Figure 77. Photograph of the Completed Heat Pump Test Bed in the Test Chamber

\section{$\underline{\text { Subtask 4.2 Heat Pump Test Bed Operation with Metrics Improved Components }}$}

The heat pump test bed was installed in the test chamber for testing in the cooling and heating modes. Included in the installation procedure was connection of the chilled water and gas lines, connection of temperature, flow and pressure sensors as well as modifications to the data acquisition software.

The initial focus of the heat pump test bed testing was on cooling mode operation. The heat pump controls were tuned and the system operated at the design point $95^{\circ} \mathrm{F}$ ambient air condition with $55^{\circ} \mathrm{F}$ inlet water.

During testing, less than optimal operation of the air coil was hypothesized. Subsequent infrared imaging revealed some starving of one of the air coil circuits. For this reason, the manifolding of the air coil was modified and the heat pump test bed was then reinstalled in the test chamber. 
Tests were then conducted at two different ambient temperatures in the cooling and heating modes. After some initial tuning tests, the following results, shown on Table 7 were obtained.

$\begin{array}{rcrrrrrr}\text { Test Date } & \text { Cool/Heat } & \begin{array}{c}\text { Tambient } \\ { }^{\circ} \mathrm{F}\end{array} & \begin{array}{c}\text { Capacity } \\ \text { Btu/hr }\end{array} & \text { COP } & \begin{array}{c}\text { Phigh } \\ \text { psia }\end{array} & \begin{array}{c}\text { Plow } \\ \text { psia }\end{array} & \begin{array}{c}\text { Conc. } \\ \text { 2/7/2007 }\end{array} \\ & \text { cool } & 96.1 & 53523 & 0.625 & 289.4 & 67.9 & 0.033 \\ 2 / 8 / 2007 & \text { cool } & 74.7 & 57235 & 0.664 & 241.5 & 64.7 & 0.033 \\ 2 / 12 / 2007 & \text { heat } & 45.6 & 104944 & 1.219 & 286.0 & 51.8 & 0.040 \\ 2 / 16 / 2007 & \text { heat } & 16.7 & 90273 & 1.046 & 263.7 & 26.5 & 0.031\end{array}$

Table 7. Metrics Reversing Heat Pump Test Results

The performance of the reversing heat pump was a little lower than that obtained in the hydronic test apparatus with the same components, but still acceptable. This is due to two reasons. First, the circuiting of the air coil may not have been balanced well enough to fully utilize the coil in the most effective manner. Second, upon subsequent examination, it was found that the seals of the reversing valve were slightly damaged, likely causing some cross leakage. Particles of metal in the system were observed at the valve and this likely contributed to seal damage with successive opening and closing cycles.

\section{Task 5. DFM Packaged Prototype Fabrication/Field Testing (Complex Compound} Absorption Technology)

\section{Subask 5.1: Field Prototype Fabrication and Assembly}

In Task 5, a Design For Manufacturing (DFM) solid-vapor absorption refrigeration prototype was assembled. An engineering prototype was used in an earlier development effort for performance and reliability testing. The DFM prototype built upon lessons learned from this engineering prototype. Specifically, efforts focused on reducing the size and mass of the unit. These improvements would aid both the prototype assembly and performance.

The engineering prototype from previous efforts is shown in Figure 78. This engineering prototype demonstrated 9000 BTUh cooling at an evaporator temperature of $-20^{\circ} \mathrm{F}$. The DFM prototype consisted of three circuits to provide cooling. A schematic of the three circuits of the system are shown in Figure 79. The first circuit, shown in green in Figure 
79 , is the refrigerant circuit that provides refrigeration to the external hydronic loop. A steam circuit, driven by a steam generator, heats the sorbers to drive refrigerant flow to the reservoir. This circuit is shown in red in Figure 79. A sorber coolant circuit maintains the complex compound at roughly $122^{\circ} \mathrm{F}$ to provide adequate refrigerant suction, shown in blue. The DFM prototype underwent testing with a performance goal of 7,500 Btu/h $( \pm 5 \%)$ at $-28.9^{\circ} \mathrm{C}\left(-20^{\circ} \mathrm{F}\right)$ evaporator temperature.

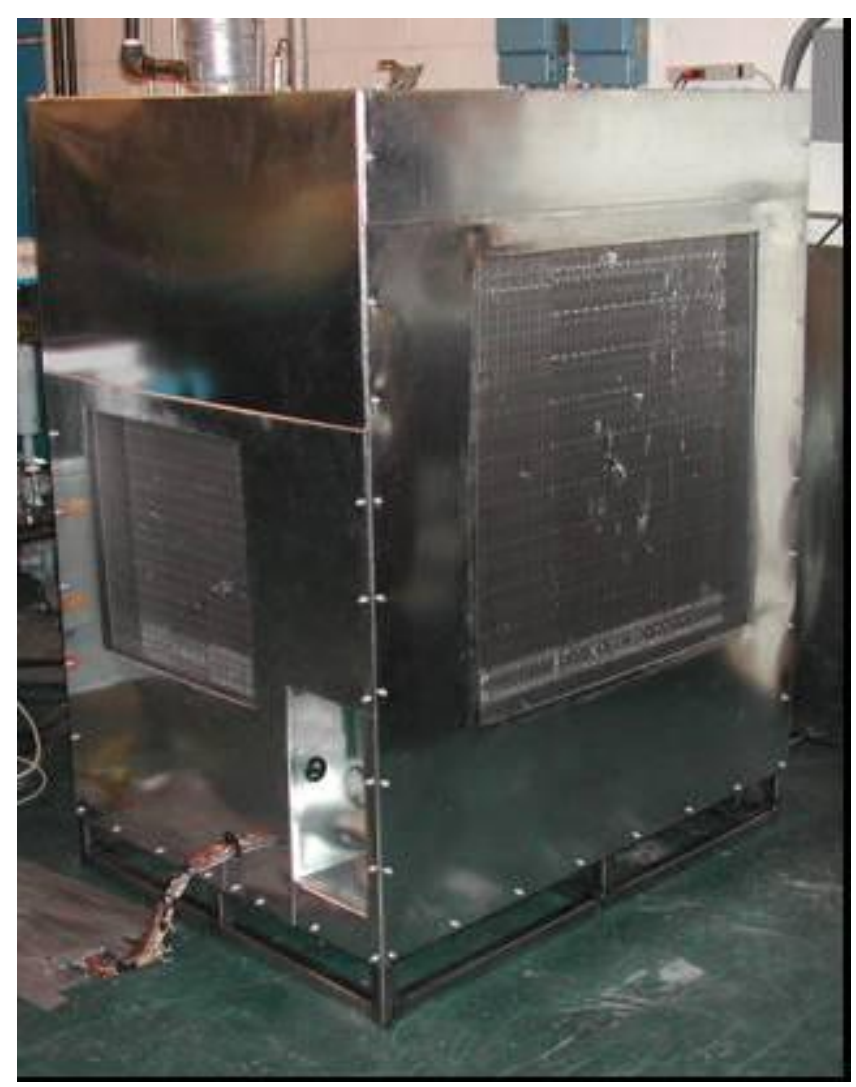

Figure 78. Engineering Prototype 


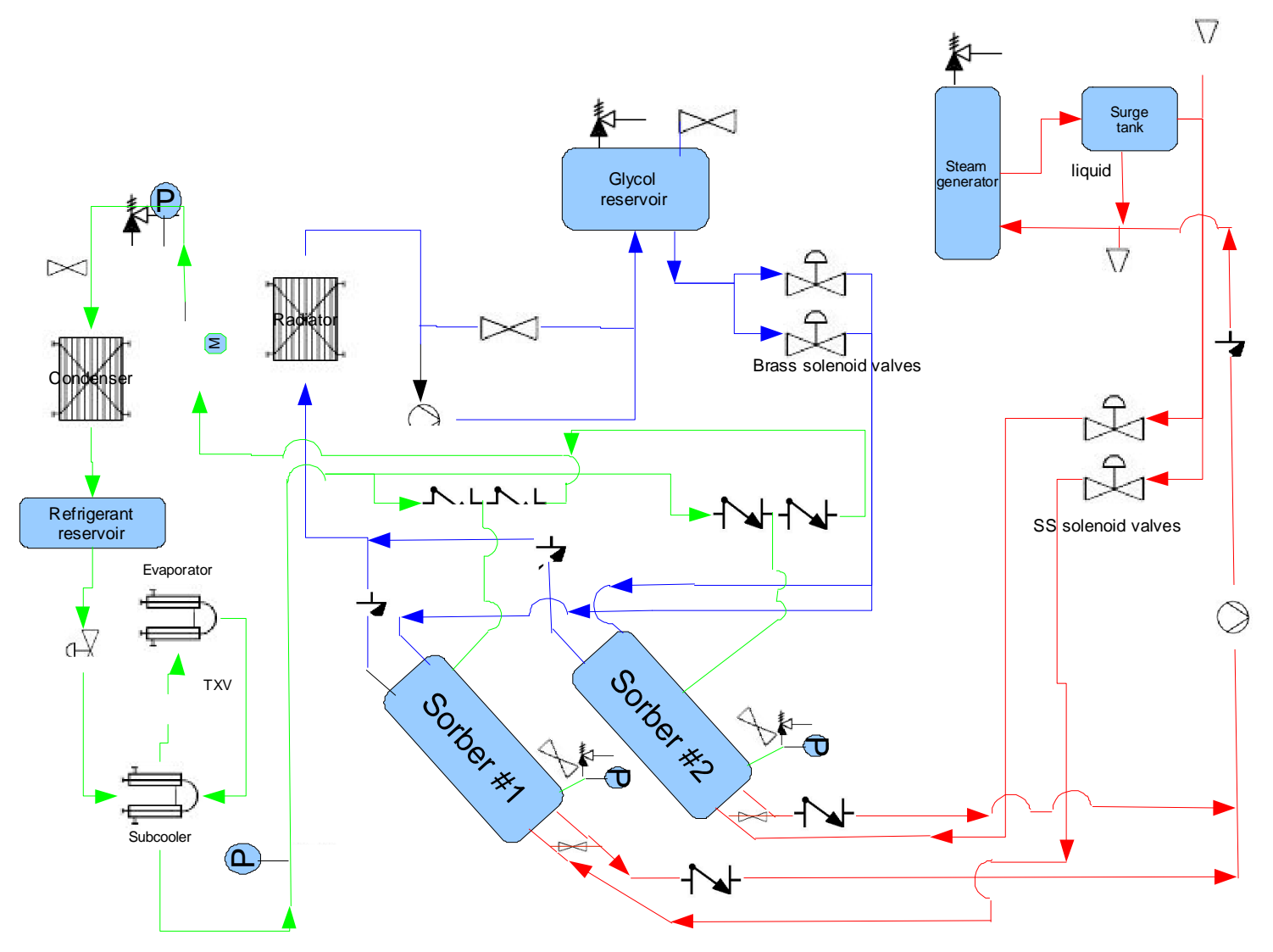

Figure 79. Schematic of DFM Prototype Circuits

\section{Redesigned Sorbers and Generator}

To reduce the mass of the unit, focus was placed on the complex compound sorbers and on the steam generator which are the heaviest components. Three approaches were followed in reducing sorber mass: (1) reducing the sorber heat transfer fin count (fins per inch of length), (2) increasing the fin height, and (3) utilizing a complex compound with a lower molecular weight but the same refrigerant holding capacity. With the above design changes, the mass of each sorber was calculated to be reduced by more than $10 \%$ with an overall length of roughly 37 inches. As a result, each sorber built weighed 110 pounds.

Two sorbers were fabricated for the packaged prototype. Attention was placed on assembling the complex compound sorbers with techniques that are practical in a manufacturing environment. The inorganic salt-impregnated substrate was processed using the machinery purchased and modified by Rocky Research under its own auspices process substrate in a continuous web processing operation. 
Impregnated rolls were cut to form discs for the complex compound sorber. After investigation, a rolling die cutter was chosen as the most cost-effective means to rapidly form discs for the prototype. The rolling die cutter used for these prototype sorbers is shown in Figure 80. The rolling die cutter is suited for small manufacturing volumes, with a throughput rate of roughly 50 discs per hour. Increasing the quantity of discs to large volumes would require automation of a clicker style press.

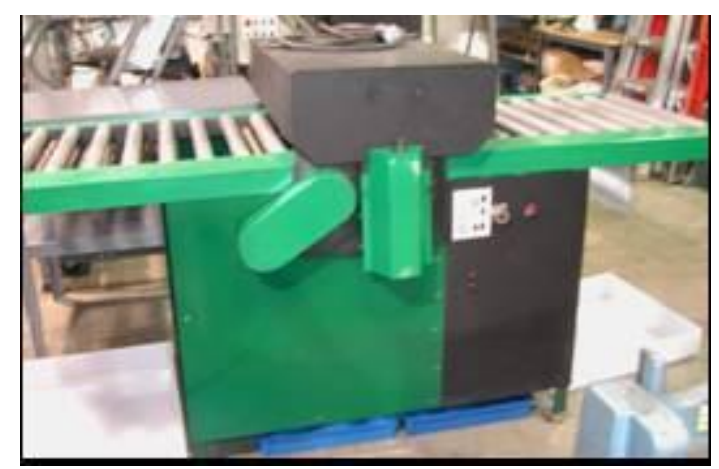

(a) Rolling die cutter

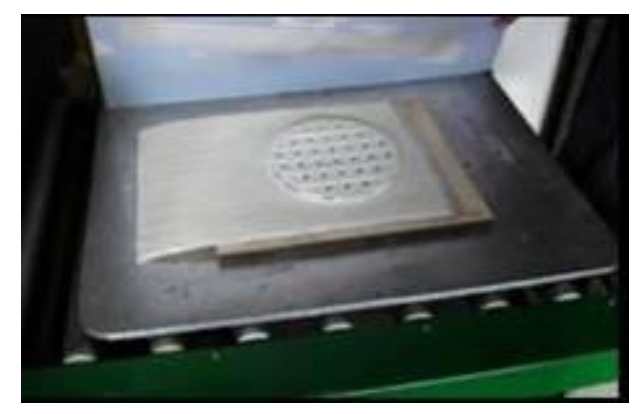

(b) Die cut disc on rolling die cutter

Figure 80. Equipment to Die Cut Impregnated Substrate Discs

The sorbers were manually stacked for the prototype which is a labor intensive process. For fabricating significant quantities of sorbers, automated stacking equipment would be more cost-effective. A proof-of-concept automated stacker has been successfully demonstrated at Rocky Research and is shown in Figure 81. A vendor generated a preliminary design for an automated stacker for multiple tube sorbers, as used in this prototype. Views of this design are shown in Figure 82. The fabricated DFM prototype sorbers are shown in Figure 83. The sorbers were inspected for leaks using both a helium leak detector and gas-lake ${ }^{1}$ testing shown in Figure 84. 

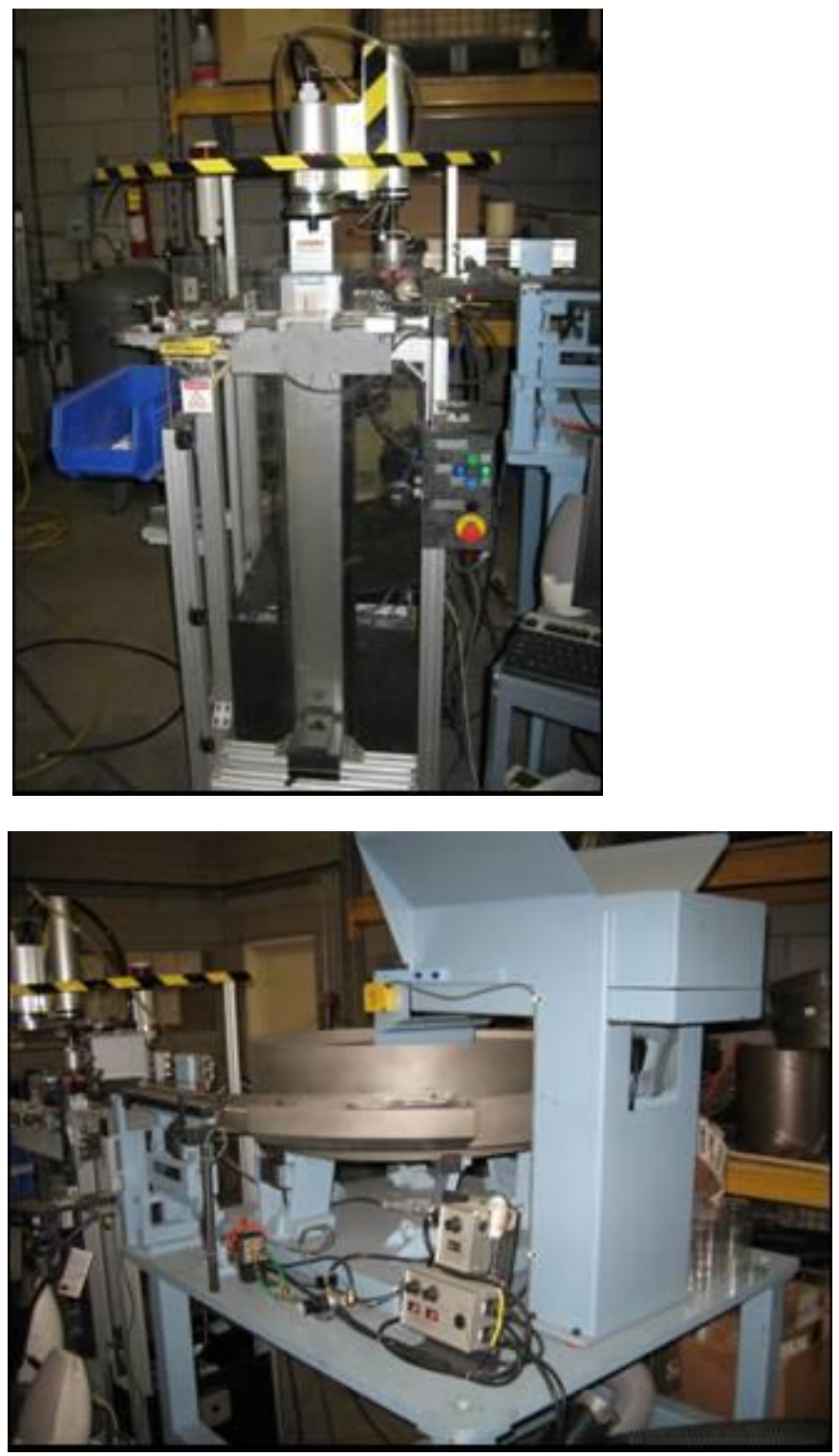

Figure 81. Automated Sorber Core Stacker 

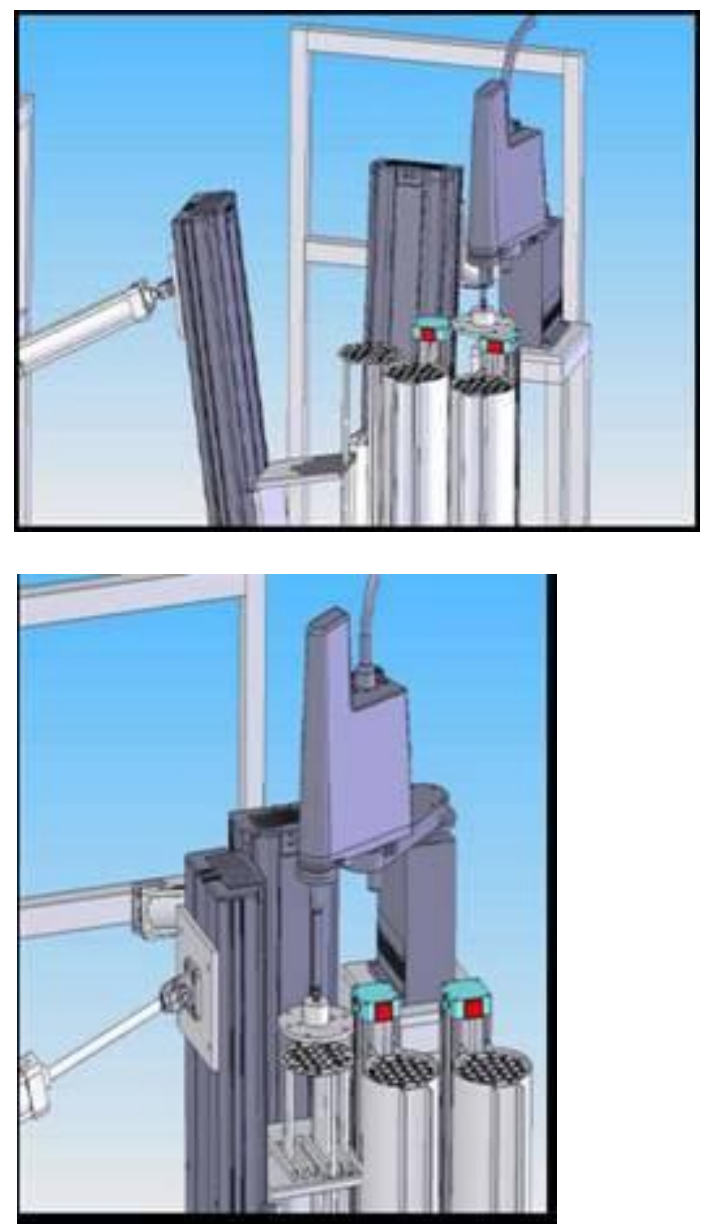

Figure 82. Multiple Tube Sorber Automated Stacker Schematic

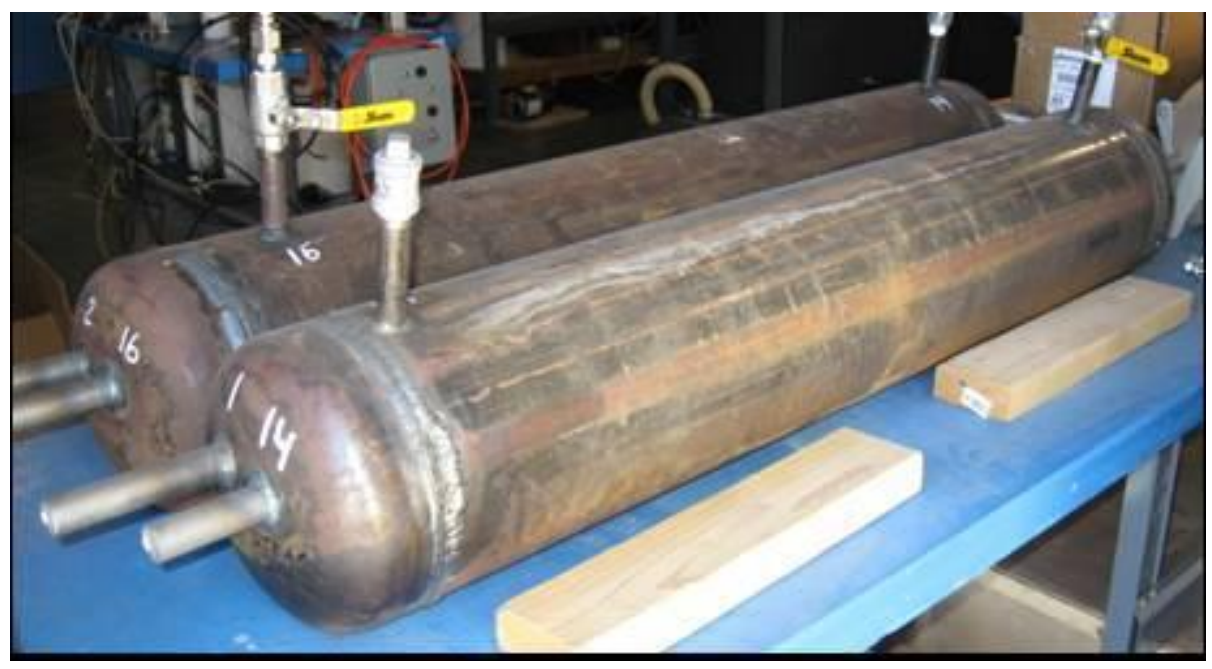

Figure 83. DFM Packaged Prototype Sorbers 

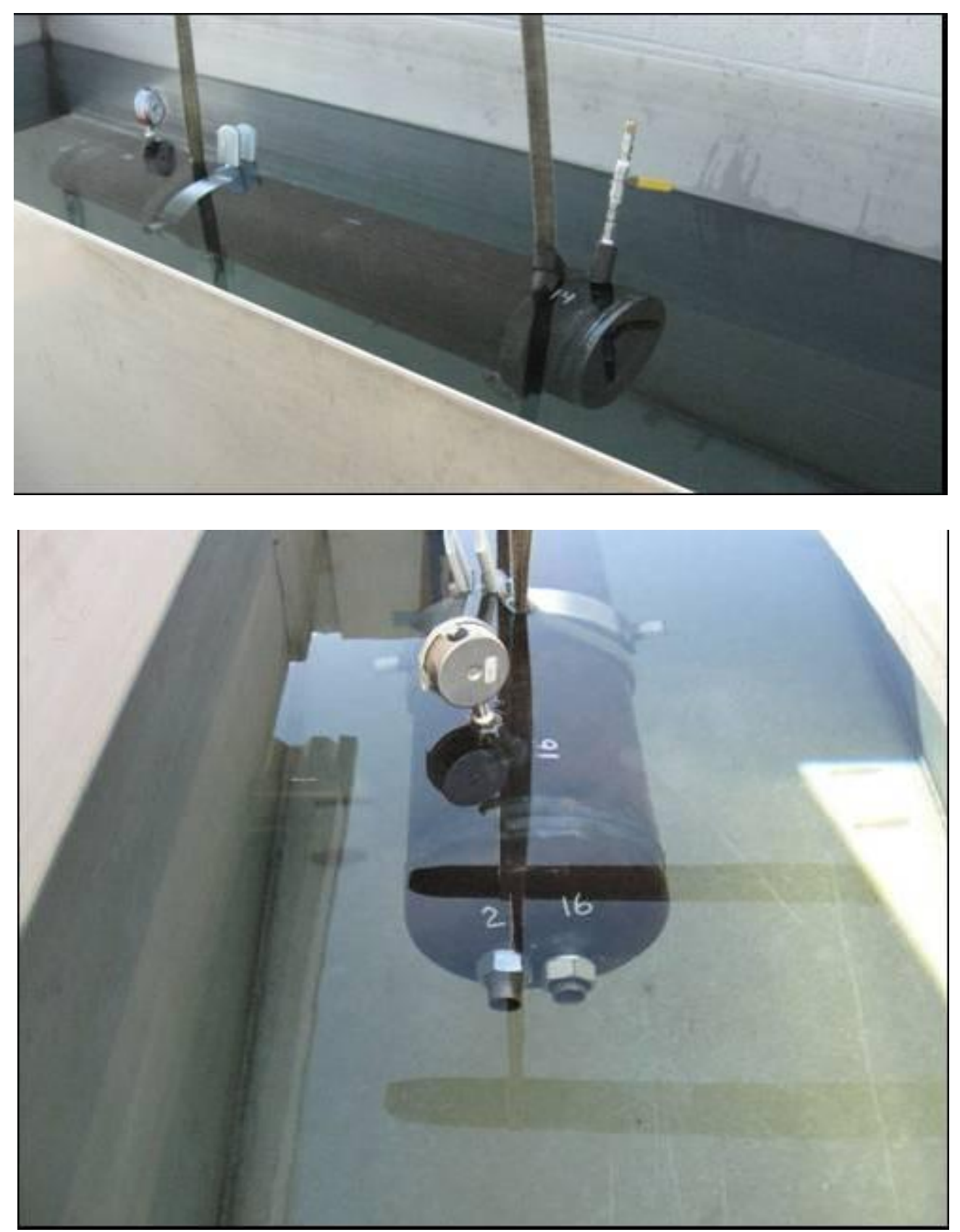

Figure 84. Gas Lake Leak Test of Sorber

The volume and mass of the steam generator was also reduced after incorporating lessons learned from previous generators. Figure 85(a) shows the steam generator in the engineering prototype, having a height of nearly 50 inches. Figure 85 (b) shows the redesigned DFM prototype steam generator with a height of 37 inches. 


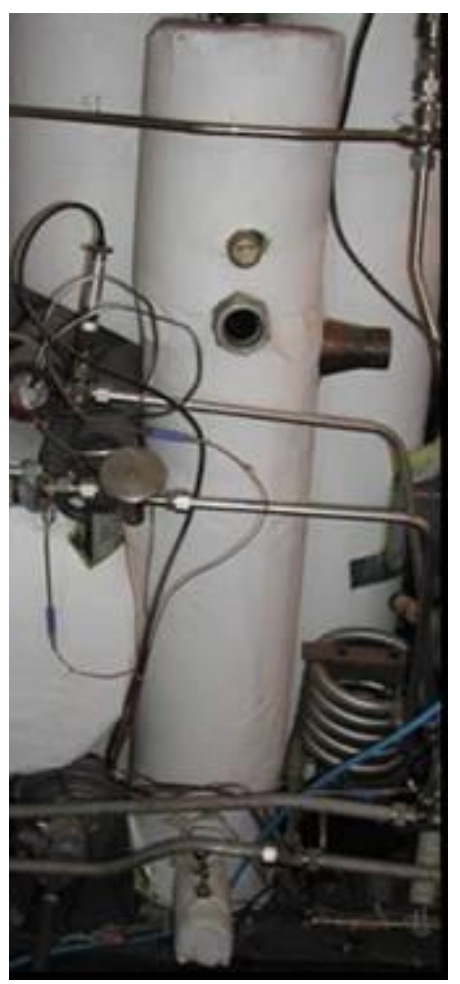

(a) Engineering Prototype

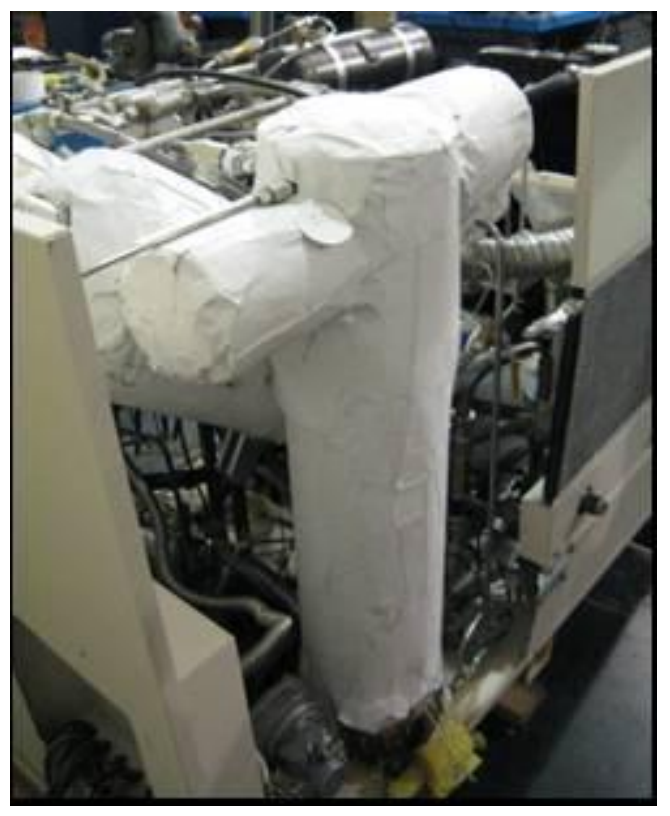

(b) DFM Packaged Prototype

Figure 85. Steam Generator Modification 


\section{Heat Exchanger Modifications}

As shown in Figure 86, the steel tube heat exchangers and fans consumed a significant volume in the engineering prototype. Reducing these heat exchanger volumes provided significant flexibility in reducing the overall volume of the DFM prototype.

An aluminum tube coolant heat exchanger was purchased that provides the same capacity as the current radiator with a $74 \%$ volume reduction. Similarly, compact aluminum automotive heat exchangers were examined to reduce the volume of the refrigerant condenser. In the packaged prototype, the coil is required to provide 11,000 BTUh $(3200 \mathrm{~W})$ of condensing capacity with the refrigerant at a saturation temperature of $50^{\circ} \mathrm{C}$ or lower. A condenser that is $80 \%$ smaller in volume than the current steel tube condenser was found to have sufficient capacity when bench tested on the setup in Figure 87.

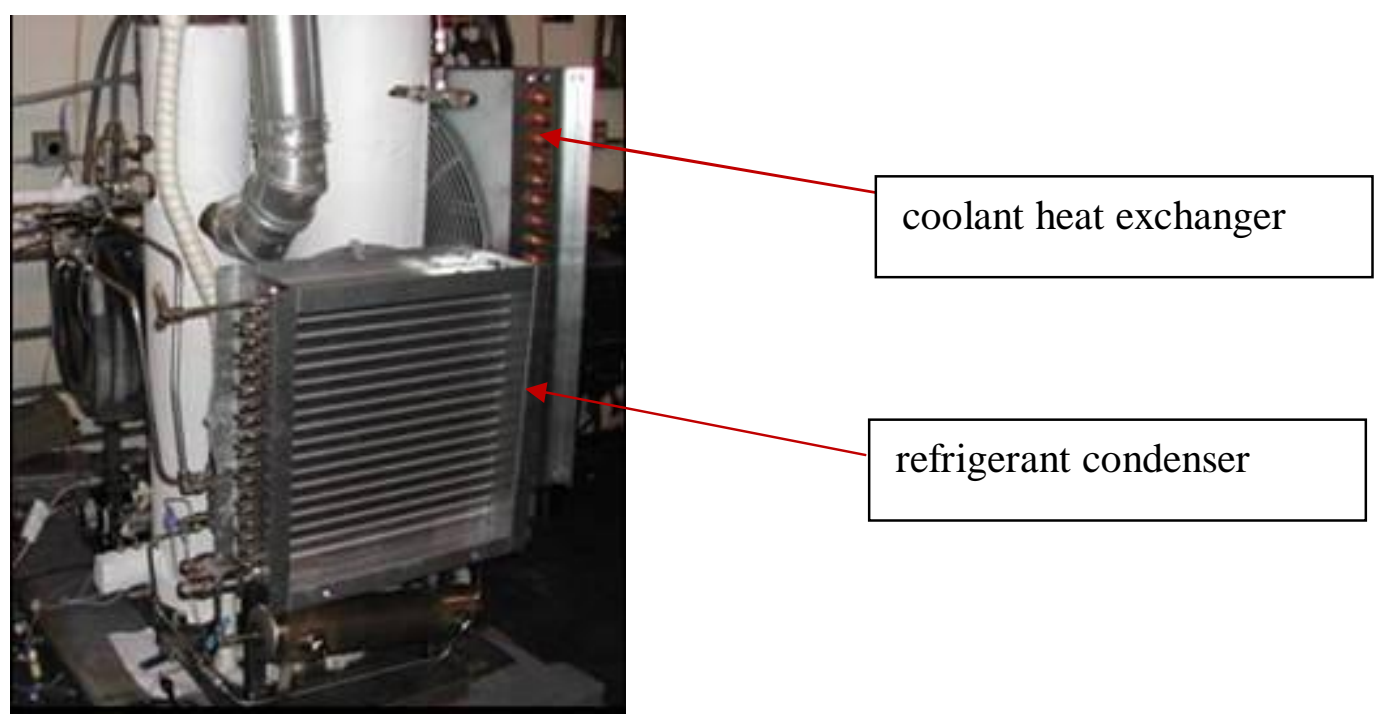

Figure 86. Engineering Prototype Heat Exchangers 


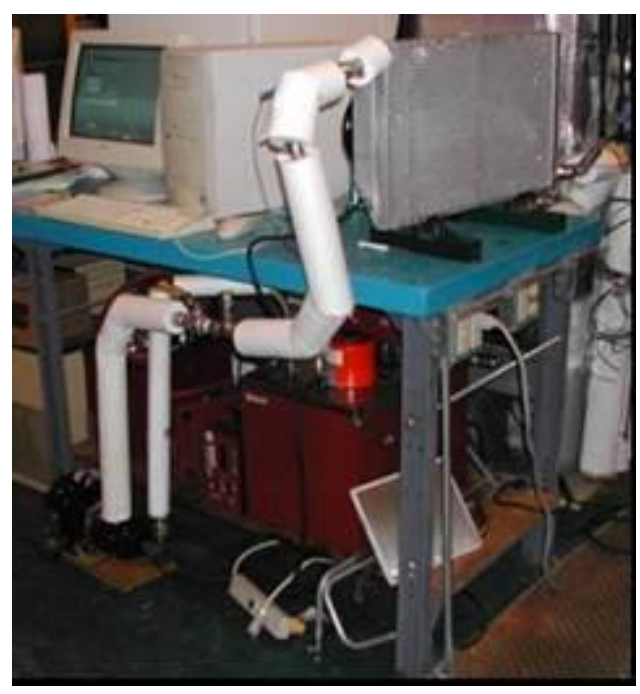

Figure 87. Condenser Capacity Test Stand

\section{DFM Packaged Prototype Design and Assembly}

With the smaller and lighter sorbers, generator, and heat exchangers, solid modeling software was used to package the prototype. The engineering prototype volume was 55 $\mathrm{ft}^{3}$ with a height of 59 inches. The DFM packaged prototype has a volume of $46 \mathrm{ft}^{3}$ with a height of 38 inches. The solid model of the packaged prototype is shown in the views in Figure 88. Shown is the packaging of the internal components. 

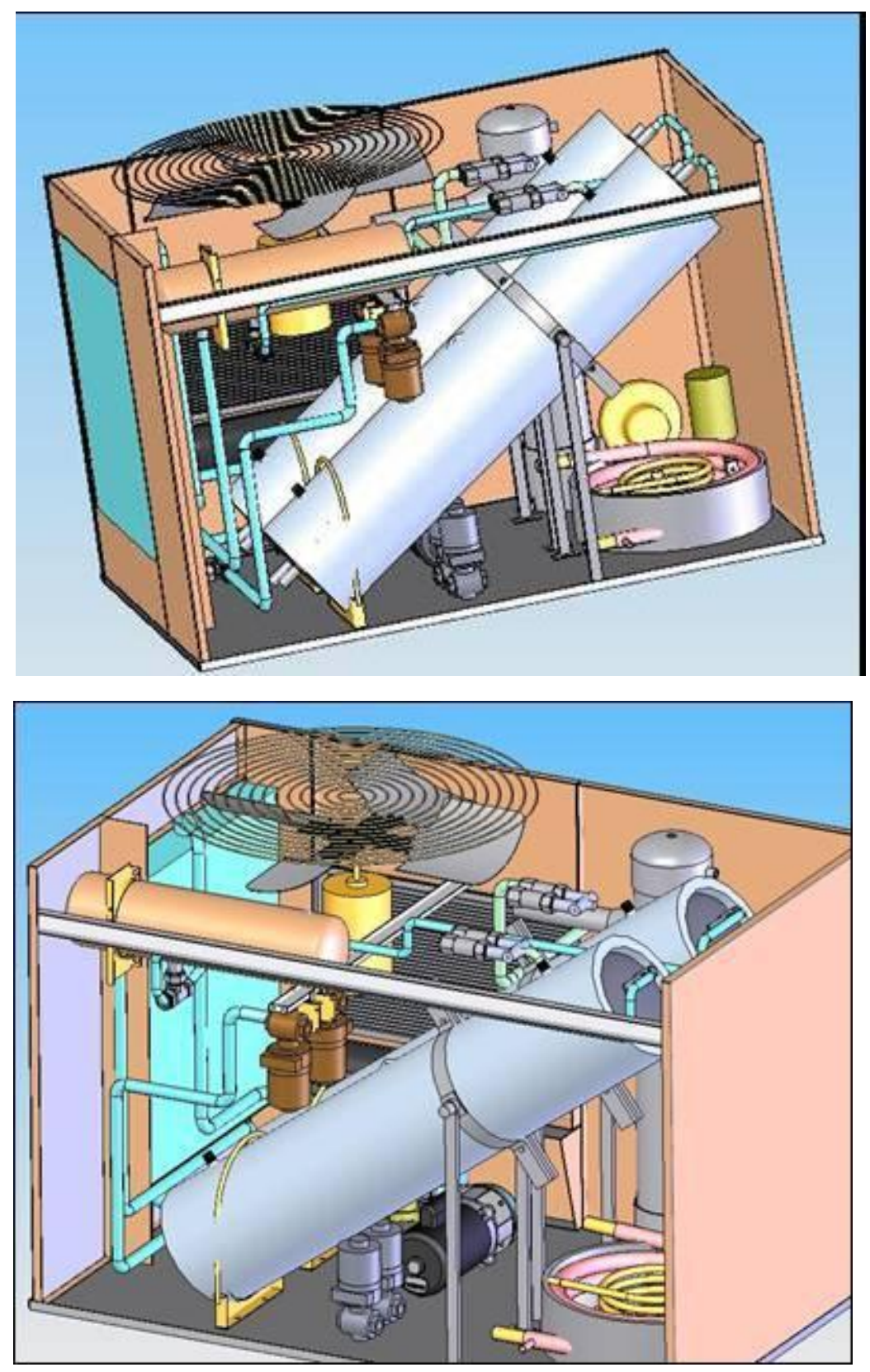

Figure 88. Solid Model of DFM Packaged Prototype

The system was assembled and instrumented with thermocouples, Resistance Temperature Detector (RTD) probes, pressure transducers, and flowmeters for prototype testing. The refrigerant and steam circuits were pressure tested. Pictures of the engineering prototype and the smaller DFM prototype are shown in Figure 89. 


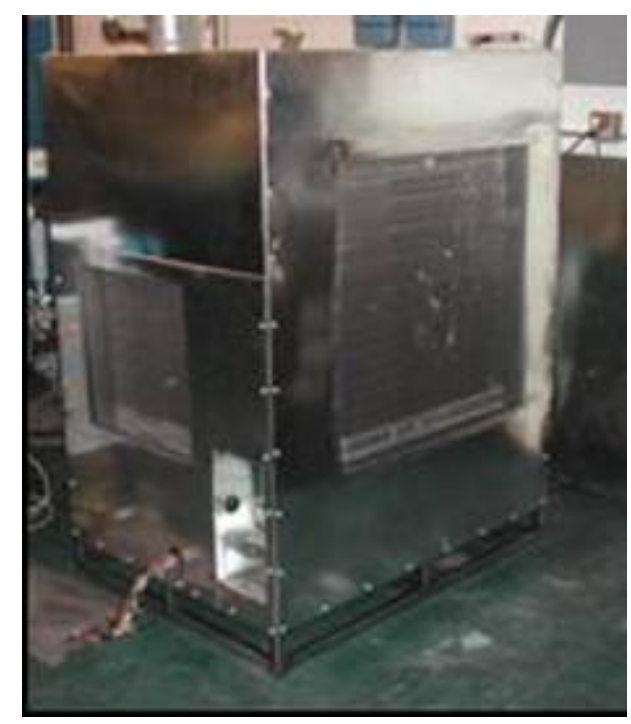

(a) engineering prototype

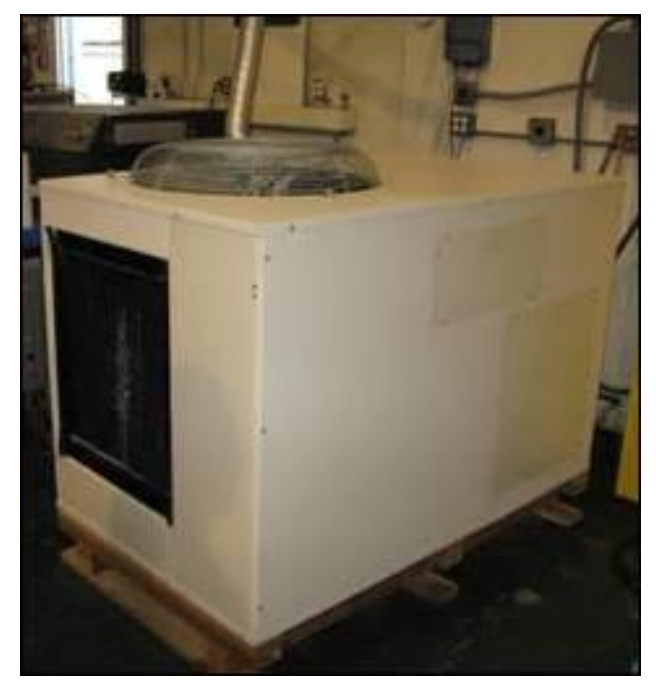

(b) DFM prototype

Figure 89. Engineering Prototype and DFM prototype

Next the complex compound was dried. Figure 90 shows the internal components of the prototype during this drying process. The refrigerant low pressure line was connected to a vacuum pump through a cold trap. The steam circuit was charged and the generator operated at $180^{\circ} \mathrm{C}$ with a temporary control circuit. Steam and condensate temperatures and sorber pressures were monitored to manually cycle the generator. The amount of water collected in the cold trap was recorded; a total of $3.19 \mathrm{~kg}$ of water was removed 
during drying. The completed assembly is shown in Figure 91.
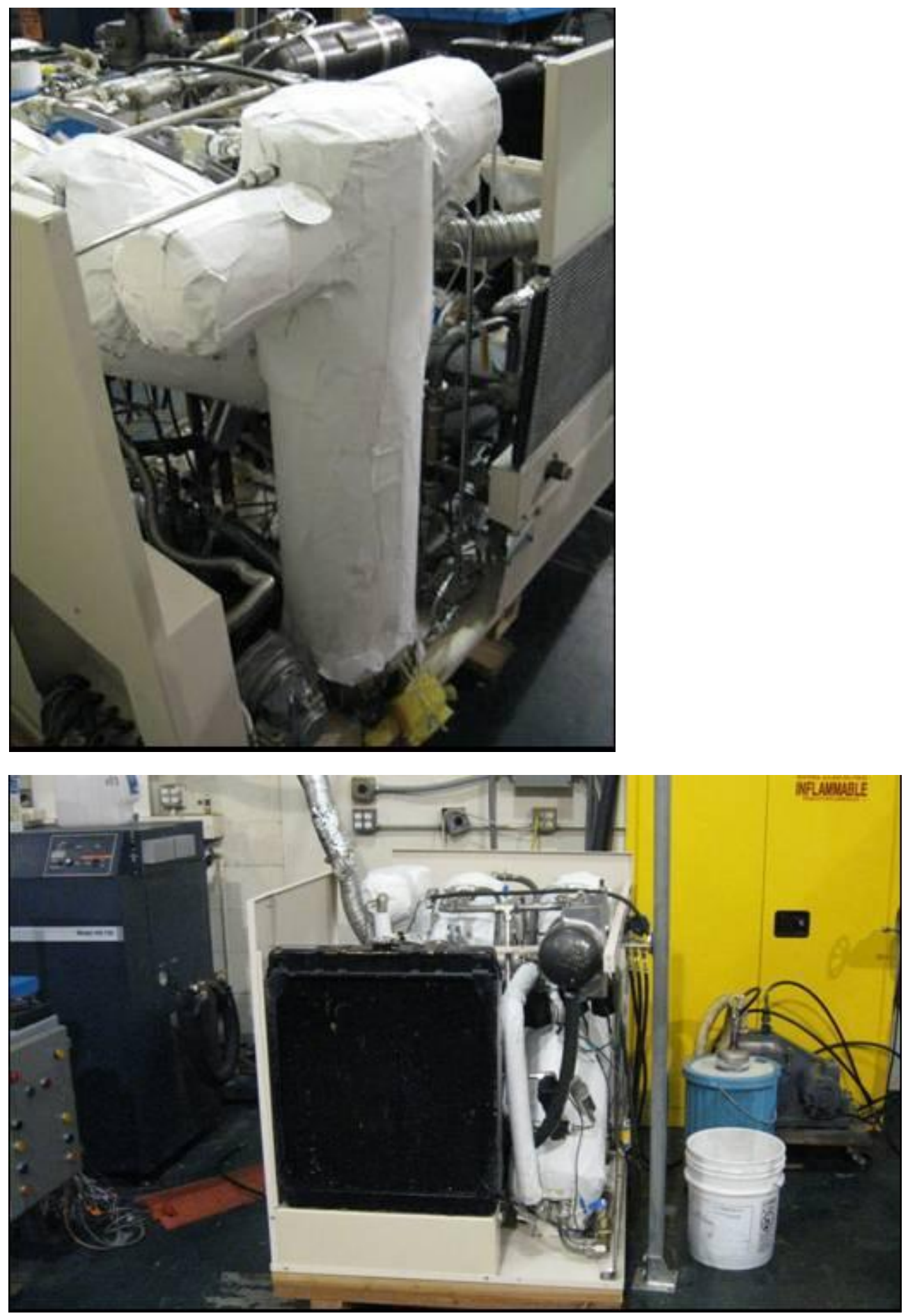

Figure 90. DFM Packaged Prototype Internal Components 

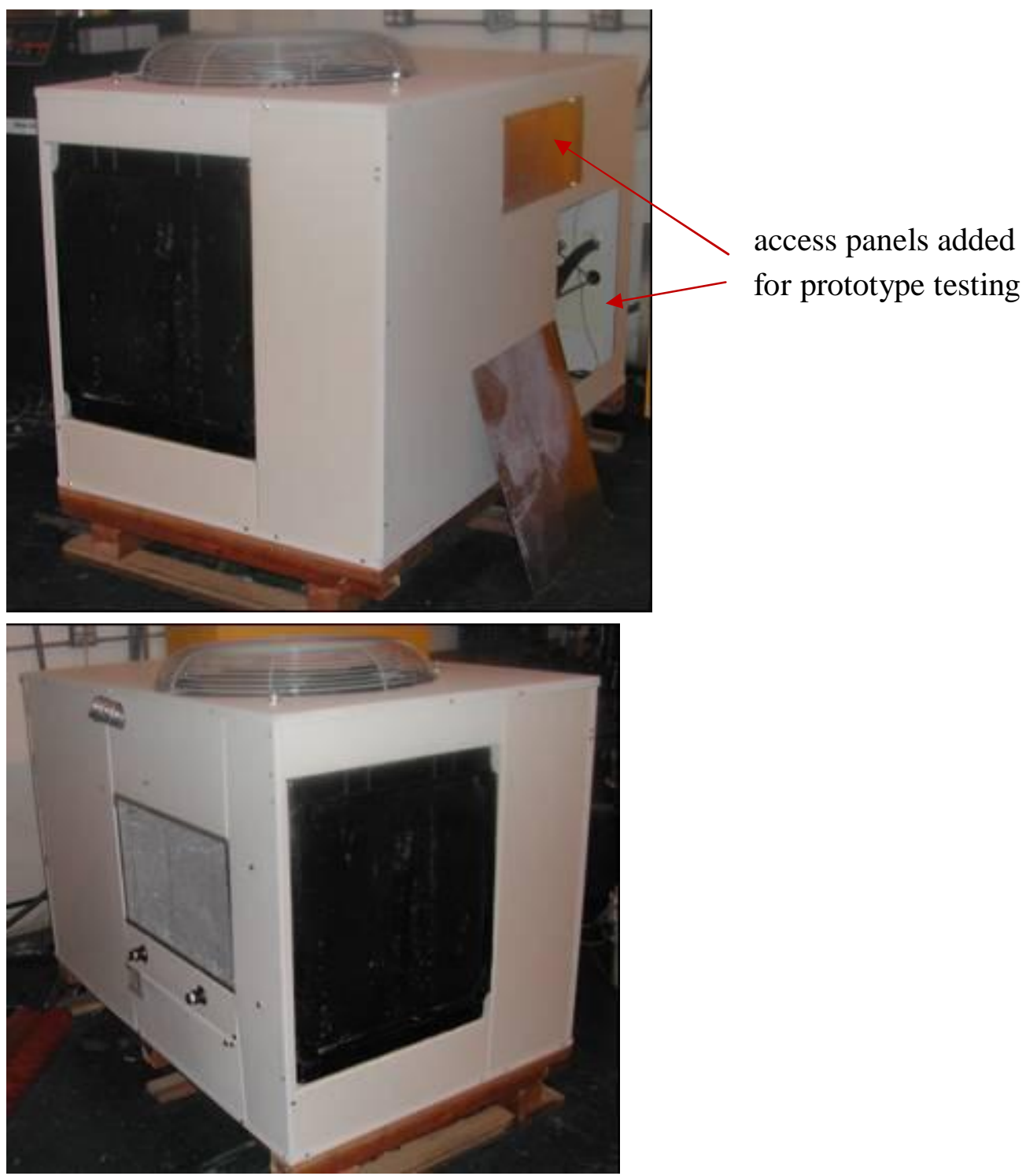

Figure 91. DFM Packaged Prototype

\section{Subtask 5.2 Performance Verification of Field Prototype and Subtask 5.3 Field} Prototype Test

The system was charged with refrigerant through a charge port in the evaporator side of the refrigerant system. Refrigerant mass flow rate was monitored and this initial refrigerant charge was measured to be $10.2 \mathrm{~kg}$ of refrigerant.

A microprocessor based unitary controller was installed to govern all of the system operation including fan, generator firing rate, pumps, and solenoids as well as safeties. High pressure switches were installed on both the generator and the refrigerant reservoir. 
A flow switch protected the coolant pump from running dry. Figure 92 is a picture of the unitary controller.

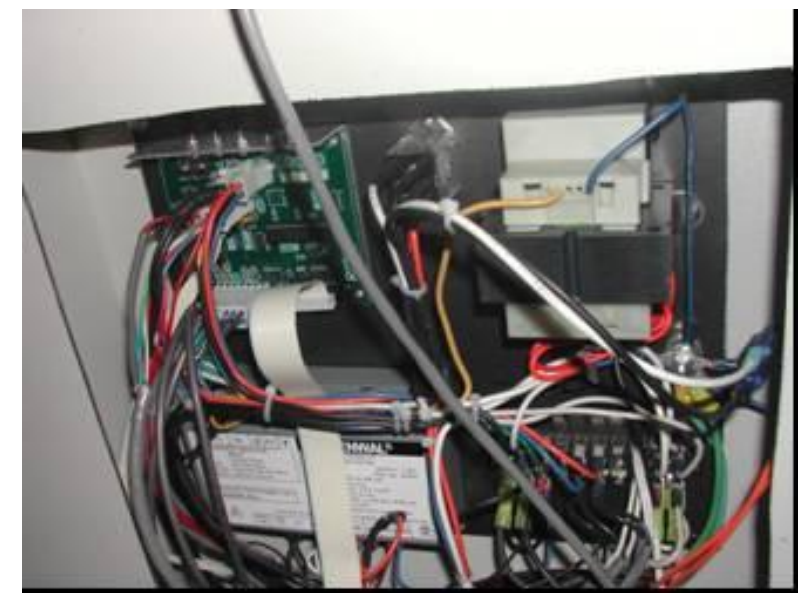

Figure 92. DFM Prototype Unitary Controller

Several issues that were causing poor refrigerant recharging were addressed. A lack of liquid discharged back to the refrigerant reservoir indicated additional refrigerant charge was needed. A total refrigerant charge of $14.7 \mathrm{~kg}$ was added to the system. A larger refrigerant reservoir, shown in Figure 93, was fabricated and installed to accommodate this larger refrigerant charge. The generator gas valve was adjusted for $30 \%$ excess air and firing rate for the generator was increased from under 30,000 BTU/h to between 40,000 BTU/h and 80,000 BTU/h. A liquid drain was added to the sorber steam inlet; liquid carried over by the generator would trap at this inlet and impede steam flow. Figure 94 shows this liquid drain. A heat exchanger and liquid sensor were added to the condensate pump suction to avoid dryout or exceeding the maximum operating temperature of the condensate pump. These are shown in Figure 95. With these changes, the refrigerant recharging rate increased significantly. 


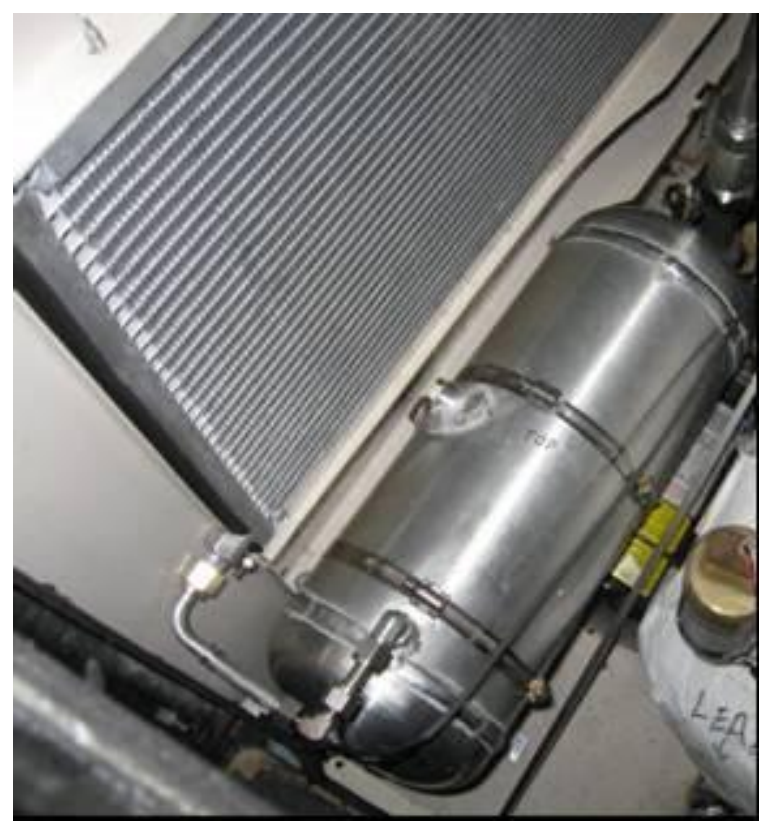

Figure 93. Larger Refrigerant Reservoir Installed

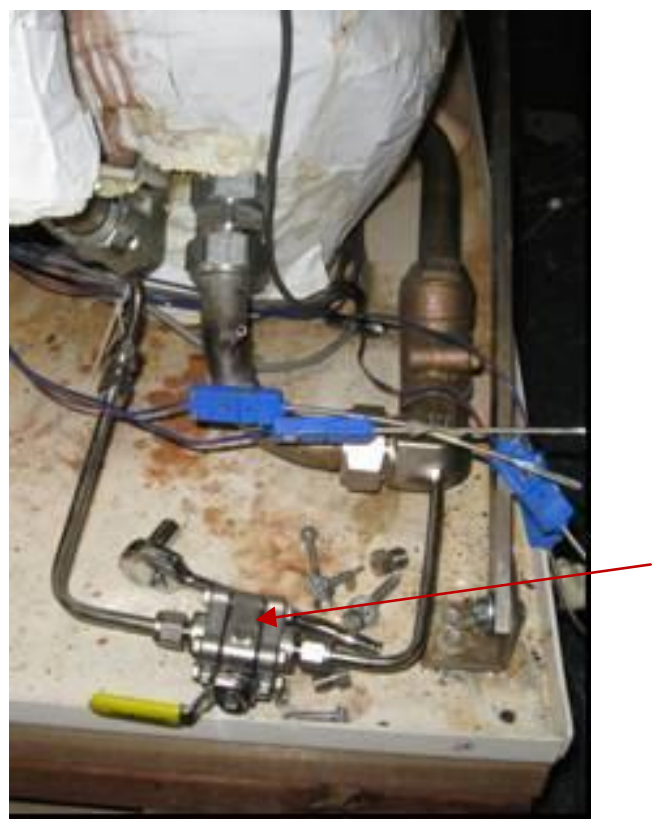

liquid drain to condensate pump suction

Figure 94. Liquid Drain at Low Point on Sorber Steam Inlet 


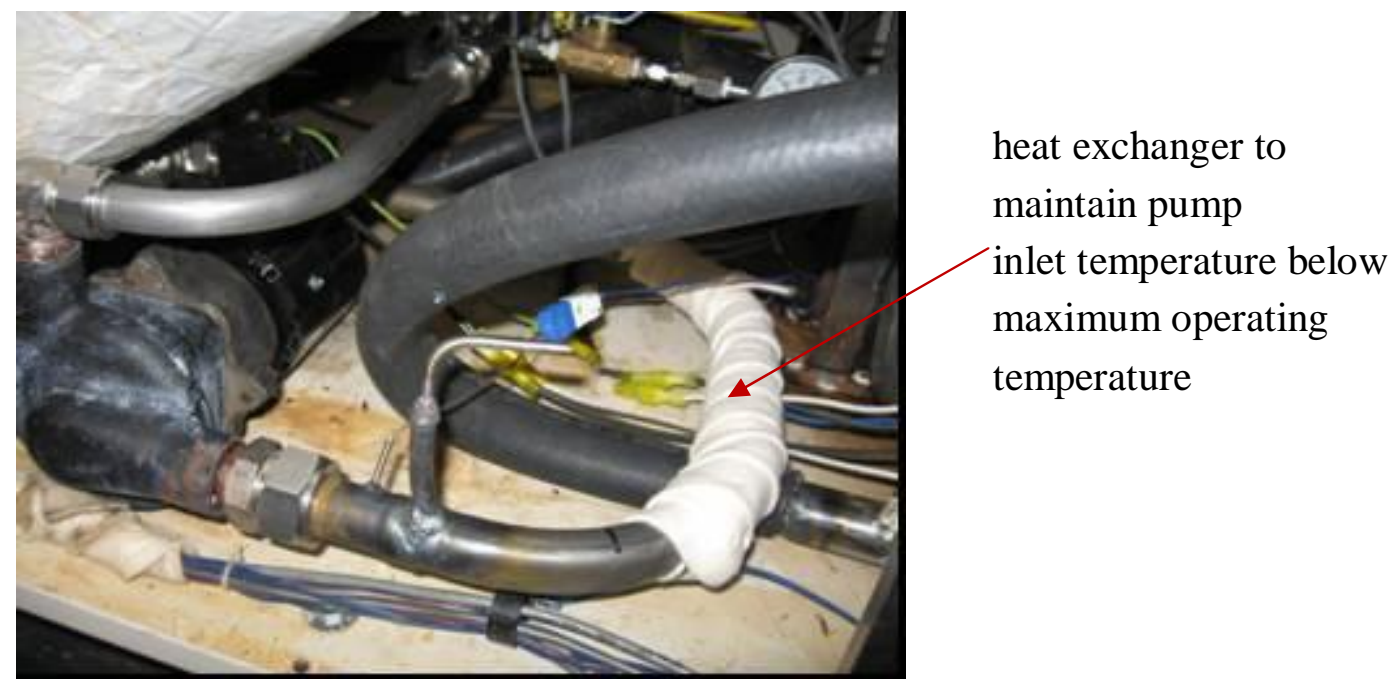

Figure 95. Heat Exchanger Added to Steam Circuit for Condensate Pump

A hydronic loop connected a Thermofisher HX-750 constant temperature bath to the unit. This unit provided a constant load for capacity calculations. Figure 96 shows the hydronic loop and bath simulating the system load. In determining system performance, capacity was calculated at an evaporator temperature dictated by the refrigerant saturation temperature. A MicroMotion DS150 flow meter output hydronic mass flow ( through the evaporator. A 20 -junction thermopile monitored the reduction in temperature of the hydronic fluid through the evaporator $(\Delta)$. The transducer has an accuracy of $\pm 0.07^{\circ} \mathrm{F}\left(0.04^{\circ} \mathrm{C}\right)$. Cooling capacity is calculated based on these measured quantities as

$$
=\Delta
$$

where is the heat capacity of the hydronic fluid ${ }^{2}$. The hydronic flow was adjusted to between 800 and $1,200 \mathrm{~kg} / \mathrm{hr}$ so that $9,000 \mathrm{BTU} / \mathrm{h}$ translates to a measured temperature difference of between $2^{\circ} \mathrm{C}$ and $3^{\circ} \mathrm{C}$. 


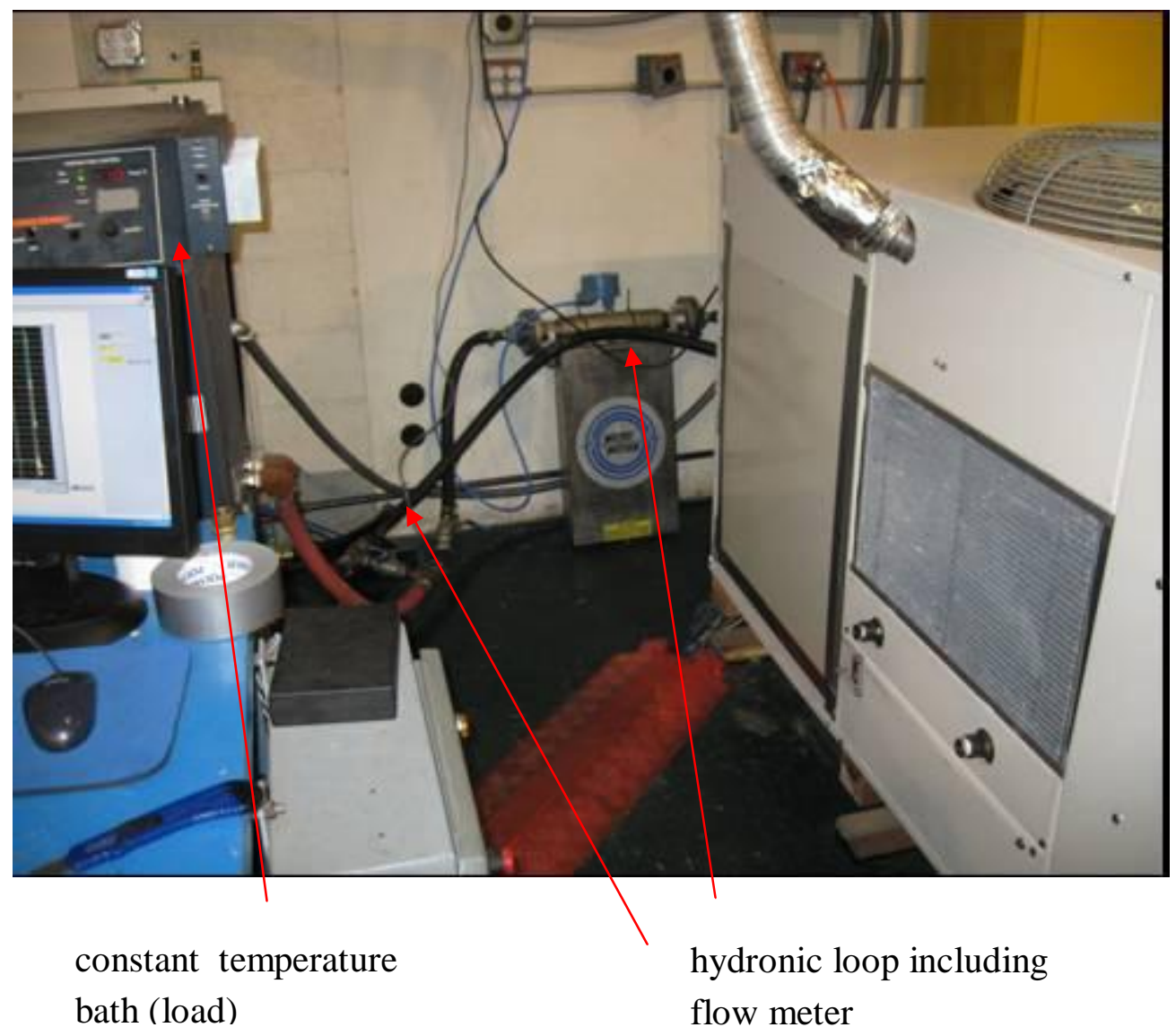

Figure 96. Hydronic Loop To and From Constant Temperature Bath (Load)

\section{$\underline{\text { System Performance }}$}

Figure 97 shows the measured and time integrated cooling provided by the DFM prototype. Figure 98 shows the refrigerant saturation temperature at evaporator pressure. The DFM prototype demonstrated highly peaked cycles of cooling. As each sorber began drawing refrigerant from the evaporator, cooling rates of over 20,000 BTU/h were measured on the hydronic loop. The integrated cooling rate, as measured by the hydronic loop, averages $4,900 \mathrm{BTU} / \mathrm{h}$ at the end of testing. The median evaporator temperature is $-1^{\circ} \mathrm{F}$ during cooling with evaporator temperatures reaching as low as $-30^{\circ} \mathrm{F}$. The integrated generator firing rate during the test was $69,000 \mathrm{BTU} / \mathrm{h}$. This results in a measured Coefficient of Performance (COP) of 0.09. 


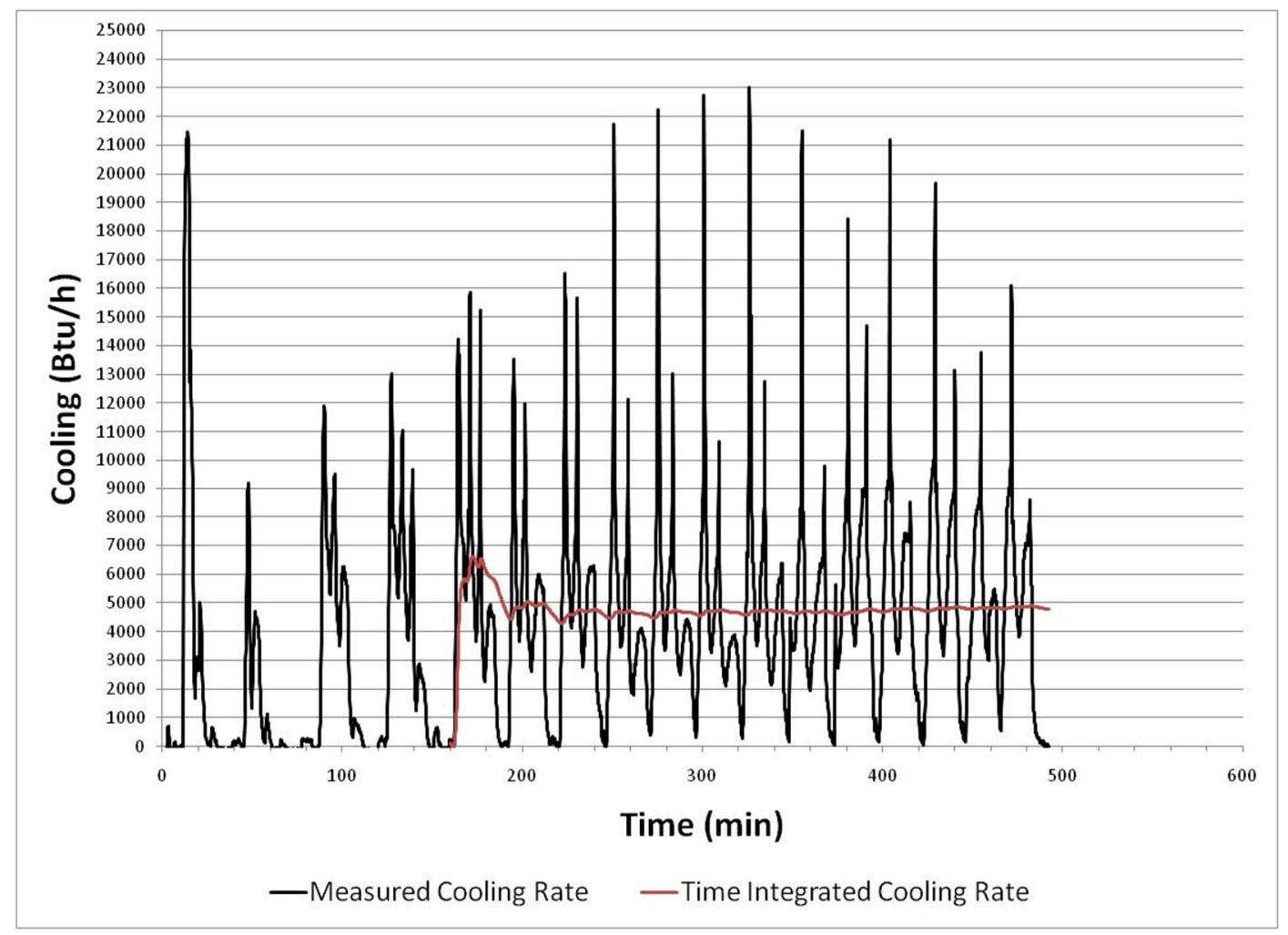

Figure 97. Cooling Performance of DFM Prototype

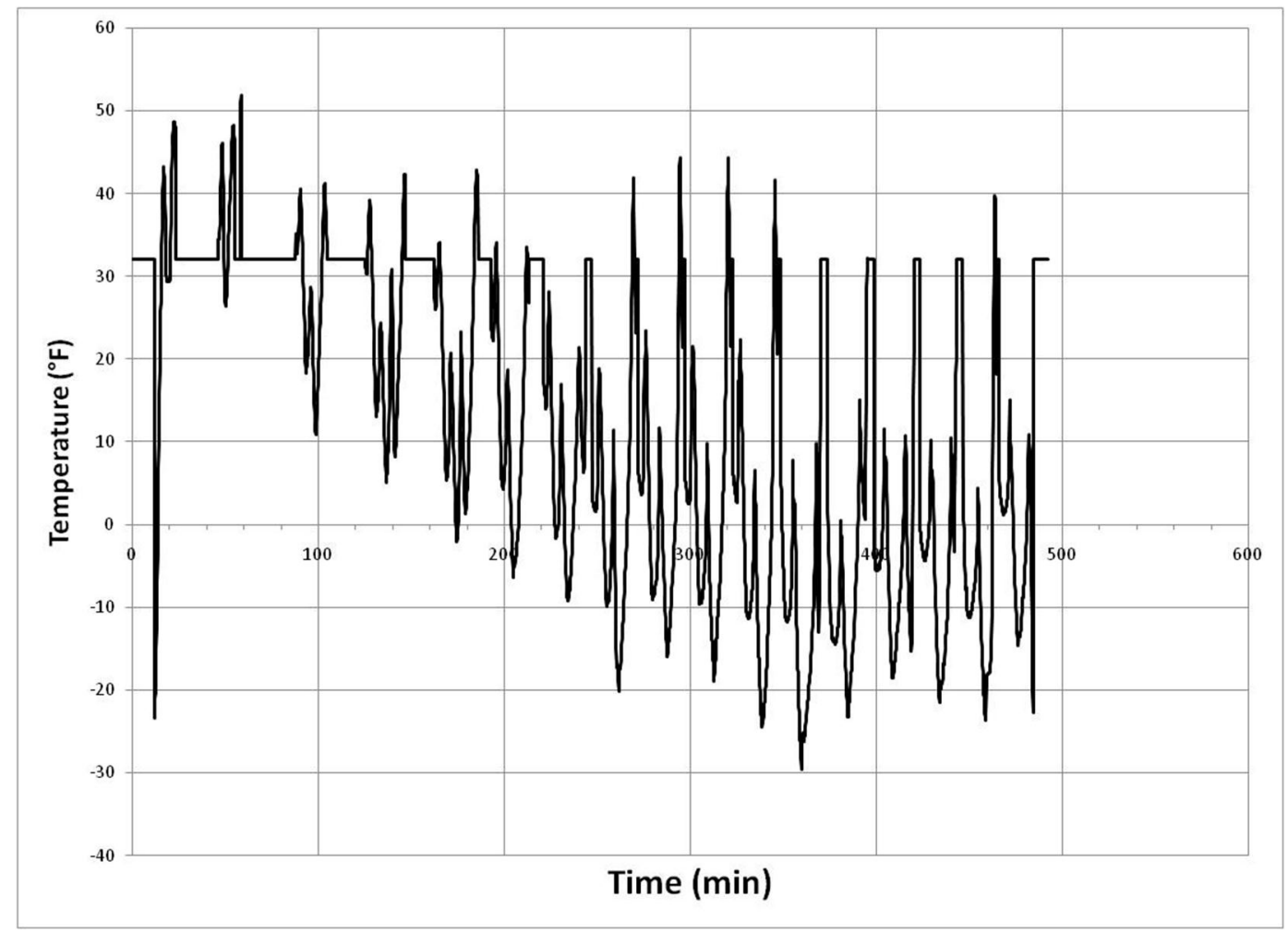

Figure 98. Evaporator Temperature during DFM Performance Testing 
These results fall short of the 7,500 BTU/h performance goal with a COP of 0.27 . The limitation does not appear to be sorber cooling capacity. The sorbers were sized to provide 1,500 BTU of cooling (7,500 BTU/h x 12 minutes). The sorbers provided 2,041 BTU of cooling $(4,900 \mathrm{BTU} / \mathrm{h} \times 25$ minutes). The main driver of this shortcoming is the 25 minute cycle time required to fully desorb; this is twice of the designed 12 minute desorption period.

Much of the sorber mass savings resulted from reducing the number of steam and coolant tubes inside the sorber. The reduced number of coolant tubes does not negatively impact absorption, since the sorber demonstrated sufficient cooling capacity and peak cooling rates $300 \%$ of design $(23,000 \mathrm{BTU} / \mathrm{h} \div 7,500 \mathrm{BTU} / \mathrm{h})$. However, the fact that the sorbers do not desorb in 12 minutes at a steam temperature close to the design temperature of $185^{\circ} \mathrm{C}$ and a heat input rate of $69,000 \mathrm{BTU} / \mathrm{h}$ likely means that the number of steam tubes needs to be increased or the steam temperature had to be increased. Unfortunately, in the DFM prototype, condensate pump temperature had to be maintained below the $160^{\circ} \mathrm{C}$ maximum operating temperature of the condensate pump. Above this temperature, impeller failures were observed. This limited the steam temperature to a median temperature of $184^{\circ} \mathrm{C}$.

These tests were conducted over an extended period of time (greater than 6 month) at Rocky Researchô Boulder City, Nevada facility under simulated commercial refrigeration loads.

\section{$\underline{\text { Requirements for Propane or Exhaust Heat Operation }}$}

To operate the DFM prototype using propane or fuels other than natural gas, the fuel and air orifice diameters of the generator burner need to be adjusted. For example, to operate with propane with $25 \%$ excess air at $120,000 \mathrm{Btu} / \mathrm{h}$ and $50 \%$ excess air at 70,000 BTUh, the air and gas orifice diameters need to be increased from the values in Table 7 to the diameters of Table 8 .

\begin{tabular}{|l|l|}
\hline Gas Orifice Diameter (in) & Air Orifice Diameter (in) \\
\hline 0.218 & 0.860 \\
\hline
\end{tabular}

Table 7. Orifice Diameters for Natural Gas Operation

\begin{tabular}{|l|l|}
\hline Gas Orifice Diameter (in) & $\underline{\text { Air Orifice Diameter (in) }}$ \\
\hline 0.242 & 0.968 \\
\hline
\end{tabular}

Table 8. Orifice Diameters For Propane Operation 
The steam generator for the solid-vapor absorption refrigeration system is nearly identical to the aqua-ammonia steam generator. The aqua-ammonia generator has been proven to effectively use waste heat in Task 11. The DFM steam generator could therefore directly use exhaust gas as the heat source instead of natural gas combustion. The burner and blower assembly would have to be removed. For control, a solenoid or motor-operated ball valve or gate valve on the flue exhaust would be needed for the unitary controller to stop and start exhaust gas flow. Positioning the valve on the exhaust instead of flue inlet reduces the operating temperature for the valve from $800^{\circ} \mathrm{F}$ or higher to $400^{\circ} \mathrm{F}$. Exhaust gas would drive steam generation controlled to $180^{\circ} \mathrm{C}$ to $200^{\circ} \mathrm{C}\left(356^{\circ} \mathrm{F}\right.$ to $\left.392^{\circ} \mathrm{F}\right)$ by the unitary controller.

\section{Conclusions and Recommendations}

The DFM prototype provides an integrated cooling capacity of 4,900 BTU/h at a median evaporator temperature of $-1^{\circ} \mathrm{F}$. Peak cooling rates of over $20,000 \mathrm{BTU} / \mathrm{h}$ were recorded with evaporator temperatures as low as $-30^{\circ} \mathrm{F}$. The volume of the engineering prototype was reduced from $55 \mathrm{ft}^{3}$ to $46 \mathrm{ft}^{3}$ with the height of the unit reduced from 59 inches to 38 inches. The sizes of the generator and heat exchangers were reduced. The sorbers were 7 inches shorter and $10 \%$ lighter than those of the engineering prototype and demonstrated $36 \%$ more integrated cooling capacity than designed. The DFM prototype also integrated a microprocessor based unitary controller that was not present on the engineering prototype.

To achieve 7,500 BTU/h cooling the unit would not have to be proportionally larger in volume and mass. However, component changes would be required. The highly variable cooling rate indicates that a larger evaporator should be considered for this system. As a part of the effort to reduce the size and weight of the DFM prototype, the evaporator from the engineering prototype was replaced with a smaller heat exchanger. The evaporators are shown in Figure 99. The TXV appears to be performing as designed, maintaining a median superheat, shown in Figure 100 , of roughly $30^{\circ} \mathrm{C}$. However the large fluctuations in superheat indicate flooding and starving of the smaller evaporator. Since this TXV provided smooth refrigerant flow control with the larger evaporator on the engineering prototype, a larger evaporator which fits within the DFM package would likely result in more uniform cooling. The maximum operating temperature of the condensate pump impeller limited steam temperature. If the condensate pump plastic impeller were replaced with an impeller that could operate at higher temperatures, cycle times could be significantly reduced, improving overall performance dramatically. 


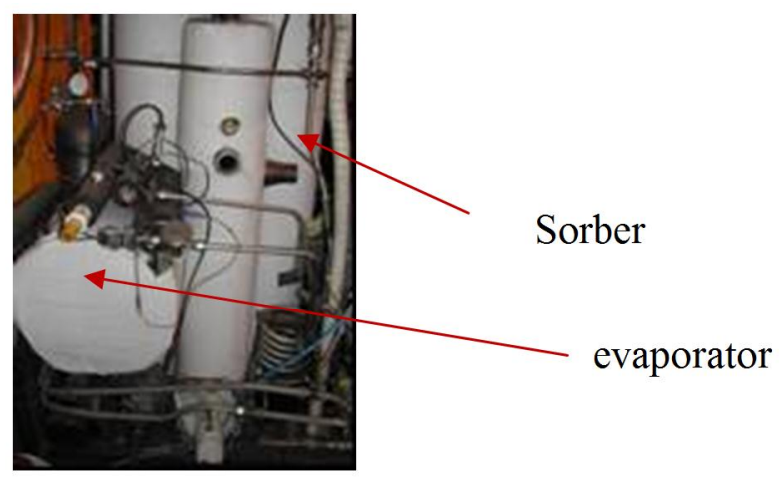

(a) Engineering Prototype

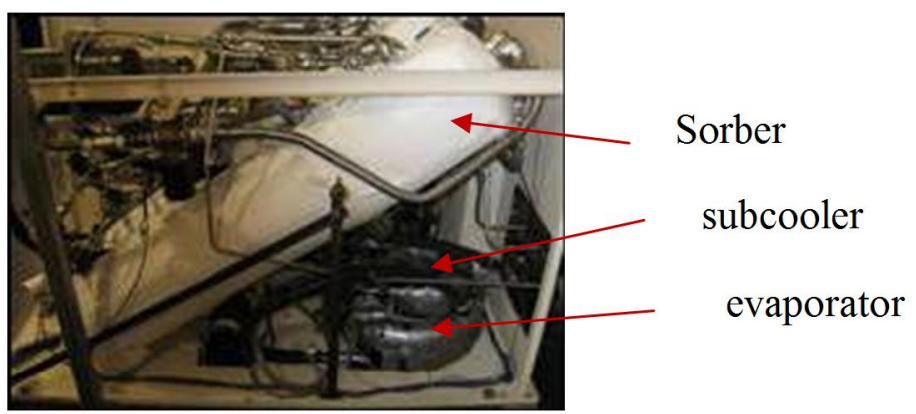

(b)DFM Prototype

Figure 99. Evaporators on Engineering and DFM Prototype

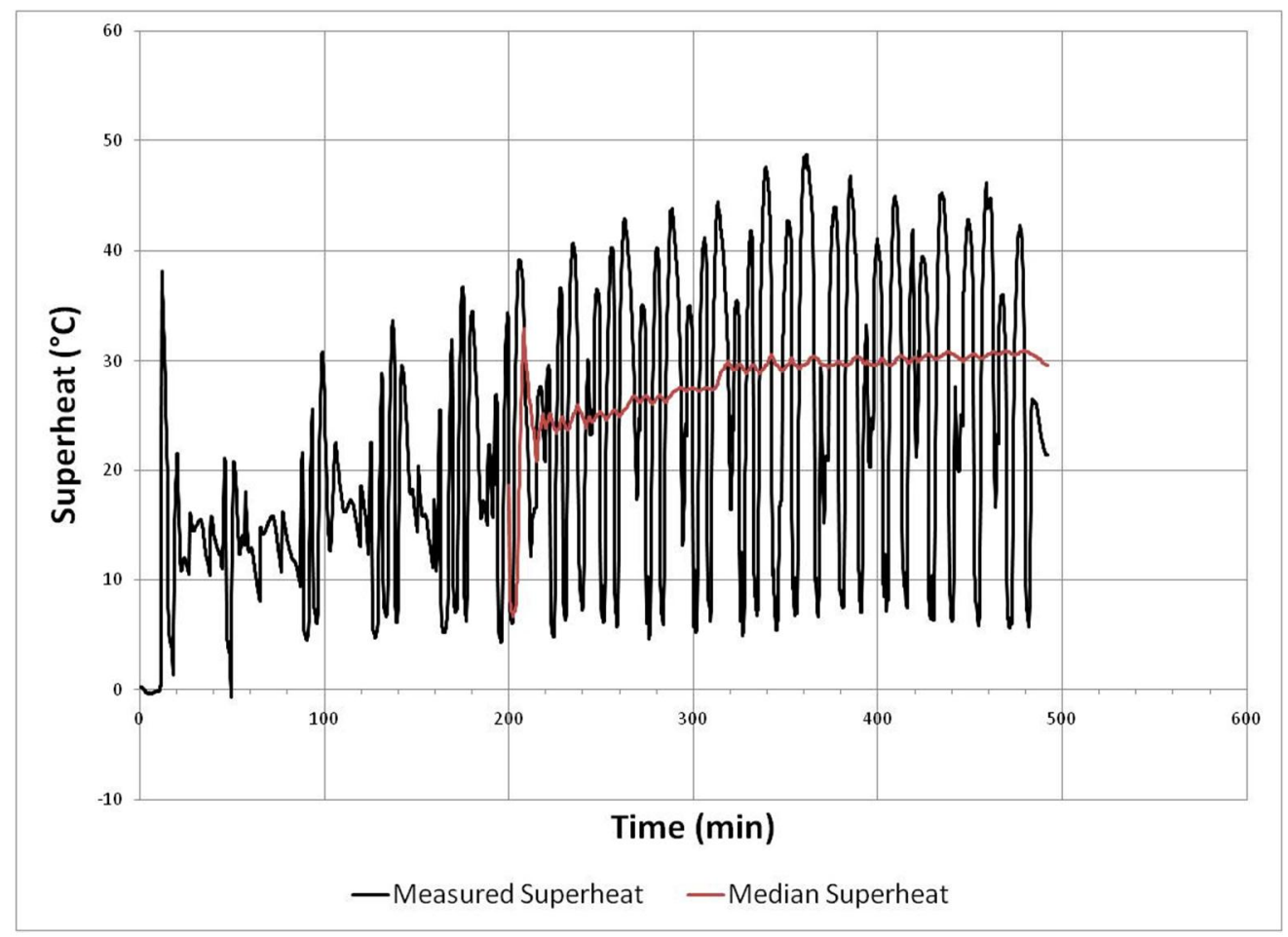

Figure 100. DFM Prototype Evaporator Superheat 


\section{Task 6. Cost Effective Absorber Heat Transfer Surfaces (Aqua-Ammonia}

\section{Absorption Technology)}

\section{Oxidation}

Oxidation of a surface can promote wetting. Conventional wisdom holds that oxidation improves wetting of the surface and is therefore beneficial to absorption and the subsequent heat evolution and heat recovery.

Performance tests were conducted of the RR-A2 and RR-A3 absorbers which were built with essentially an identical pitch pattern to each other. The heat exchange surface RRA3 was not oxidized and RR-A2 was. The goal of these tests was to determine the performance impact of oxidation and high and low fire conditions.

The following is a list of tests performed and their results. The tests were conducted at a constant weak solution concentration of approximately $4 \%$ NH3. The tests were conducted in a hydronically cooled absorption system assembly.

$\begin{array}{llll}\text { Absorber } & \begin{array}{l}\text { Firing Rate } \\ (\mathrm{Btu} / \mathrm{hr})\end{array} & \begin{array}{l}\text { Capacity } \\ (\mathrm{Btu} / \mathrm{hr})\end{array} & \text { COP } \\ \text { RR-A3 } & 86,079 & 58,988 & 0.685 \\ \text { RR-A3 } & 86,250 & 60,370 & 0.700 \\ \text { RR-A3 } & 86,309 & 59,389 & 0.688 \\ \text { RR-A3 } & 45,967 & 40,588 & 0.883 \\ \text { RR-A2 } & 86,235 & 61,982 & 0.719 \\ \text { RR-A2 } & 86,570 & 61,818 & 0.714 \\ \text { RR-A2 } & 86,589 & 61,862 & 0.714 \\ \text { RR-A2 } & 42,726 & 38,970 & 0.912\end{array}$

Figure 101 shows these results graphically. As shown on the figure, all of the test results for the system run with the oxidized sorber are higher than those for the un-oxidized sorber. This difference in performance is slight at the low fire rate, but results in a capacity improvement of approximately 2,000-3,000 Btu/hr at the high firing rate. 


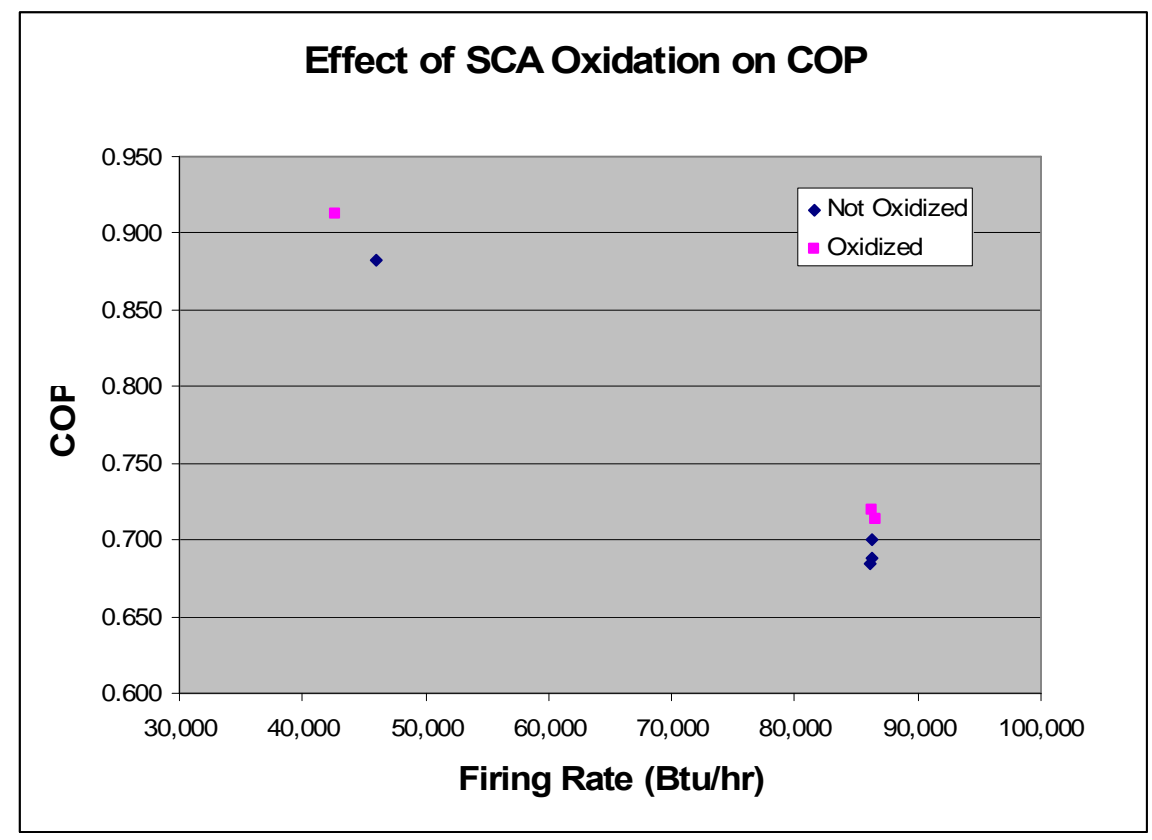

Figure 101. Effect of Absorber Oxidation on System COP

Based on the results for the first pair of absorbers, it appeared that oxidation may be desirable for performance enhancement.

Due to these preliminary results, two new absorbers were built and tested. Absorbers RR-A6 and RR-A7 were completed with coil pitches very similar to RR-A2 and A3. RRA6 was oxidized while RR-A7 was not. As shown on Table 9, both absorbers performed relatively the same with no dramatic difference shown from the oxidizing process.

Figure 102 shows a comparison of system COPQ̂ for absorbers A2, A3, A6 and A7 as a function of firing rate and whether they were oxidized or not. As seen from this plot with more data points, there is no conclusive evidence that the expense of surface oxidation of the absorber is warranted. With dubious performance improvement possibilities and the possibility that improper oxidation causing flaking, which could clog system passages, it was decided to abandon this enhancement technique.

$\begin{array}{lrrrl}\text { Absorber } & \begin{array}{l}\text { Firing } \\ \text { Rate } \\ (\text { Btu/hr })\end{array} & \begin{array}{l}\text { Capacity } \\ \text { (Btu/hr })\end{array} & \text { COP } & \\ \text { RR-A7 } & 86,001 & 59,558 & 0.693 & \text { not oxidized, new evaporator } \\ \text { RR-A7 } & 40,945 & 40,631 & 0.992 & \text { not oxidized } \\ \text { RR-A6 } & 85,978 & 59,207 & 0.689 & \text { oxidized, new evaporator }\end{array}$




$\begin{array}{lllll}\text { RR-A6 } & 86,602 & 58,045 & 0.670 & \text { oxidized, new evaporator } \\ \text { RR-A6 } & 86,274 & 58,122 & 0.674 & \text { oxidized, new evaporator }\end{array}$

Table 9. Test Results for RR-A6 and RR-A7 Absorbers

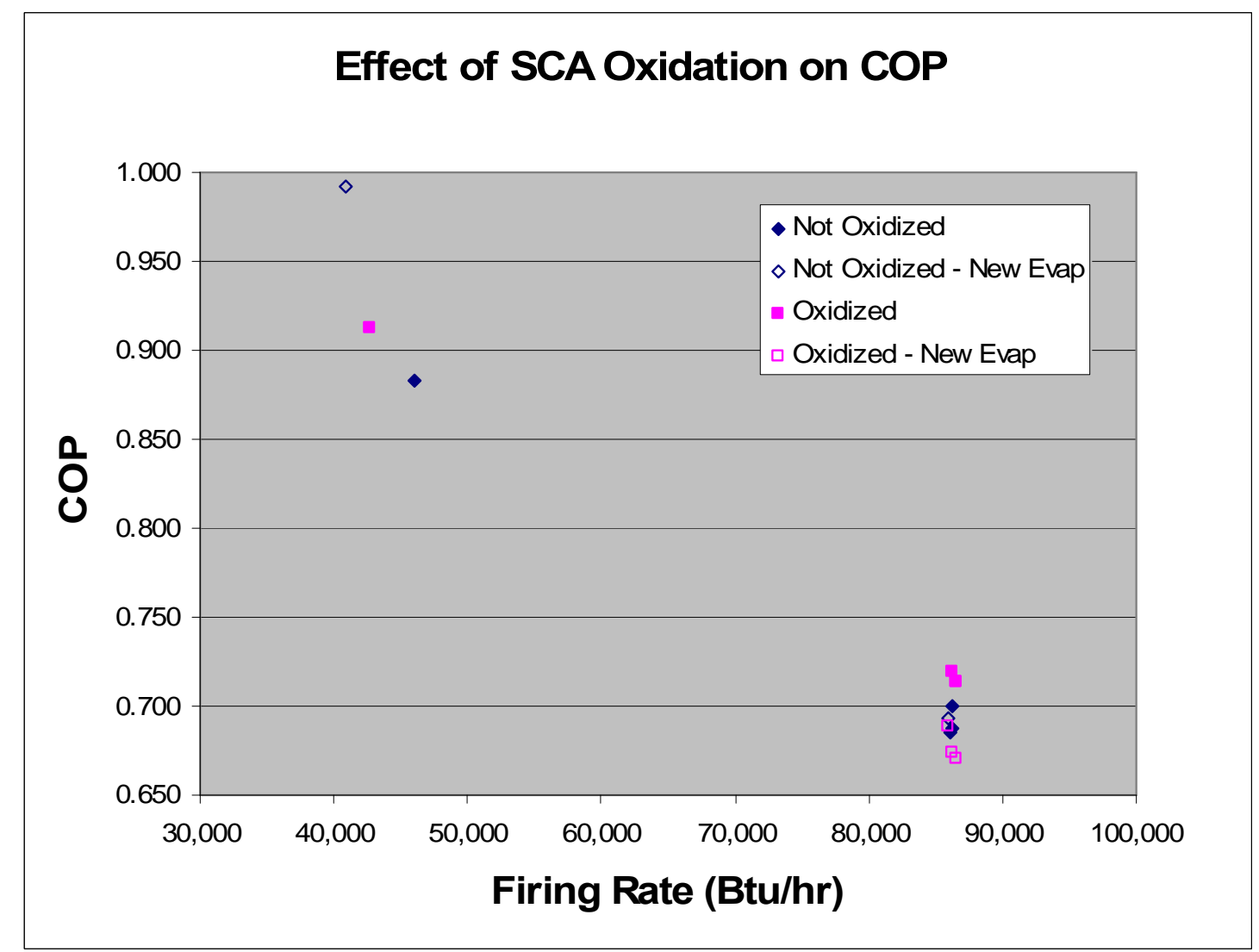

Figure 102. Comparative System Performance of Oxidized vs. Non-Oxidized Absorbers

\section{Tube Enhancement Technique}

A comparison of tubing enhancement using the original method, threading, versus a new method, knurling, was made. Knurling for enhancing the absorber tube has been chosen because of possible process time savings a heat transfer improvement. The desired method for applying this enhancement is similar to the threading enhancement with a spinning tool holder that can be utilized in any simple turning center apparatus such as a lathe. See Figure 103 for a picture of the head chosen. 


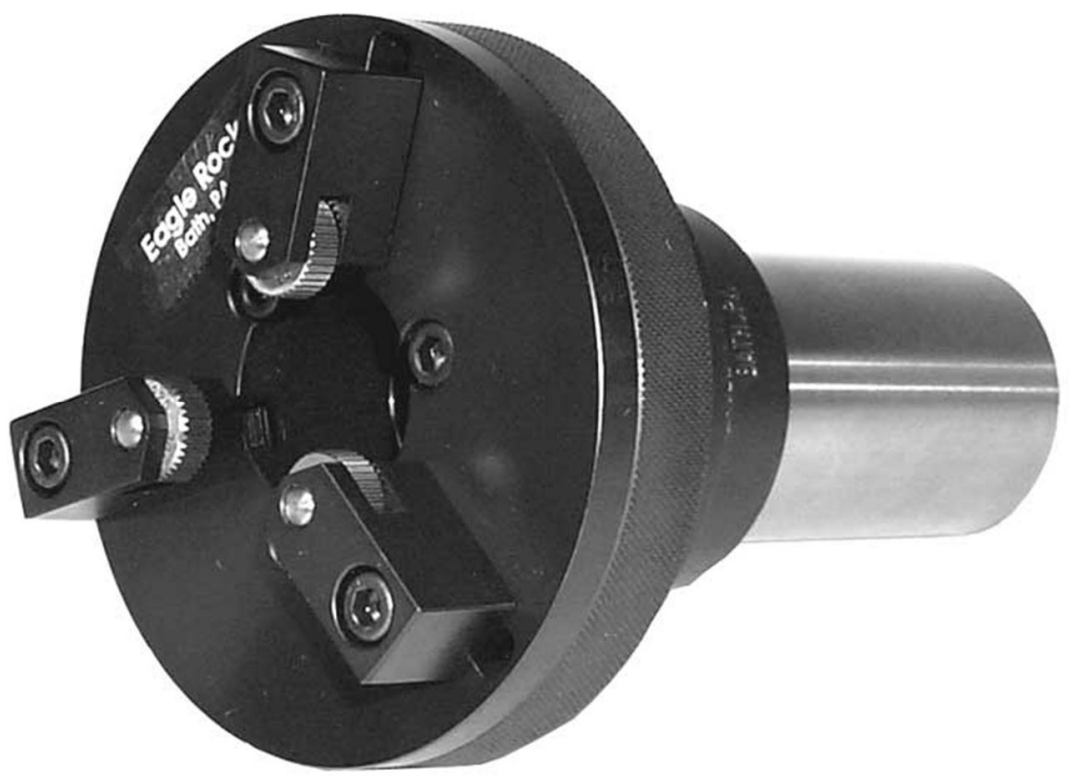

Figure 103. Knurling Head

Figure 104 shows the knurling enhancement of the absorber tube using this tool.

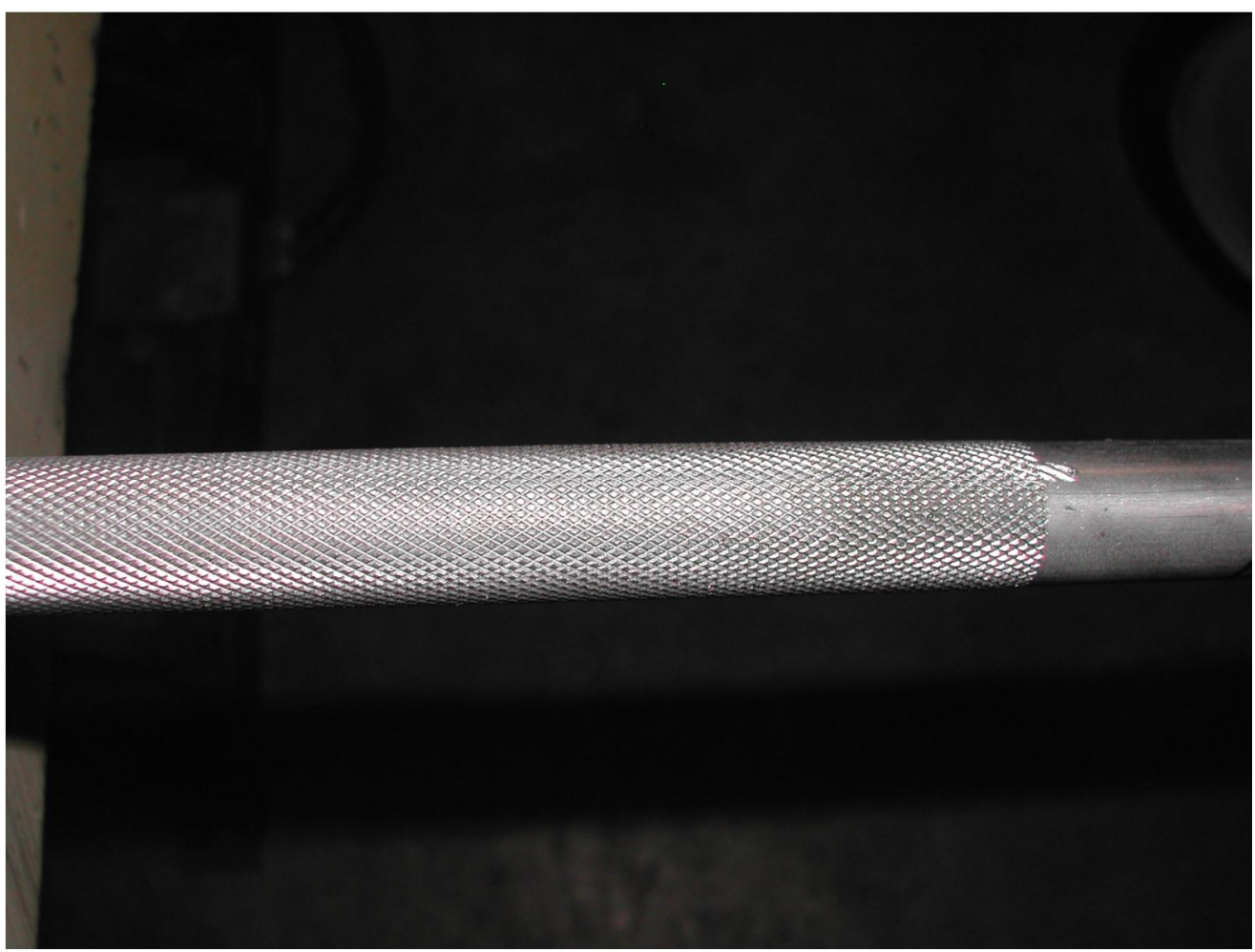

Figure 104. Knurled Tube Sample 
Feed rates for the lathe with the knurling tool were as high as $5.5 \mathrm{ft} / \mathrm{min}$ as opposed to 2.5 $\mathrm{ft} / \mathrm{min}$ with threading. However, at the highest knurling rates, the quality of the knurl would suffer, as determined by examination with an optical comparator. The pressure exerted by the tool also had to be adjusted to very high levels at high feed rates, which was difficult to do properly

An absorber with an optimal (from a quality standpoint) knurl enhanced absorption surface was fabricated. Figure 105 is a picture of the completed absorber (rust colored).

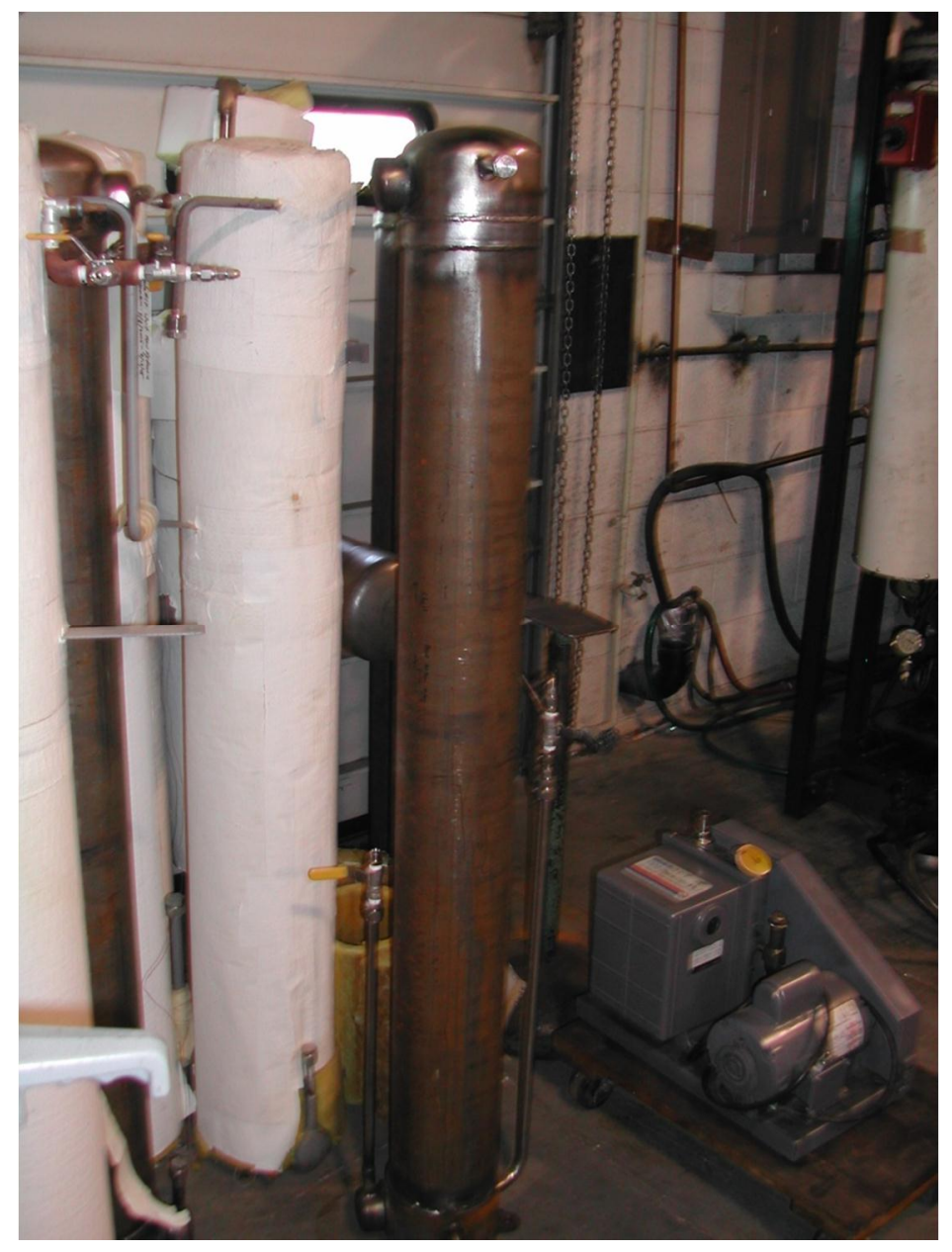

Figure 105. Knurled Tube Absorber

Tests were conducted in the hydronically cooled absorption test apparatus with the knurled tube absorber that was assembled in the previous month at Rocky Research. Test results comparing the performance of the system with this absorber vs. the conventional threaded tube absorber is shown in the following table: 


$\begin{array}{rcrrrrrr}\begin{array}{c}\text { Test } \\ \text { Date }\end{array} & \begin{array}{c}\text { Absorber } \\ \text { Type }\end{array} & \begin{array}{c}\text { Weak } \\ \text { Flow }\end{array} & \begin{array}{c}\text { Capacity } \\ \text { Btu/hr }\end{array} & \text { COP } & \begin{array}{c}\text { Phigh } \\ \text { psia }\end{array} & \begin{array}{c}\text { Plow } \\ \text { psia }\end{array} & \begin{array}{c}\text { Wk } \\ \text { Conc. }\end{array} \\ 5 / 2 / 07 & \text { Threaded } & \text { Normal } & 61575 & 0.719 & 276.3 & 66.3 & 0.040 \\ 5 / 9 / 07 & \text { Knurled } & \text { Normal } & 61593 & 0.721 & 274.5 & 67.3 & 0.052 \\ 5 / 9 / 07 & \text { Knurled } & \text { Normal } & 62060 & 0.731 & 274.5 & 67.1 & 0.043 \\ 5 / 12 / 07 & \text { Knurled } & \text { High } & 56615 & 0.654 & 276.2 & 70.3 & 0.120\end{array}$

The results show that the performance of the knurled tube absorber is similar to that of the threaded tube absorber. The last test shown was a flow test at high relative pumping rates to determine whether flooding would occur if too much weak solution was pumped to the absorber. No indication of flooding was indicated even at the $12.0 \%$ weak solution concentration. Obviously, because of the high weak solution concentration resulting from the high flow rate, the COP was lower than the other tests.

Therefore, it was concluded that the knurled tube absorber did have comparable heat and mass transfer and robust operation (with respect to high flow rates) of the threaded tube absorber. However, the knurling process required both feed rate and pressure adjustment rather than just feed rate adjustment for the threaded tube absorber enhancement. For this reason, it was determined that the threading process would be more advantageous in a manufacturing environment.

\section{Task 7. Generator Firetube Life Testing (Aqua-Ammonia Absorption Technology)}

\section{Generator Test Stand}

A test apparatus was designed for the simultaneous testing of generator castings and firetubes under firing conditions. The generator test stand had four stations for generator testing, each with its own ignition control system, power burner system, exhaust system and water cooling capability.

Because the assembly of an entire aqua-ammonia cycle for each of these stations was neither practical nor desirable, the generators built included a condenser in each. In this way, water, with corrosion inhibitor could be used on the solution side of the test (reflux) generator. The water would boil around the encased firetube. The rising steam would come in contact with the condensing tubes, condense and recirculate to the liquid level. The heat rejected from the cooling water was piped to a cooling tower for heat rejection. 
Because of this, a small water pump for the cooling tower was installed at the cooling tower.

Figure 106 shows four reflux generators containing these firetubes on test.

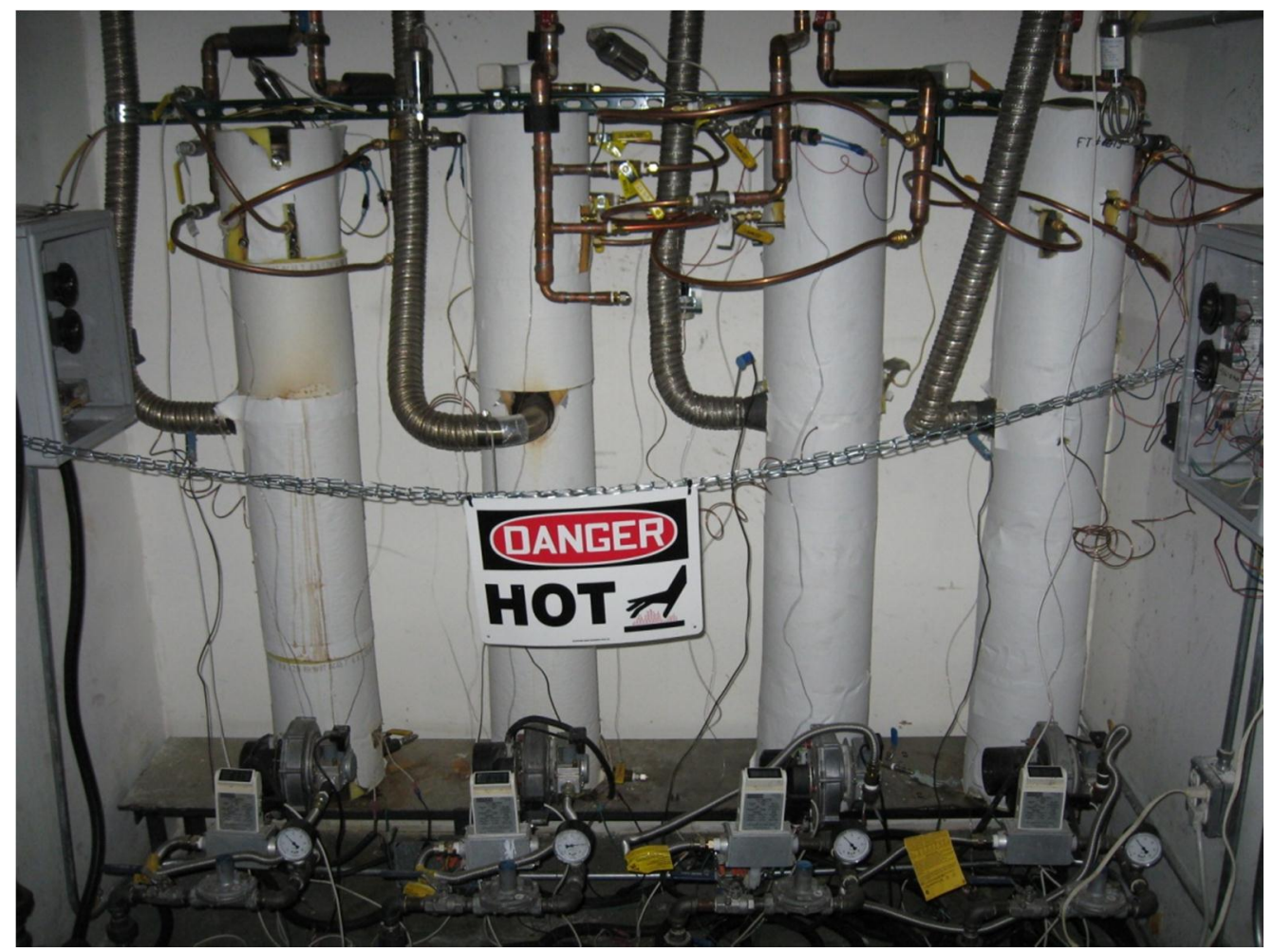

Figure 106. Photo of Reflux Generators on Test

Over the course of testing, five firetubes were tested with their associated castings. Tests were conducted for over 20,000 cycles and over 5500 operating hours on each of these. For approximately the first 500 operating hours, the generators were run continuously. After that, the generators were cycles on and off for the next 5000 operating hours with the cooling water circulating to maximize the stress on the firetube and casting.

Table 10 shows the examination log of all of the firetubes tested under our life testing program. 
Reflux Generator Firetube Examination Log

Firetube Position 1 (Bar Machined) - Installed 9/24/07

\begin{tabular}{lrccc} 
Date & & & \multicolumn{2}{c}{ Observations } \\
Hours & Cycles & Fin Wear & Fin Contact \\
$9 / 25 / 2007$ & 10 & $\mathrm{n} / \mathrm{a}$ & none & good \\
$10 / 1 / 2007$ & 107 & $\mathrm{n} / \mathrm{a}$ & none & good \\
$10 / 8 / 2007$ & 234 & $\mathrm{n} / \mathrm{a}$ & none & good \\
$12 / 11 / 2007$ & 500 & $\mathrm{n} / \mathrm{a}$ & none & good \\
$1 / 2 / 2008$ & 923 & 1692 & none & good \\
$1 / 24 / 2008$ & 1272 & 3088 & none & good \\
$6 / 25 / 2008$ & 3528 & 12112 & none & good \\
$9 / 3 / 2008$ & 4559 & 16236 & none & good \\
$11 / 10 / 2008$ & 5531 & 20124 & none & good
\end{tabular}

FINISHED

Firetube Position 2 (Bar Machined) - Installed 10/23/07

\begin{tabular}{|c|c|c|c|c|}
\hline \multirow[b]{2}{*}{ Date } & \multirow[b]{2}{*}{ Hours } & \multicolumn{3}{|c|}{ Observations - } \\
\hline & & Cycles & Fin Wear & Fin Contact \\
\hline $10 / 14 / 2007$ & 509 & $\mathrm{n} / \mathrm{a}$ & none & good \\
\hline $10 / 20 / 2007$ & 630 & 484 & none & good \\
\hline 10/27/2007 & 775 & 1064 & none & good \\
\hline $12 / 11 / 2007$ & 1022 & 2052 & none & good \\
\hline 1/2/2008 & 1445 & 3744 & none & good \\
\hline $1 / 24 / 2008$ & 1793 & 5136 & none & good \\
\hline 4/3/2008 & 2993 & 9936 & none & good \\
\hline $6 / 25 / 2008$ & 3914 & 13620 & none & good \\
\hline 9/3/2008 & 4958 & 17796 & none & good \\
\hline $11 / 10 / 2008$ & 5593 & 20336 & none & good \\
\hline
\end{tabular}

FINISHED

Firetube Position 3 (Bent) - Installed 7/2/08 Firetube \#10

\begin{tabular}{|c|c|c|c|c|}
\hline \multirow[b]{2}{*}{ Date } & \multirow[b]{2}{*}{ Hours } & \multicolumn{3}{|c|}{ 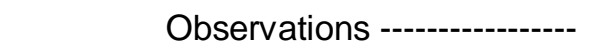 } \\
\hline & & Cycles & Fin Wear & Fin Contact \\
\hline $8 / 4 / 2008$ & 547 & $\mathrm{n} / \mathrm{a}$ & none & good \\
\hline $9 / 3 / 2008$ & 995 & 1792 & none & good \\
\hline 1/7/2009 & 2842 & 9180 & none & good \\
\hline $7 / 13 / 2009$ & 5553 & 20024 & none & good \\
\hline
\end{tabular}

Firetube Position 4 (Bent) - Installed 7/2/08

Firetube \#13

\begin{tabular}{|c|c|c|c|c|c|}
\hline \multirow{3}{*}{$\begin{array}{l}\text { Date } \\
7 / 29 / 2008\end{array}$} & \multirow{3}{*}{$\begin{array}{r}\text { Hours } \\
551\end{array}$} & \multicolumn{3}{|c|}{ Observations ------------- } & \\
\hline & & Cycles & Fin Wear & Fin Contact & \\
\hline & & $\mathrm{n} / \mathrm{a}$ & none & good & \\
\hline 9/3/2008 & 1125 & 2296 & none & good & \\
\hline 1/7/2009 & 2874 & 9292 & none & good & \\
\hline 7/13/2009 & 5570 & 20076 & none & good & FINISHED \\
\hline
\end{tabular}


Firetube Position 2 (Bent) - Installed 4/7/09

Firetube \#17

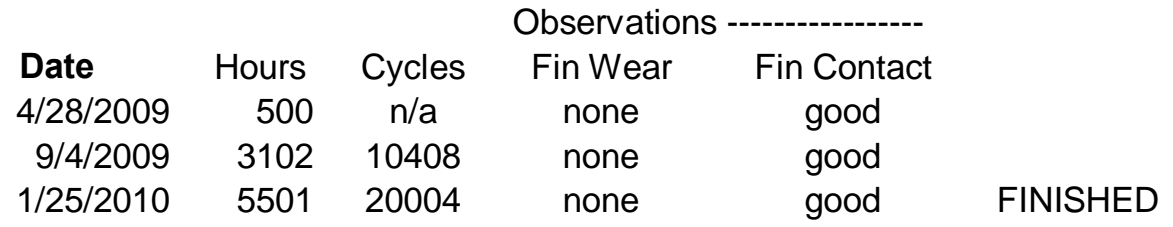

Table 10, Reflux Generator Firetube Examination Log

The results showed excellent durability of the firetube and its fins under difficult cyclic operation for over 5500 operating hours each. Even though each of the five firetubes tested had operated for over 20000 on/off cycles, the thermal stresses have not caused any of the 200 fins in each firetube to become detached from the firetube. Also, no signs of firetube degeneration wear due to burning at the tips were observed. These results prove that the firetube design is robust enough for product use.

No leakage from any of the castings was observed. Therefore, both the castings and firetubes have considered to be robust enough for product use.

\section{Task 8. Controls Optimization (Aqua-Ammonia Absorption Technology)}

The original controller for the aqua-ammonia system was replaced with an advanced microprocessor based controller, shown in Figure 107. The controller allows operation of the aqua-ammonia with true variable speed with load tracking capabilities. This controller was adapted for use with the as a chiller, heat pump, exhaust fired chiller and dual temperature aqua-ammonia system. 


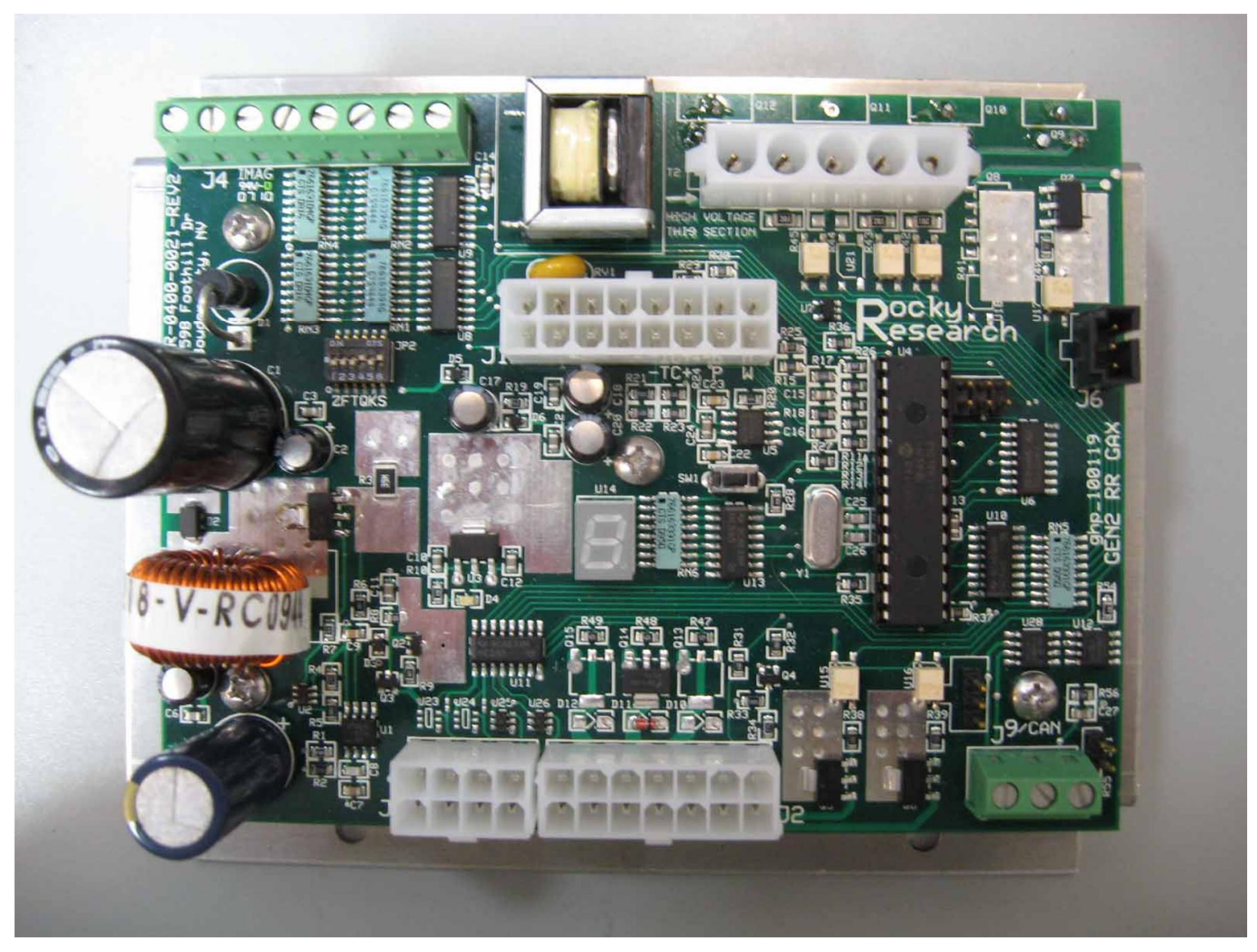

Figure 107. Microprocessor Based Controller for

The controller design integrates with the following controlled components:

Inputs:

- Chilled water outlet temperature

- Generator temperature

- High side pressure

- Liquid level

- Water flow switch

Outputs:

- Ignition Controller

- Condenser Fan Motor

- Solution Pump

- Solenoid valve

- Burner blower

- Reversing valves 
The primary safeties of high pressure, high generator temperature and high flue temperature are monitored by the controller for fault codes, but they act directly and independently of the controller to stop natural gas firing.

One major modification of the controller that was made was that the need for ambient temperature sensing was eliminated in favor of closed loop control of the high side pressure. This allows good control of high side pressure at all ambient conditions and chiller capacities while minimizing power consumption by the outdoor fan motor.

The controller has a series of fault codes that are indicated in case of system failure. These fault codes are indicated on the annunciator display. In addition, the annunciator provides real time indication of adequate liquid level. During normal operation, the annunciator will give indication of generator temperature and high side pressure in a hexadecimal code so that these critical operating parameters can be monitored in real time.

The controller also has a dip switch that allows a technician to test components such as the solution pump, outdoor fan and solenoid valve while not firing the system. This is useful in troubleshooting component failures. The dip switch also allows factory modifications of set points and other operating system parameters.

The controller also has the capability of communicating with multiple (up to 8 total) chillers in a chiller linked system using a CAN bus protocol. Operation as a chiller link allows for maximum system COP for a given load. This is accomplished by varying the speed of the chillers in tandem as the load decreases from the peak. If the load drops to below the minimum turndown level, one chiller is turned off and the rest modulate in tandem.

\section{Flow Controls}

As a part of the solution control system, the possibility of the use of a condenser discharge orifice to more rapidly build pressure in the condenser was investigated. The goal of this effort was to improved start up capability for the system.

For this task, an orifice for the condenser discharge was sized such that when the system was under full fire, if vapor is passing through the orifice, the pressure drop though it 
would be 35 psi, while if liquid were passing though, the pressure drop would be less than 1 psi.

The new orifice section was added to the condenser discharge in the hydronic test apparatus. Tests were conducted under the following four conditions:

- Without the condenser orifice, cooling water turned on when high side pressure reaches 200 psia

- With the condenser orifice, cooling water turned on when high side pressure reaches 200 psia

- Without the condenser orifice, continuous cooling water flow

- With the condenser orifice, continuous cooling water flow

Tests were conducted with cooling water turned on at 200 psi in an attempt to mimic the ramp up of fan speed in an actual chiller as condenser pressure increases.

The results of these tests are shown on Figure 108. As seen in the figure, without the orifice, long time periods for pressure build up and steady state operation can be encountered under certain conditions. With the inclusion of the condenser orifice, steady high pressure is reached in a little over 20 minutes.

For this reason, a condenser discharge orifice will be included on all future aquaammonia systems.

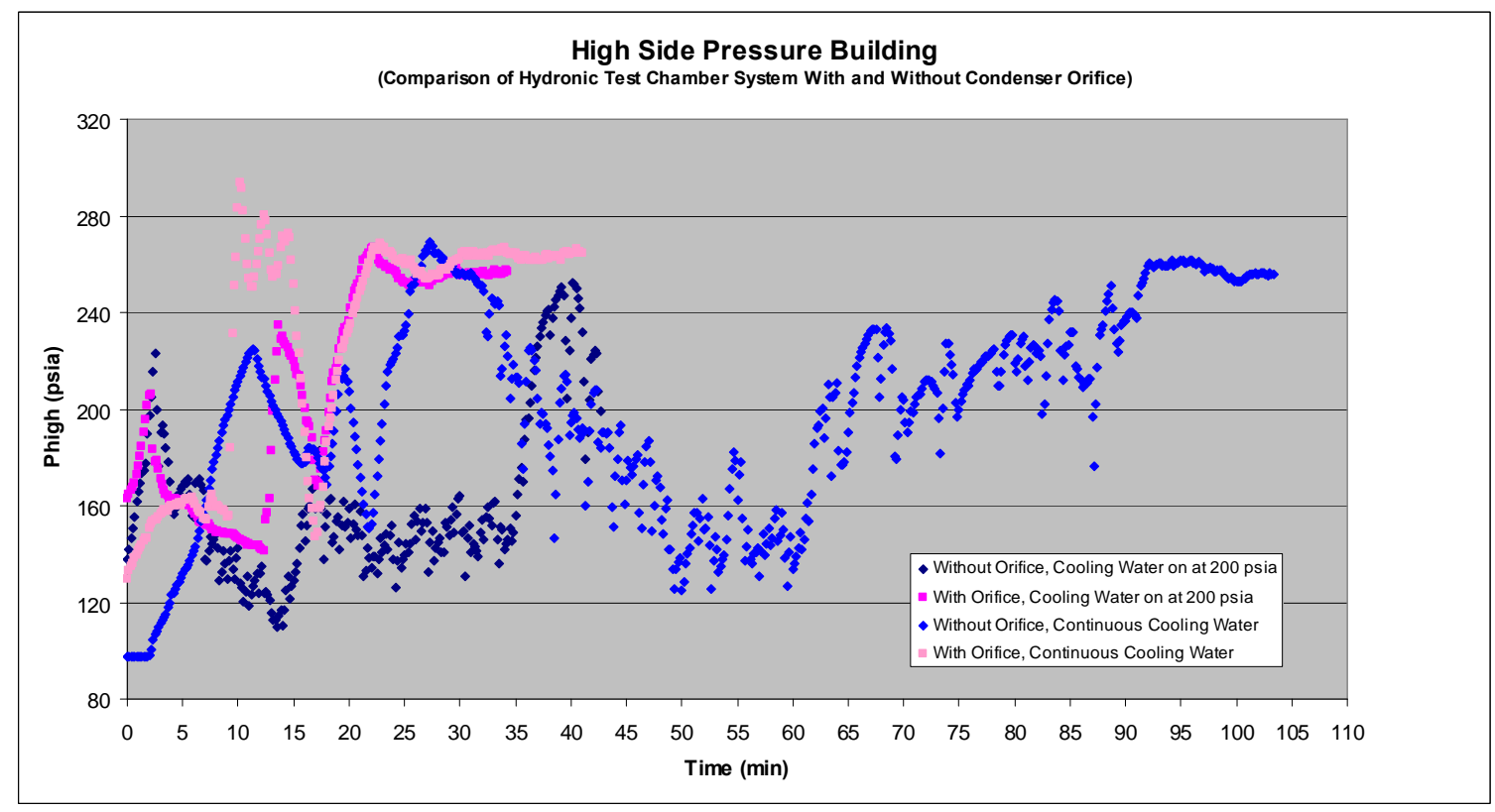

Figure 108. High Side Pressure Building for Various System Configurations 


\section{Task 9. Dual Temperature Use of Absorption System Design (Aqua-Ammonia}

Absorption Technology)

\section{Design}

The design of the system that can operate simultaneously in heating and cooling mode was completed. The system is capable of cooling and dehumidification while utilizing the heat rejected for heating. To this end, a chiller is being constructed with a hydronically cooled condenser and absorber.

For this application, which does not include and air coil and fan, the components have been positioned in the solid model of the package. Shown are the generator, GAX/SCA absorber, the hydronically cooled absorber (HCA), the rectifier, the evaporator, the subcooler and the condenser. The design is shown in Figure 109. Because the system does not have a fan, the exhaust gas must flow though a flue pipe to reach the outside of the cabinet.

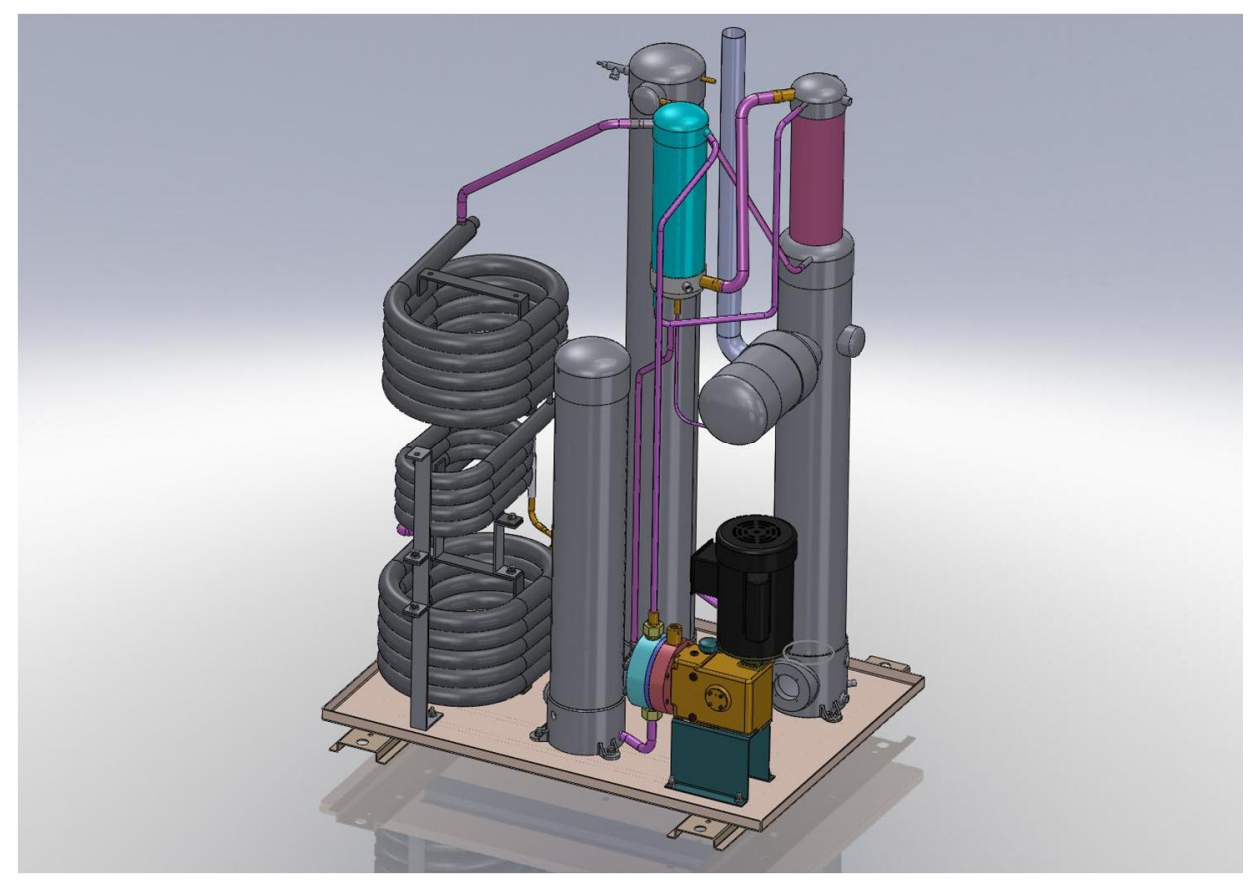

Figure 109. Solid Model of the Dual Temperature System

The sheet metal design of the package is shown as Figure 110. 


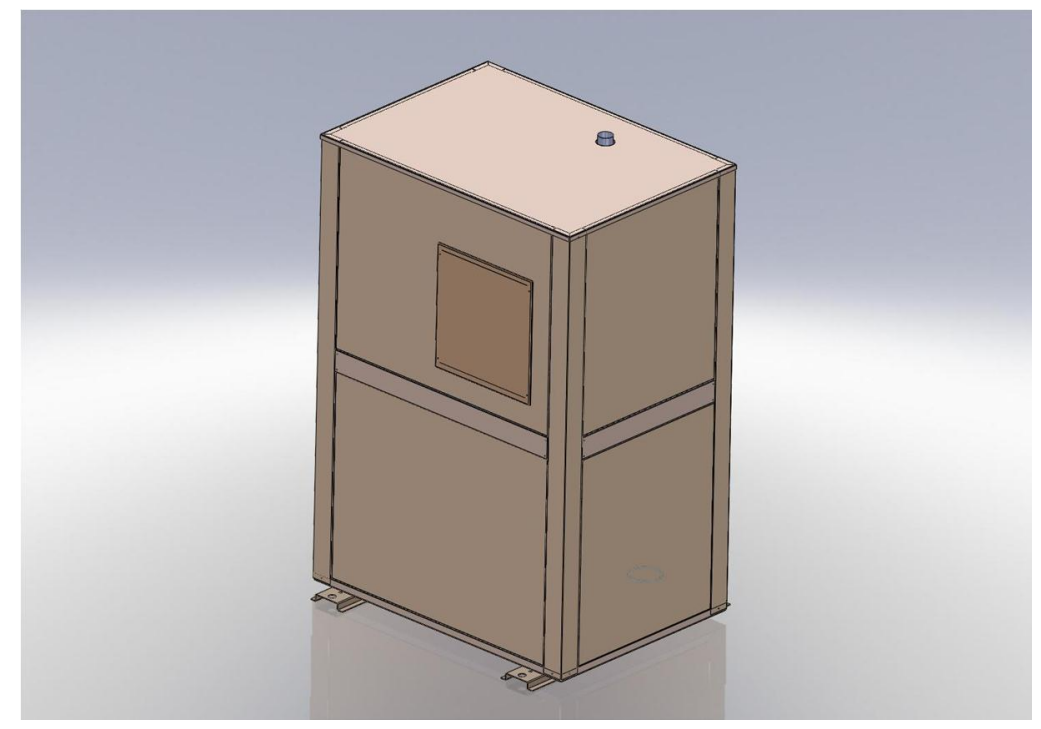

Figure 110. Water-to-Water Chiller Sheet Metal Design

\section{Component Pre-Testing}

Previous to system assembly, evaporator/subcooler/condenser/TXV subassembly for the chiller was installed into the hydronic test bed for performance testing. Figure 111 shows this subassembly on test. The condenser is located at the top, the subcooler in the middle and the evaporator at the bottom.

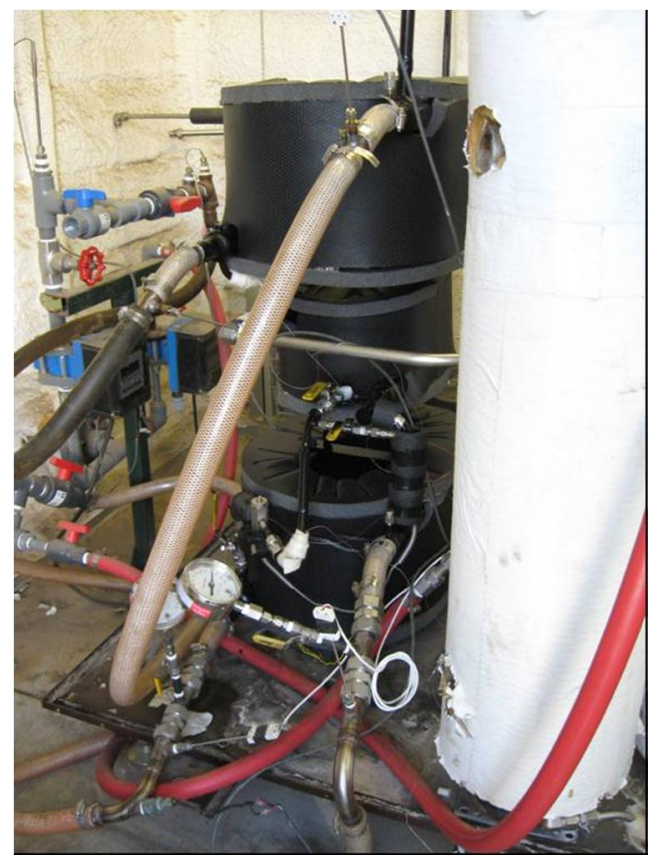

Figure 111. Evaporator, Subcooler, Condenser and TXV Subassembly on Test 
Subsequent to these tests, tests of the most of the components were done together in the hydronic test apparatus to prove their performance before installation into the Dual Temperature Use Chiller. Tests were conducted with the generator, absorber (SCA), evaporator, condenser, subcooler and TXV installed. The only major components for the chiller not included in this testing were the hydronically cooled absorber (HCA) and the solution pump.

Figure 112 shows the results of one of the tests. As the figure shows, the components collectively obtained a capacity of $58,832 \mathrm{Btu} / \mathrm{hr}$ with a COP of 0.687 . The test also showed good flue efficiency $(81.3 \%)$ as well as nominal temperature conditions for the generator and absorber inlets and outlets.

Based on these results, these components were removed from the test stand for installation in the prototype.

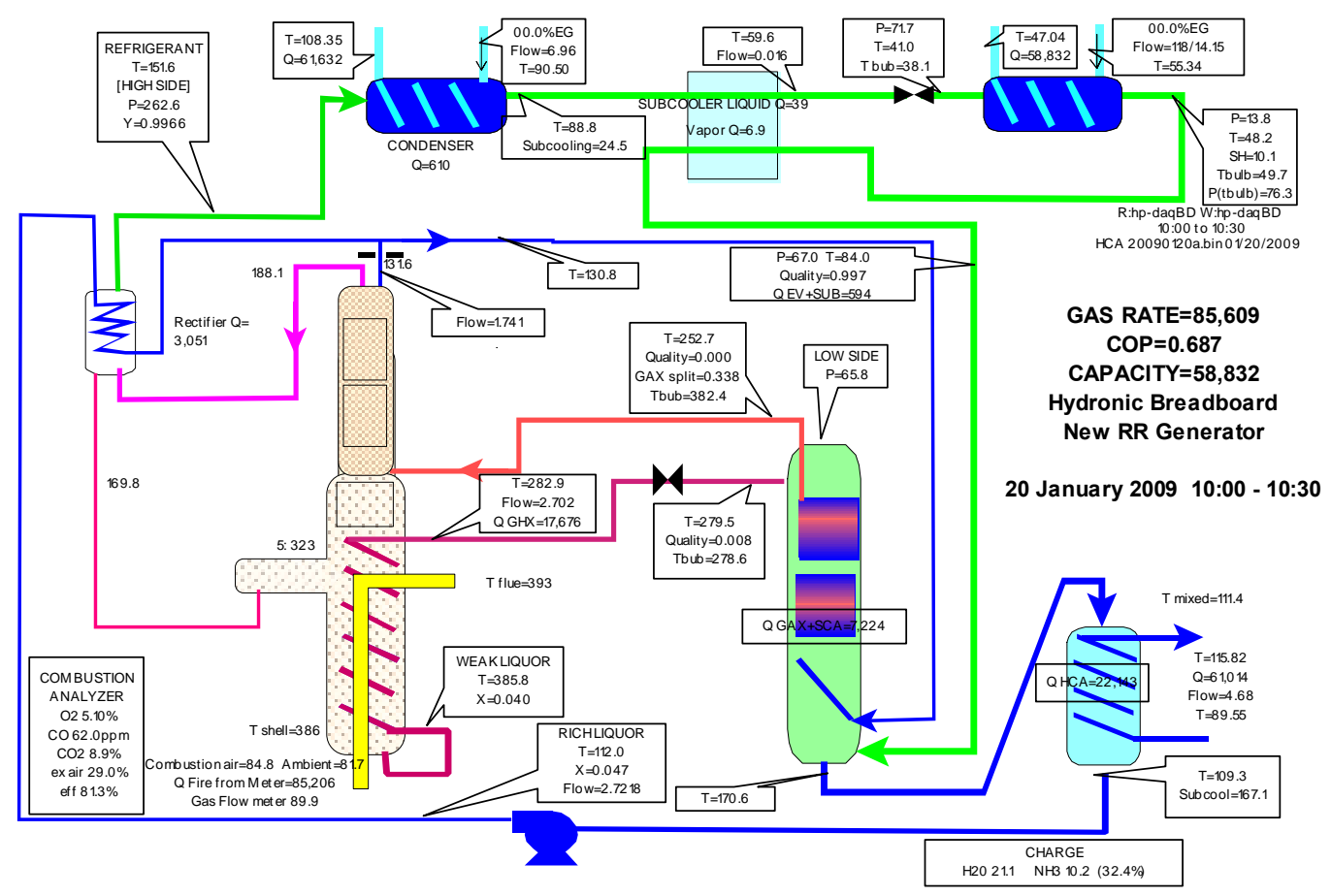

Figure 112. Test Results for Components

\section{Construction of Prototype}

The system required a hydronically cooled absorber (HCA) to reject the low grade heat of absorption. The HCA is shown in Figure 113. The core of the HCA uses the same helically would enhanced surface tubing that the solution cooled absorber (SCA) does. 
However, this core is of a reduced size due to its heat transfer duty and temperature approach relative to the SCA.

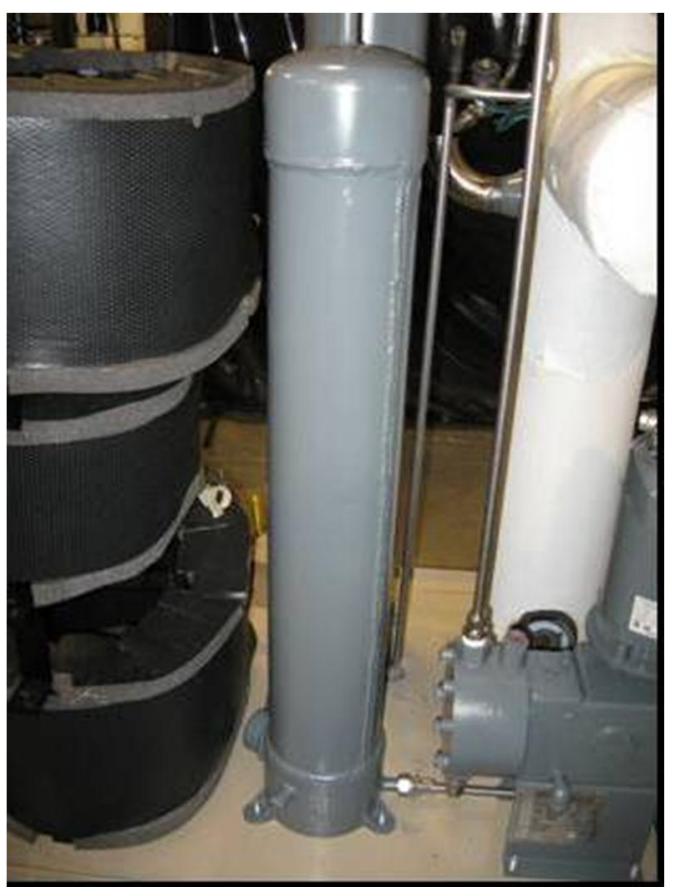

Figure 113. Hydronically Cooled Absorber (HCA)

The HCA in addition to all of the other heat transfer components and the pump were installed on to the chiller baseplate. Figure 114 shows the partly assembled chiller.

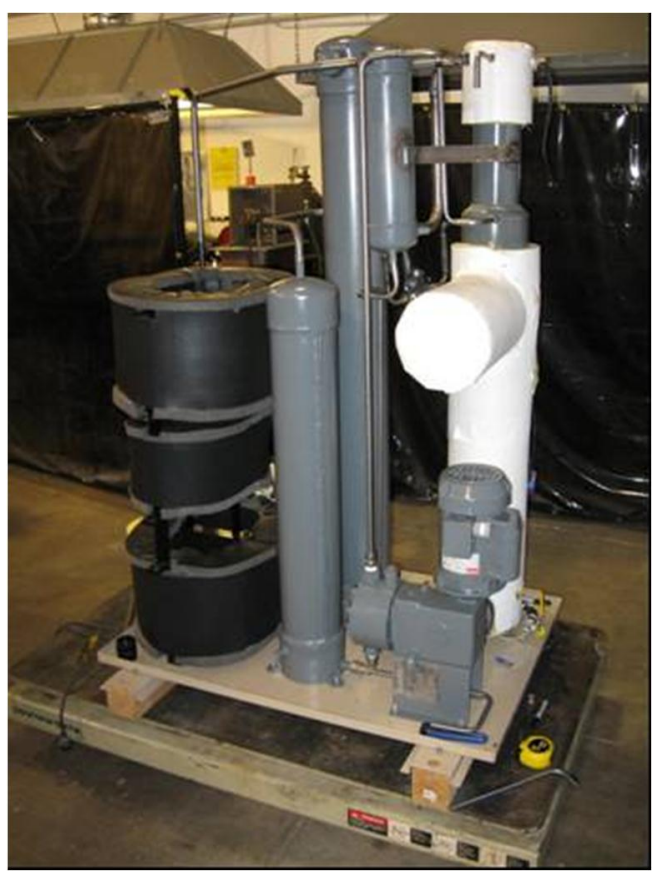

Figure 114. Dual Temperature Use Chiller Under Construction 
Figures 115 and 116 show the prototype as sheet metal was being installed subsequent to piping, leak check and insulation.

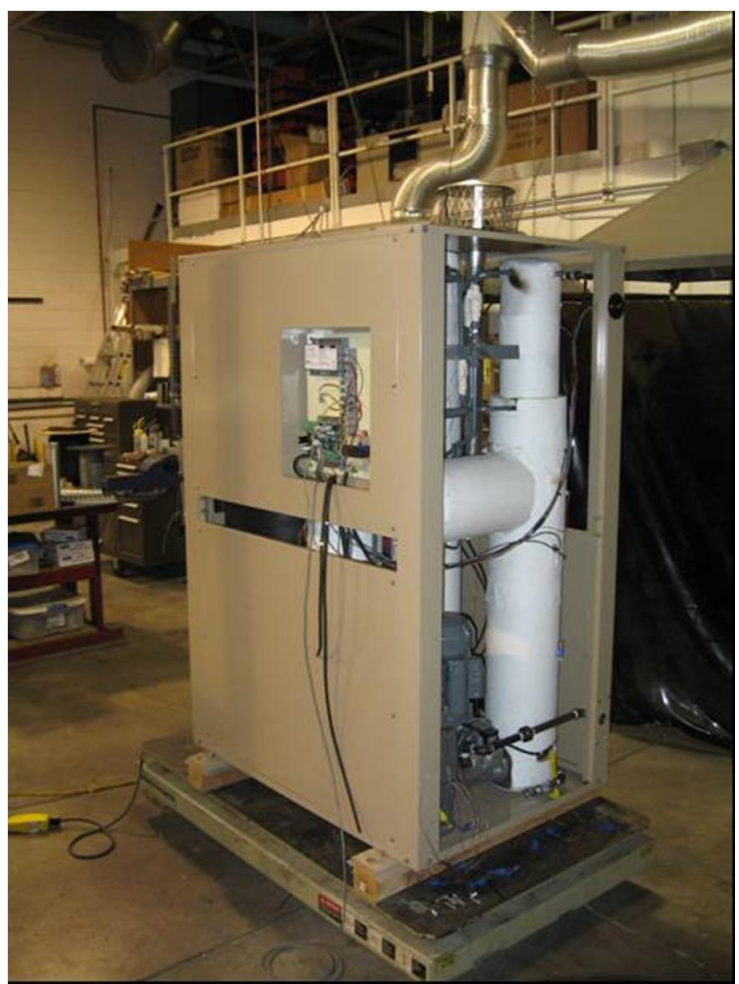

Figure 115. Dual Temperature Use Chiller

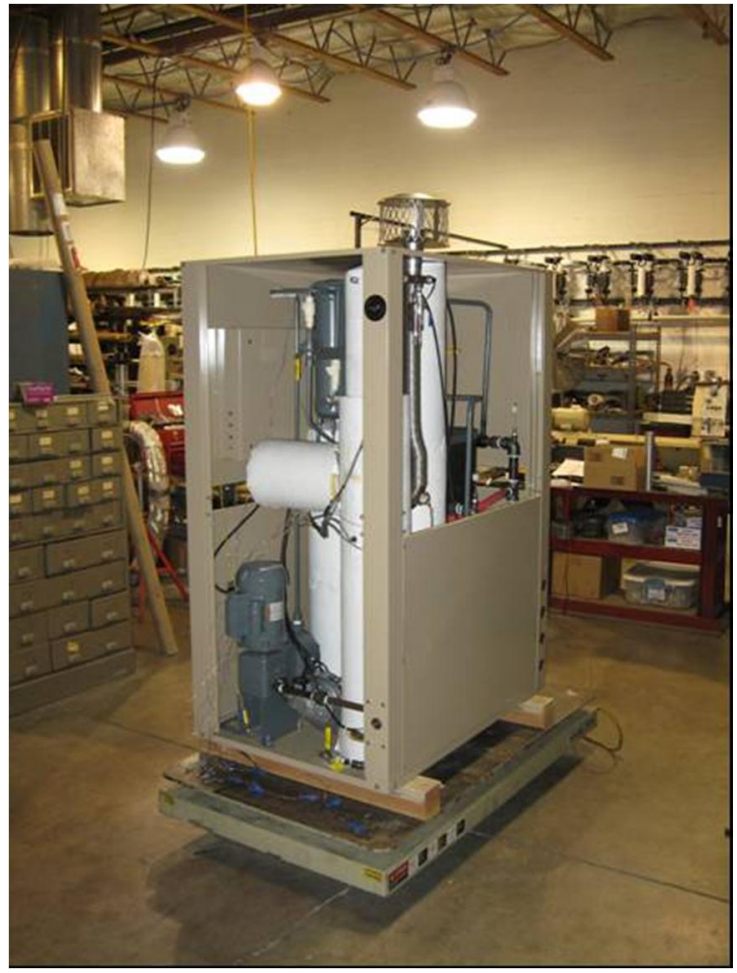

Figure 116. Dual Temperature Use Prototype 


\section{Testing}

The final packaged system, shown in Figure 117, was mounted on a stand outside the hydronic test chamber. This was done to make use of the hydronic test chamberôs source and sink calorimetrics, gas supply and data acquisition system. As with other absorption system tests at Rocky, combustion analysis is done with a mobile system with a probe that is mounted in the flue.

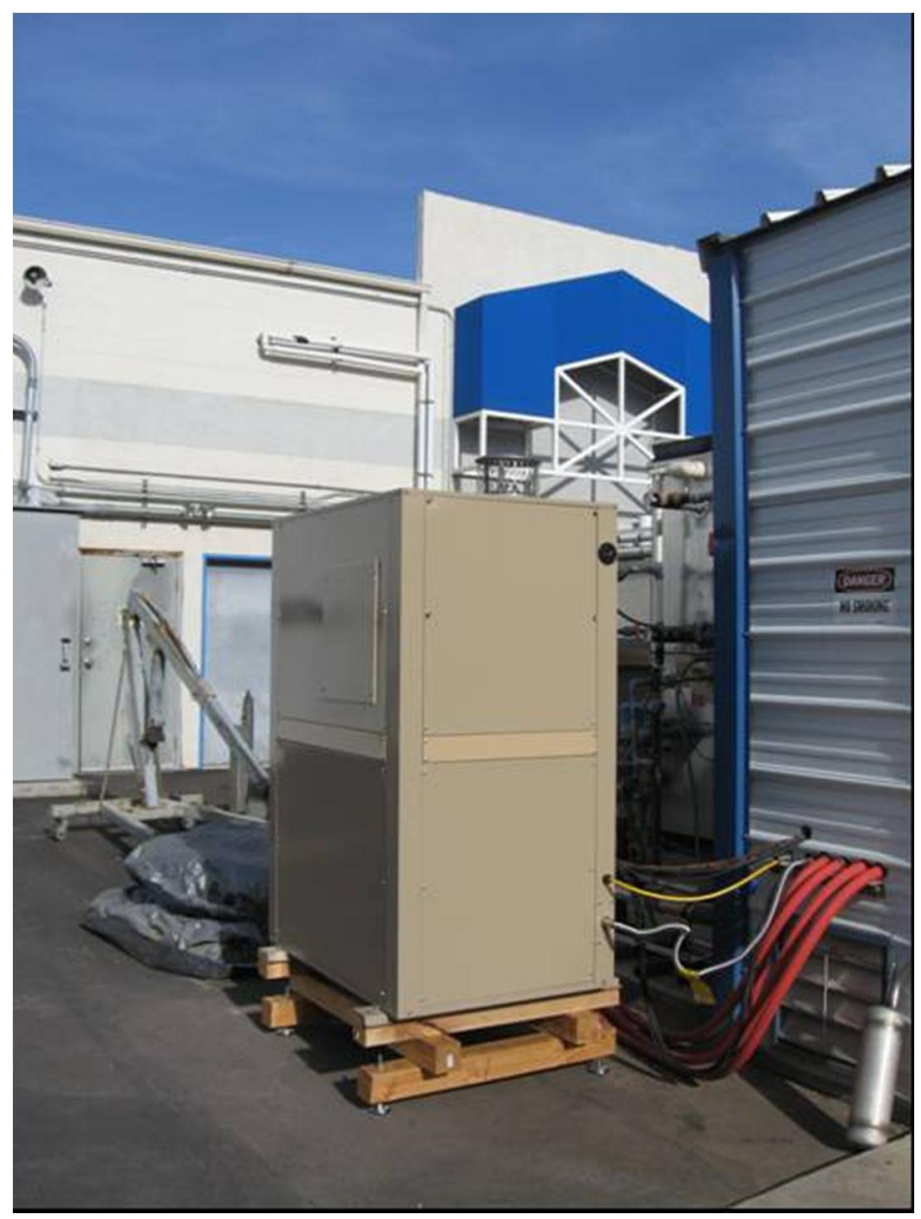

Figure 117. Packaged, Dual Temperature Use Absorption System on Test

After some initial shakedown tests where the GAX split and water flow split to the absorber and condenser were adjusted for best performance and then performance mapping was begun. Figures 118 and 119 show the results of a couple of tests at the 95 ${ }^{\circ} \mathrm{F}$ entering cooling water and $55^{\circ} \mathrm{F}$ return chilled water temperature. The results show excellent performance at this baseline condition with a cooling capacity of 59,977 and 60,284 Btu/hr at a COP of 0.697 and 0.703, respectively. 


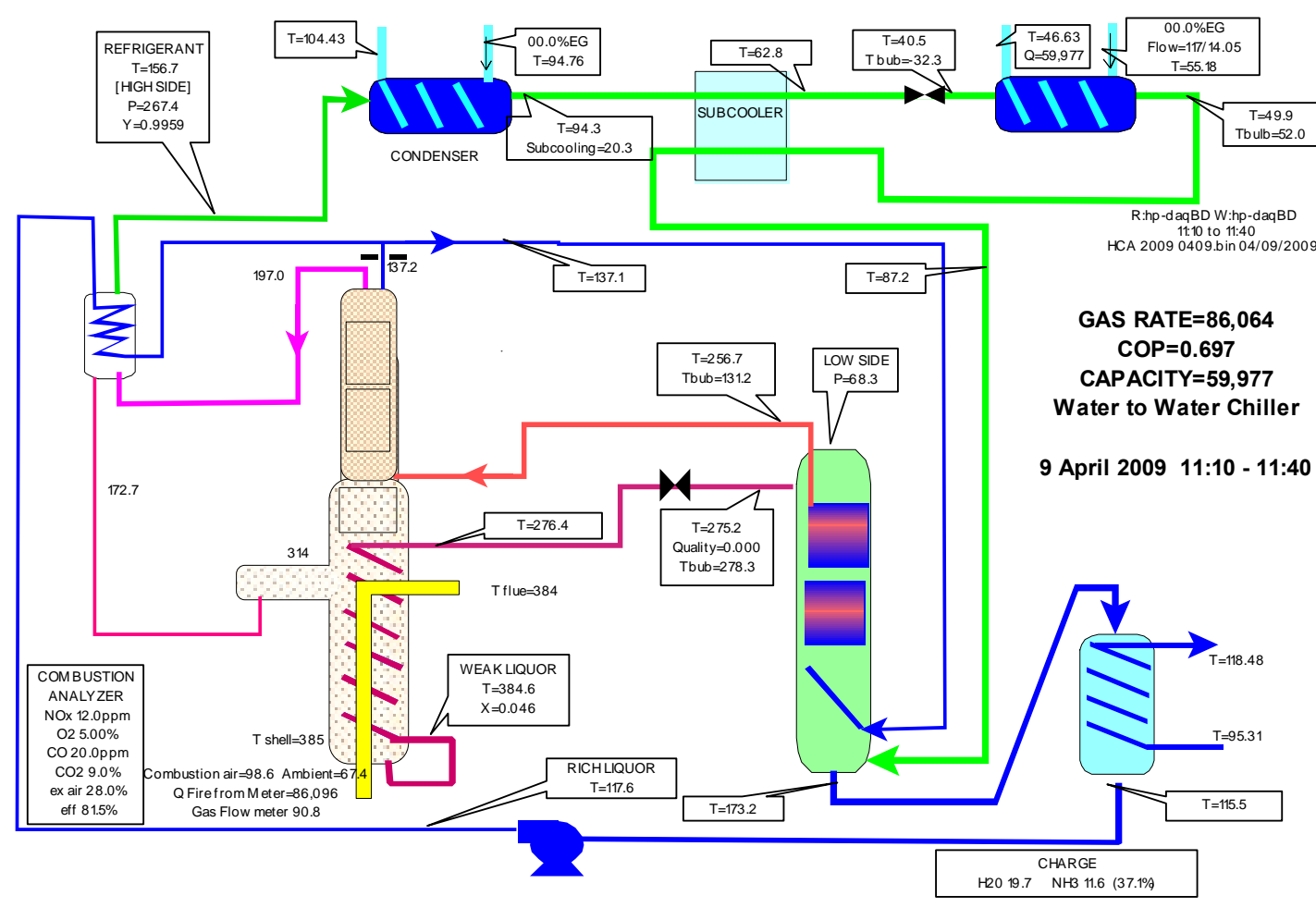

. Figure 118. First Results for $95^{\circ} \mathrm{F}$ Entering Cooling Water, $55^{\circ} \mathrm{F}$ Return Chilled Water

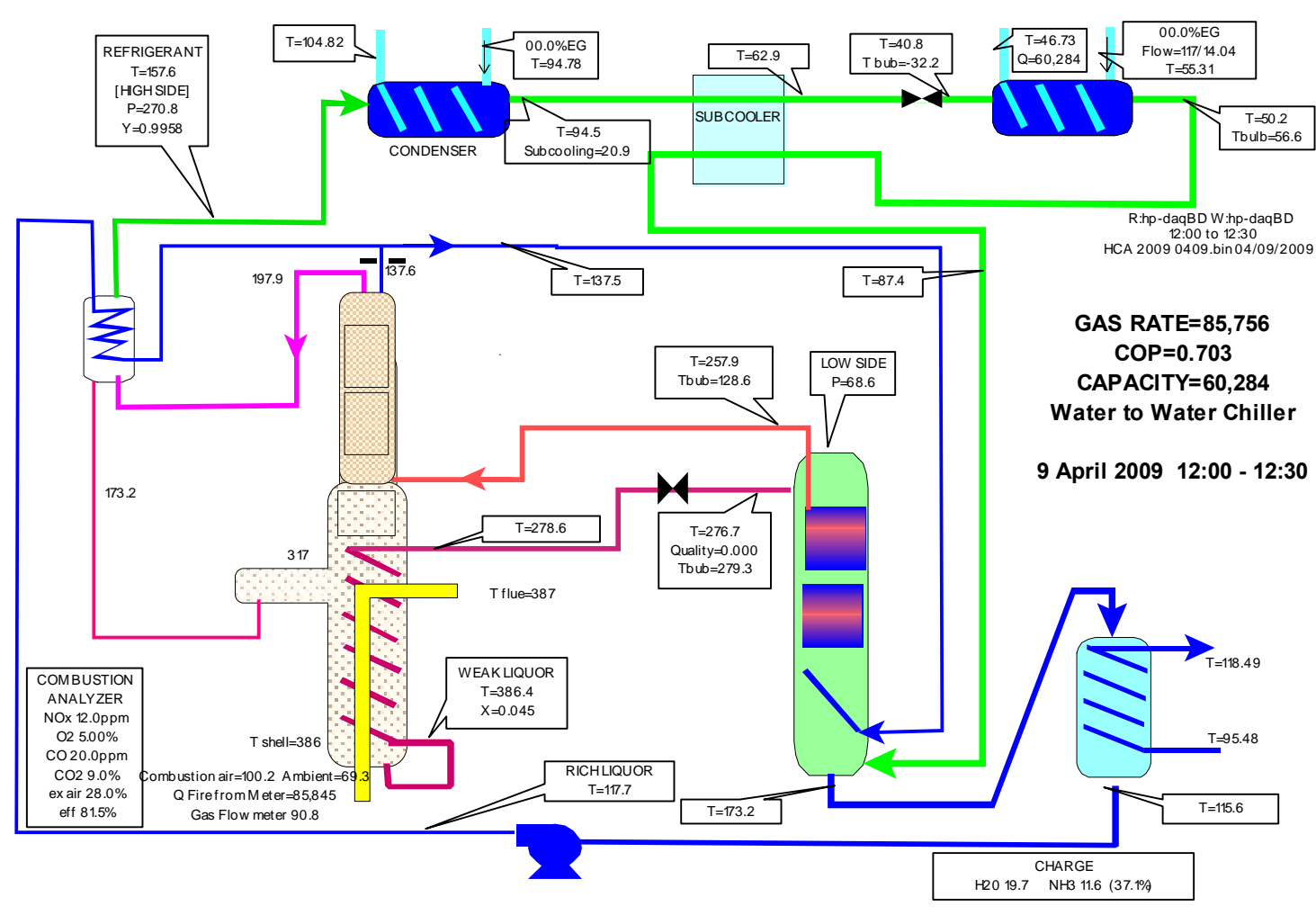

Figure 119. Second Results for $95^{\circ} \mathrm{F}$ Entering Cooling Water, $55^{\circ} \mathrm{F}$ Return Chilled Water 
Additional tests were performed over a range of cooling water outlet temperatures. For all of these tests, the cooling water was partitioned in parallel between the condenser and absorber and the outlet temperature is the mixed temperature of these two flows. All tests were conducted with a nominal 14 gpm chilled water flow and 18 gpm cooling water flow.

Figures 120 through 123 show the results of this testing. Figure 120 shows the cooling capacity, which, like the other plots, is shown as a function of cooling water outlet temperature. As the plot shows, the capacity decreases with coolant outlet temperature. At the $85^{\circ} \mathrm{F}$ inlet, $99.5^{\circ} \mathrm{F}$ outlet condition, the capacity is over $63,245 \mathrm{Btu} / \mathrm{hr}$.

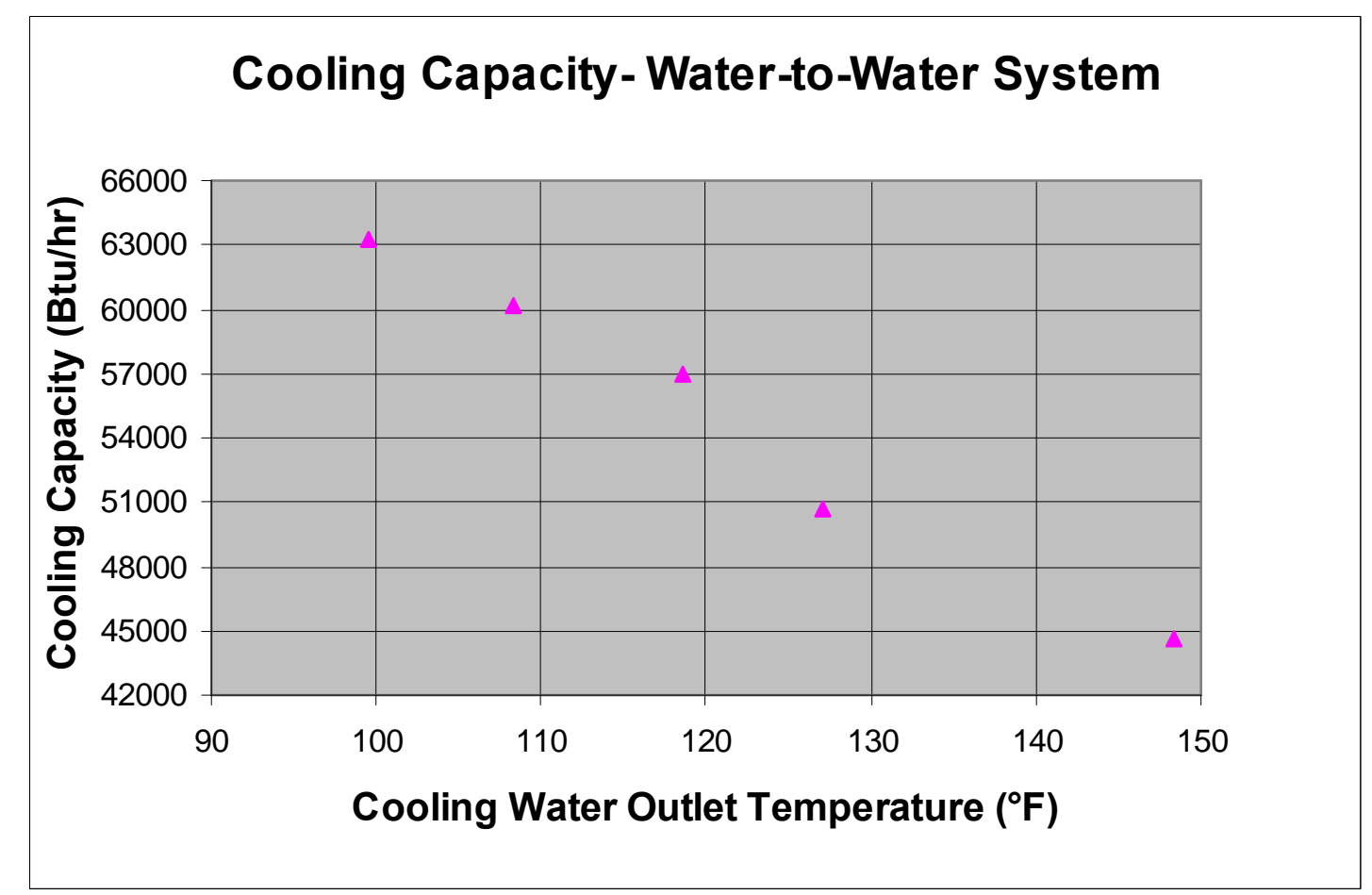

Figure 120. Water-to-Water System Cooling Capacity vs. Coolant Outlet Temperature

Figure 121 shows the corresponding cooling COP for the system. As the figure shows, at the $99.5^{\circ} \mathrm{F}$ outlet condition, the COP is 0.739 and at $108.3^{\circ} \mathrm{F}$ the COP is still above 0.70 . The COP does decrease with increasing cooling water temperature, as would be expected thermodynamically. 


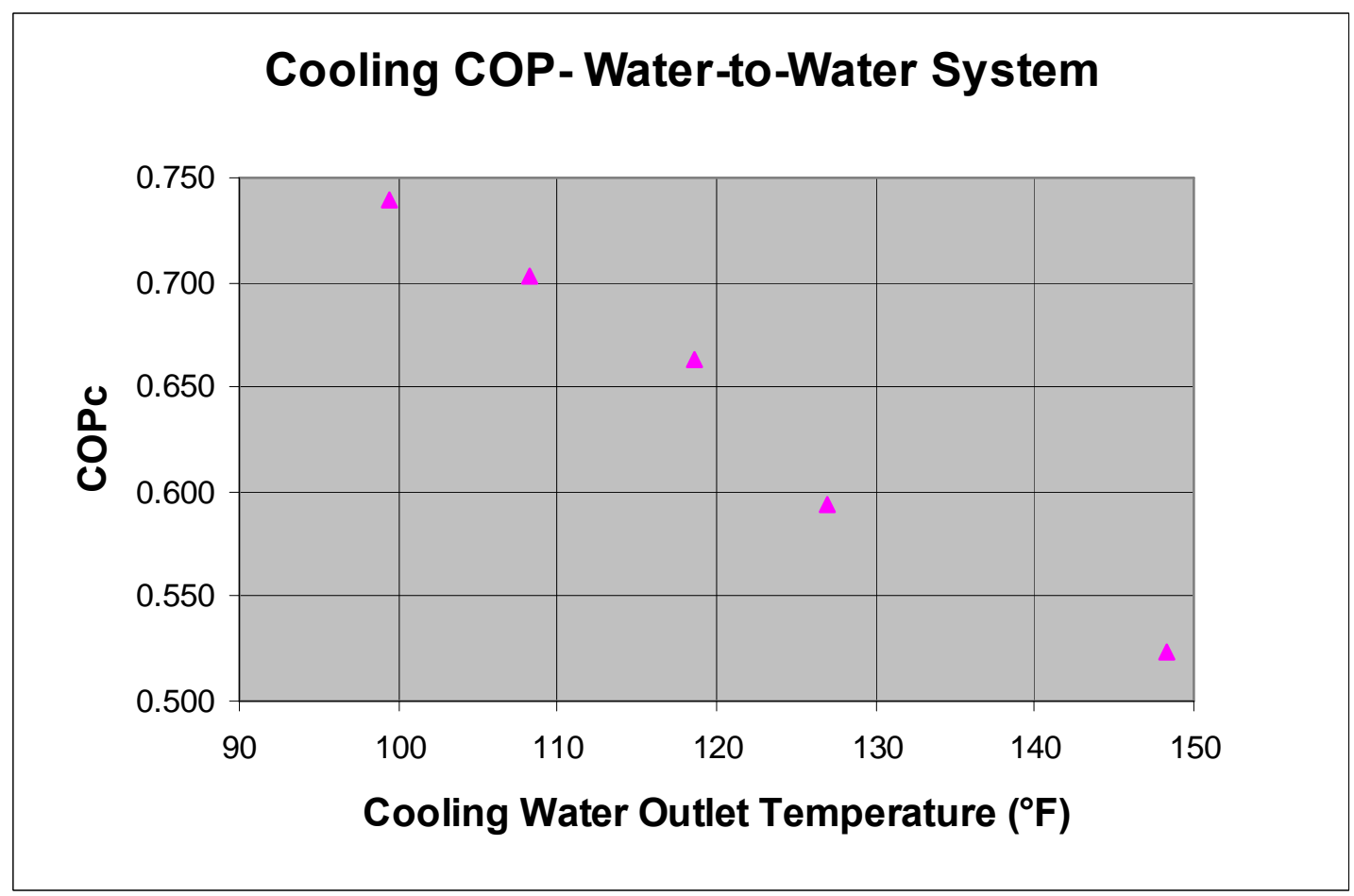

Figure 121. Water-to-Water System COP vs. Coolant Outlet Temperature

One important benefit of the system is the large amount of heat available from the condenser and absorber as a useful cogenerated byproduct. Figure 122 shows the heat generated as a function of the cooling water outlet temperature. As the figure shows, the heat output also decreases with coolant outlet temperature, but is over $120,000 \mathrm{Btu} / \mathrm{hr}$ of heating capacity to $110^{\circ} \mathrm{F}$ outlet temperature. 


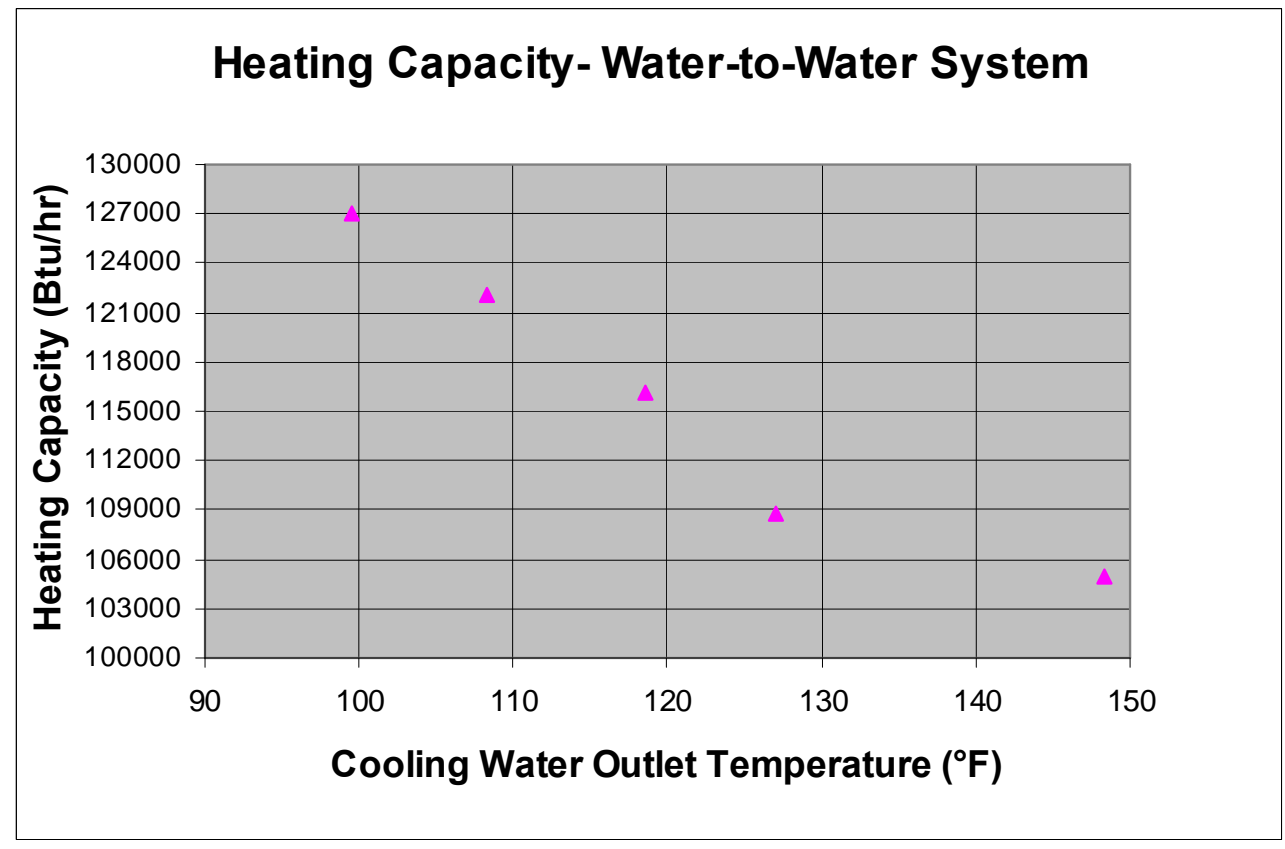

Figure 122. Water-to-Water System Heating Capacity vs. Coolant Outlet Temperature

Power consumption for the system itself is minimal, as shown on Figure 123, which depicts the power consumption as a function of the cooling water outlet temperature. The power consumption ranges from $343 \mathrm{~W}$ to $384 \mathrm{~W}$. This power consumption does not include water pump power for the chilled or cooling water flows, since these will be largely installation dependent.

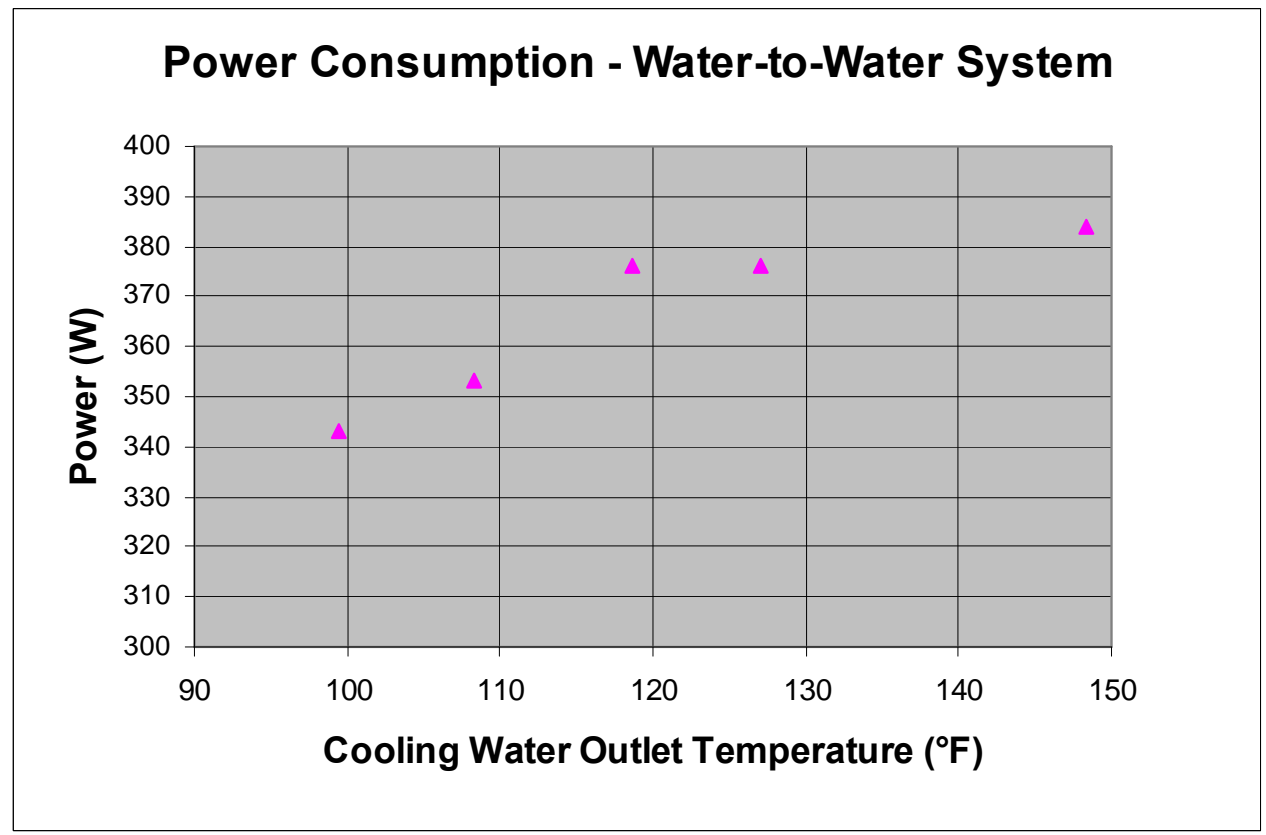

Figure 123. Water-to-Water System Power Consumption vs. Coolant Outlet Temperature 


\section{Task 10. OEM Manufacturing (Aqua-Ammonia Absorption Technology)}

Efforts under this task were directed in four areas: components, fixtures, procedures and documentation. High cost components were addressed in an effort to reduce OEM manufacturing costs. Fixtures to speed the production process were designed. Capabilities for a manufacturer and specific procedures for the production of various components were codified. Documentation, including design drawings and a bill of materials was developed.

\section{Components}

The bulk of the efforts under this task addressed the structured packing used in the generator, the upper GHX section of the generator, the need for an eductor and the pressure relief valve component.

\section{Structured Packing Material:}

The original structured-packing material is used for the adiabatic section and the upper GHX section of the generator worked very well, but at the price made it one of the more expensive items in the bill of materials. Because of this, less expensive alternative suppliers were investigated. During the search for alternatives, it was discovered that the structured packing we presently use may be obtained from foreign sources at prices far less than presently paid. One source in particular had a very similar product to what we originally used. To verify the quality and performance of this product, a small quantity was ordered for testing. Unfortunately, the packings were not cleaned properly since a petrochemical application was assumed by the manufacturer. For this reason, the packings were cleaned successively in both acetone and boiling water previous to testing.

To perform the test, baseline data was collected for the original packing. The generator was then disassembled and the original packing replaced with the low cost packing. The tests were then repeated.

Figure 124 shows these results. Plotted on the figure is the COP as a function of the firing rate for each of the packing. As the figure shows, the COP, which is an indicator of the overall efficiency of the cycle is significantly higher with the new packing. The difference in firing rate of approximately $1000 \mathrm{Btu} / \mathrm{hr}$ should have little to no impact on $\mathrm{COP}$, and this difference is in the noise level of the testing. 
The results indicate that not only was the new structured packing lower cost, but it actually performs better than the original packing.

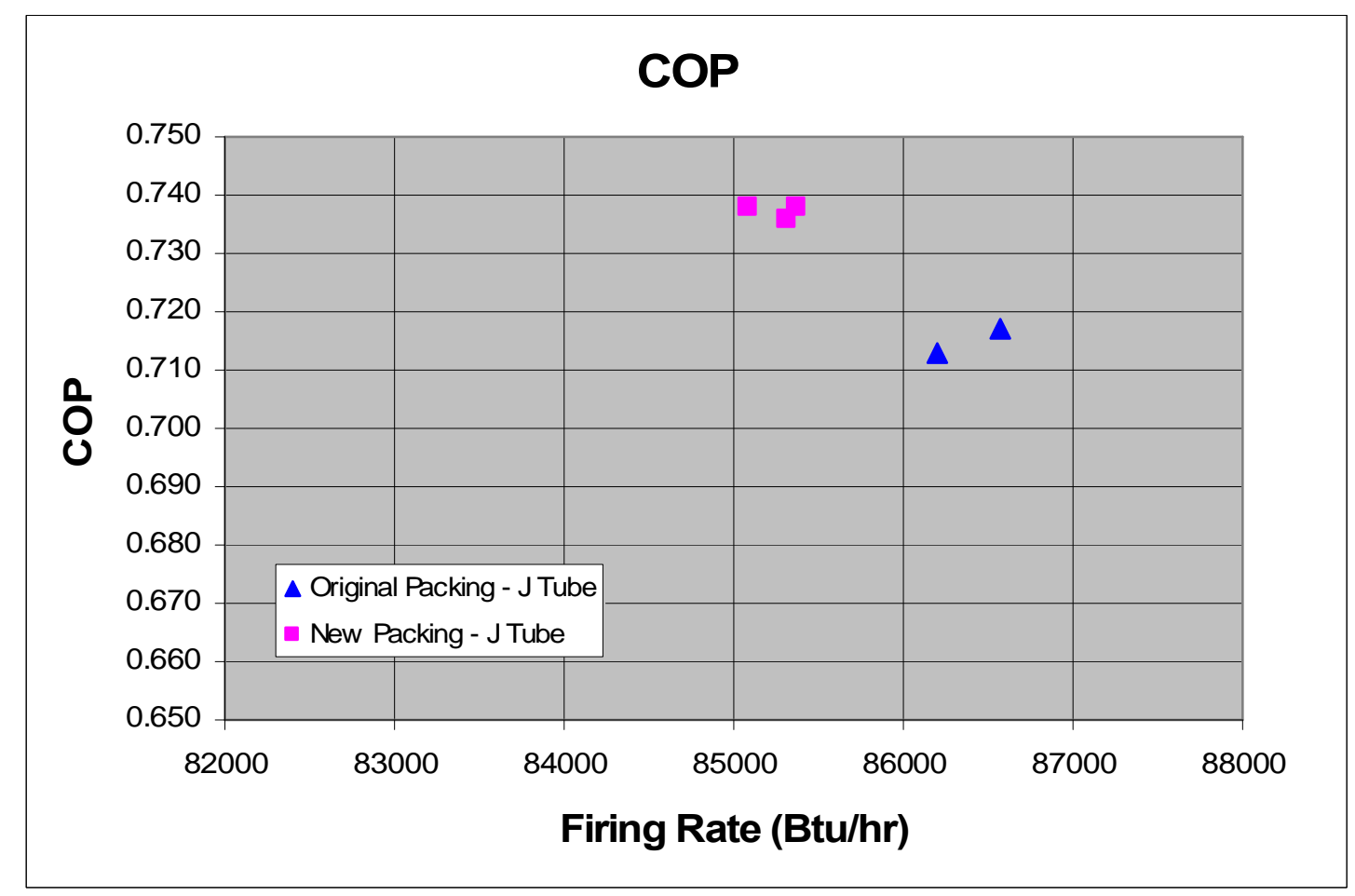

Figure 124. COP for Two Different Structured Packings

\section{Upper GHX Section Evaluation}

As a potential cost saving measure, the possibility of upper GHX section elimination was examined in the past month. For this testing, a modification to the generator and its associated piping was made to be able to stop the flow of solution to the upper GHX coil. Tests were then conducted at the same operating condition on the same day with and without the upper GHX coil in use.

Results from three tests show an average increase in cooling capacity of $815 \mathrm{Btu} / \mathrm{hr}$ when the upper GHX coil is in use. This was associated with a decrease in weak solution temperature of an average $19.3^{\circ} \mathrm{F}$ when utilizing the upper GHX. This temperature difference is important, because without upper GHX use, there is a tendency for the solution to flash across the weak solution valve, which decreases its temperature before it enters the absorber. This, in turn, tends to decrease the heat transfer capability of the GAX/SCA absorber. 
For these reasons, it was deemed not useful to eliminate the upper GHX coil of the generator.

\section{Eductor Elimination}

The hydronic test apparatus was modified to allow for operation with or without the eductor. Possible elimination of the eductor is desirable because of the additional cost for the eductor and its installation during manufacturing.

During operation without the eductor, the reflux from the rectifier is drained to the storage side tank of the generator. While this is a thermodynamic penalty, the low flow rate of reflux limits this to a small amount.

Figure 125 shows the impact on vapor purity from making this change. As the figure shows, the purity of the vapor changes by far less than 0.001 . The impact of this difference on COP was found to be within the accuracy of the testing.

Therefore it was determined that the use of a J-tube for reflux delivery to the side tank of the generator is preferred over the use of an eductor.

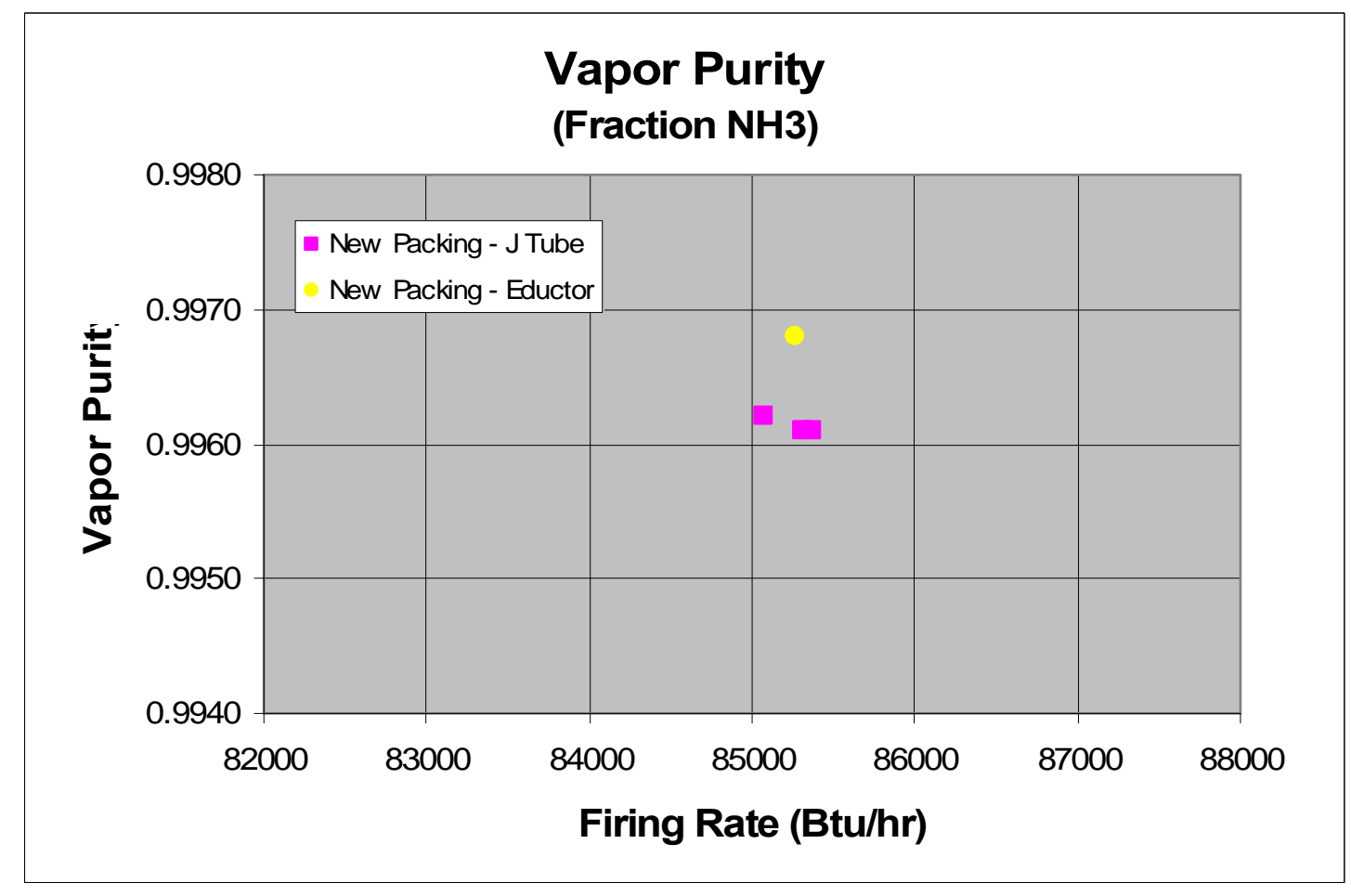

Figure 125. Vapor Purity for J-Tube and Eductor Reflux Methods 


\section{Pressure-Relief Valve:}

The pressure relief valve is located at the upper end of the adiabatic section of the generator. As the name implies, its purpose is to prevent over pressurization of the GAX system. The valve specifications are:
- Type:
In-Line or Tee
- Material:
Carbon or Stainless Steel
- Temp. Range:
$-25^{\circ} \mathrm{F}$ to $300^{\circ} \mathrm{F}$
- MAWP:
3000 psi
- Cracking Pressure:
400 psi, adjustable
- Inlet/Outlet Size:
$1 / 4$ NPT, or equal socket weld
- Sealing Material:
Ethylene Propylene

The valve presently used is from a vendor who has this item as a regularly stocked product. Attempts to find other vendors with a valve that would meet these specifications, so far, have been unsuccessful. As an alternative, the specifications have been sent to numerous valve manufacturers with request-for-quotes to produce the valve in quantities required. Only one vendor responded with a quote that was considerably less than the original price.

One issue of concern with the new valve is its discharge capacity. To get a feel for the required discharge capacity of the pressure relief valve needed for the Rocky Research GAX system design, basic calculations were preformed. Procedures from both ASME and ASHRAE were reviewed and followed. The equation used is as follows:

$$
\mathrm{C}=\mathrm{FDL}
$$

where:

$\mathrm{C}=$ minimum required discharge capacity of the relief device in pounds of air per minute

$\mathrm{D}=$ outside diameter of the pressure vessel in feet

$\mathrm{L}=$ length of the pressure vessel in feet

$\mathrm{F}=$ factor dependent upon type of refrigerant (which is 0.5 for Ammonia)

Based on the dimensions of the GAX Generator, the required discharge coefficient is on the order of $1.31 \mathrm{lb} / \mathrm{min}$. A review of one company that provides discharge capacity information with its valve selection shows that this discharge capacity value is well below the minimum offered by any of its pressure relief valves that meet the 
specifications. This fact implies that the discharge capacity of the new vendor valve will be sufficient for the pressure relief needs of the GAX system.

Ten of the new valves were procured for inspection and testing for quality and performance verification.

As part of the pressure relief valve review, consideration was given to using either a rupture disk instead of a pressure relief valve, or a combination of the two (rupture and pressure relief in separate openings). After much discussion, the idea of using a rupture disk was discarded since the objective is to release as little of the working fluid as possible during an over-pressure event. Naturally, all the material would be lost with the activation of a rupture disk device.

The assessment of the particular valve to use for GAX Generator pressure relief was completed, and the conclusion was reached that either the check valve shown in Figure 126 or the relief valve shown in Figure 127 can be used. The operations of both valves will provide the required pressure relief protection. The determining factor as to which will be used will be primarily cost.

The check valves ordered from a vendor which quoted a lower price than we have paid in the past were tested to replace the ones used to date shown in Figure 4. As an initial screening for quality and performance testing, the valves were pressure tested using a nitrogen bottle. Unfortunately, they all leaked at a pressure significantly lower than the 400 psi maximum pressure specified in the requirements.

For this reason, we continued to use the original pressure reliefs.

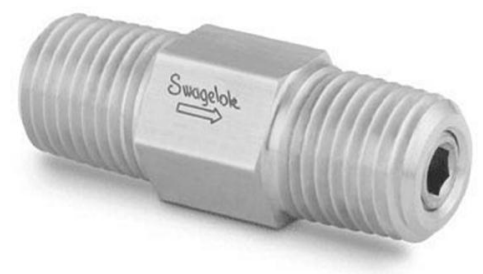

Figure 126. Check Valve 


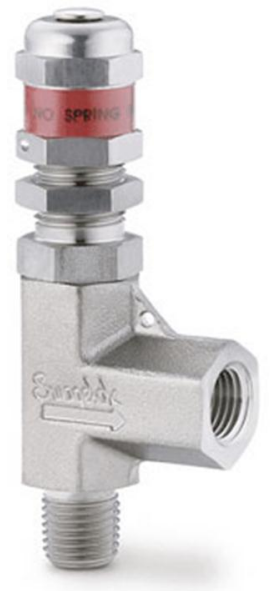

Figure 127. Pressure Relief Valve

\section{$\underline{\text { Fixtures }}$}

Fixtures are required for system assembly in a production environment to reduce production time and to improve quality control. Critical fixtures for the air coil manifolds and tubing, the weak solution line, the generator/absorber/rectifier and absorber bundle assembly were developed under the project.

\section{Air Coil Manifolds and Tubing}

Designs of fixtures for the assembly of the air coil manifold, air coil supply and return tubing as well as the weak solution line were completed during the past month.

Figure 128 shows the air coil inlet manifold distributor. The fixture allows for the proper assembly of the manifold for subsequent welding. The fixture is used as a guide for drilling the air coil manifold. 


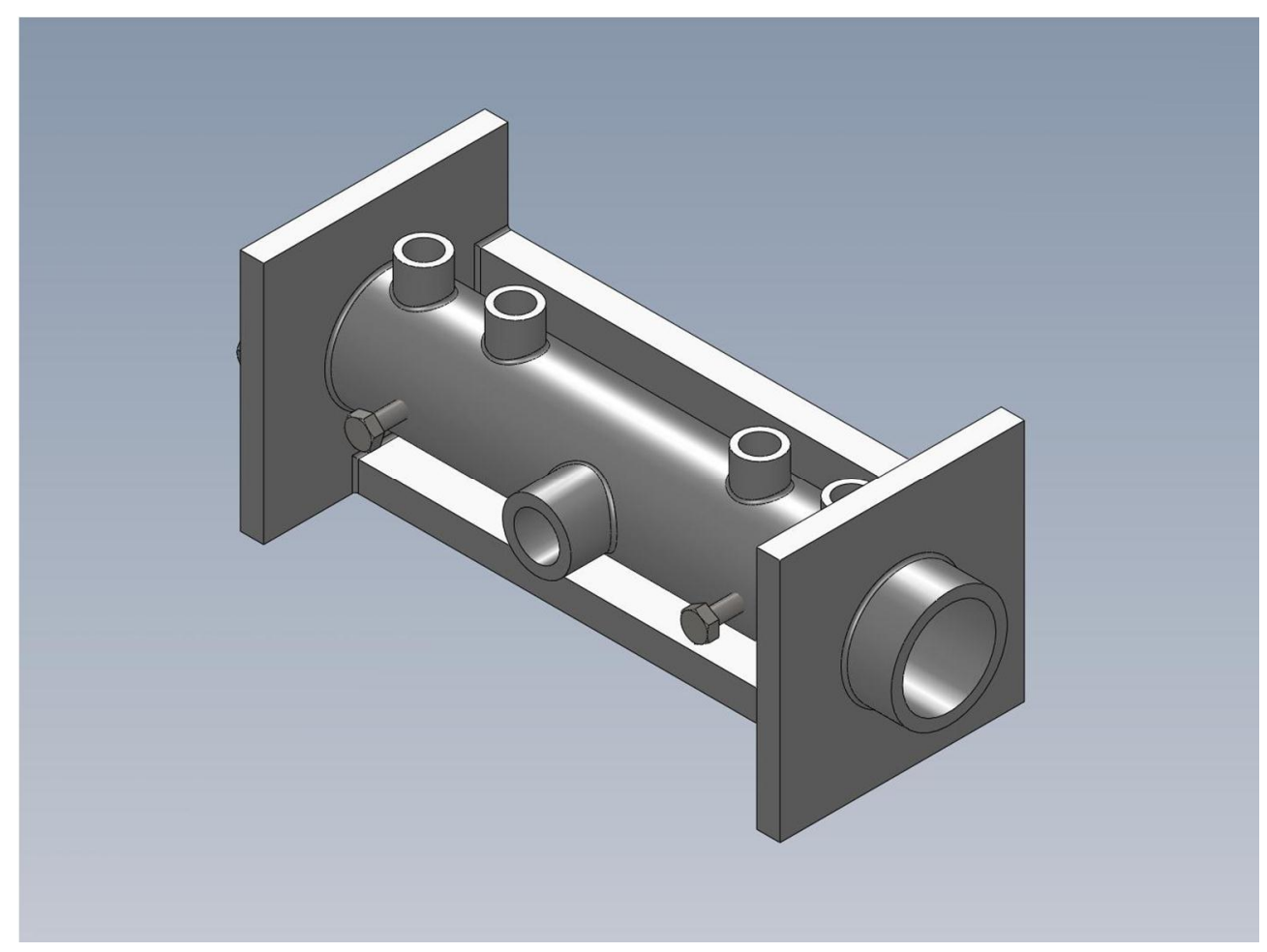

Figure 128. Air Coil Manifold Fixture

Figures 129 and 130 show the air coil outlet and inlet tubing fixtures. These fixtures allow proper positioning of the tubes into their respective manifolds so that they can be tacked and then seal welded.

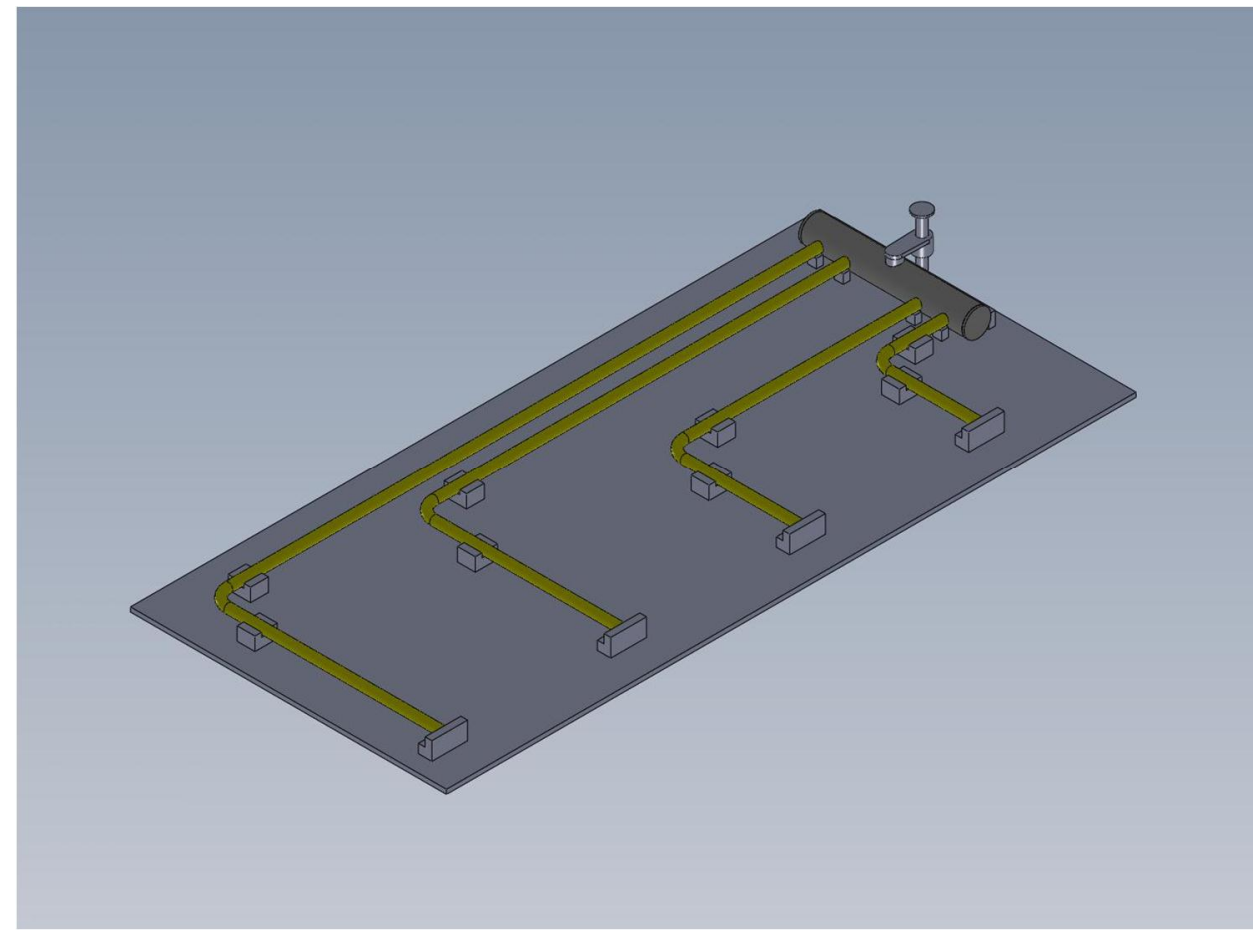

Figure 129. Air Coil Outlet Tubing Fixture 


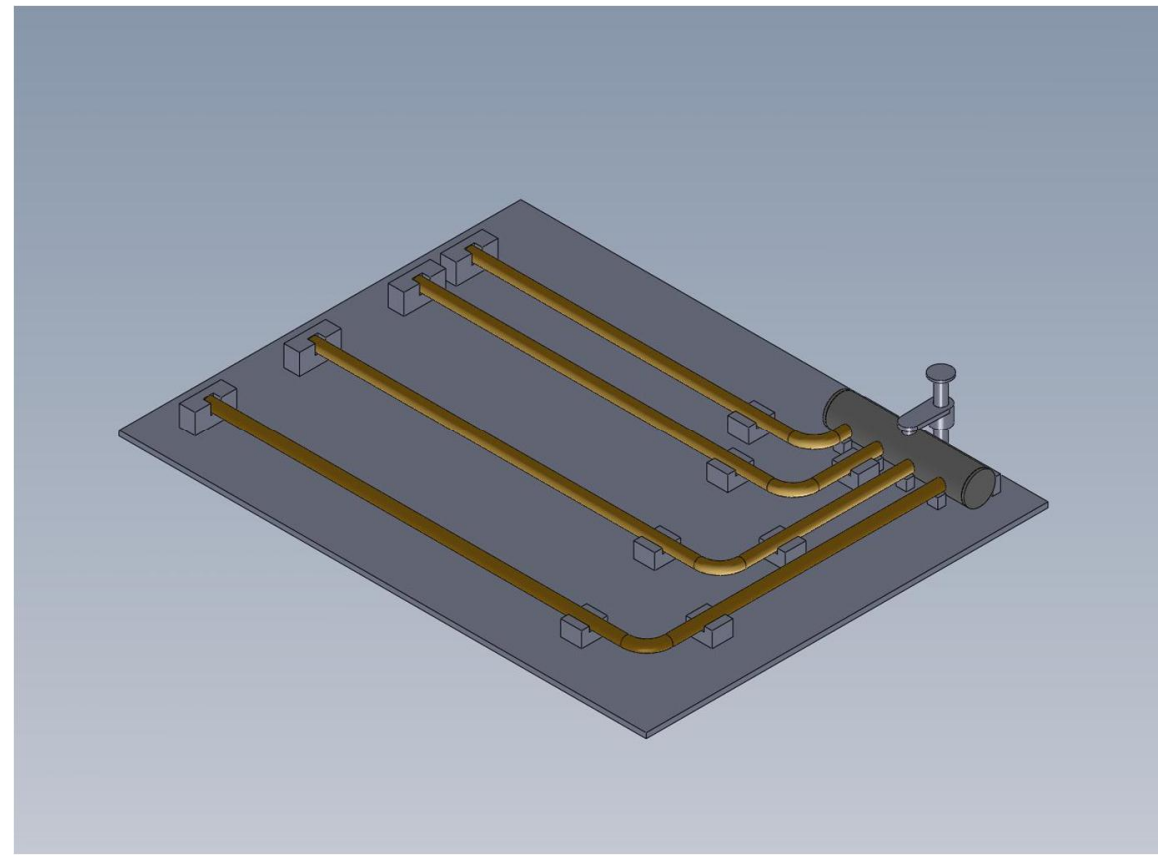

Figure 130. Air Coil Inlet Tubing Fixture

\section{Weak Solution Line}

Figure 131 shows the weak solution line fixture. This fixture allows proper positioning of the solenoid valve and filter in the tubing sections.

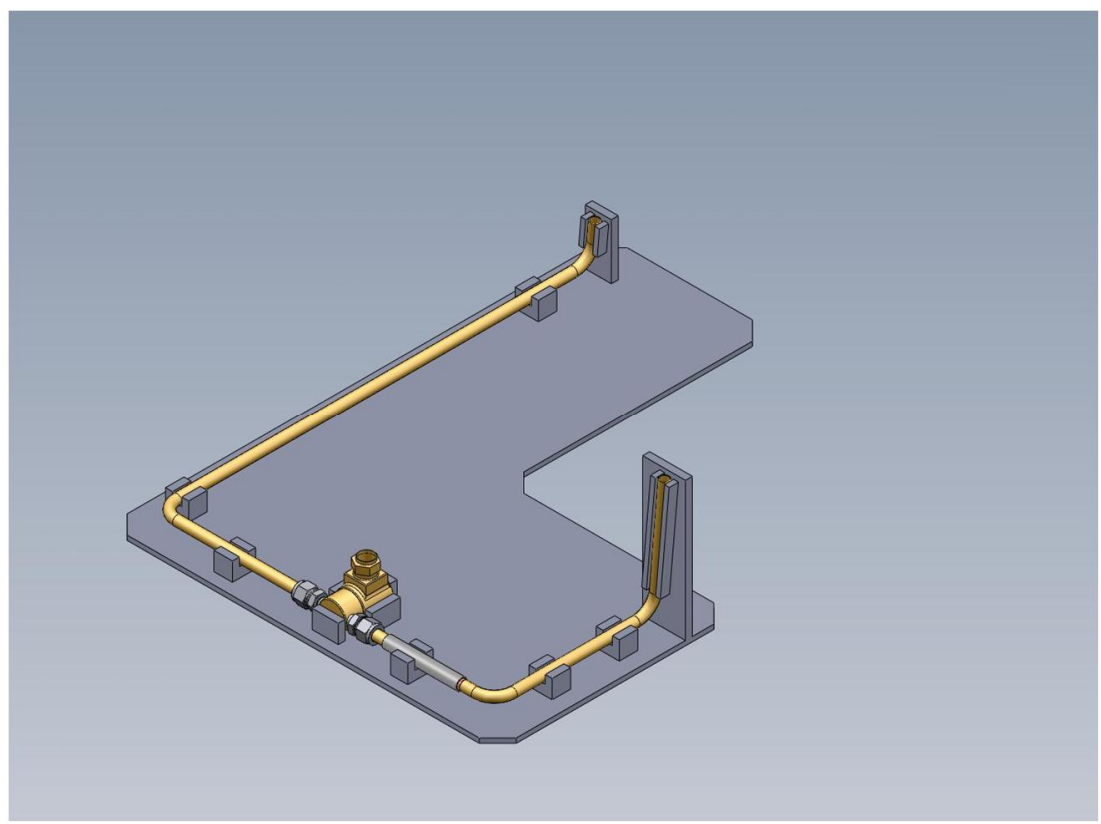

Figure 131. Weak Solution Line Fixture 


\title{
Generator/Absorber/Rectifier
}

The GAR fixture, shown in Figure 132, positions the generator, absorber and rectifier properly so that interconnected tubing can be fitted accurately. The fixture has mounting points for each of the individual components. It can also be lifted and put iinto a weld positioner because of the cylindrical pipe mounted on its bottom. This allows better positioning for welding the interconnecting tubes from all angles.

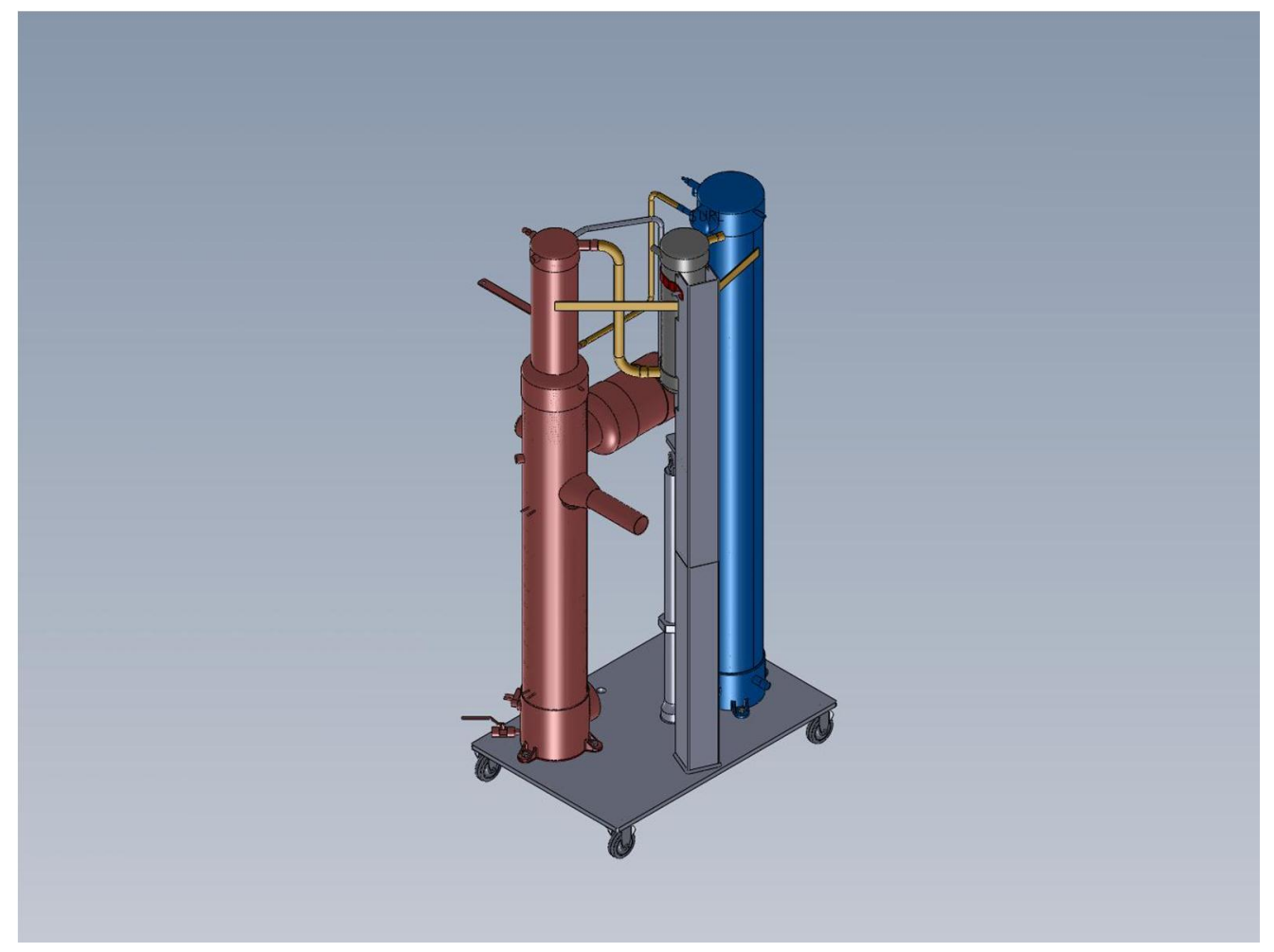

Figure 132. Generator/Absorber/Rectifier Fixture

\begin{abstract}
Absorber Bundle
To improve the assembly of the absorber bundle into the casting and head, absorber bundle tube bending fixtures were developed. These are different for the top and bottom of the bundle and the fixtures are marked ñcasting endò and ñcap endò respectively. The casting end fixture is shown in Figure 133. The cap end fixture is shown in Figure 134.
\end{abstract}




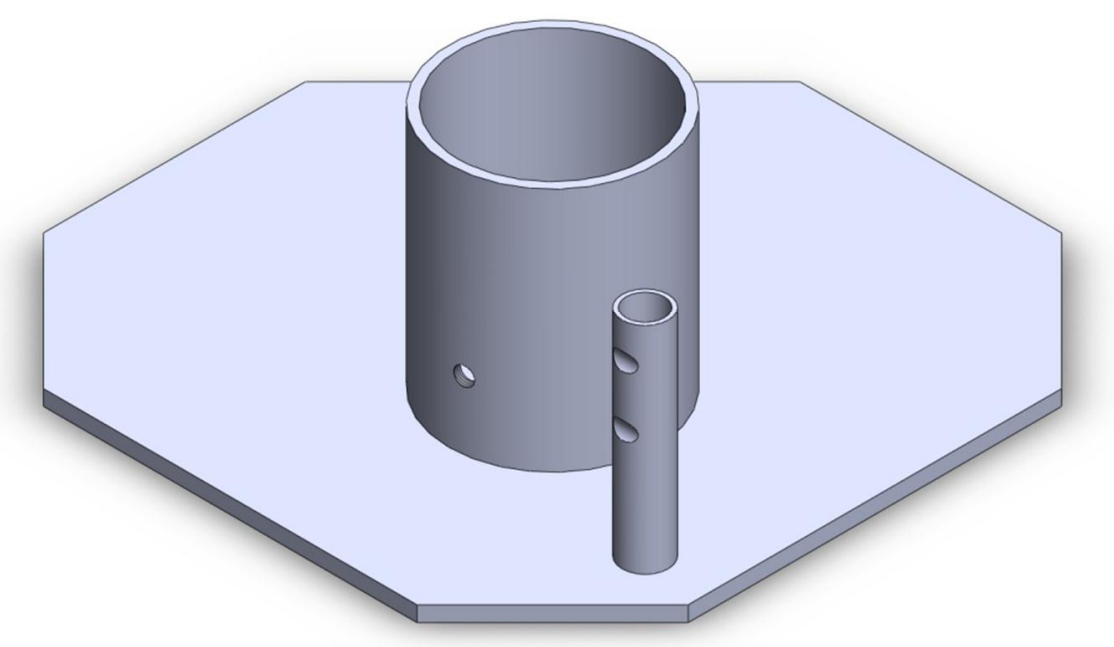

Figure 133. Solid Model of Casting End Fixture

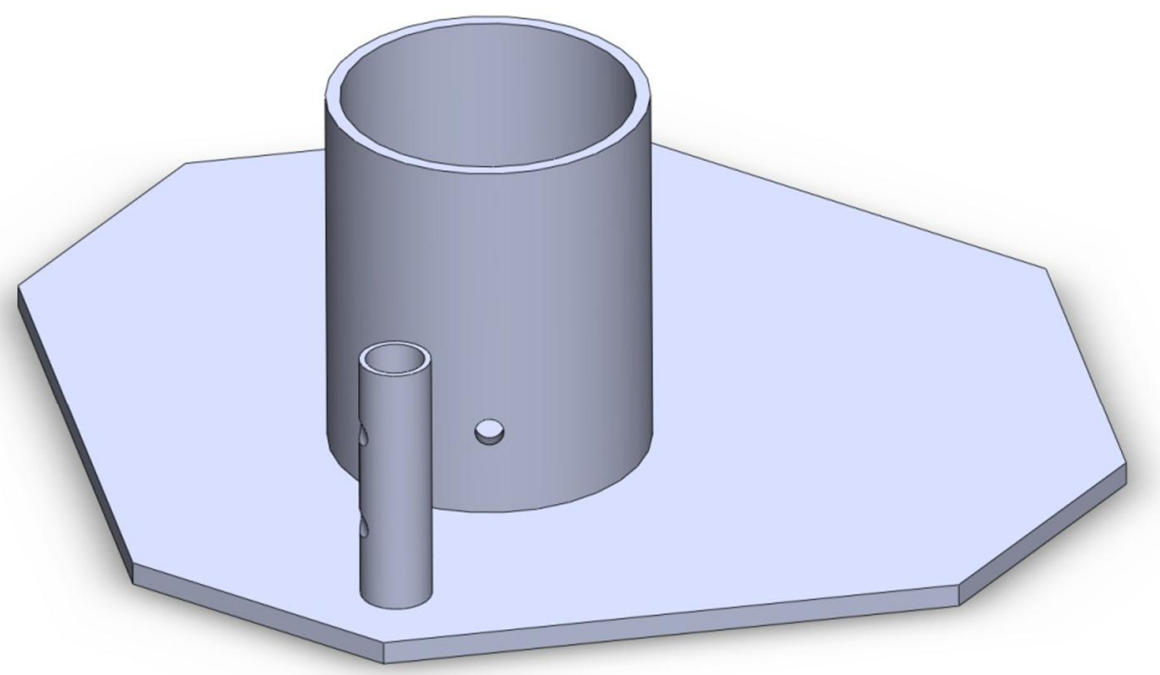

Figure 134. Solid Model of Cap End Fixture

As shown in Figure 135, the bundle should be wound with locating holes facing up (12:00 ộlock position). The bundle should then be wound as usual on the absorber winder. Figure 135 shows the resulting bundle. This is a subscale length bundle for demonstration only. 


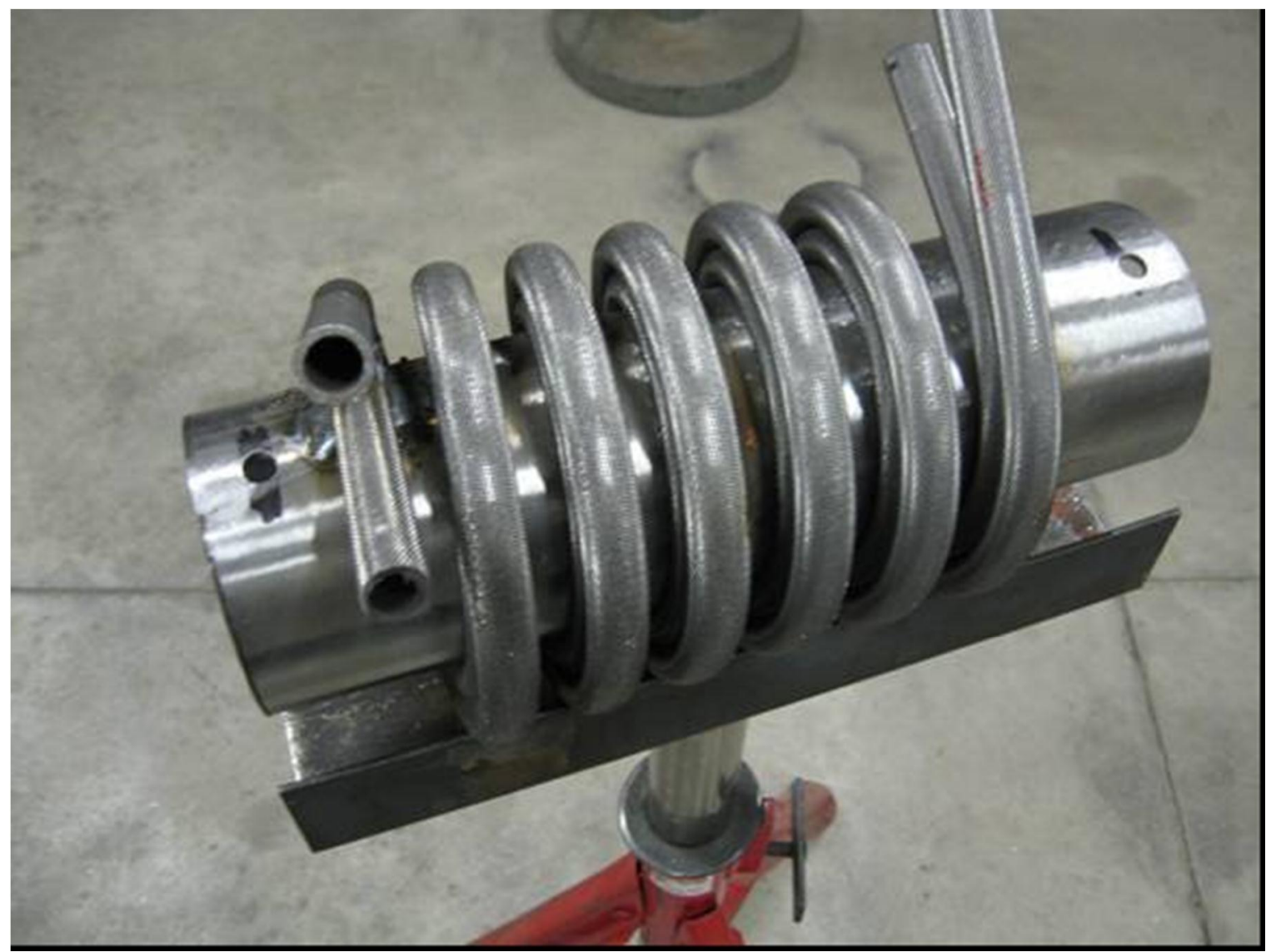

Figure 135. Absorber Tube Subscale Bundle Showing Locating Holes at the 12 Oấlock Position

The mandrel of the assembly is slid over the center post of the fixture and secured using the bolt through the hole drilled earlier. Figure 136 shows this being slid over the fixture. 


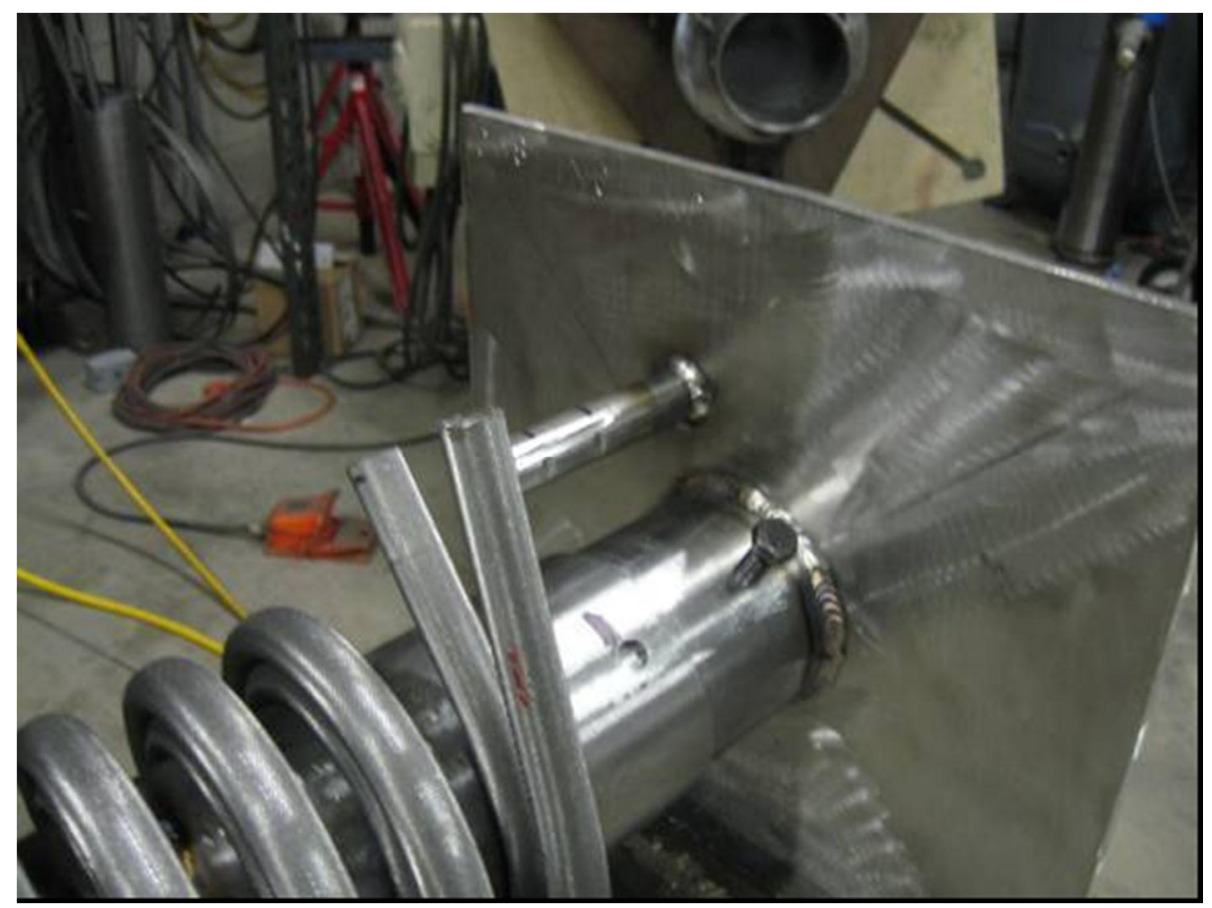

Figure 136. Photo Shows the Absorber Assembly Being Slid Onto Casting End Fixture

The coil is mounted on the fixture is shown as Figure 137

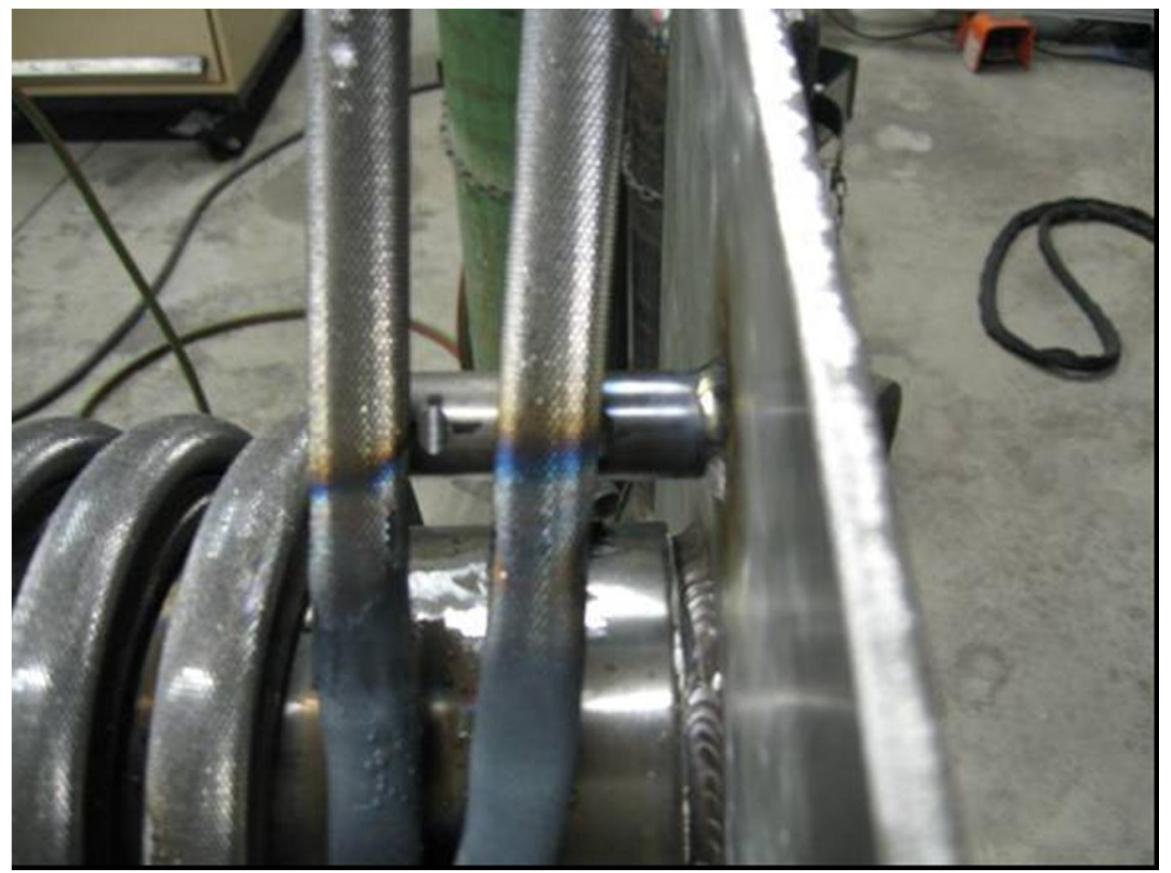

Figure 137. Outer Tube Aligned with Reference Mark on Post 
The bending process is then done by heating and bending the outer tube and gradually working it into position by aligning it with the reference marks on the small post of the fixture. This is shown in Figure 138. When both tubes are positioned the ends can be trimmed off along the centerline of the small post, as shown in Figure 139. This leaves enough material to weld the tube ends into the casting.

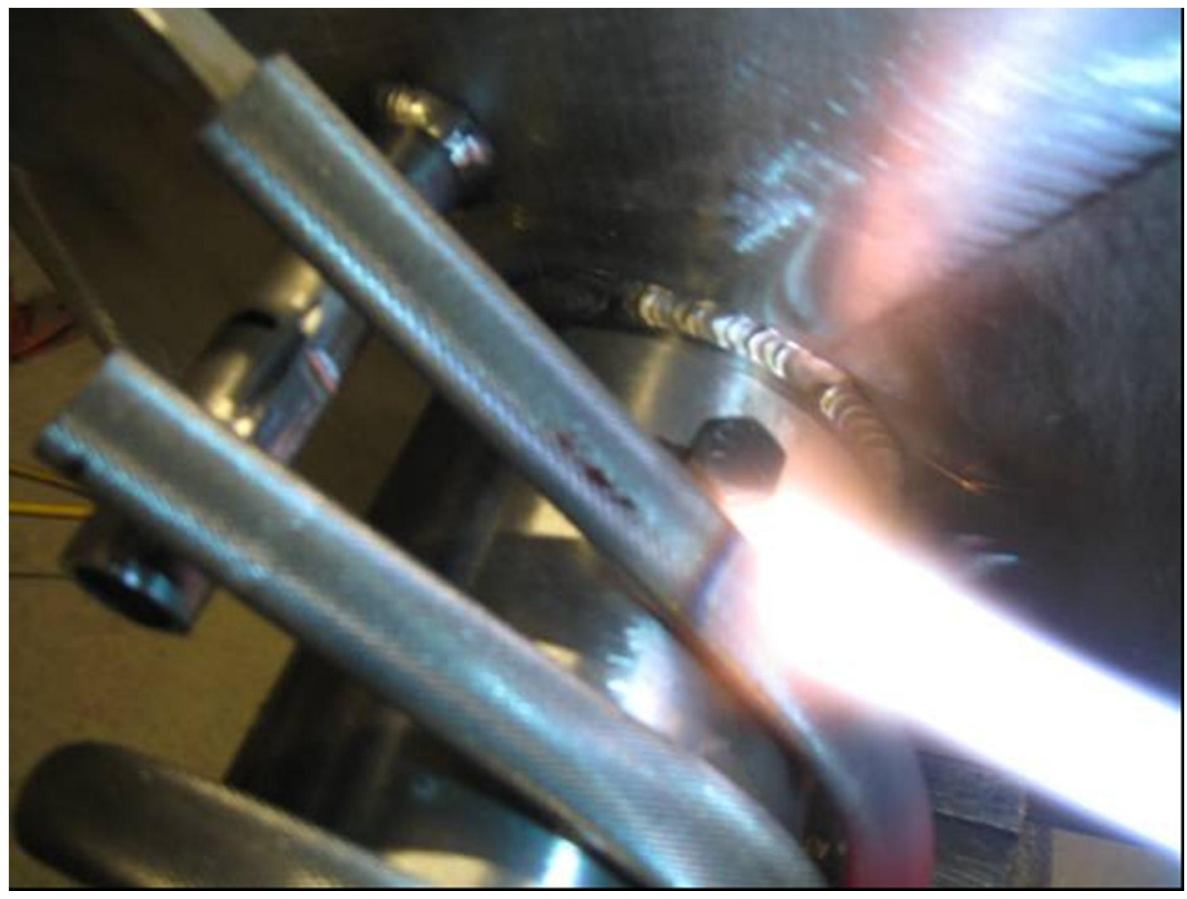

Figure 138. Bending of Tubes Into Place

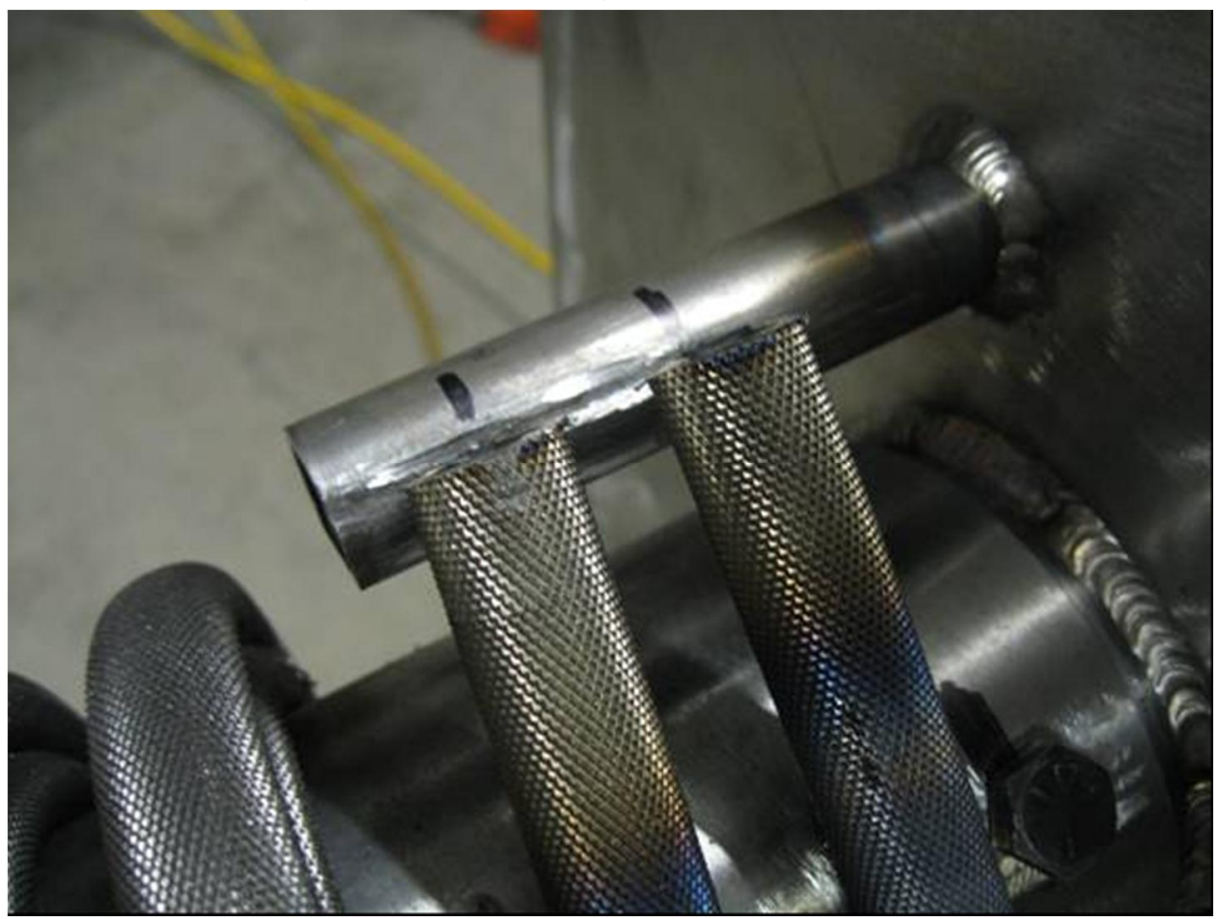

Figure 139. Tube Trimming 
The top (cap end) of the bundle is then done in the same way, using the same procedure. This should position the upper and lower manifold caps vertically with each other on the completed absorber. At this stage, the upper locating hole can now be welded closed and the mandrel top cap welded into place to continue the assembly of the absorber. Figure 140 shows the final configuration of the assembly, but does not show the outer shell of the absorber.

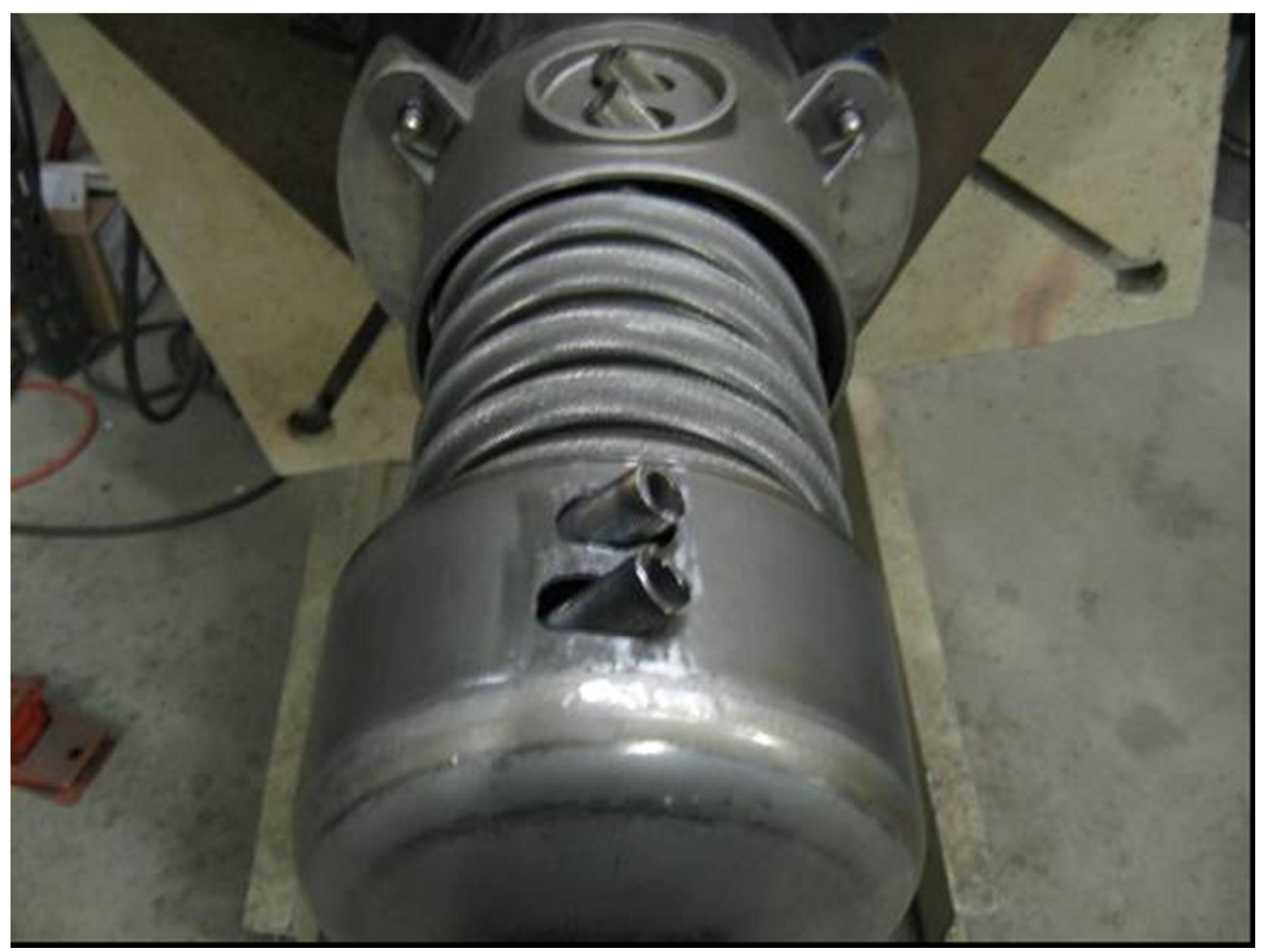

Figure 140. Upper and Lower Manifold Caps

\section{Capabilities and Procedures}

\section{Manufacturing Considerations for GAX Production}

A manufacturing consultant was utilized to provide an overview of issues germane to the production of the GAX water chiller and heat pumps. This was done to provide an independent evaluation insuring that Rocky Researchôs manufacturing focus was not in error. Excerpts from his evaluation follow. 
The production of GAX water chillers and heat pumps requires a manufacturer with a multiplicity of skills. In selecting a manufacturing partner some of the key requirements that must be evaluated are the companyôs ability to perform the following tasks:

- Steel welding capability $\ddot{i}$ the ability to perform both Metal Inert Gas (MIG) and Tungsten Inert Gas (TIG) is critical. Welders should be certified to build pressure vessels

- Steel bending capabilities should include tube winding and roll forming.

- Steel forming requires punch press machinery

- Incoming material inspection and vendor control. Sourcing capabilities should be in compliance with ISO 9001 requirements. The manufacturer must be able to certify that the purchased components, even if sourced offshore meet the performance and structural requirements specified.

- Leak detection. The vendor should be able to perform helium leak detection, initially on subcomponents, and them on the entire system.

- Refrigerant charging using ammonia. The manufacturer must possess evacuation pumps to remove the air from the completed system. After evacuation the system must be charged with ammonia and water. The manufacturer must have the ability to store sufficient ammonia on site to meet the production requirements. Procedures must be in place to avoid ammonia leaks during charging.

- Hydrostatic pressure testing. The manufacturer must possess a hydrostatic test facility sufficiently large to handle hydrostatic testing of the generator and absorber. These components must be tested to 440 psi. Should a failure occur the hydrostatic pressure-testing chamber should be sufficiently robust to handle parts rupture. A facility that is able to perform testing to failure is desirable.

- Dedicated manufacturing and warehousing space. Production of the GAX may require up to 10,000 square feet of space. Depending on production volume the manufacturer must set up for station build or an assembly line. Warehousing must be sufficiently automated that all the parts necessary for station build can be brought quickly and reliability to the assembly workers.

- The GAX housing requires the ability to form sheet metal and punch holes in specific places. A numerical control punch press capable of handling sheet metal panels up to 5ôx 200̂is desirable. If the manufacture does not possess this equipment they must be allied with a vendor that is able to provide the services.

- Painting and paint preparation are important for life. The manufacturer should have a shot blasting facility for removal of rust and scale prior to painting. The painting can be either powder coat or spray.

- Electrical wiring capability. The manufacturer will likely outsource the production of wiring harnesses. They must possess the ability to verify circuit continuity and proper operation of the wiring harnesses.

- Printed Circuit board production. The PCB in each GAX is a critical component that requires the sourcing of individual logic components from multiple vendors and the assembly of the board. The manufacturer must be able to automate the testing of each PCB to verify that each function works properly before it is installed. A wave soldering capability and robotic insertion of components onto 
the board is desirable. However, this component can be outsourced to a competent supplier.

- The manufactureôs Quality Control procedures must focus on 6-sigma production. Records must be maintained for 25 years showing who performed each assembly operation. All components must be bar coded so that tracking is automated.

- Proper insulation of the major components requires that the manufacturer be skilled in the application of precut insulation. An ideal manufacturing partner will be producing other systems that require insulation.

- Continuous product improvement is key to cost reduction and market place competitiveness. The manufacturer must have mechanical engineers that are able to maintain the engineering data base using SolidWorks. The engineering data base must be linked to the one at Rocky Research so that whenever revisions are made to the data file all systems are updated.

- Machining capability needs to include the ability to use numerically controlled lathes, milling machines and boring machines. Tolerance control is critical. Production of the solution pump is one of the critical machining operations.

- Access to natural gas and propane are important for functional testing. The ideal manufacturer will have an environmental test chamber that can the used to prove the performance of each unit.

- Cleanliness is key to good production. All oil and weld slag must be removed from the metal component prior to assembly.

In evaluating the capabilities of a manufacturing partner we have found that the ability to work with steel is the key capability.

\section{Pump Manufacturing Issues}

Because of the need for 5 axis machining of the raw pump castings to prepare the casting for assembly, a system was built that allows machining with a standard milling machine and will allow the casting to be rotated and fixed in position after rotation. Figure 141 shows a photograph of this fixture. The fixture allows proper positioning for machining and rotation with a positive and exact stop for machining on all faces. A complete set of drawings for this fixture has been made. 


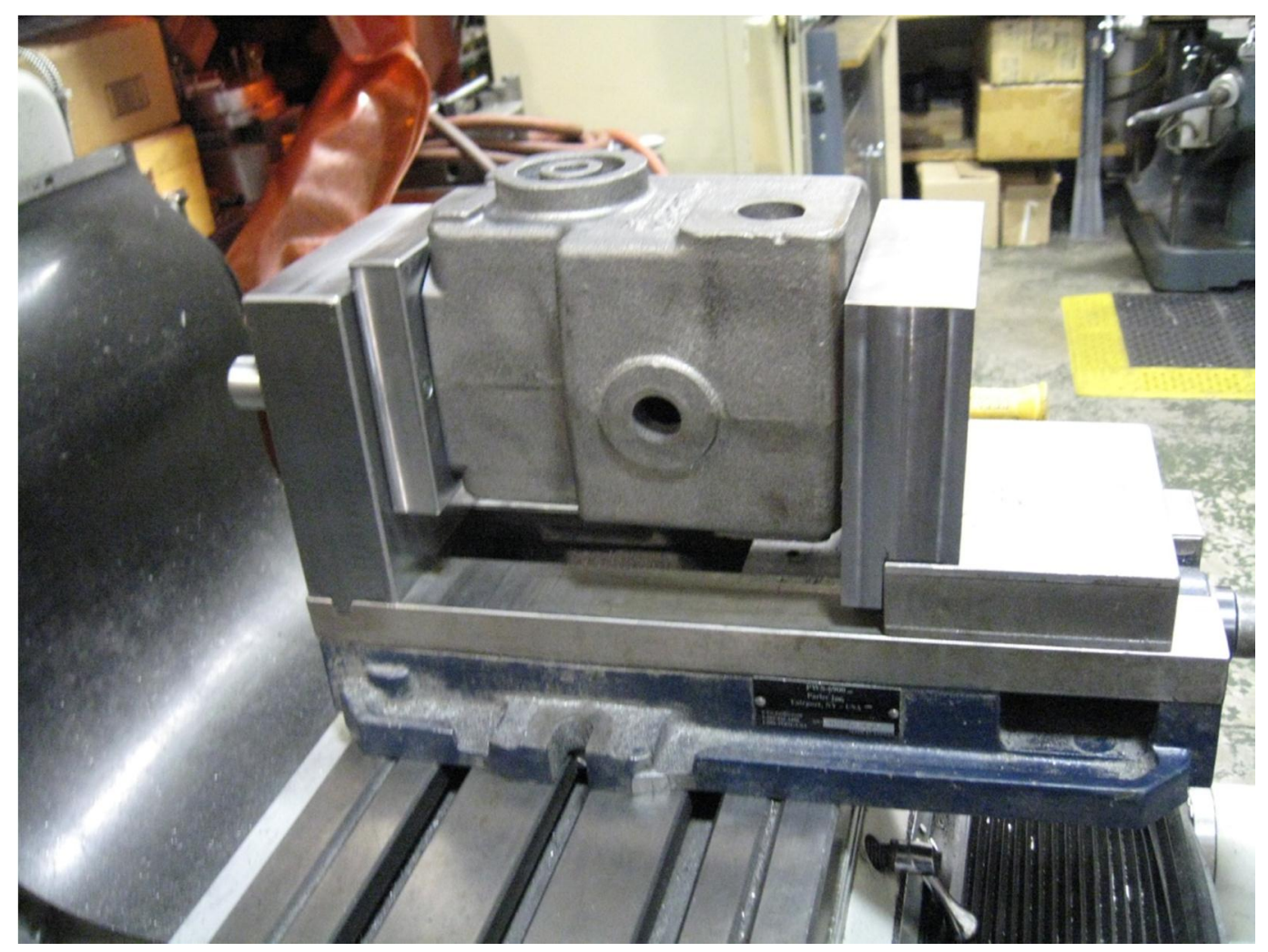

Figure 141. Pump Casting Fixture

Because of the cost of some of the solution pump parts, alternative means of making them are being addressed. One such component is the plunger body, shown in Figure 142. The plunger body is one of the most expensive parts of the pump for two reasons. First, because it is made from bar stock, an excessive amount of machining manpower is required to arrive at the general shape of the part. Second, there is a lot of scrap material generated by hogging out material from the bar stock to form the proper shape. 


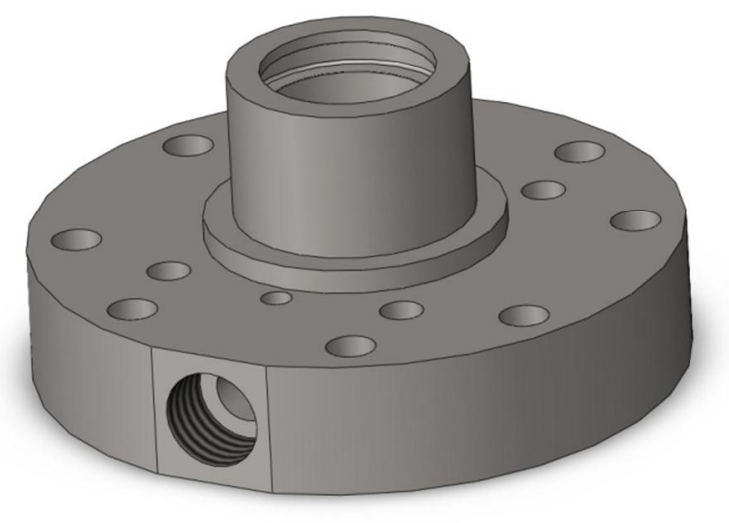

Figure 142. Solid Model of Plunger Body

To reduce both of these costs, an alternative cast part was devised as a replacement of bar stock as the starting point for machining. A solid model of the cast part is shown on Figure 143. The casting will significantly reduce machining time. Also, the amount of steel used will be far lower than the for raw bar stock, thereby reducing material costs.

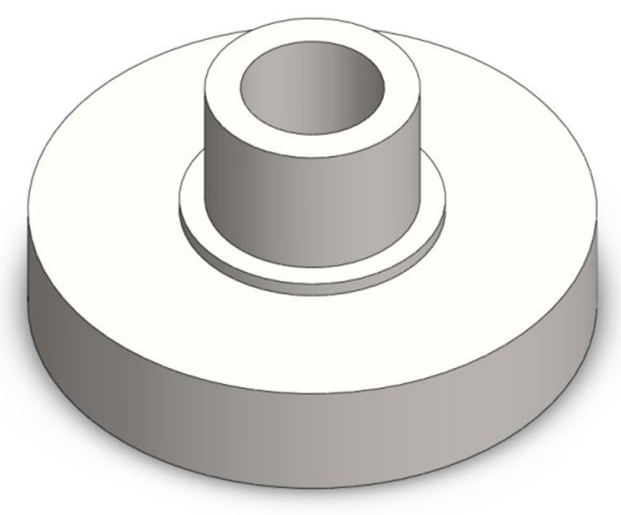

Figure 143. Solid Model of Casting 
A part mimicking the ñcastò plunger body was built. A time study revealed that a casting would save approximately 2 hours of machining time (vs. a solid blank) and would reduce the amount of steel required by 20 pounds from 34 pounds to 14 pounds.

\section{Cleaning of Steel for Manufacturing}

The low carbon steel that is required for the aqua-ammonia components typically is provided by suppliers with an oil coating to prevent excessive rusting and also is likely to have some rust on it. Oil and rust both can adversely affect the performance of an aquaammonia system, and must be removed. To this end, a three primary step cleaning process is required. The following steps are required: oil removal, rust removal and passivation. The passivation step is necessary to allow the steel to have shelf life without excessive rusting.

Efforts to evaluate the efficacy of methods for each of these steps were undertaken. The oil removal stage was the first to be investigated. To gauge the effectiveness of the oil removal step in the steel cleaning procedure, weighing of multiple small samples before and after cleaning was employed. Clean Raschig rings, weighing about $5 \mathrm{~g}$ each, were weighed to $0.1 \mathrm{mg}$ before and after immersion in machine oil, and again after soaking in a cleaning bath. 20 Raschig rings were used, with 5 replicates for each of four cleaning soak times. Two separate tests were done.

The cleaning bath is a 4:1 solution of isopropanol distilled water, saturated with sodium hydroxide. Agitation is provided by pumping the solution through a manifold of perforated tubes in the bottom of the bath. The volume of solution was $13.5 \mathrm{~L}$ and the flow rate was $18 \mathrm{~L} / \mathrm{min}$, for a residence time of $0.75 \mathrm{~min}$.

Results of the cleaning tests are shown in Figures 144 through 147. In Figures 144 and 146, where the initial oil weights are plotted, the soak time on the x-axis is used only to identify the groups of Raschig rings, as there was essentially no soak time in the machine oil. From Figures 144 and 146, the initial amount of oil on the rings was fairly consistent at approximately $20-30 \mathrm{mg}$. In the first test, Figure 145, the final oil weight is about 2-3 mg after 1,2, and 5 minutes of soaking, and slightly negative after 10 minutes. This may be due to some residue on the rings prior to the test. The second test, Figure 147, shows final oil weights near zero for soak times from 2 to 20 minutes. It would appear that only a few minutes are required to remove the oil. 


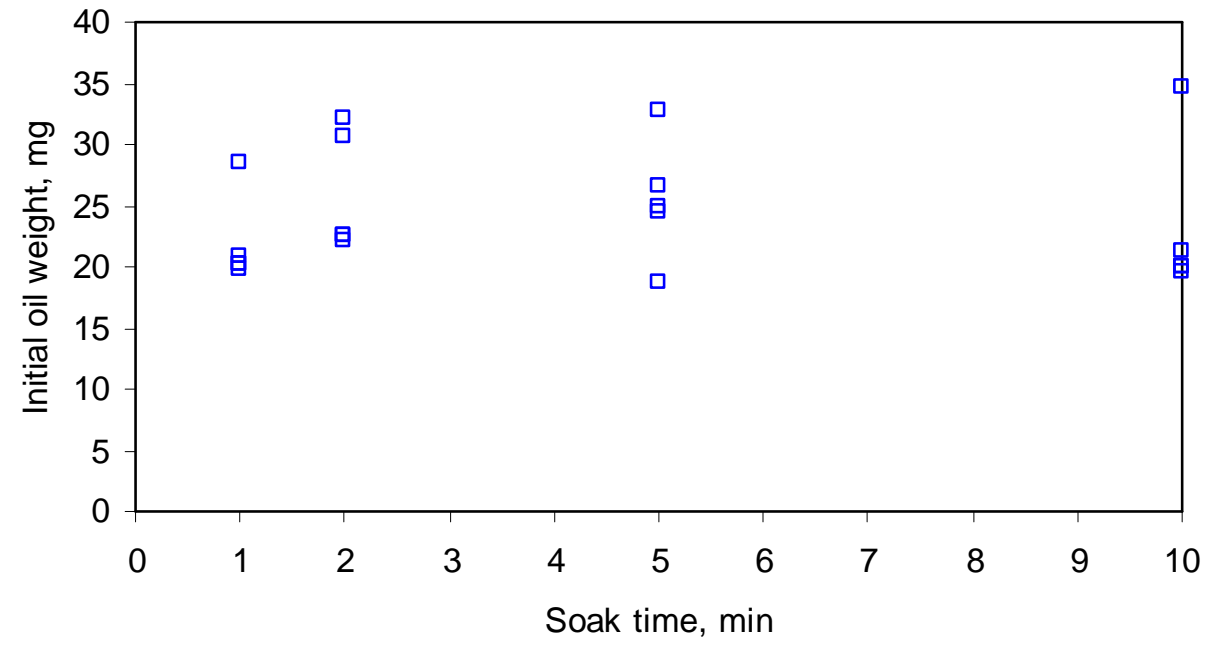

Figure 144. Initial oil weight ï Test 1.

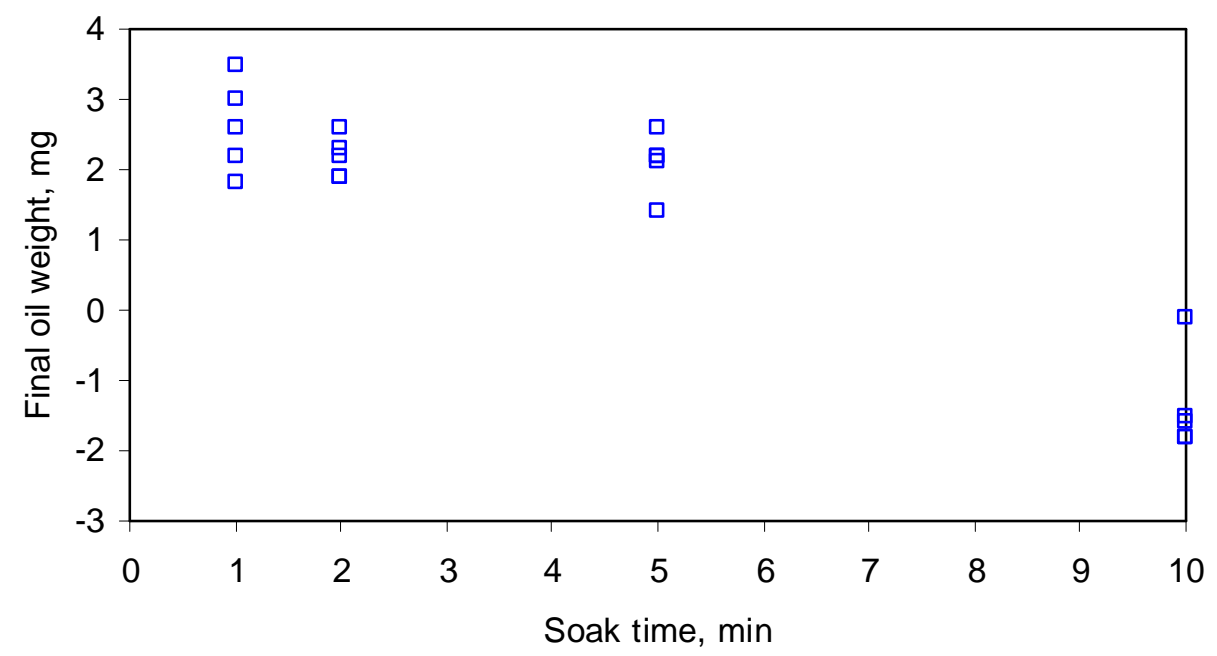

Figure 145. Final oil weight ï Test 1. 


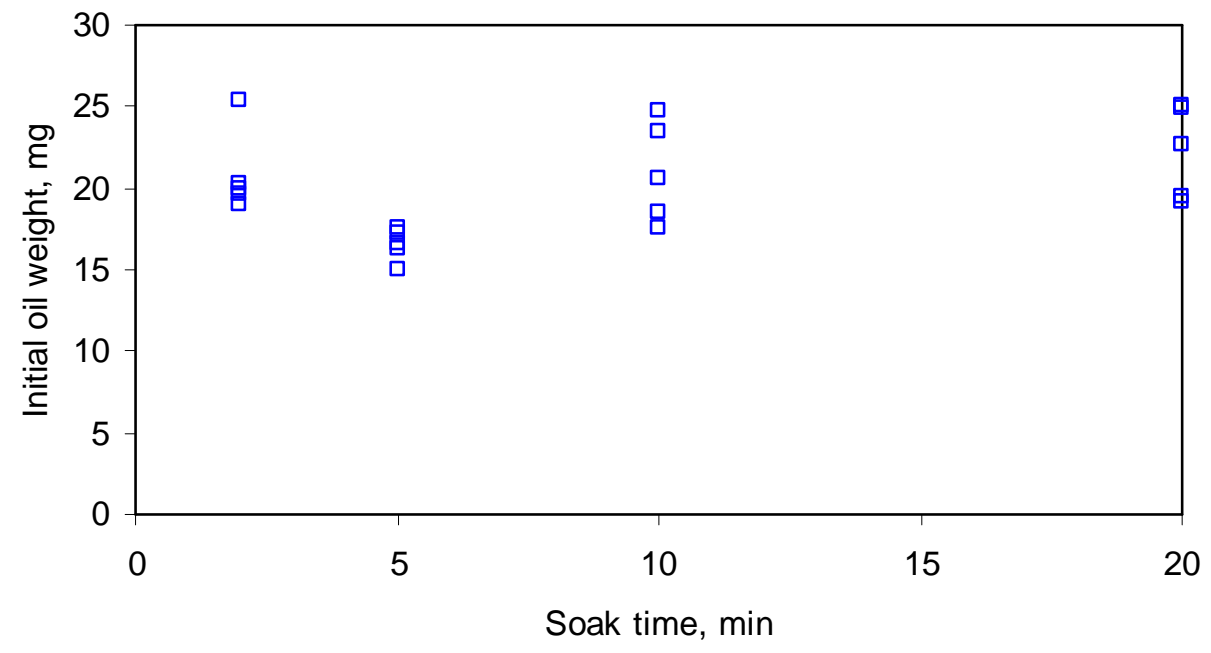

Figure 146. Initial oil weight ï Test 2

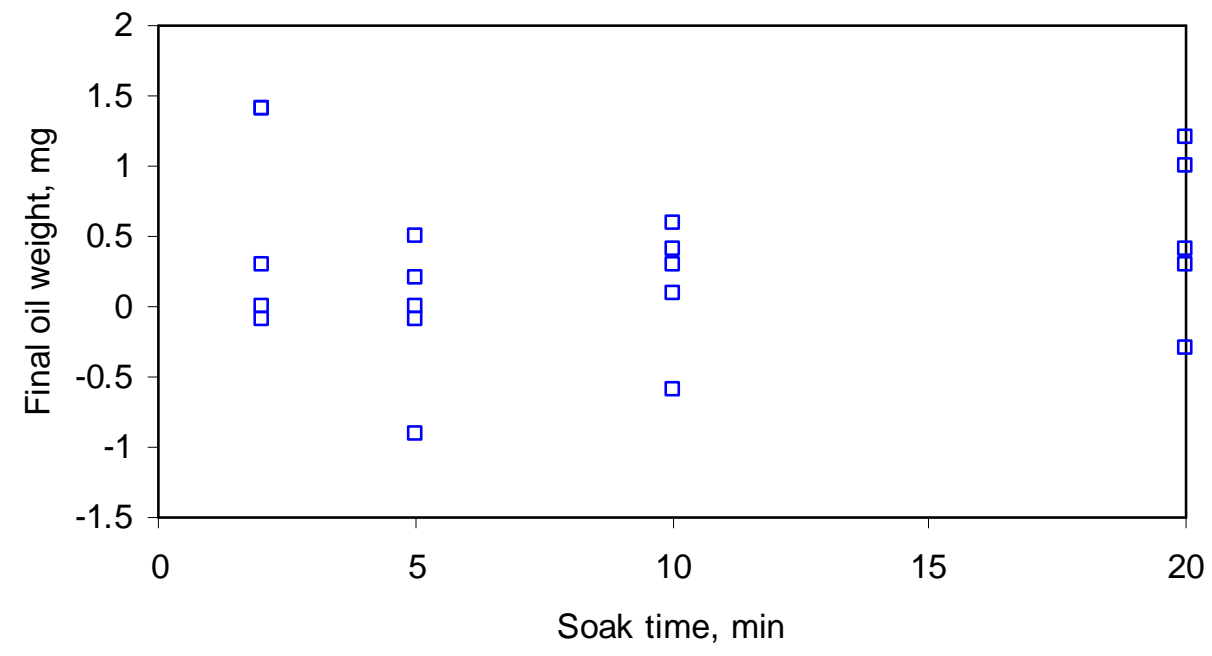

Figure 147. Final oil weight ï Test 2.

Testing was done to determine the solubility of oil in the oil cleaning bath solution. The oil used for testing is Ridgid Nu-Clear Thread Cutting Oil, composed of $>95 \%$ by weight mineral oil with a sulfur additive package. Various amounts of oil were added to test tubes containing the cleaning solution. The tubes were vigorously shaken several times and then visually inspected for a solution/oil interface after allowing the contents to settle. 
For the first test, $0.5-5 \mathrm{~mL}$ oil was added in $0.5 \mathrm{~mL}$ increments to $5 \mathrm{~mL}$ of solution, for a concentration range of approximately 9 - 50 percent oil by volume. An oil layer remained, even at the lowest oil concentration, as seen in Figure 148. The oil layers are on the bottom because the solution density is less than the oil density.

The test was repeated with $10 \mathrm{~mL}$ solution and 0.2 - $2.2 \mathrm{~mL}$ oil. Again, an interface was seen at the lowest oil concentration, however, the lower layer was clear unlike the others. Furthermore, the clear layer was larger than the layer in the $0.4 \mathrm{~mL}$ oil sample (Figure 149). This sample was redone and no interface was observed. Presumably the first sample was contaminated with water. This test indicates that the cleaning solution will dissolve up to about $2 \%$ oil.

Rust removal testing with hydrochloric acid solutions was also done. For these tests, Raschig rings with a layer of rust were immersed in stirred solutions of various concentrations and the time required for the rust layer to visually disappear was measured. The visual presence of undissolved rust remaining in solution was also noted. 2:1, 3:1, and 5:1 water/acid solutions removed the rust in $2 \frac{1}{2}$ to $3 \frac{1}{2}$ minutes but had undissolved rust remaining in solution. A 1:1 solution removed the rust in one minute with no undissolved rust remaining. 


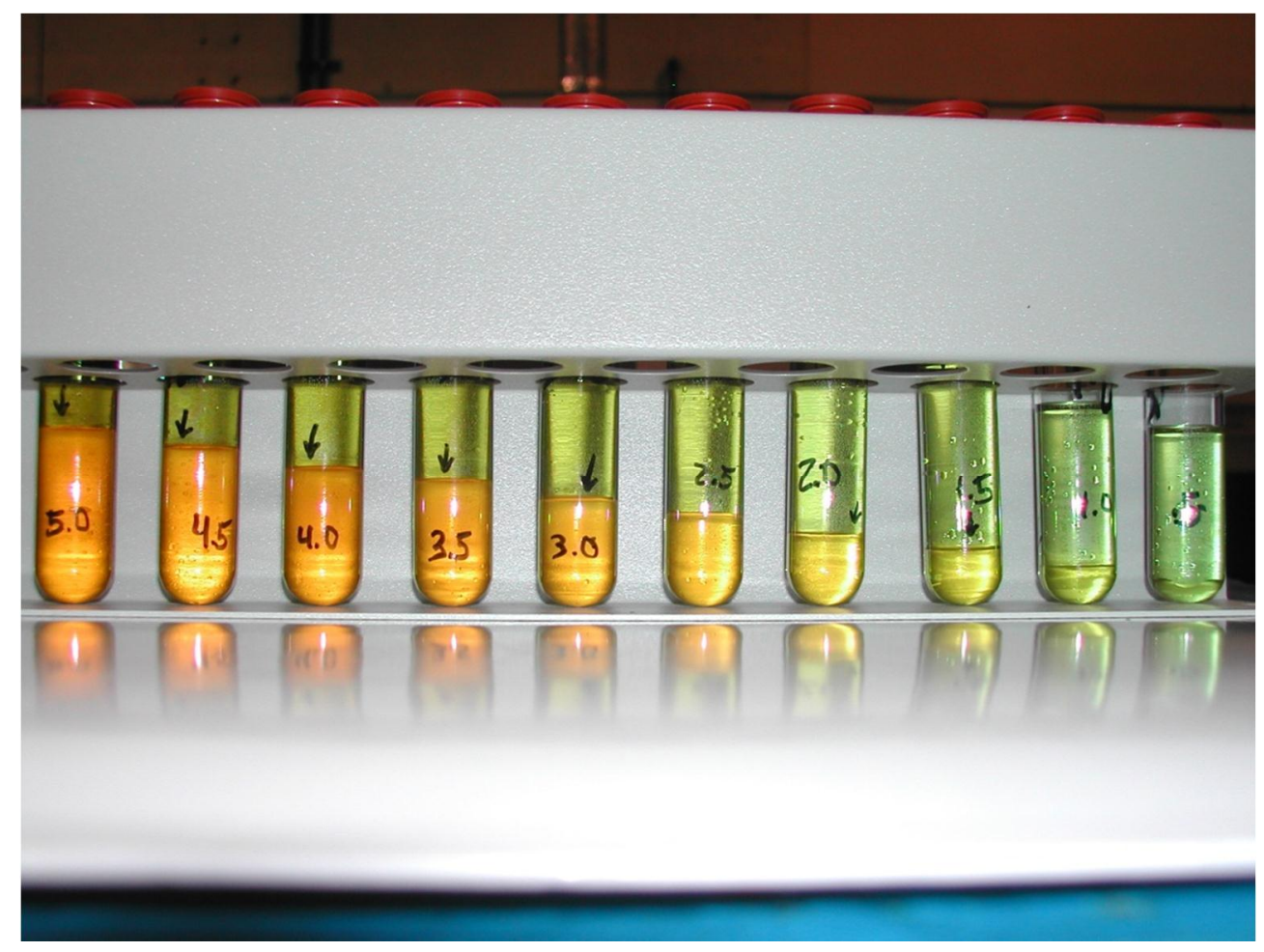

Figure 148 . Oil solubility test with $5 \mathrm{~mL}$ cleaning solution.

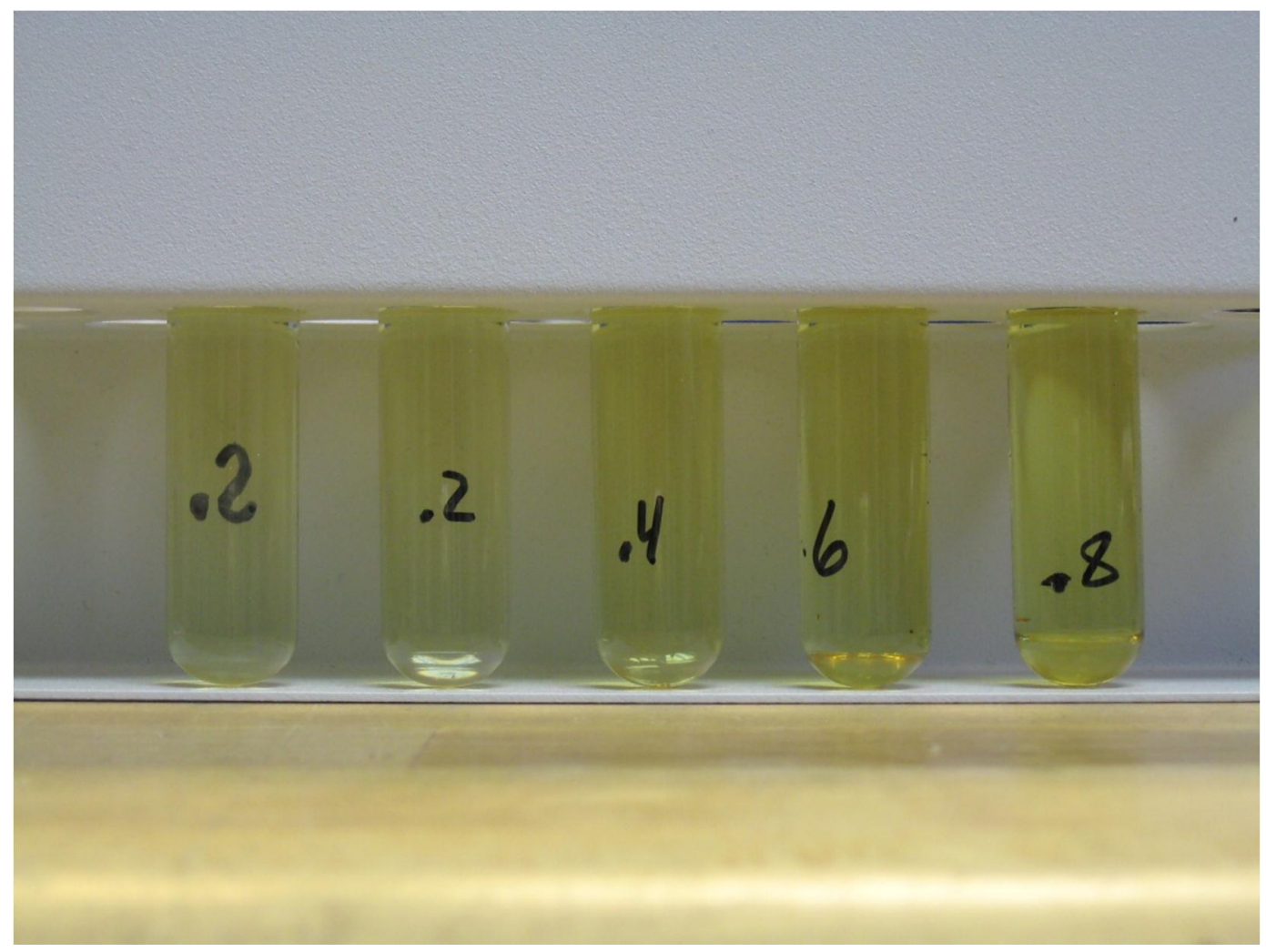

Figure 149. Oil solubility test with $10 \mathrm{~mL}$ cleaning solution. 
Testing was initiated to determine the effect of treating cleaned steel with caustic soda to inhibit rust formation.

Clean Raschig rings were soaked in caustic soda solution (saturated solution of sodium hydroxide in water) for various times, rinsed with water, and allowed to air dry at room temperature. Half of the samples were also rinsed with isopropanol to displace the rinse water before drying. One set of samples was not soaked in the caustic soda solution as a control. The only rust observed after four weeks was that formed while drying from rinse water left on the samples.

The local climate is very dry, with indoor relative humidity normally lower than $25 \%$ in the winter, so a humidity enclosure was fabricated to accelerate rust formation. A stirred, saturated solution of ammonium sulfate is used in the enclosure to maintain relative humidity near $80 \%$. A photograph of the humidity enclosure with the Raschig ring samples is shown in Figure 150.

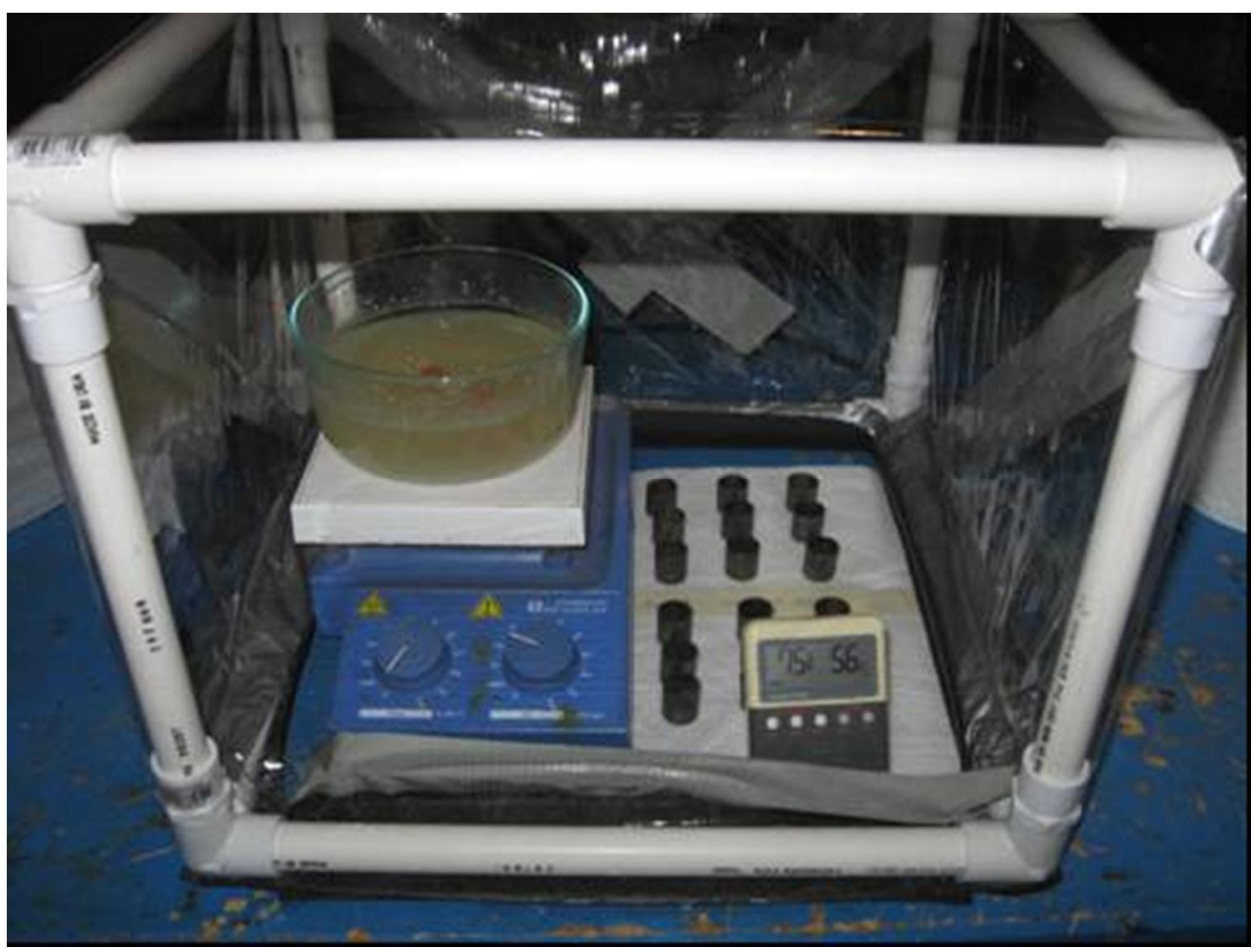

Figure 150. Humidity enclosure.

Figures 151a and 151b are photographs of the Raschig ring samples after one week in the humidity enclosure. In the middle of Figure 151a are the samples rinsed with water alone 
and in the middle of Figure $151 \mathrm{~b}$ are the samples rinsed with water followed by isopropanol. From left to right along the tape marker in both photographs, the columns of samples were soaked for 0,10 , and 60 minutes in the caustic soda solution. With the exception of the water-rinse-only, 0-minute samples, which have more rust than the others, there is no clear difference among the samples.

Figure 152 shows the Raschig ring samples after three weeks in the humidity enclosure. Although more rust formation has occurred, there again remains no clear difference among the samples aside from the water-rinse-only, 0-minute samples.

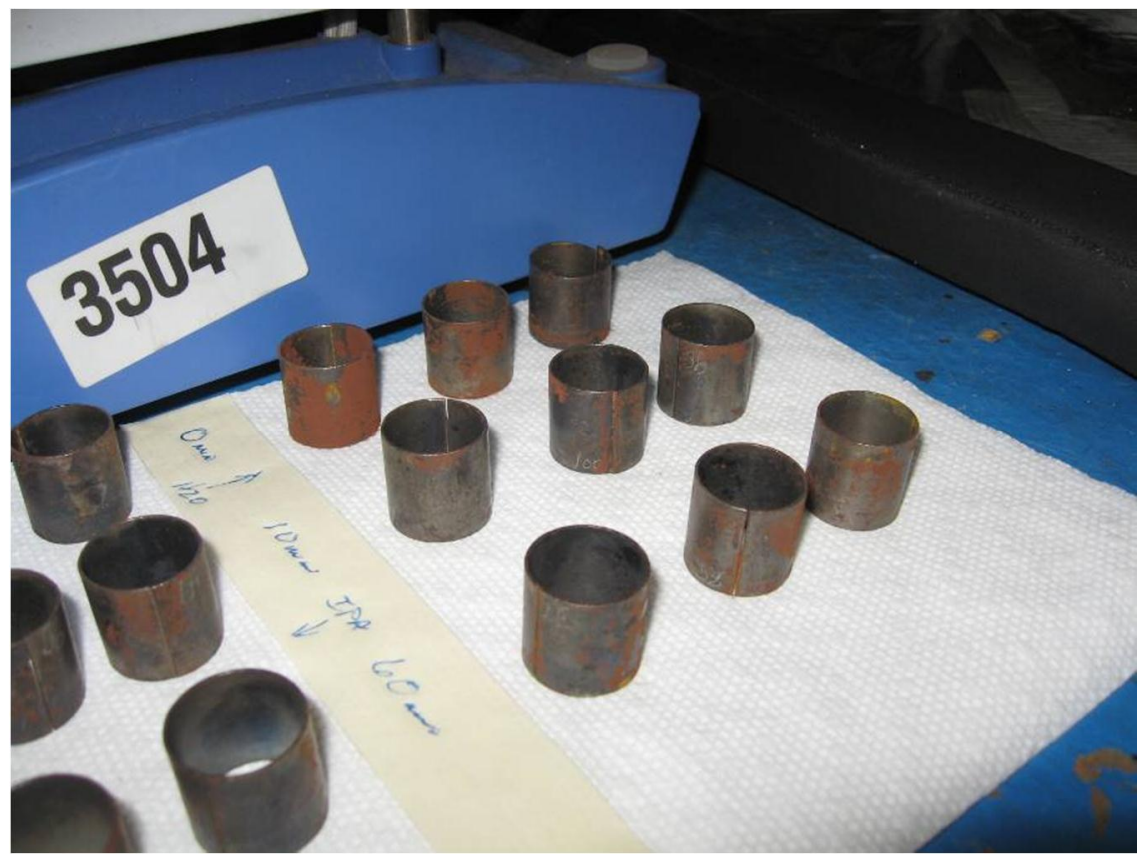

Figure 151a. After one week in humidity enclosure. 


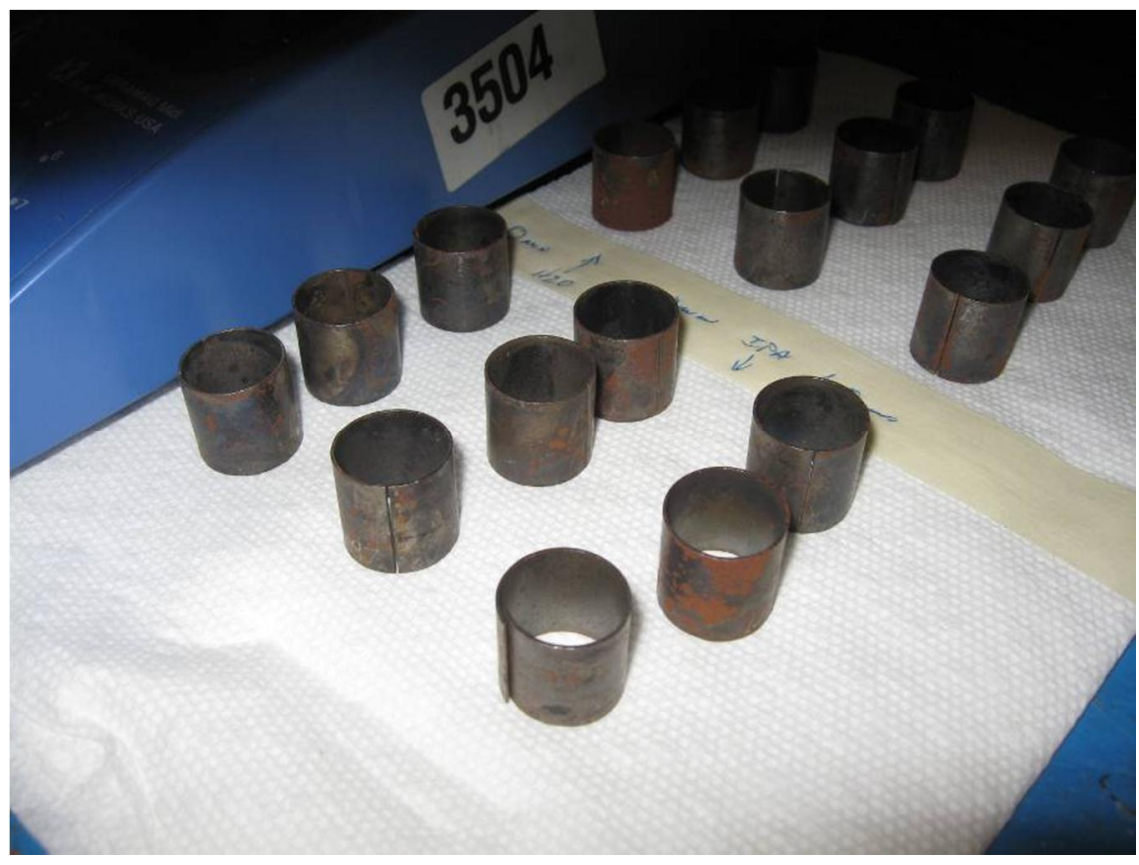

Figure 151b. After one week in humidity enclosure.

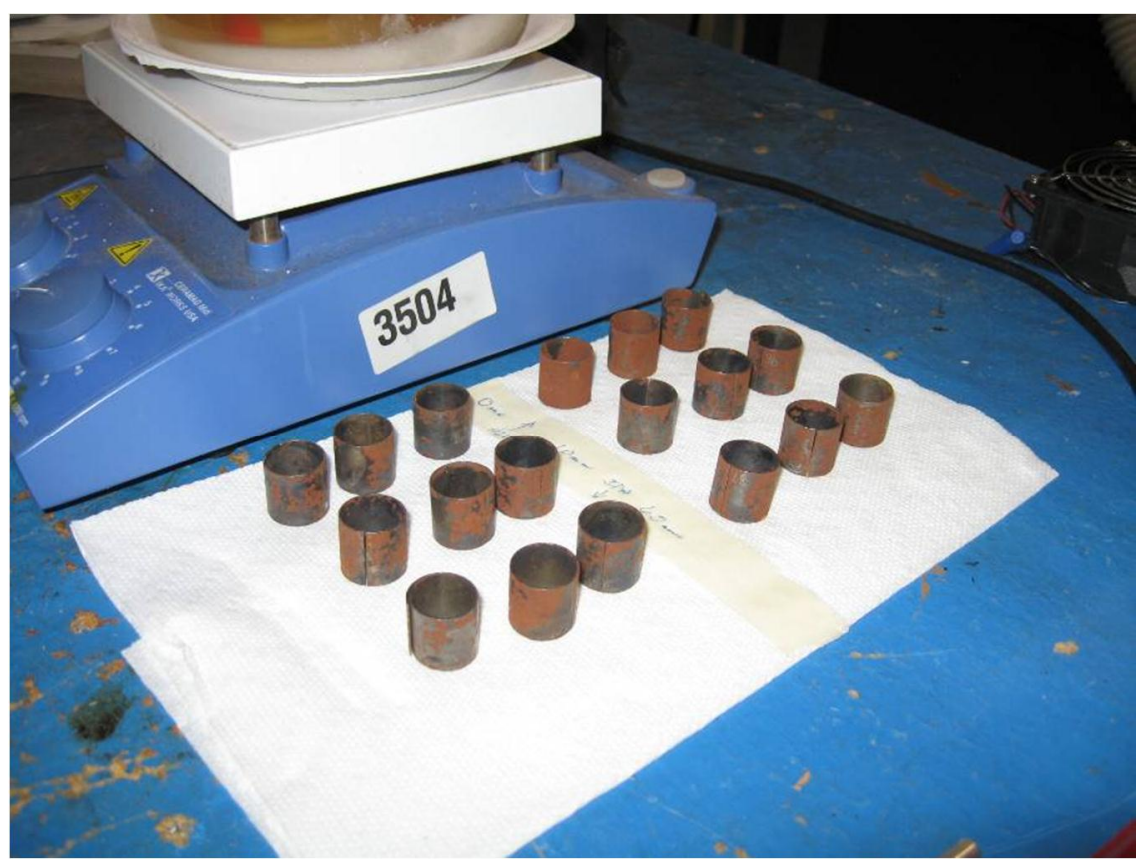

Figure 152. After three weeks in humidity enclosure. 
Based on these results, the passivation procedure may not be very effective. However, what was very effective for shelf life was to remove the droplets of water after cleaning using isopropal alcohol.

\section{$\underline{\text { Documentation }}$}

Rocky Research has documented the design of all the major developments related to the aqua-ammonia units built under this project. The documentation includes solid models and two dimensional drawings. Some of these are suitable for production drawings while others offer a good first step towards being production quality.

Rocky has also developed a bill of materials for the systems that are more production oriented. While these may require updates as a system moves to production, they are a good first step towards material and manufacturing cost estimation.

\section{Task 11. Application to Reciprocating Engines (Aqua-Ammonia Absorption}

\section{Technology)}

\section{Generator Design Issues}

Under this task, the integration of an aqua-ammonia absorption system with waste heat firing from a reciprocating engine was addressed. The aqua-ammonia chiller was designed, built, laboratory tested and then field tested. Field testing was done in conjunction with General Electricố Research Division, which received a subcontract for the field integration of the chiller with a Jenbacher $1 \mathrm{MW}$ engine, including the instrumentation and data acquisition.

One of the first issues to be addressed was the integration of the chillerô firetube with the engine exhaust, which is expected to be at between $800^{\circ} \mathrm{F}$ and $1000^{\circ} \mathrm{F}$ with a low allowable back pressure (40 in. wc maximum).

An apparatus to allow flue side pressure drop testing of the generator as a function of air flow rate was built. Also, a separate apparatus was designed and built to allow heating of hot air to near reciprocating engine exhaust conditions $\left(800^{\circ} \mathrm{F}\right)$ at volumes commensurate with requirements of the chiller. This function is intended to be added to the test chamber to allow hot air firing of the chiller under varying ambient (outdoor) air conditions. 
Testing was done to determine the pressure drop testing of the generator firetube under ambient temperature conditions. These tests were intended to allow the measurement of pressure drop for screening purposes as a precursor to testing at elevated temperatures in the test chamber. The reduced test results are shown in Figure 153, which is a plot of pressure drop as a function of mass flow rate of air. The tests were conducted on a generator with the original corrugated fins and the generator with longitudinal fins which had been welded in place. As the figure shows, at the design point of $644 \mathrm{lbm} / \mathrm{hr}$ of air flow, the pressure drop is in the range of 35 to 38 in WC.

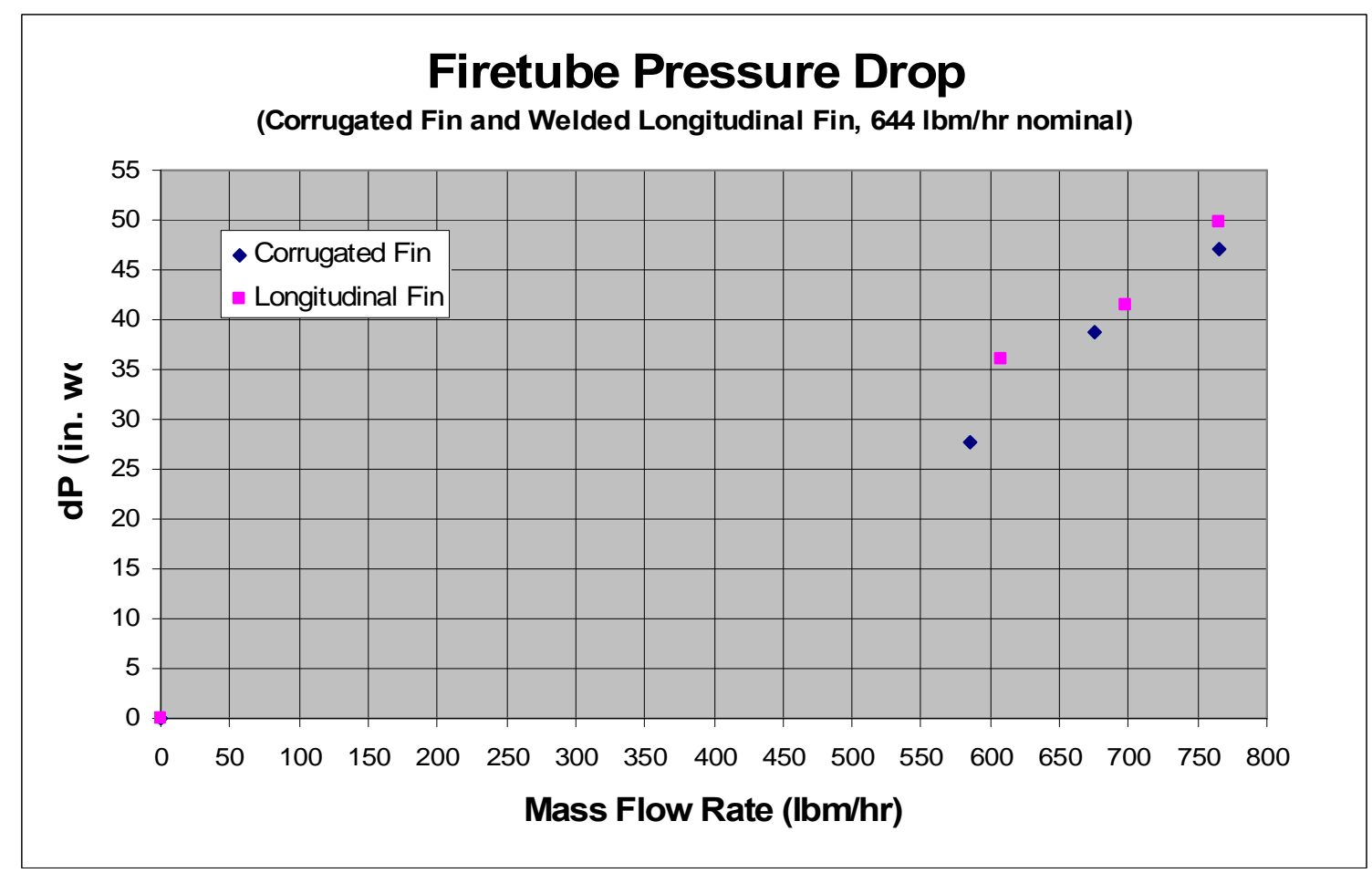

Figure 153. Firetube Pressure Drop Test Results

The performance of a 10 fin row firetube design and an alternative 5 fin row firetube was investigated for application to the exhaust of the Jenbacher engine. This was done using Solidworks and the Floworks FEA/CFD modeling.

Figure 154 is an example of the results indicated for the original firetube. The plot shows the temperature distribution in the firetube and fins for an exhaust flow rate of $750 \mathrm{lbm} / \mathrm{hr}$ and an inlet temperature of $800^{\circ} \mathrm{F}$. 


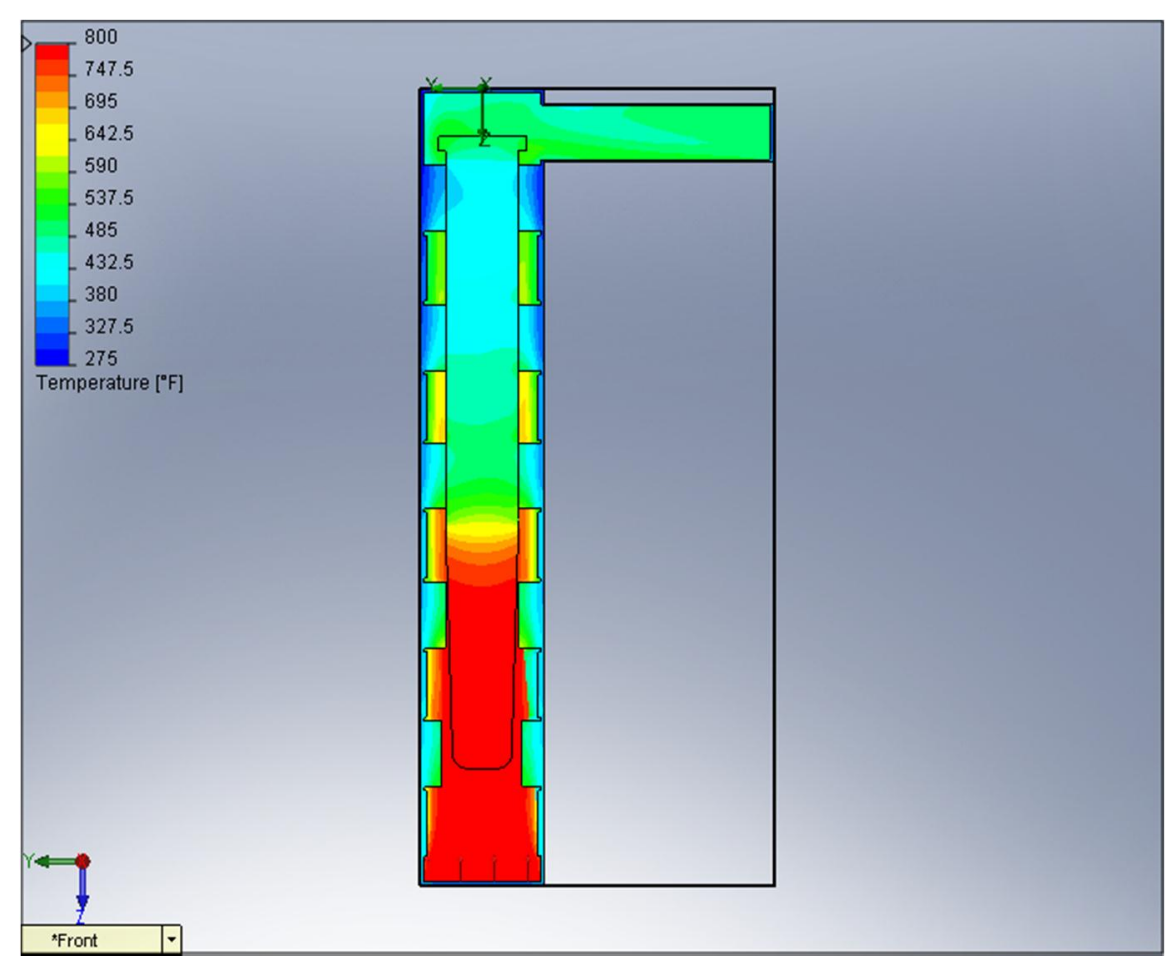

Figure 154. Representative Temperature Profile for Firetube

The corresponding velocity profile is shown on Figure 155 . Note that the velocity profile only shows the gas passages while the temperature profile shows both the gas and the solids.

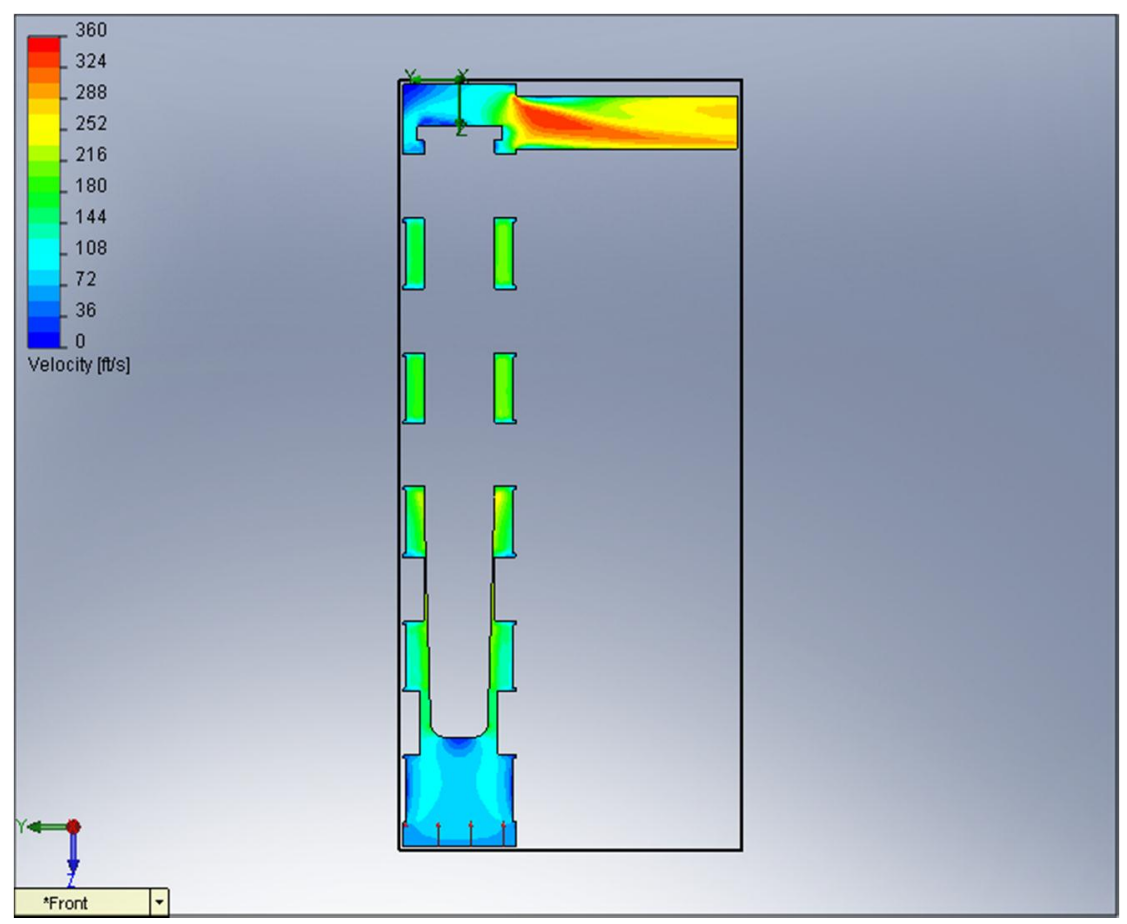

Figure 155. Representative Velocity Profile for Firetube 
The Floworks model also outputs tabulated values for heat transfer and pressure drop. These results were plotted for both the original 10 row staggered fin design as well as a 5 row staggered fin design, which was expected to provide lower pressure drop.

Figure 156 shows the heat transfer rate as a function of the mass flow rate of engine exhaust at $800^{\circ} \mathrm{F}$. As the figure shows, the 10 row (original) staggered pattern is capable of providing more heat to the generator at a given flow rate. This is because the staggering tends to break up the boundary layer, thereby enhancing heat transfer.

However, when the heat transfer rate is plotted as a function of the difference between the total pressure entering the generator and the ambient (static) pressure, as shown in Figure 157 , the plots are very similar. The result of this exercise is that for an allowable total pressure of $40 \mathrm{in} \mathrm{wc}$ at the inlet to the firetube, a heat transfer rate of 58,200 Btu/hr is possible. If the 10 row fin design is utilized, only $797 \mathrm{lbm} / \mathrm{hr}$ of flow rate is required, which is approximately $100 \mathrm{lbm} / \mathrm{hr}$ less than if the 5 row pattern is utilized.

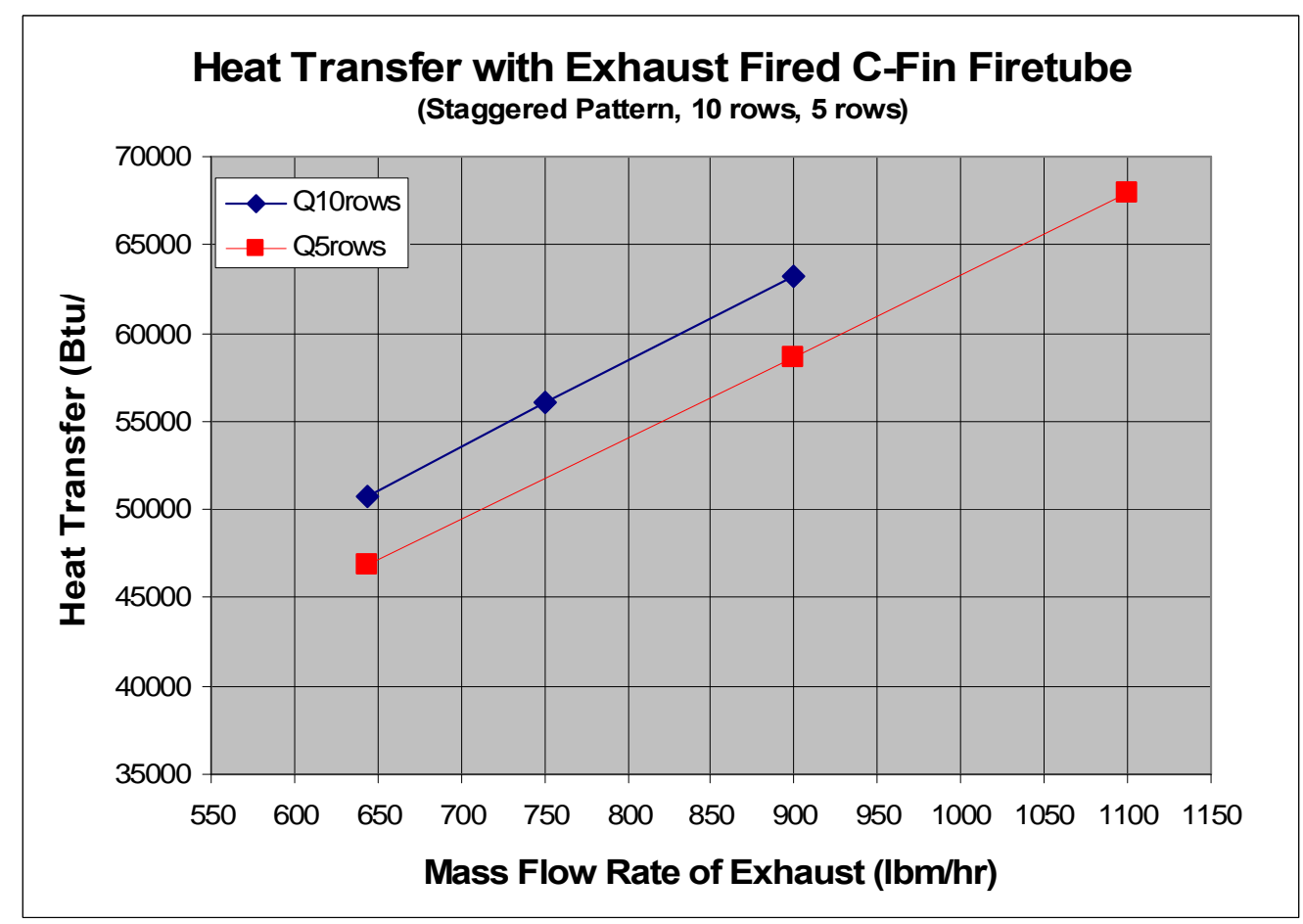

Figure 156. Heat Transfer as a Function of Mass Flow Rate for Two Fin Patterns 


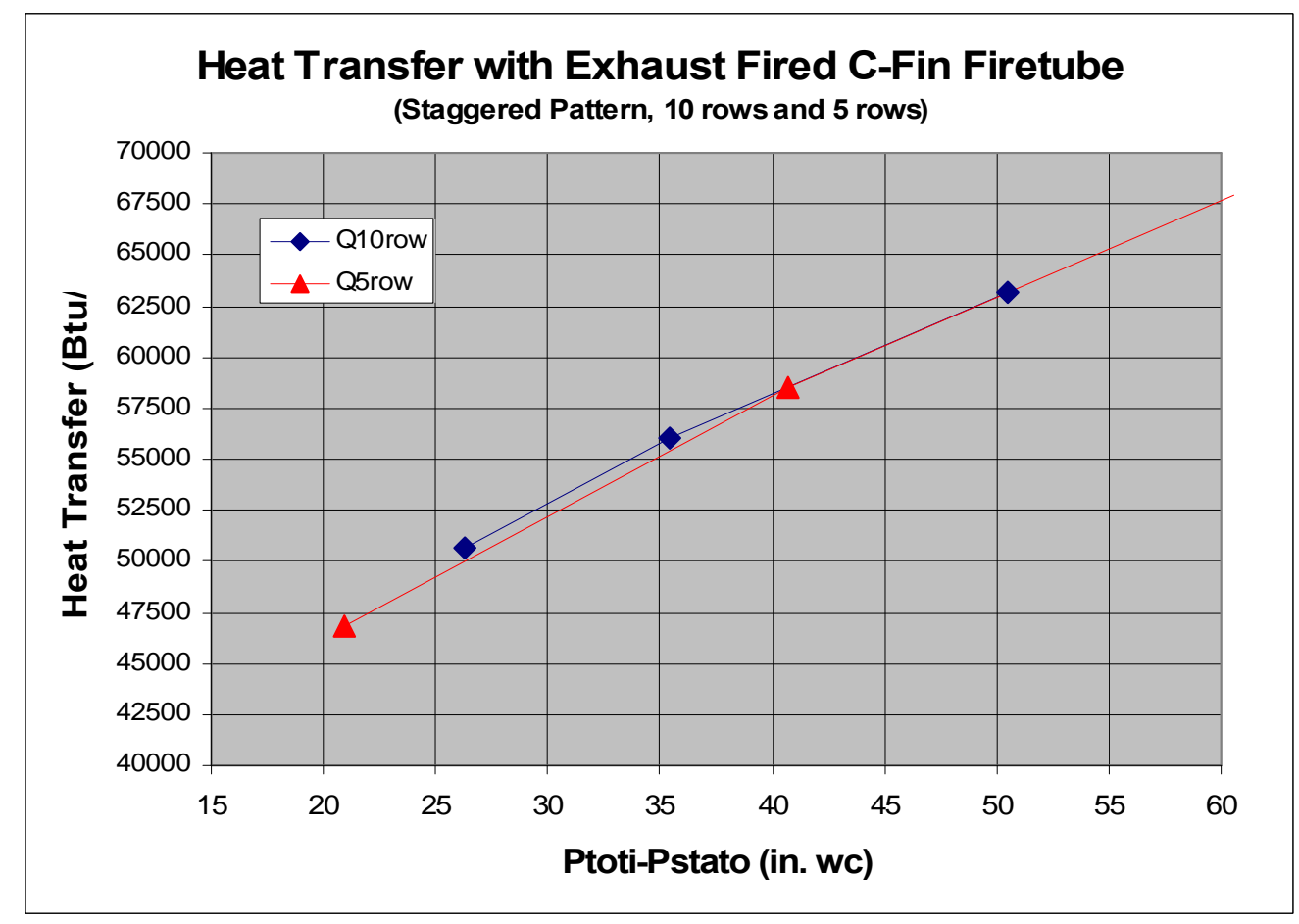

Figure 157. Heat Transfer as a Function of Pressure Difference for Two Fin Patterns

Based on this result, it was decided to proceed with the 10 row design for this application. Another practical benefit of this is that since this is the same fin pattern used in natural gas combustion applications, there will be a savings in production costs.

An analysis was performed to determine the possible heat transfer to the generator and the ensuing chiller capacity of the aqua-ammonia chiller when fired by the exhaust heat from a GE Jenbacher engine. The analysis was based on the CFD analysis that was reported last month in conjunction with performance information for a Beta chiller that was tested in the test chamber.

Figure 158 shows the ensuing chiller capacity as a function of ambient temperature. As the figure shows, due to the relatively low temperature of the exhaust gas along with the limitation of 40 in wc pressure drop, capacities will range between approximately 52,000 and 56,000 Btu/hr. However, detailed measurement of the performance at the engine at the installation may reveal higher exhaust temperatures which would increase this capacity. 


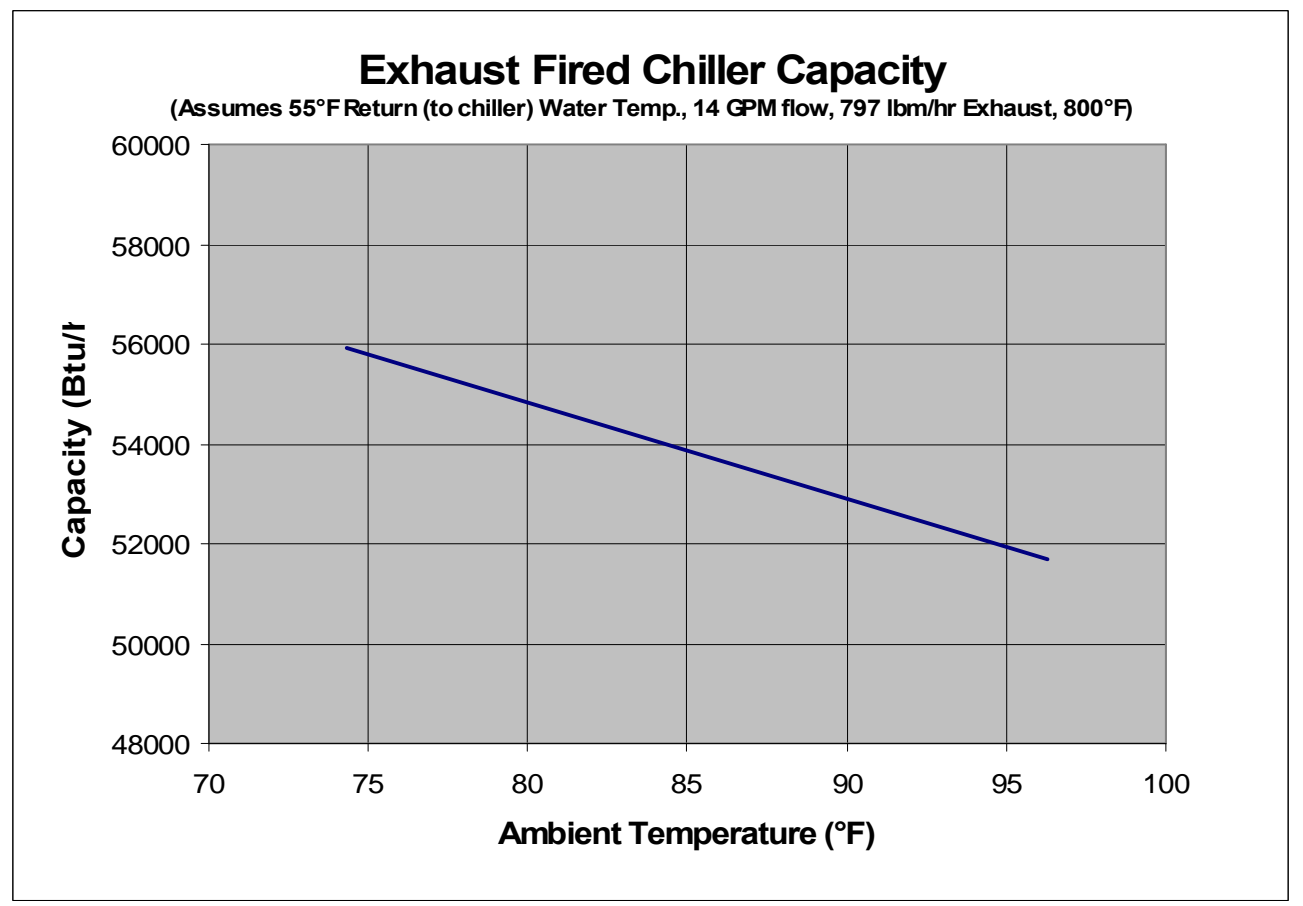

Figure 158. Exhaust Fired Chiller Capacity as a Function of Ambient Air Temperature

The corresponding thermal COP for the cycle is shown in Figure 159. As the figure indicates, over the range of conditions studied, the thermal COP will range between 0.89 and 0.96. It should be noted that at part load conditions, the thermal COP will increase above these levels.

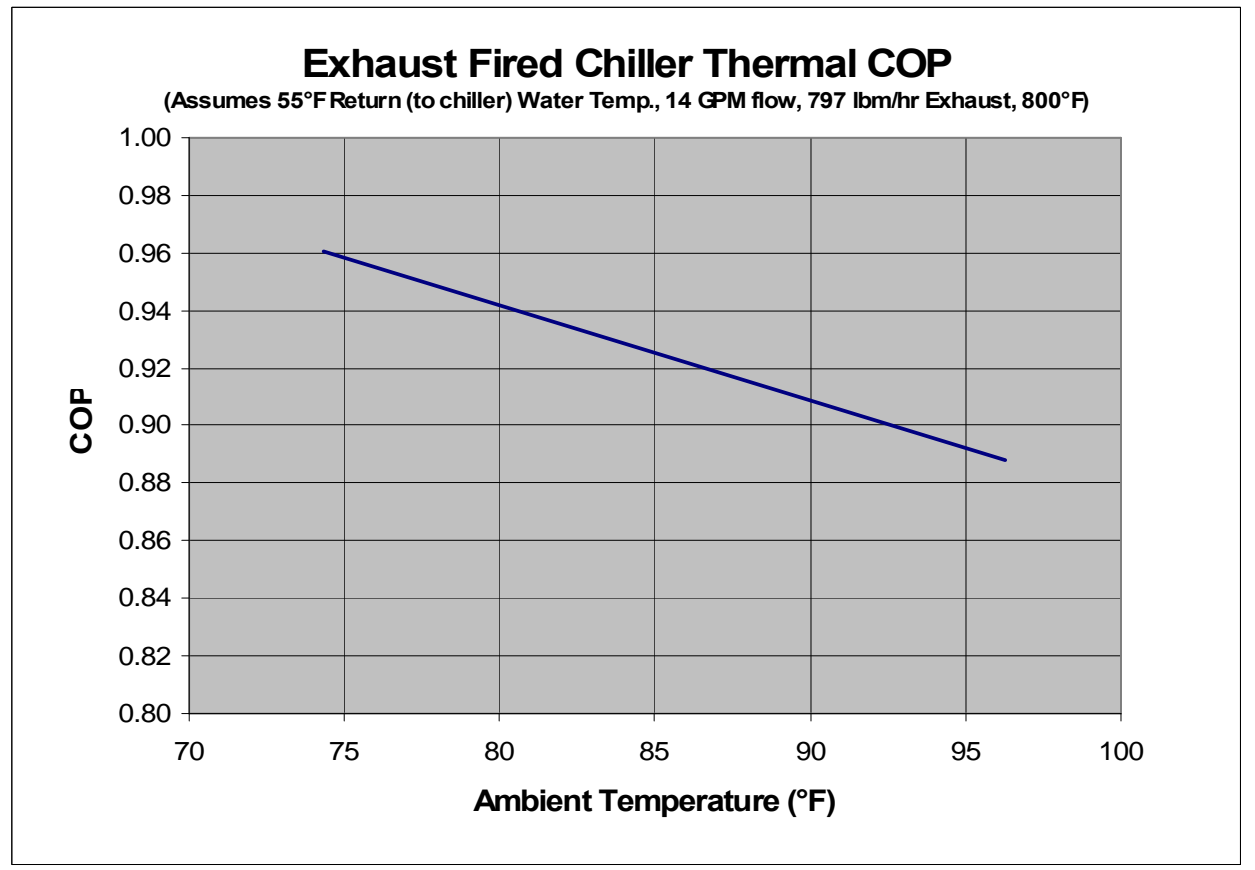

Figure 159. Exhaust Fired Chiller Thermal Capacity 


\section{Exhaust Fired Chiller Assembly}

A generator for the reciprocating engine application was completed. Figure 160 shows a photograph of this generator. It was installed in the hydronic test apparatus to determine its performance vs. a baseline. During this test period, it was fired using natural gas, for which a good baseline performance has been established.

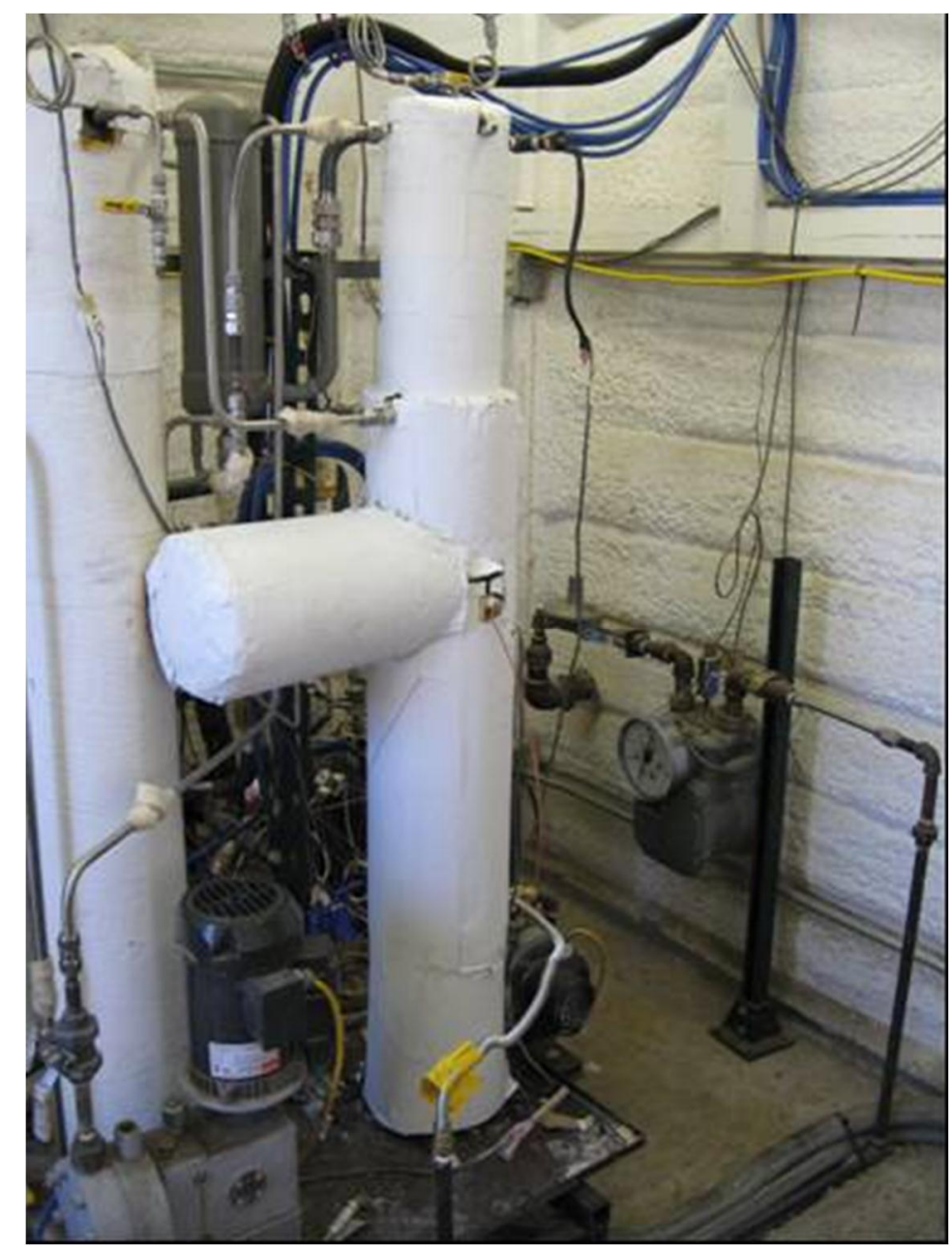

Figure 160. Generator for Exhaust Fired Chiller

Performance testing of the generator showed that the generator performed nominally when fired using natural gas.

The generator was installed in the exhaust heat fired chiller along with the absorber, rectifier, air coil and solution pump. A photograph of this during assembly is shown on Figure 161. 


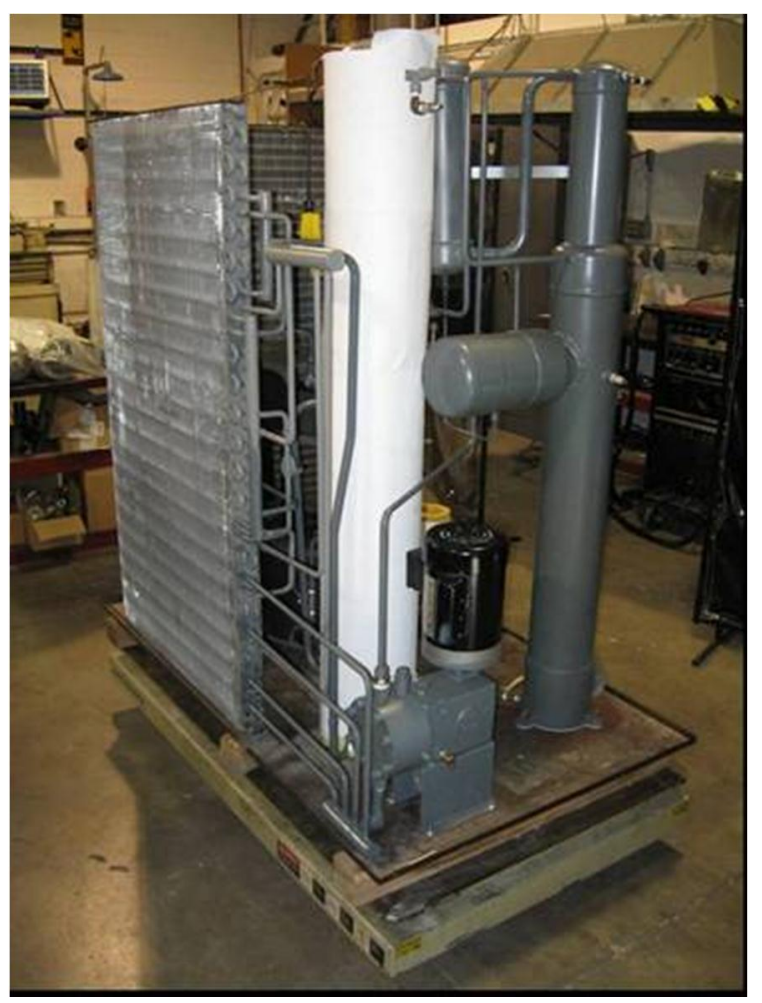

Figure 161. Photo Showing Status of Exhaust Heat Fired Chiller

Figure 162 shows a picture of the completed chiller installed in Rocky Researchôs test chamber.

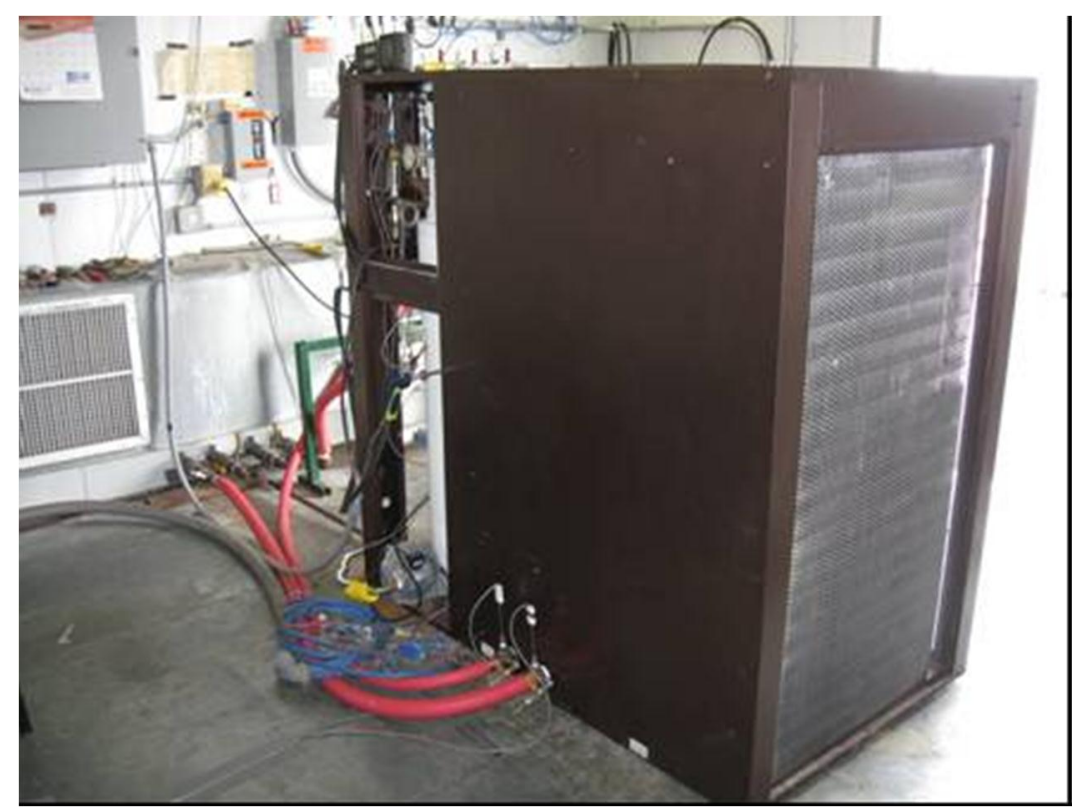

Figure 162. Exhaust Heat Fired Chiller 


\section{Laboratory Testing}

Initial testing of the chiller was done by firing with natural gas. Figure 163 shows the results of one of the tests, which was conducted at $75^{\circ} \mathrm{F}$ under reduced firing rate. The capacity and COP for this test were $54,030 \mathrm{Btu} / \mathrm{hr}$ at a COP of 0.706 . Because of the low ambient condition, the power requirement by the chiller was very low, only 534 Watts.

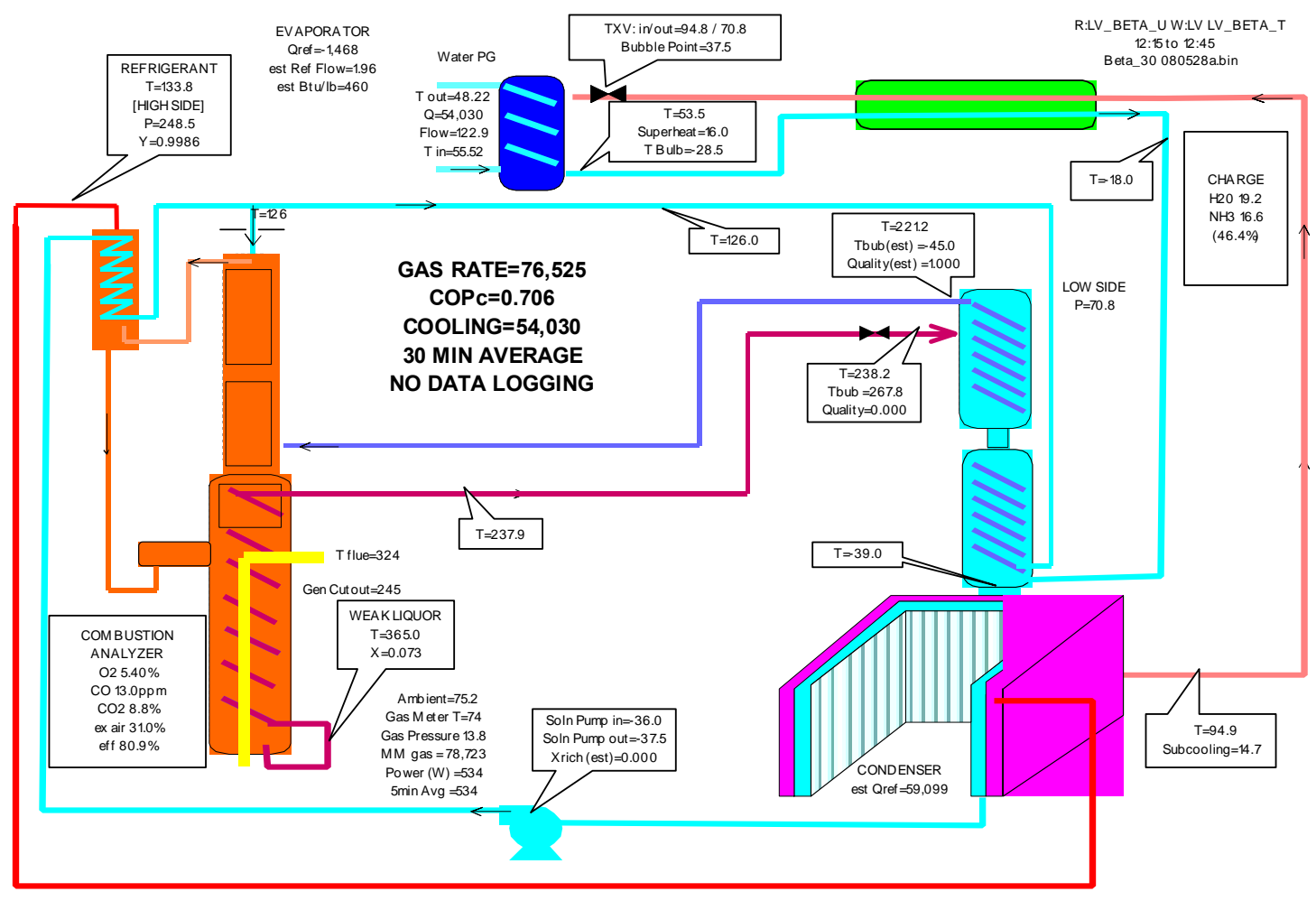

Figure 163. Operation of the Chiller with Firing by Natural Gas

For this initial testing, a gas burner blower was installed outside of the chiller. After baseline testing wa completed, the burner blower was removed and replaced with the connection hardware for exhaust gas firing.

Rocky worked closely with GE Global Research on installation issues for the field test with the Jenbacher engine. Mounting supports for the hot air valve were designed. Figure 164 shows a solid model of the valve with its supports. These support parts were fabricated and will be installed in the test chamber, and would later be installed at the field site. 


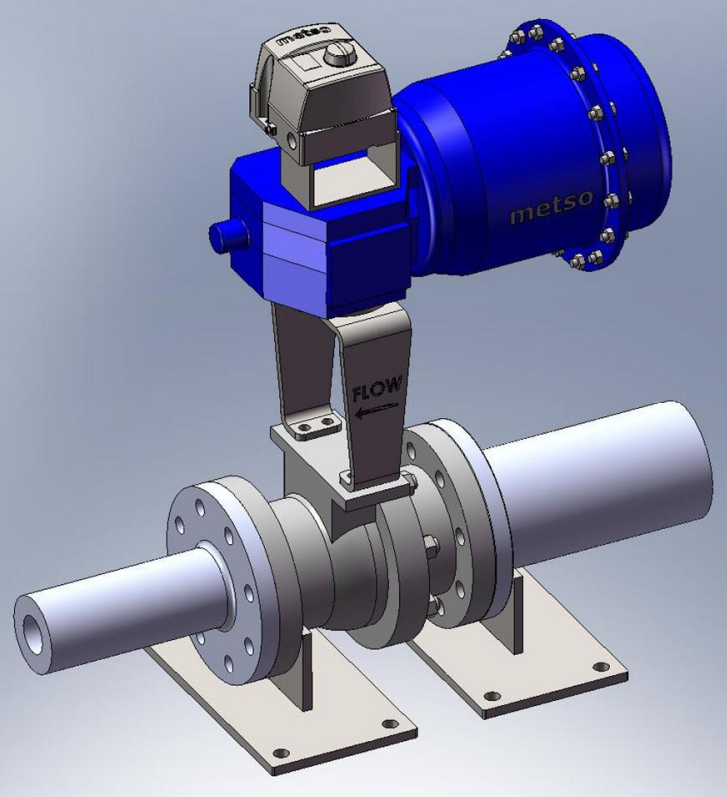

Figure 164. High Temperature Air Valve with Supports

Testing of the chiller for use with exhaust gas from a reciprocating engine was completed. Figure 165 is a photo of the chiller on test. The photo shows

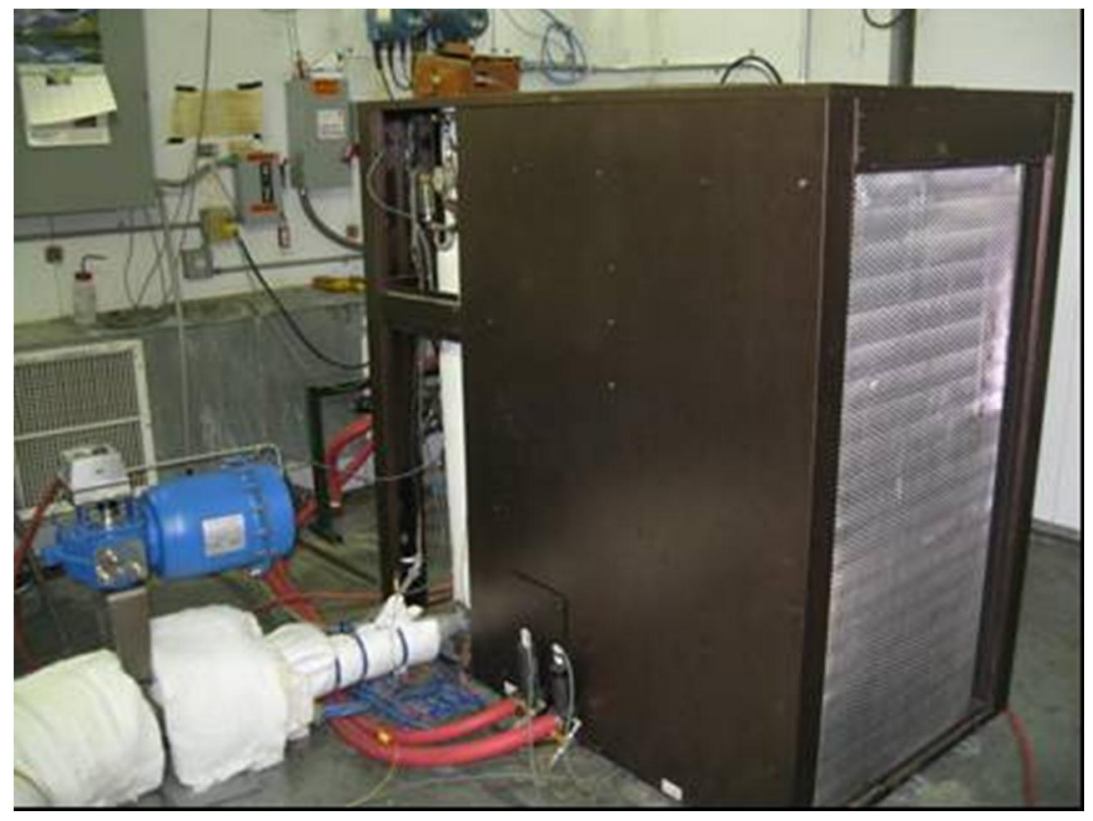

Figure 165. Exhaust Fired Chiller for Reciprocating Engine Applications 
the chiller along with the control valve (blue) for the inlet gas. The chiller is being ñfiredò with hot air. Although the specific heat of air is approximately $11 \%$ lower than the specific heat of engine combustion products, it was deemed acceptable for preliminary testing since installation of a gas engine solely for this testing was cost prohibitive.

Tests were conducted at three entering pressure levels (24, 32 and $40 \mathrm{in.} \mathrm{wc.),} \mathrm{two}$ entering temperatures $\left(650\right.$ and $\left.700^{\circ} \mathrm{F}\right)$ and three different ambient temperatures $(95,85$ and $75^{\circ} \mathrm{F}$ ). It should be noted that the pressure was measured upstream of the heater so it includes the heater pressure drop. However, since this pressure drop is fractions of an in. wc, it was deemed insignificant. The entering temperature was measured at the generator entrance. Because of maximum limitations of the heater $\left(932^{\circ} \mathrm{F}\right)$ and the temperature drop in the piping from the heater, we were not able to test the chiller at a temperature significantly higher than $700^{\circ} \mathrm{F}$. However, $700^{\circ} \mathrm{F}$ is likely to be close to the practical entering temperature at the test site.

Figure 166 shows the resultant mass flow rates of air as a function of inlet pressure for both hot air temperature levels. The mass flow rate of air is calculated based on the temperature rise across the heater, the heat input to the heater and the specific heat of air.

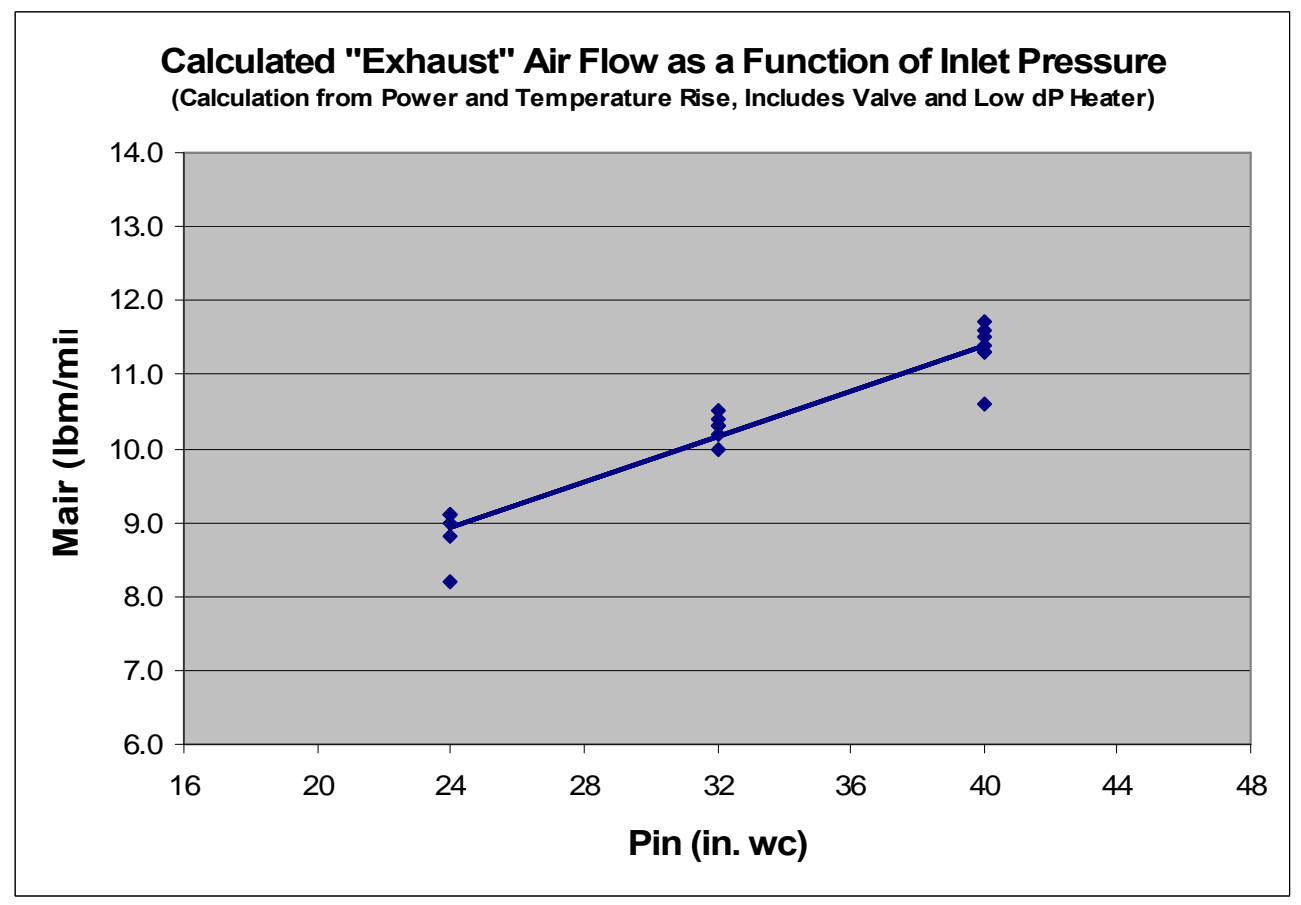

Figure 166. Calculated Air Flow as a Function of Inlet Pressure 
Results of testing are shown in Figures 167 to 169. Figure 167 shows the cooling capacity as a function of inlet pressure for two air temperatures and three ambient temperatures. All tests were conducted with $55^{\circ} \mathrm{F}$ entering chilled water temperature and $123 \mathrm{lbm} / \mathrm{min}$ (14.7 gpm) chilled water flow rate. The figure shows increasing capacity with increasing inlet pressure and temperature.

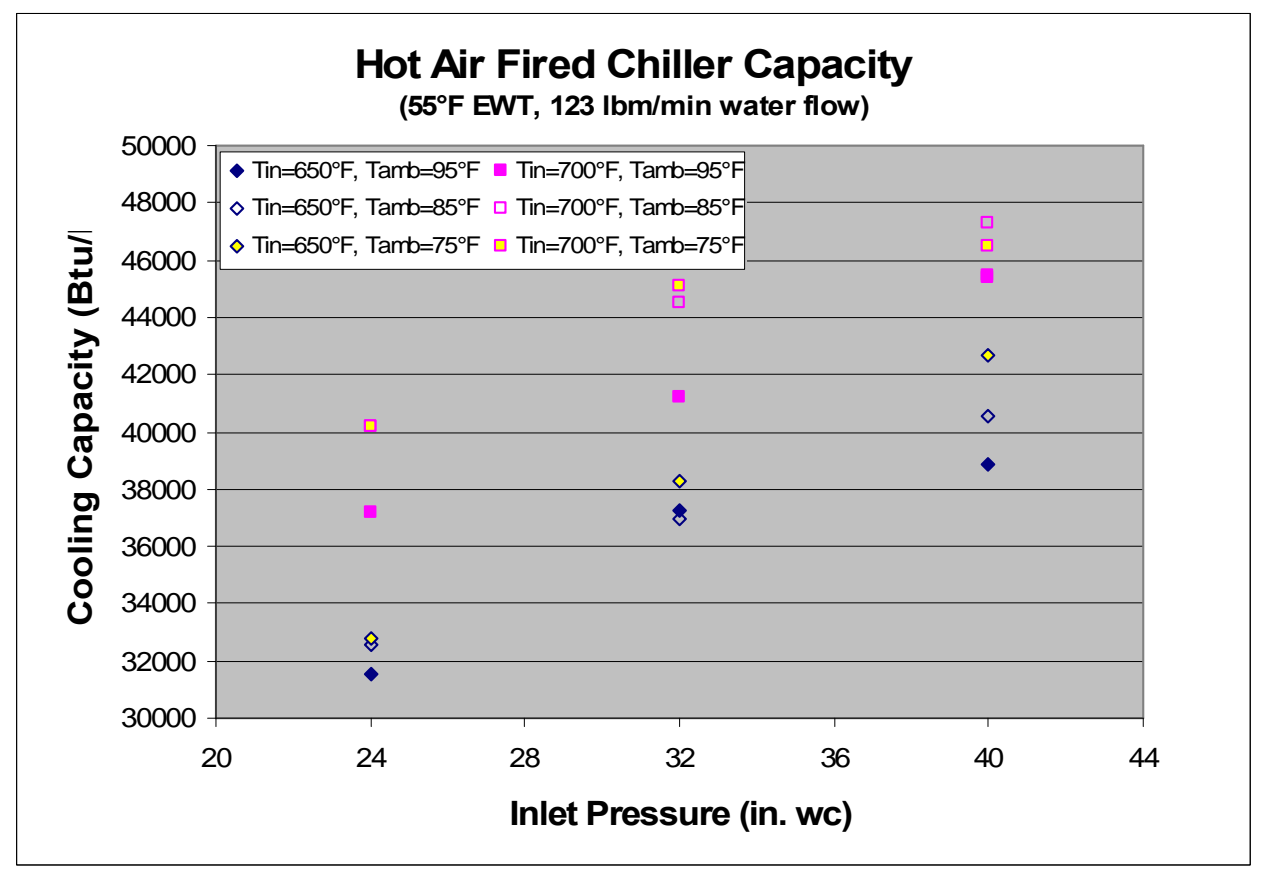

Figure 167. Chiller Capacity as a Function of Inlet Pressure, Ambient Temperature and Firing Temperature

Figure 168 shows the chiller COP as a function of inlet pressure. While there is some variability in $\mathrm{COP}$ with inlet pressure and firing temperature, the results show a very high $\mathrm{COP}$, in the range of 0.95 to 1.10 . 


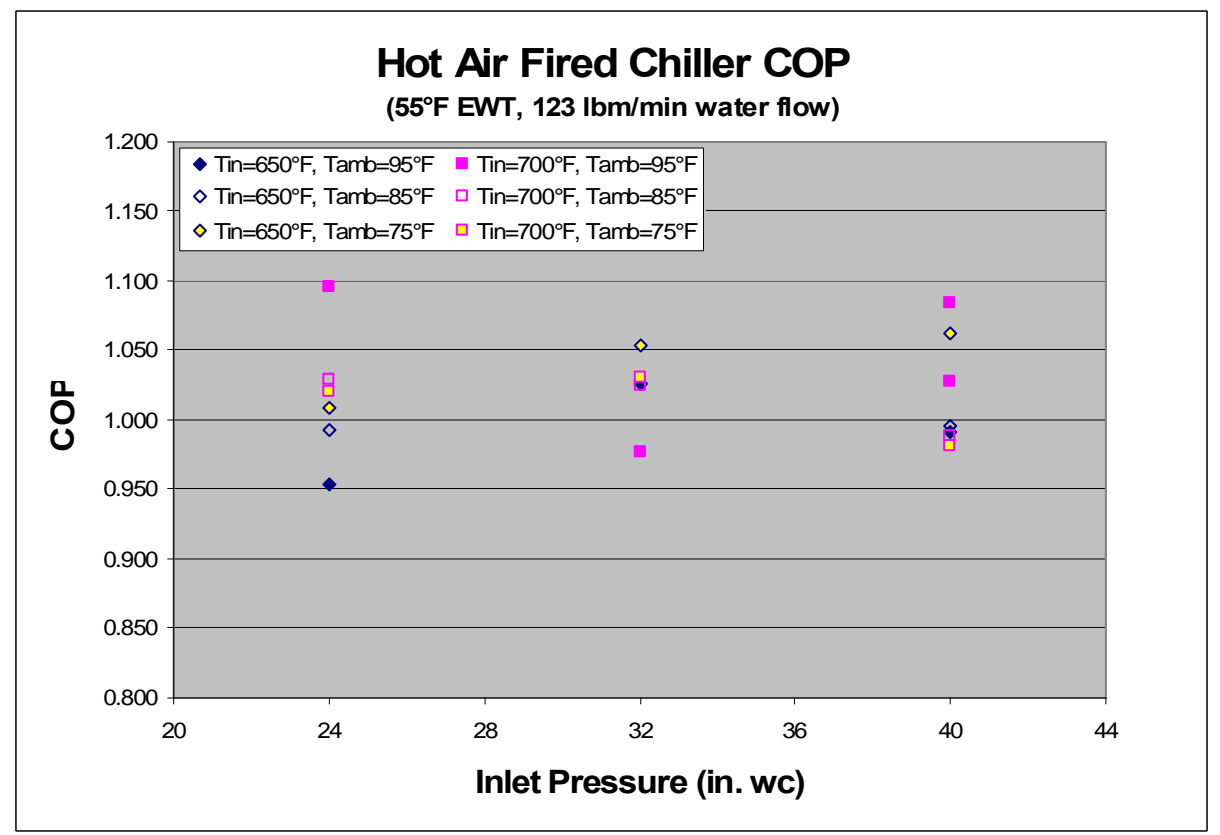

Figure 168. Chiller COP as a Function of Inlet Pressure, Ambient Temp. and Firing Temp.

Figure 169 shows the power consumption for this same set of data. As the figure shows, the power consumption is very low, with a maximum of $860 \mathrm{~W}$ for any of the test conditions.

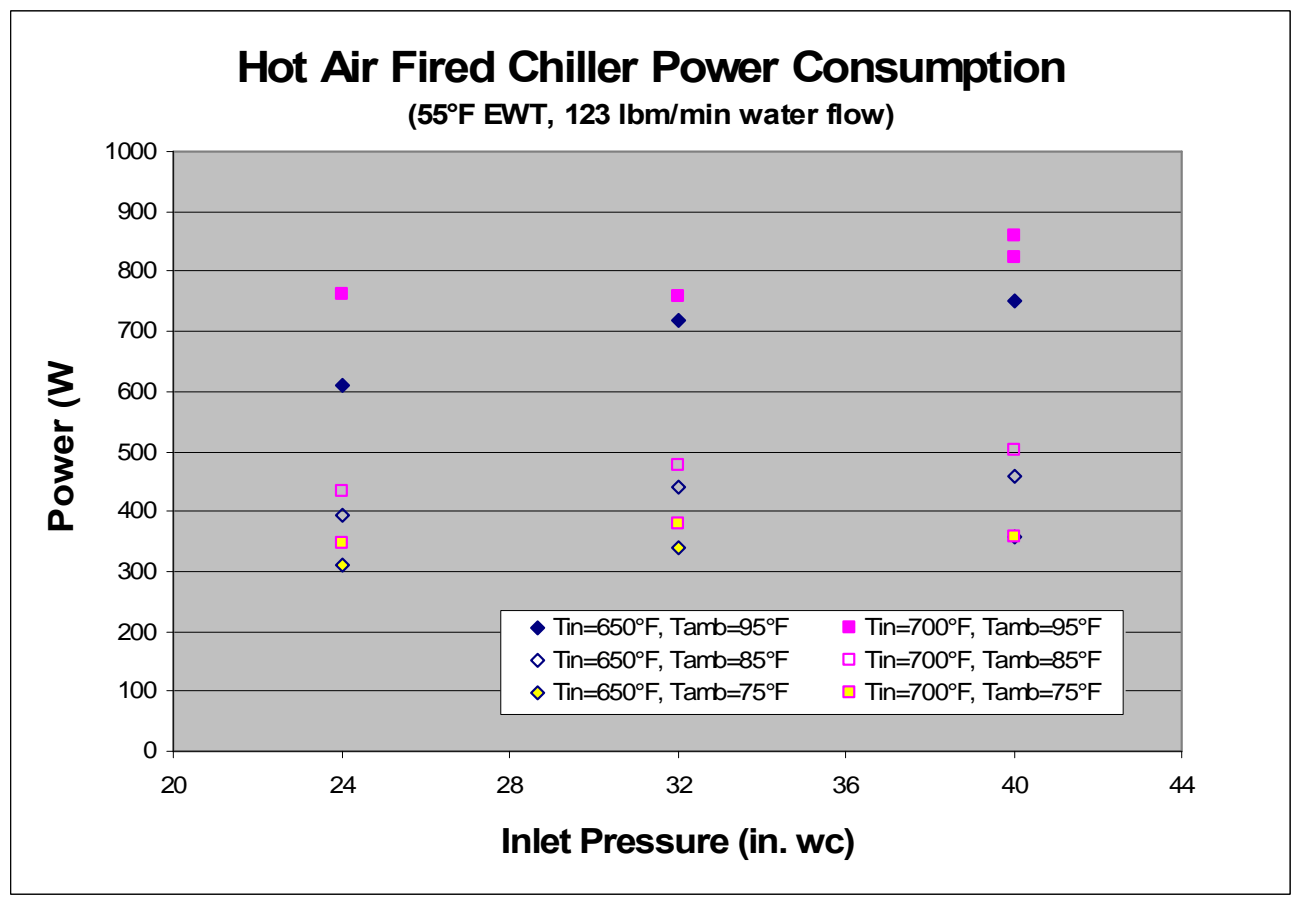

Figure 169. Power as a Function of Inlet Pressure, Ambient Temp. and Firing Temp. 
It should be noted that original estimates of performance anticipated a capacity of 52,000 $\mathrm{Btu} / \mathrm{hr}$ and a COP of 0.89 , but this estimate assumed a firing temperature of $800^{\circ} \mathrm{F}$ and a flow rate of $13.3 \mathrm{lbm} / \mathrm{min}$, which is $100^{\circ} \mathrm{F}$ hotter and $14 \%$ higher flow rate than any of the data taken. Based on these results, it is anticipated that the predicted performance can easily be exceeded if the higher flow rates and temperature are available. Furthermore, even at an inlet pressure of $40 \mathrm{in} \mathrm{wc}$, (with a corresponding flow rate of only 11.5 $\mathrm{lbm} / \mathrm{min}$ )., the predicted capacity and COP may likely be achieved if $800^{\circ} \mathrm{F}$ exhaust gas is available.

\section{Controls Testing}

The controls for the reciprocating engine application of the chiller have been demonstrated at various conditions. The condenser fan speed and solution flow algorithms have been active continuously during testing. Minor tuning adjustment measures have been carried out to maximize stability at both steady-state and transient response conditions.

The heat input algorithm, based on feedback control of chilled water temperature, is traditionally used to directly control combustion inducer / blower speed, which directly and conveniently translates to the quantity of natural gas being burned in the generator. This method has been comfortably established with stability and positive response for temperature maintenance. In the field installation, the heat source is instead hot engine exhaust gas, and so the blower speed signal is to be translated to an analog valvepositioning signal. An adapter board has been constructed which achieves this purpose, and the unit has demonstrated proper response to it. This adapter board showed some noise pickup, so a new version has been constructed which indeed appears to be quieter and more stable in present testing. After thorough testing, this new adapter version replaced the existing device in the chiller at the field installation site, in order to ensure steady, quiet operation.

\section{Field Testing}

In the field test application, the engine exhaust fired chiller was to use engine exhaust to produce cooling to pre-cool air to a $1 \mathrm{MW}$ GE Jenbacher engine/generator to produce increased power or higher efficiency. The Catawba County Landfill site uses landfill gas to power the engine/generator set. 
Much of the field test site preparation at the Catawba County Landfill in North Carolina were done by GEôs Research Division personnel. Their efforts involved piping of the exhaust, installation of the chilled water loop and heat exchanger

GE installed instrumentation for the field test system and wrote an EES based (Engineering Equation Solver) data reduction program to access data from their data acquisition system. GE personnel installed and calibrated all sensors.

The chiller and control valve were removed from Rocky Researchô test chamber and sent to the test site where they were installed, as shown on Figure 170. Rocky Research personnel were on site at the Catawba County Landfill in North Carolina for the initial startup of the chiller with its integration with a reciprocating engine.

Despite the lower than desired ambient temperatures, first test runs were performed to test the data acquisition system and the functionality of the chiller in September of 2008. First system startup worked without any major issues and the overall setup worked smoothly in conjunction with the Jenbacher engine.

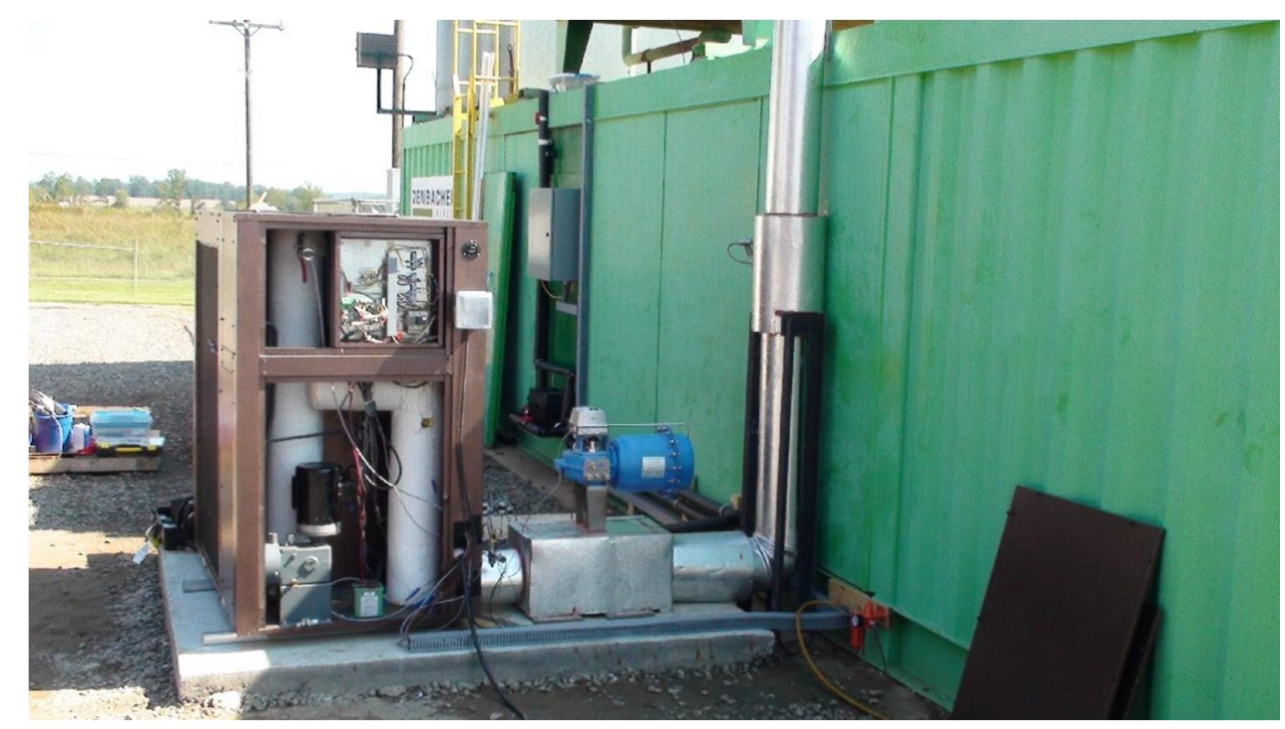

Figure 170. View of the exhaust Fired Absorption Chiller attached to the Engine Exhaust

The setup has been left in a manner that it does not interfere with required O\&M on the engine and will be quickly reassembled during the next test period. 
Although testing was limited in 2008, excellent test results were obtained on the day that test were conducted, September 18, 2008. Figure 171 shows the backpressure that was applied to the Jenbacher engine over the testing period. The values in blue represent the pressure drop between the exhaust and the ambient before the bypass, while the values in red represent the actual pressure drop though the chiller. There is some drift in the backpressure because of the mechanical means that was used to apply backpressure. This will be alleviated for the next tests.

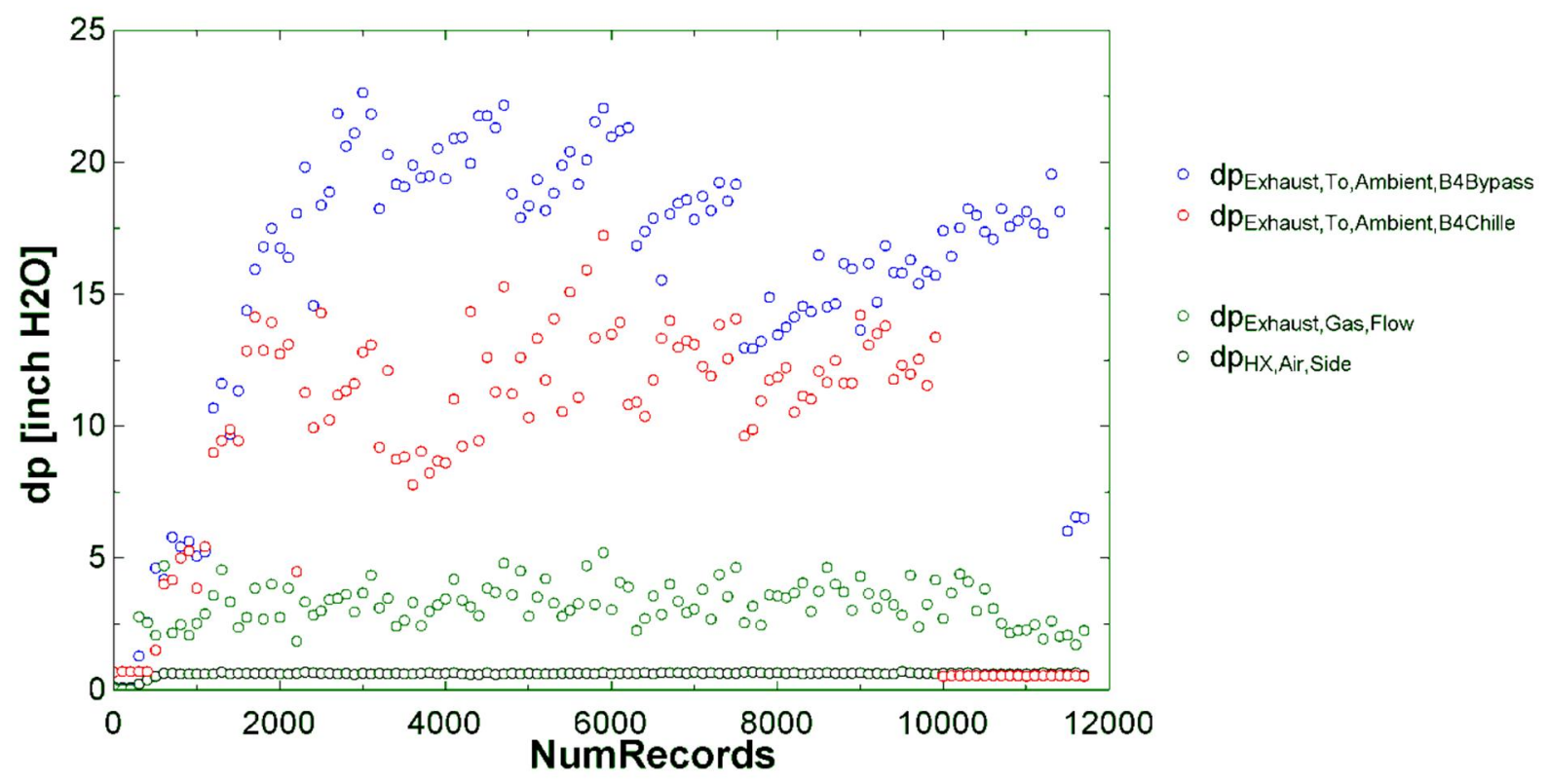

Figure 171. Engine Backpressure

The controlled testing period can be broken up into the following, with the corresponding backpressures.

- $\quad$ 1st Datapoint Time: 12:17-12:47, Engine Backpressure: 20"H2O, NumRecords: 3650-4549

- 2cnd Datapoint, Time: 13:05-13:35, Engine Backpressure: 18"H2O, NumRecords: 5096-5995

- 3rd Datapoint, Time: 13:51-14:21, Engine Backpressure: 16"H2O, NumRecords: 6478-7377

- 4th Datapoint, Time: 14:36-15:06, Engine Backpressure: 13"H2O, NumRecords: 7836-8735

- 5th Datapoint, Time: 15:14-15:44, Engine Backpressure: 16"H2O, NumRecords: 8952-9851

It should be noted that the engine backpressure without the chiller is 6" $\mathrm{H} 2 \mathrm{O}$. 
Figure 172 shows the ambient air temperature as well as inlet air temperatures measured at the chiller and the inlet to the radiator (cooling coil) used to precool the engine inlet air.

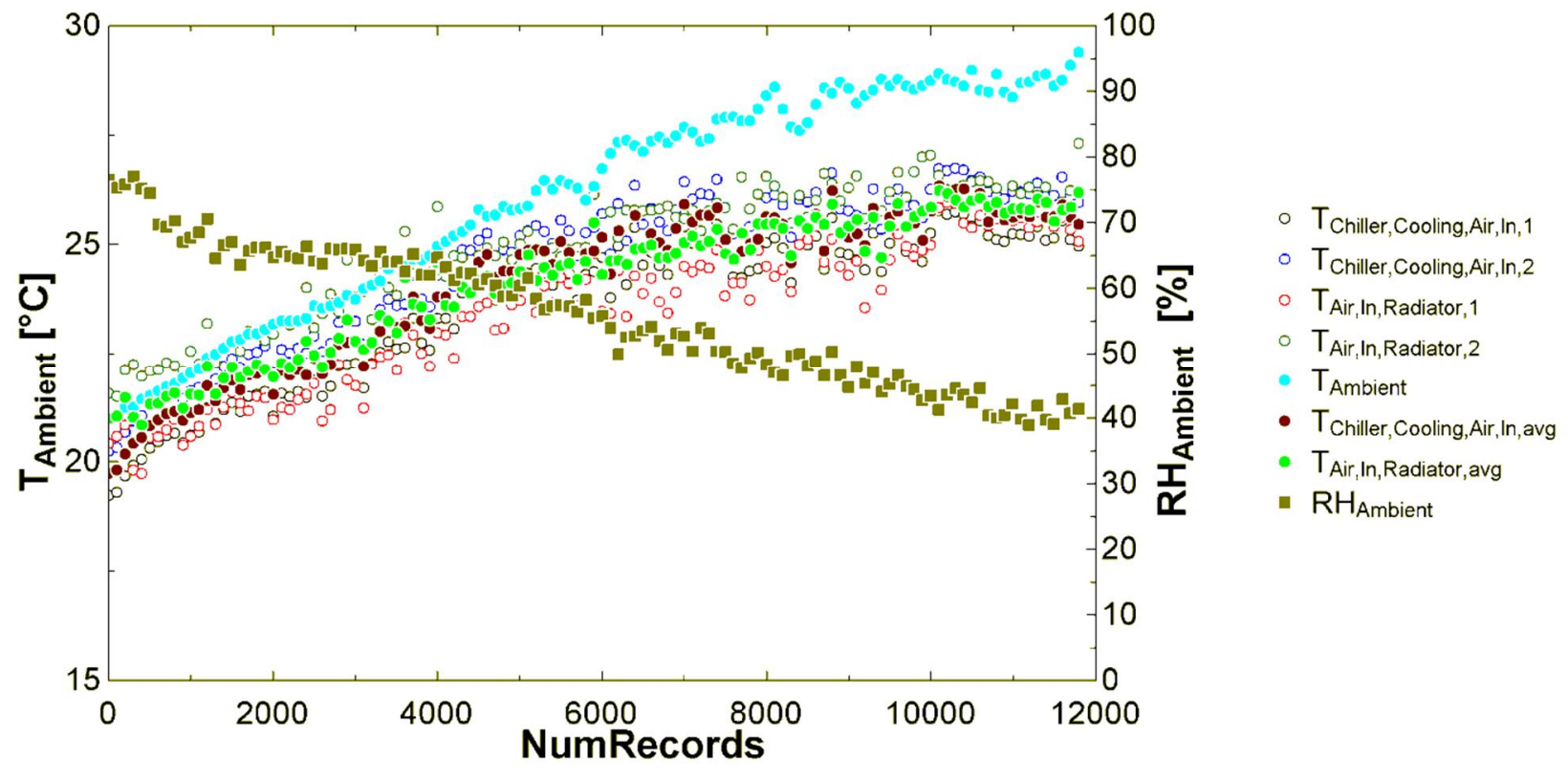

Figure 172. Air Temperatures During Testing

The outlet air temperatures from the engine inlet air cooling coil are shown in Figure 173. These measurements were made using a grid of thermocouples. The black dots represent the average values from this temperature grid. A comparison of this figure with the previous one shows that inlet air temperature drops of up to approximately $7^{\circ} \mathrm{C}\left(13^{\circ} \mathrm{F}\right)$ were obtained during some of the tests.

The tests were conducted with a chilled fluid flow rate of $12 \mathrm{gpm}$, which is lower that the rated flow rate of $14 \mathrm{gpm}$. However, even with this lower flow rate and backpressures that were lower than expected at the site, the chiller was able to obtain a capacity of up to $15 \mathrm{~kW}$ at the chiller, as shown in Figure 174. This figure shows the capacity as measured from the water flow at the chiller and at the heat exchanger radiator coil. It also shows the difference between these two values, at least part of which is due to line losses. 


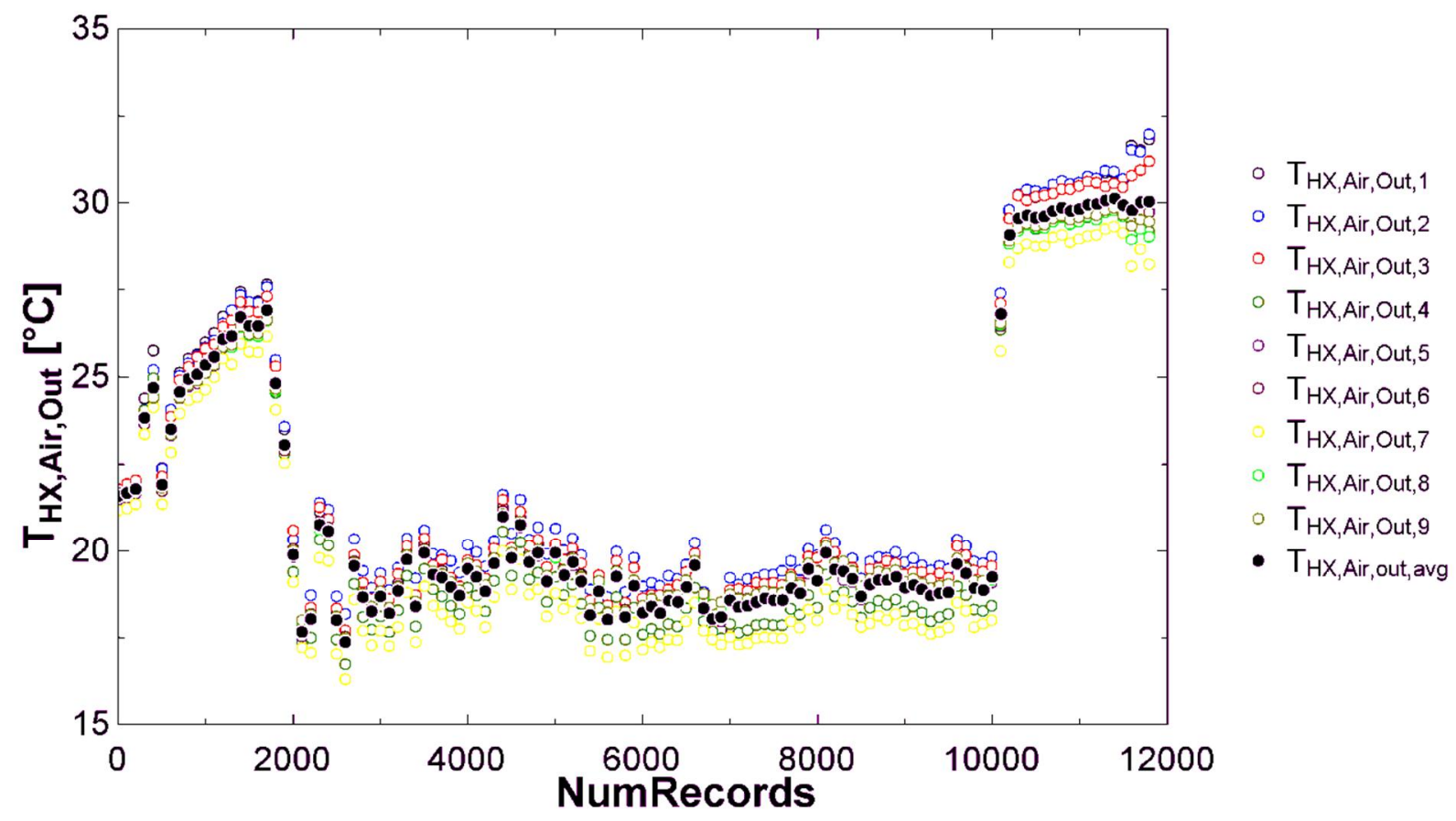

Figure 173. Chilled Water Temperatures

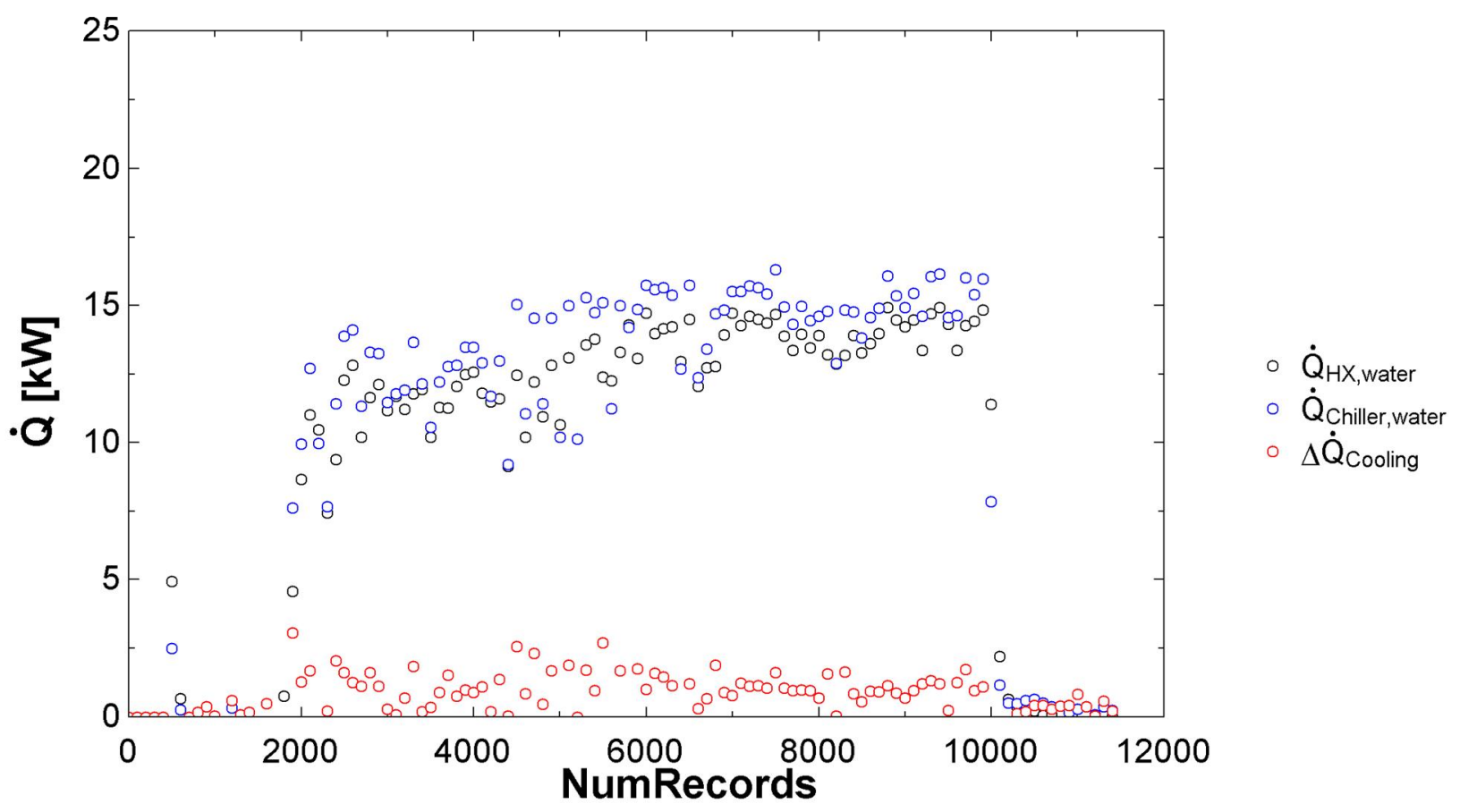

Figure 174. Exhaust Gas Fired Chiller Cooling Capacity 
Power consumption by the chiller was relatively low during these tests, with the average being in the 350 to $400 \mathrm{~W}$ range. Figure 175 shows all of the data during this test period. There is a large population of values near the $0.2 \mathrm{KW}$ level. It should be noted that these tests were conducted at ambient temperatures that represent a moderate ambient air temperature day.

Unfortunately, during these tests the flowmeter for the exhaust gas did not function properly. For this reason, the heat input to the chiller could not be determined and therefore plots of COP could not be generated.

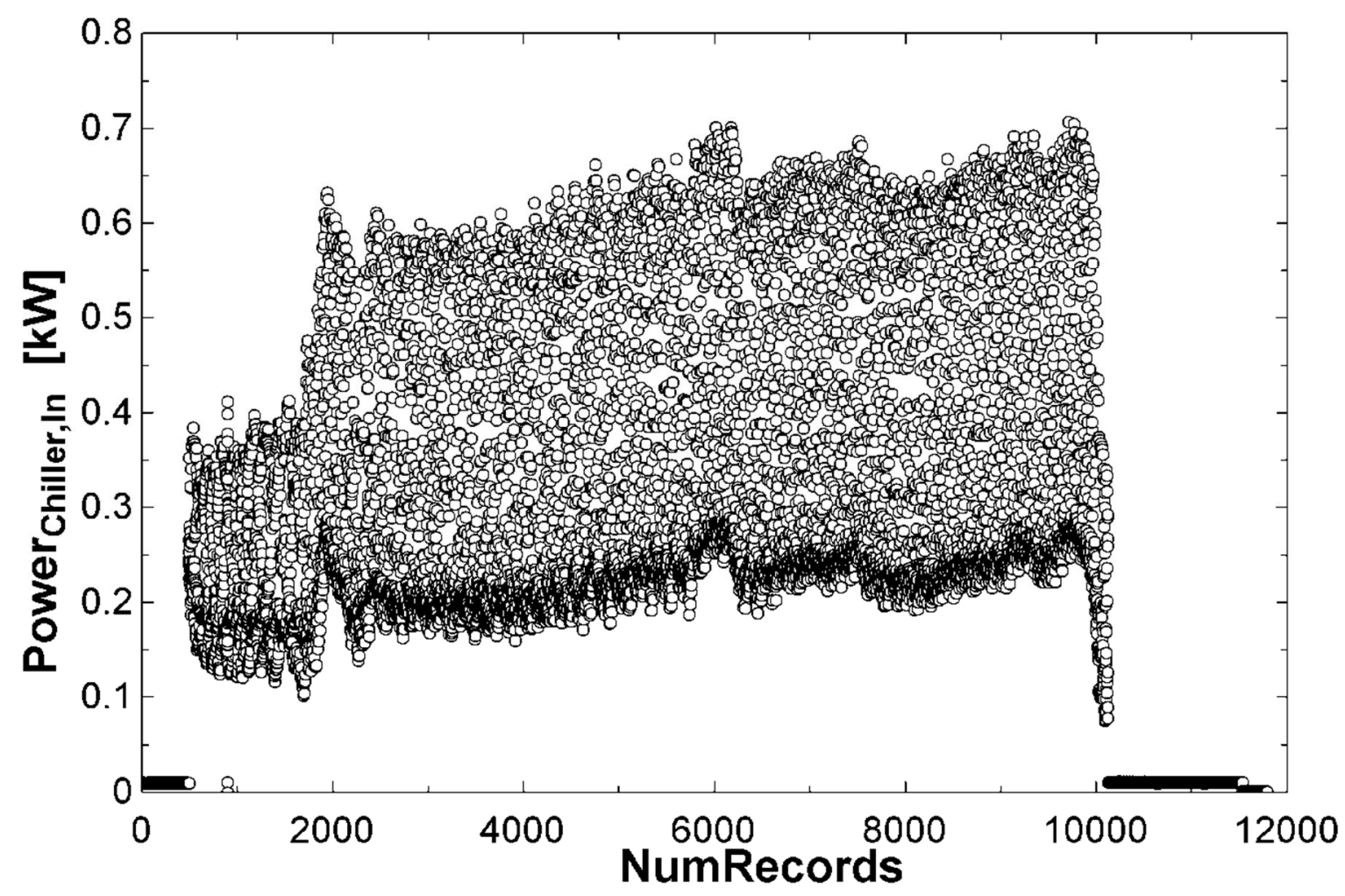

Figure 175. Chiller power consumption

These initial tests were very encouraging and both Rocky Research and GE looked forward to continuing testing when warmer weather returns at the host site in 2009.

At the beginning of May 2009 GE personnel visited the test site to inspect the test setup and ensured the conditions were nominal after the winter months. During this time period the complete engine block got exchanged, however, the operators had taken great care of not to damage our equipment. Necessary upgrades as a follow up to the shakedown test in 2008 were performed. Also at the time of our visit the radiator on the roof got exchanged 
against a larger unit. This helped with the heat rejection on the oil side, but has no impact on our experiment.

On August $6^{\text {th }}$ and $7^{\text {th }} 2009$, data points were taken to determine the impact of the chiller on the engine. During the test no issues were observed from the chiller during start-up and shutdown. Following the experiment (and confirmation of the quality of the data collected), the setup was disassembled and the hardware was shipped to Rocky Research. The test site in North Carolina has been returned into its original condition. The raw engine data has been sent off to GE Jenbacher and has been returned in a decrypted format for analysis.

GE Jenbacher completed their final report documenting the testing of the waste heat fired aqua-ammonia chiller at the Catawba County Landfill test site. The discussion of results and recommendations from this report are as follows:

A ammonia/water absorption chiller has been connected to a GE J320 engine. A fraction of the exhaust gas was used to produce chilled water. The chilled water was used to cool the inlet air of the engine. The chiller overall performed as expected. Initially there was some fine-tuning necessary to minimize the backpressure on the engine while maintaining at the same time the cooling capacity of the chiller. Due to the low ambient temperatures for the past 1.5 years it was no possible to collect data on the positive impact of inlet air cooling on the engine performance on a hot summer day. However, even with the backpressures tested and the additional pressure drop from the air inlet heat exchanger no significant deterioration in engine performance could be measured within the measurement accuracy.

In the test the chiller has shown a potential to decrease the chiller inlet temperature by 8$9^{\circ} \mathrm{C}$. Improved insulation on the chilled water loop should help to increase this temperature drop to $\sim 10^{\circ} \mathrm{C}$. At $41^{\circ} \mathrm{C}$ ambient temperature the full engine power could be maintained using the chiller, while the power output would decrease by $\sim 10 \%$ without the chiller. The currently available alternative for high altitude locations or areas with frequent high temperatures would be to use a larger turbo charger. While a larger turbo charger would help to avoid the power rating decrease, it will also penalize the yearround engine efficiency by 0.3 points.

Overall, the absorption chiller poses and interesting option to maintain engine power output on hot days or at high altitude without using a larger turbo charger. Following this report the results will be presented to GE Jenbacher for review and discussion of followup activities. 
In case of implementation of absorption chillers there are a few takeaway points from the tests performed:

- The required backpressure on the engine to drive sufficient flow through the chiller is one of the most critical points that has to be determined early on. During the test there was always a little bit of extra backpressure necessary to provide sufficient exhaust gas flow. Also we have shown in the experiments that by locating the chiller on the roof of the container, next to the silencer may be sufficient to ensure chiller operations by eliminating the major portion of the line pressure loss and no backpressure necessary. Jenbacher would have to supply the value of the actual pressure available and in case that it is not sufficient including line and valve pressure loss the chiller generator would have to be redesigned. Locating the chiller next to the silencer would pose a significant heat load on the chiller.

- A discussion is needed to optimize the control strategy for the chiller. The current system is focused on maximizing chiller efficiency (based on exhaust heat consumption). Given that in some cases the exhaust heat is not used anyway it might be interesting to see if a stronger focus on minimizing the electric load or decreasing the cost of the chiller might be more beneficial.

- The experiment used a control valve to fine-tune the exhaust gas flow to the chiller. Given that the exhaust gas is not a scarce resource it might be sufficient to use a simple open-close valve instead. At the same time the allowable exhaust gas leakage rate has to be defined and the impact on the chiller of a given leakage rate determined. In case that the valve is closed a path for the liquid condensing out of the exhaust in the connection line has to be engineered.

- A more interesting alternative to an additional inlet air heat exchanger would be the option to use the existing intercooler on the J320.

- The chiller has to be checked to withstand weather over extended periods of time. Even though sold as a commercial product, one of the exhaust pipe was pointed upwards and might be prone to collect rainwater. 


\section{Task 12. Sorber Manufacturing Process Development and Reliability Testing (Complex Compound Absorption Technology)}

Complex compound sorber reliability is closely linked to the manufacturing process used and its consistency. Design for manufacturing considerations in the sorber assembly process were examined in this task. Manufacturing of sorbers includes impregnation of substrate, substrate cutting, stacking and sealing of the stack and sorber. This process development required mechanical design of experimental tooling capable of building prototypes in a rapid manner with highly repeatable results. The fabrication tooling developed included equipment made by outside manufacturers.

Sorbers fabricated with the process developments were tested on Rocky Researchô automated test apparatuses. The test apparatuses allowed the automated rapid absorption/desorption cycling of sorbers on a continuous basis. After several hundred cycles at increased thermal and mechanical stress levels, two test sorbers were removed and destructively disassembled. The structural integrity of the sorber internals, specifically the holding component, was examined. Two sorbers were assembled utilizing equipment developed in this Task. These were installed in a Design For Manufacturing (DFM) prototype and tested for performance and durability.

\section{Impregnation of substrate}

Uniform complex compound loading density within the sorber is an important parameter in achieving high refrigerant absorption and desorption rates and a durable vessel. Complex compounds are impregnated onto a substrate material to achieve this uniform loading density. This impregnation has been done manually in a time-intensive process in past projects. The manual impregnations result in high variation from batch to batch. Specialty impregnator machinery was developed and purchased by Rocky Research to cure substrate impregnated with various complex compounds in a continuous processing operation.

Once the material exits the oven portion of the impregnator, it is quite stiff. Large diameter rollers are used to preclude cracking the now brittle impregnated substrate. It passes over the top rollers and heads down to the take-up reel, passing through the drive rollers on the way. The drive rollers actually pull the fabric through the machine and can be adjusted over a wide range of speeds. The process is continuous and can run roll lengths of 800 linear feet. 
The impregnator was used with thirteen substrate rolls specifically for this project. The impregnations for this project were later die cut for the sorber assembly documented in this report to be used in the Task 5 packaged prototype. Each 50ft to $100 \mathrm{ft}$ long roll takes no more than forty minutes to be processed on the machinery.

The mass of salt in the open volume of the cloth, or loading volume, is the calculated product of interest. Table 11 shows the loading volume measured for the impregnator runs, with a target loading density of 0.5 grams of complex compound per cubic centimeter of open volume $(\mathrm{g} / \mathrm{cc})$. The loading densities with substrate \#1 were much lower than the target, but were consistent. The substrate was observed to be below the manufacturerôs lower tolerance on thickness, which limited how much complex compound could be loaded into the weave. Substrates \#2 and \#3 were from a different vendor and generated consistent results within $12 \%$ of the target loading density. For these two substrates, the mean loading density was $0.46 \mathrm{~g} / \mathrm{cc}$ or $8 \%$ lower than the target, with a range of $0.08 \mathrm{~g} / \mathrm{cc}$ between the minimum and maximum loading densities

\begin{tabular}{|l|l|l||l|l|l|}
\hline Impregnator results (0.5 g/ce Target Loading Density) \\
\hline Date & Substrate & $\begin{array}{l}\text { Complex } \\
\text { Compound } \\
\text { Loading Density } \\
\text { (g/cc) }\end{array}$ & Date & Substrate & $\begin{array}{l}\text { Complex } \\
\text { Compound } \\
\text { Loading Density } \\
\text { (g/cc) }\end{array}$ \\
\hline $9 / 9 / 2005$ & $\# 1$ & $0.44-0.47^{(1)}$ & $3 / 5 / 2007$ & $\# 2$ & 0.47 \\
\hline $10 / 10 / 2005$ & $\# 1$ & 0.44 & $3 / 9 / 2007$ & $\# 3$ & 0.44 \\
\hline $9 / 5 / 2006$ & $\# 1$ & 0.40 & $3 / 23 / 2007$ & $\# 2$ & 0.43 \\
\hline $9 / 11 / 2006$ & $\# 1$ & 0.40 & $3 / 29 / 2007$ & $\# 2$ & 0.46 \\
\hline $9 / 20 / 2006$ & $\# 1$ & 0.43 & $6 / 4 / 2007$ & $\# 2$ & 0.48 \\
\hline $12 / 6 / 2006$ & $\# 1$ & 0.40 & $7 / 6 / 2007$ & $\# 3$ & 0.51 \\
\hline \multicolumn{7}{|l|}{} & $8 / 15 / 2007$ & $\# 3$ & 0.44 \\
\hline Manual impregnation results (0.55 g/cc Target Loading Density) & Sheet & $\begin{array}{l}\text { Complex } \\
\text { Compound } \\
\text { Loading Density } \\
\text { (g/cc) }\end{array}$ \\
\hline Date & Sheet & $\begin{array}{l}\text { Complex } \\
\text { Compound } \\
\text { Loading Density } \\
\text { (g/cc) }\end{array}$ & & Date & 0.52 \\
\hline $7 / 2 / 2004$ & 116 & 0.52 & $7 / 2 / 2004$ & 126 & 0.53 \\
\hline $7 / 2 / 2004$ & 117 & 0.50 & $7 / 2 / 2004$ & 127 & 0.53 \\
\hline $7 / 2 / 2004$ & 118 & 0.53 & $7 / 2 / 2004$ & 128 & 0.57 \\
\hline $7 / 2 / 2004$ & 119 & 0.56 & $7 / 2 / 2004$ & 129 & 0.55 \\
\hline $7 / 2 / 2004$ & 120 & 0.56 & $7 / 2 / 2004$ & 130 & \\
\hline
\end{tabular}




\begin{tabular}{|l|l|l|l|l|l|}
\hline $7 / 2 / 2004$ & 121 & 0.54 & $7 / 2 / 2004$ & 131 & 0.58 \\
\hline $7 / 2 / 2004$ & 122 & 0.54 & $7 / 2 / 2004$ & 132 & 0.60 \\
\hline $7 / 2 / 2004$ & 123 & 0.54 & $7 / 2 / 2004$ & 133 & 0.62 \\
\hline $7 / 2 / 2004$ & 124 & 0.54 & $7 / 2 / 2004$ & 134 & 0.58 \\
\hline $7 / 2 / 2004$ & 125 & 0.53 & $7 / 2 / 2004$ & 135 & 0.57 \\
\hline
\end{tabular}

NOTES:

(1) With significant surface salt, the loading density varied significantly on this impregnation run.

Table 11 Loading Density Comparison of Impregnator and Manual Process

With manual impregnations, less than 40ft of substrate could be impregnated per day due to limitations on drying equipment. Just as importantly, Table 11 also shows the variability typically seen with manual impregnations, with a target loading density of $0.55 \mathrm{~g} / \mathrm{cc}$. The mean loading density for these manual impregnations was on target.

However there was a $0.12 \mathrm{~g} / \mathrm{cc}$ range between minimum and maximum loading densities. It can be seen that the variability is lower with use of the impregnator.

\section{Substrate cutting}

Impregnated rolls from the impregnator, shown in Figure 176, are next cut to form for the complex compound sorber. In the past, complex compound discs for single tube sorbers would be stamped by a punch and die on a hydraulic press, laser cut by a vendor, or stamped by a vendor. Multiple tube complex compound discs had to be laser cut or stamped by a vendor. These require a press with a capacity of more than 20 tons to punch one disc.

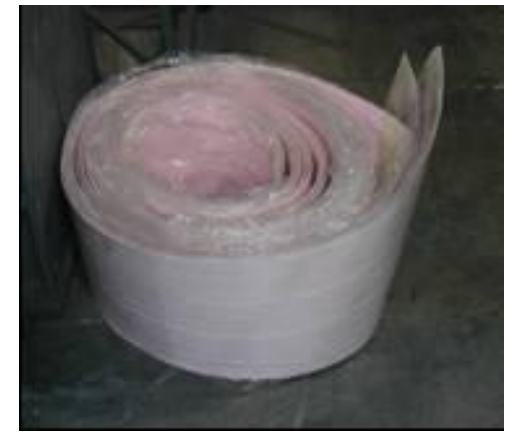

Figure 176. Impregnated Substrate

There are inherent issues with having the discs formed by a vendor. These include turnaround times of over two weeks and a need for tight control during shipment and processing to avoid moisture contamination. Complicating the issue are precautions needed to handle the complex compound, CC260-1260, used in this project and in Task 
5. Several vendors, unfamiliar with the inorganic salt, refused to quote processing the discs because of the handling precautions required. A laser cutting vendor was willing to process the discs; however the piece price for large quantities of discs is prohibitively expensive. So we investigated the equipment that would be needed to form a large quantity of discs inexpensively.

Nonmetallic material is often cut using a steel ruled die. A die maker was contacted and the steel ruled die was fabricated. An attempt was made to use a 12 ton hydraulic press with this die to punch discs. However, as was later determined, over 20 tons of force would be needed to punch this form. The die maker had successfully die cut the impregnated substrate with a rolling die cutter. A rolling die cutter was installed and is shown in Figure 177. Also shown in Figure 177 are the discs die cut with this equipment. 


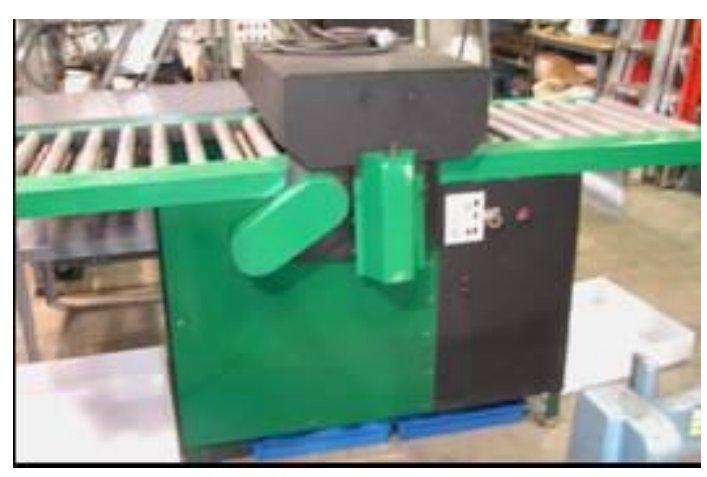

(a) Rolling die cutter

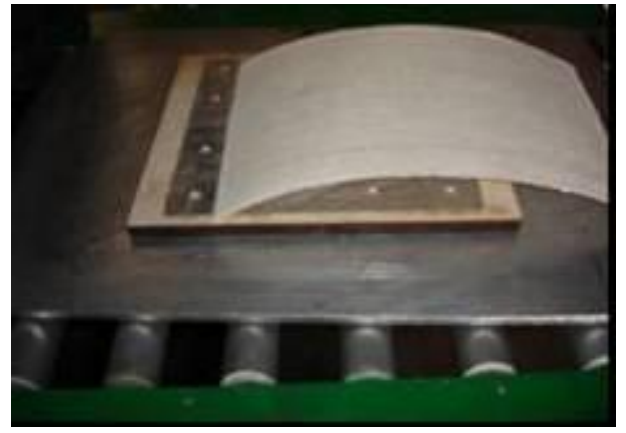

(b) Die, impregnated substrate, and cutting board on rolling die cutter

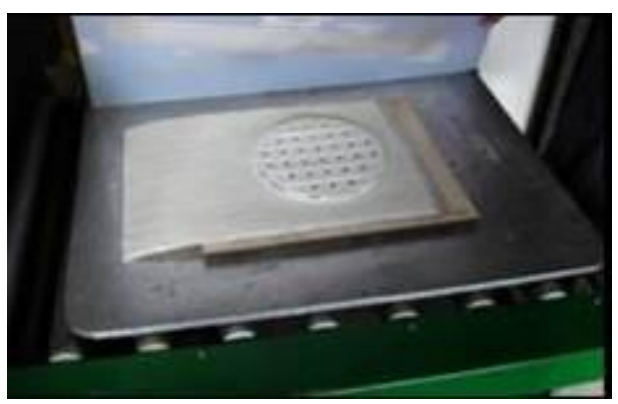

(c) Cut impregnated disc

Figure 177. Equipment and Process to Die Cut Impregnated Substrate Discs

Increasing the quantity of discs to production levels would require different die cutting equipment. Use of the rolling die cutter still requires an operator. Although far faster than previous processes, the rolling die cutter only cuts roughly 50 discs per hour. Rolling die cutter manufacturers were contacted to identify a means to automate the process. The consensus was that a clicker style press is better suited to automated die cutting. A consultant quoted the high speed hydraulic cutting press that would be required and demonstrated the capabilities with our die and material. This system feeds material from 
a payout roll through a cutting station and then separates the discs from scrap in a cut parts rewind station. An operator is required to load the impregnated substrate onto the payout roll and remove the scrap from the scrap rewind station. But the process is otherwise automatic. Based on sample cuts with our impregnated substrate and a two disc multiple tube sorber die, the consultant indicated that equipment can easily cut 240 discs per hour and possibly up to 480 discs per hour. An 80 ton model was recommended for some margin on the cutting force needed for two discs per cut, but a 60 ton press did demonstrate the capability to cut two discs per stroke.

\section{Stacking}

One of the more labor intensive steps in complex compound sorber assembly is the stacking of the impregnated substrate discs and heat transfer fins on the tubes inside the sorber. Over the past few years, we investigated the equipment needed to automate this process. A consultant was hired to develop a stacking station prototype. It was determined that a Selective Compliance Assembly (SCARA) robot arm and a single axis linear actuator could form the basis for this automation equipment. With the inclusion of a camera and vision system, vibratory bowl feeder, and Programmable Logic Controller (PLC) control, the process was automated. An initial prototype was developed to stack the internals for a simple sorber design. In this design, $2 \frac{1}{2}$ inch diameter discs and fins are stacked onto three $1 / 2$ inch diameter tubes.

The capabilities with varying impregnated substrates and varying stacking arrangements were examined. Using the prototype as a basis, the layout of a stacker for multiple tube sorbers was identified and quoted by a vendor.

The prototype assembly machine, or stacker, was designed to pick and place the heat transfer fins and impregnated substrate discs in alternating order onto three tubes. The stacker has also been programmed to stack two discs per fin. Sensors are positioned for parts presence information to the PLC. Momentary push button switches provide operational control. The PLC monitors sensors, feedback from the robot controllers, and switches from the operator interface panel to provide instructions to valves, the robot controllers, and to status lights and alarms. The robot controllers monitor inputs from the PLC and from sensors and execute predefined motion control profiles while energizing and de-energizing pneumatic valves for end effector control. Operation of the vibratory bowl feeder is controlled by the PLC. When the in-line track for heat transfer fins is not full, the bowl is turned on to feed fins to the SCARA robot. When sensors on the in-line track indicate that the track is full of fins, the bowl feeder is turned off. Figure 178 shows the key components of the stacker. 


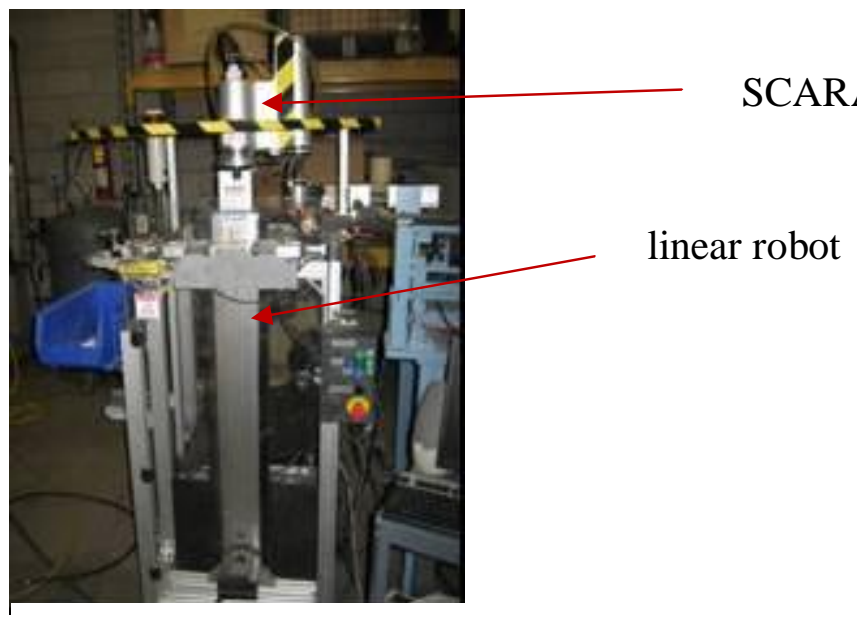

(a) robot assembly

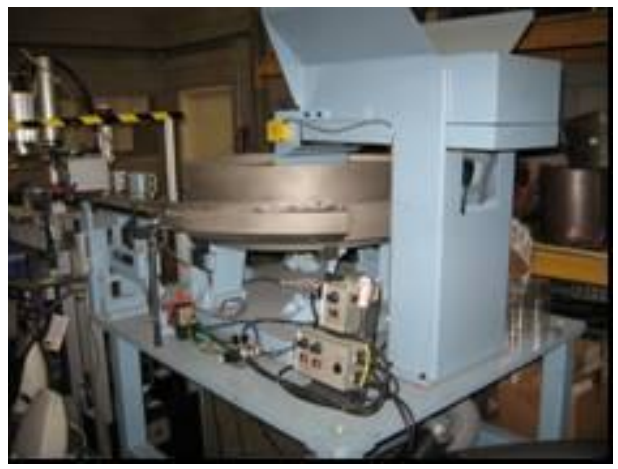

(b) vibratory bowl feeder

Figure 178. Prototype Sorber Core Stacker

For a twelve inch stack of fins and discs, the automated stacker completes a stack in approximately 20 minutes. Manually stacking the same length takes between six to eight hours. In addition to reduced assembly time, the uniformity of the stack along the length is greatly improved. This can be seen in Figure 179 in which a manually stacked core and a core assembled with the stacker are shown. Uniform force placed on the fins avoids any of the fin distortion seen in the manually stacked core. Control of positioning of every fin with the stacker ensures that the fin spacing is identical to design in cores assembled. Maintaining the fin spacing, while maintaining a speedy process has been an issue with manually stacked sorbers. 


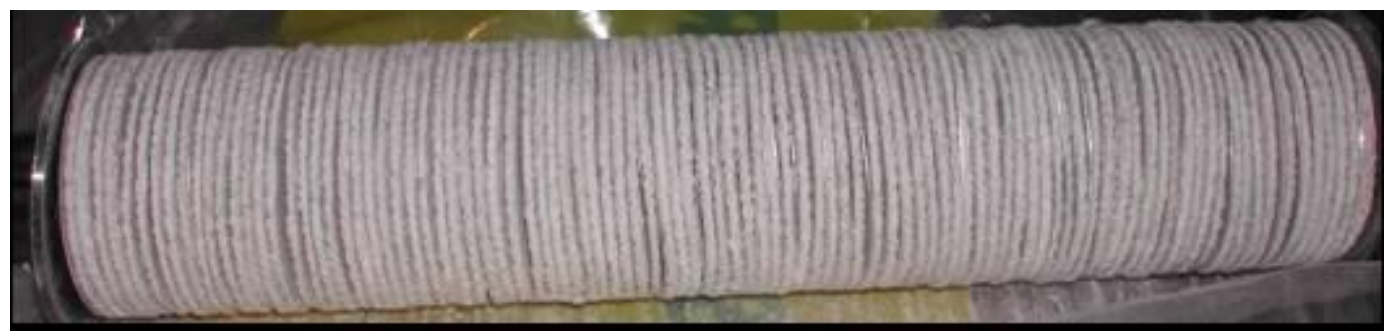

(a) manually stacked sorber core

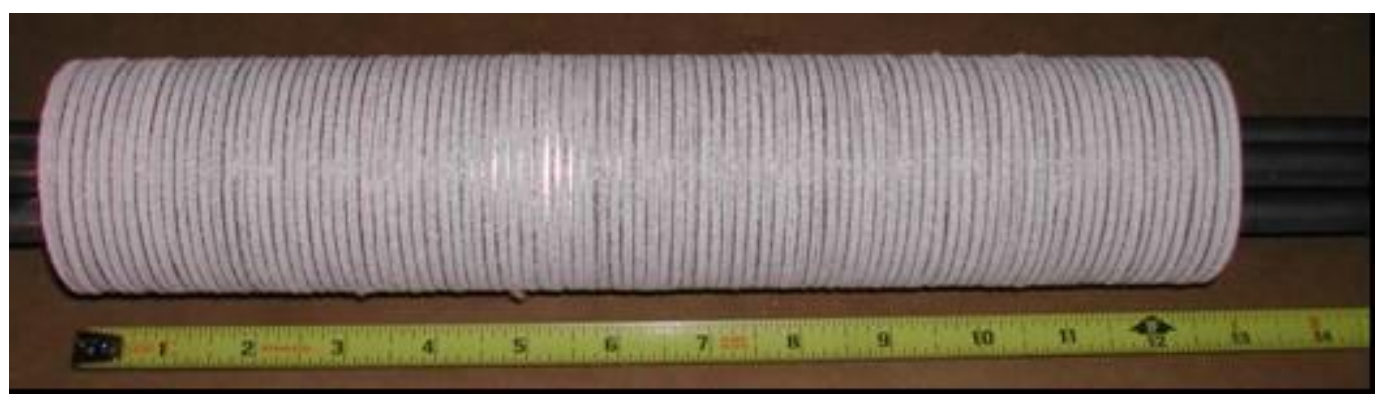

(b) sorber core stacked with automated stacker

Figure 179. Comparison of Sorber Cores Stacked Manually and With Automated Stacker

A vendor generated a preliminary design and quote for an automated stacker for multiple tube sorbers based on the lessons learned with the stacker. Views of this design are shown in Figure 180. This design does not differ significantly from the current automated stacker, so this is a very realistic design to automate the labor intensive process even with these more complicated sorber designs. 

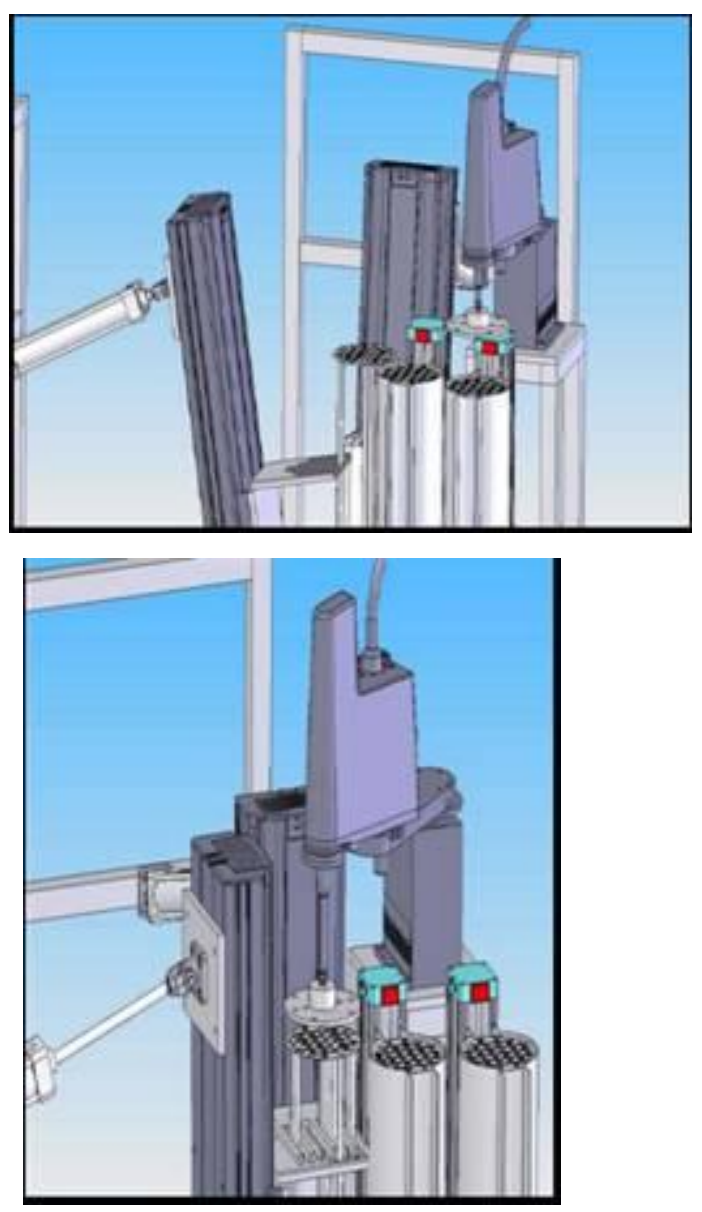

Figure 180. Multiple Tube Sorber Automated Stacker Schematic

\section{Containment sleeve}

A porous containment sleeve inside the sorber that permits ammonia flow to and from the complex compound but prohibits complex compound from escaping has been developed in previous projects. This sleeve is a braided composite sealant and braiding. A $1 \frac{1 / 2}{2} \mathrm{inch}$ diameter sleeve was cycled for over 1000 hours and found to maintain integrity. Larger 2 $1 / 2$ inch diameter sleeves have also maintained integrity in months of continuous duty. However, multiple tube sorber containment sleeves, for designs like that of the Task 5 system, had not been tested over several hundred cycles. As part of this sorber fabrication task, the durability of such larger diameter sleeves was evaluated.

A test multiple tube sorber of three inch length was assembled with the composite sleeve. This sorber was automatically cycled between absorption and desorption conditions on an automated test apparatus. The automated test apparatus consists of an ammonia 
evaporator vessel, or ligand column, with a sight glass that allows for accurate measurement of the liquid level within the vessel. Ammonia lines from the sorber are connected to the ligand column through a manifold of pressure regulators and needle valves, shown in Figure 181. Also shown in Figure 181 is the test sorber installed on the test apparatus. The mass of ammonia absorbed or desorbed by the sorber is recorded by a flowmeter and calibrated against ammonia liquid level changes in the ligand column. The ammonia pressure at which absorption or desorption occurs can be carefully controlled by the pressure regulators. Sorber and ligand column temperatures and pressures are recorded and output by the data acquisition system. With this test apparatus, ammonia flow rates at given evaporator or condenser temperatures and at a given sorber temperature are carefully measured.

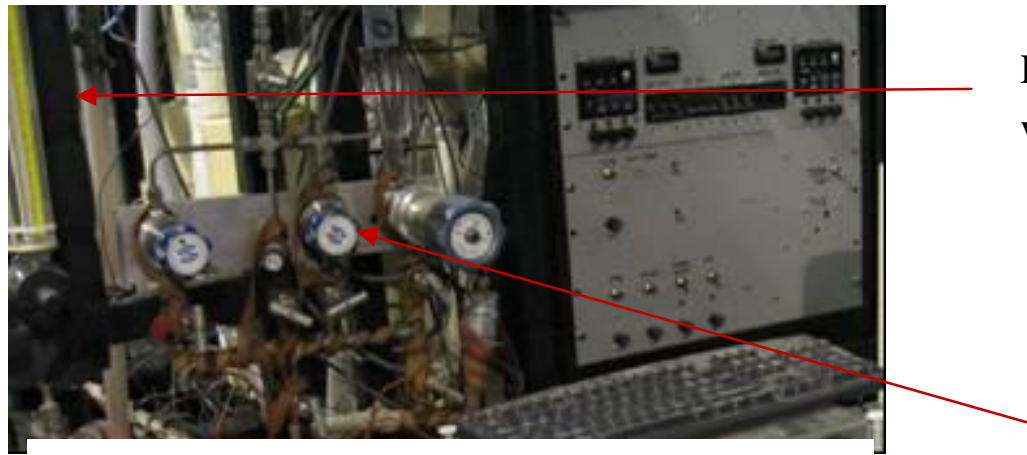

(a) Test apparatus pressure regulator manifold

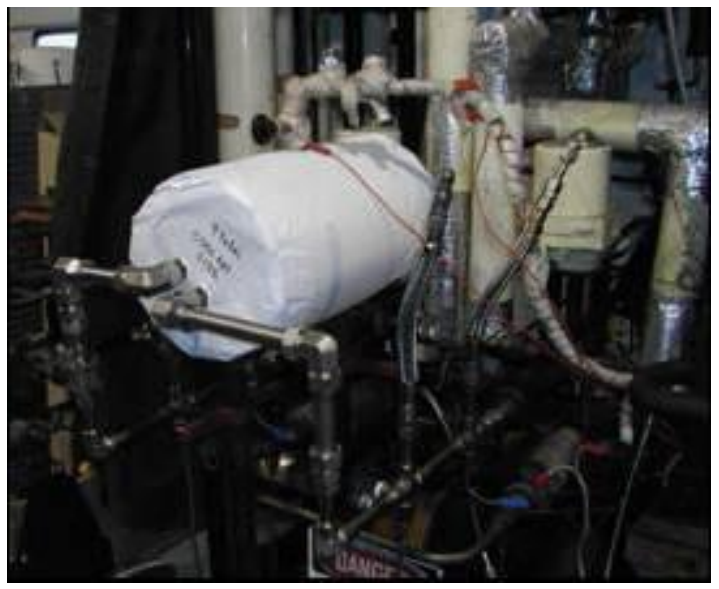

Ligand column

with sight glass

pressure

regulators

(b) Containment sleeve test sorber installed on test apparatus

Figure 181. Sorber Containment Durability Test Setup 
The test sorber was tested for over 1200 hours and 1100 absorption and desorption cycles. Ammonia flow rates were monitored for rate degradation. Based on ammonia flow rates, the sleeve appeared to remain intact after significant use.

The sorber shell was opened for destructive evaluation. A small quantity of complex compound was observed outside of the containment. However the containment was not the cause of the problem. An end fin for the stack had distorted, exposing a corner of a few salt discs. A view of this failure is shown in Figure 182. This test sorber did not have tie rods that are included in the Task 5 sorber and other multiple tube sorber designs. These tie rods restrain the endfin. The containment itself remained intact. However, the force of salt expansion appears to have swelled the sleeve outward. A $21 / 2$ inch diameter sorber was destructively examined. The containment sleeve for that sorber was also larger in diameter than when installed.

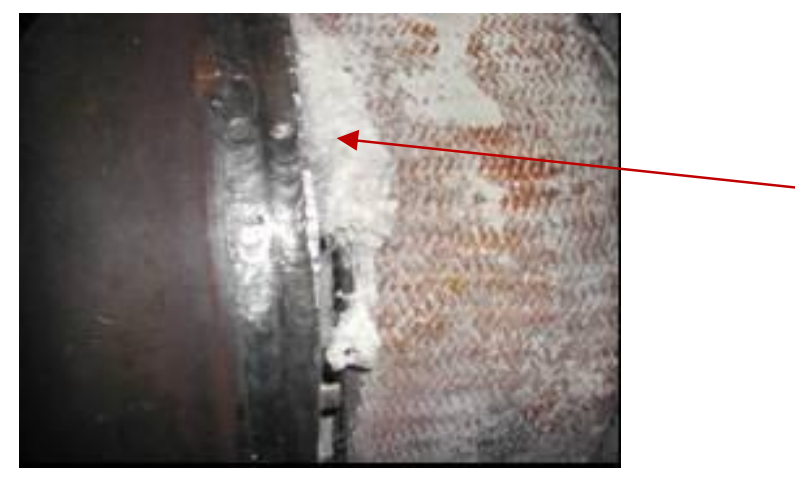

Endfin distorted and pulled away from sleeve exposing complex compound, which escaped from the containment

Figure 182. Composite Test Sorber Inspection

The swelling of the containment sleeve is a concern in that a gap may form between the outer of the fins and discs and the inside diameter of the sleeve. This path for complex compound movement could eventually lead to uneven loading density within the sorber and eventual failure. A swollen sleeve also restricts ammonia flow in the annulus between the shell inner diameter and the sleeve.

Because there is significant opportunity for inconsistent sealant application in the manual process, there is the possibility that uneven application contributed to a weaker sleeve on the test sorbers. A standard for application of the sealant, with metrics for sleeve rejection, was developed as a result. A stronger braiding for the sleeve was also considered. Vendors were contacted for wire reinforced cloth. These were not available in tube form. However, a much stronger braiding is available with carbon fibers. A $21 / 2$ inch diameter sample of this braiding was obtained. The epoxy process appeared to generate a stiffer containment. As will be described in the next section, this containment 
was installed on a test sorber using the assembly tools for impregnation, cutting, and assembly.

\section{Assembly using tools developed and reliability testing}

Two sets of sorbers were assembled using tools developed over the course of this task. One sorber from this group was also assembled with the carbon braiding sleeve. A second group of multiple tube sorbers were assembled from impregnations cut with the rolling die cutter. These sorbers are being assembled for testing in the Task 5 field prototype.

The impregnator runs with substrate \#3 were die cut with the rolling die cutter. Then the automated stacker stacked two of these discs for each heat transfer fin over a 12 inch finned length. A total of 108 discs were stacked at a spacing of 9 fins per inch. Two sorbers were stacked and are shown in Figure 183.

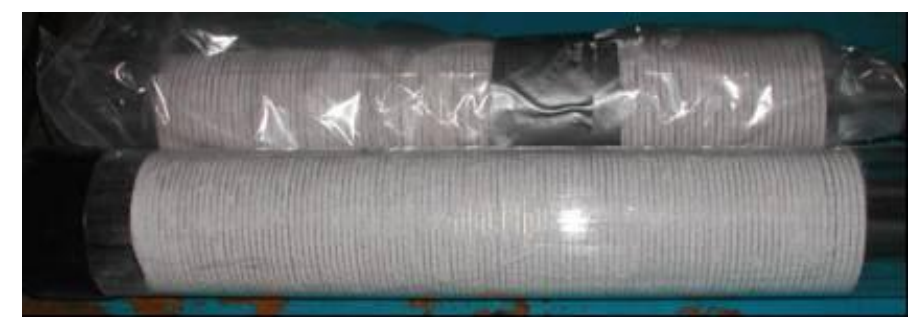

(a) internals after automated stacking

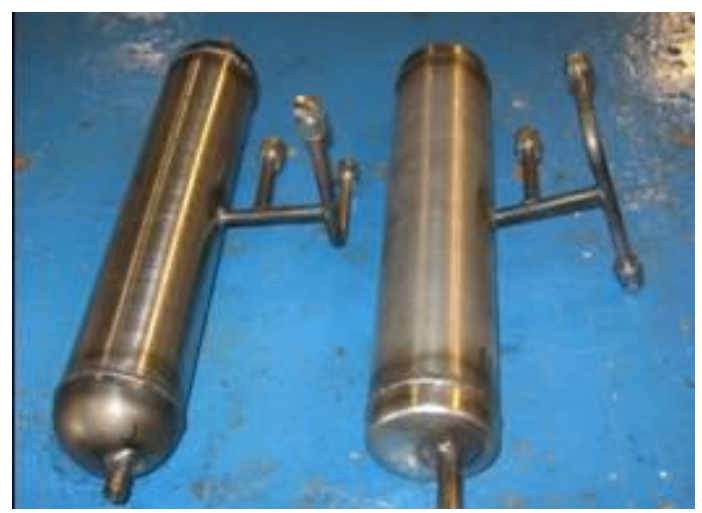

(b) sorbers after assembly and leak testing

Figure 183. Sorbers Built Using Impregnator, Rolling Die Cutter, and Automated Stacker

A third sorber was assembled using the impregnator, rolling die cutter, and automated stacker. In addition, this sorber utilized the carbon braiding containment sleeve. After assembly, this sorber was installed on a second automated test apparatus, nearly identical to the one described above. This sorber is show in Figure 184 installed on the automated 
test apparatus. It was cycled for over 650 hours, or 1300 cycles, of ammonia absorption and desorption.

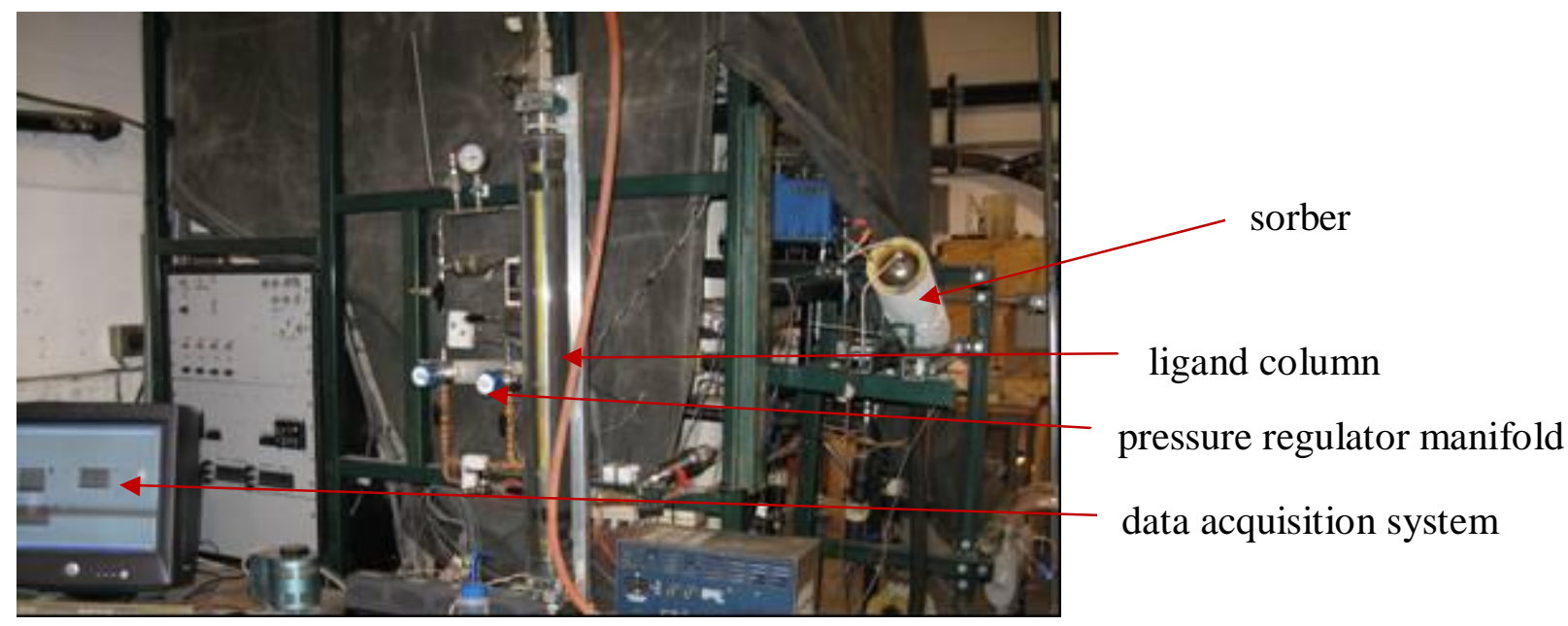

Figure 184. Sorber Assembled with Automated Tooling on Test Stand

Some degradation of ammonia flow rate was measured after 1200 cycles. The loss in the integrated ammonia flow over fifteen minutes was $8 \%$. The sorber was removed from the test apparatus and the shell cut open for a destructive evaluation of the sorber. The carbon braiding was intact. But the containment diameter swelled by as much as 0.016 inches. The swelling of the sleeve was uniform, not indicating local failure of the containment. With the swelling of the containment radially, this containment contracted in length, exposing $1 / 2$ inch length of complex compound discs on both ends. As a result, complex compound was observed outside of the containment. The containment test sorber internals are shown in Figure 185. 


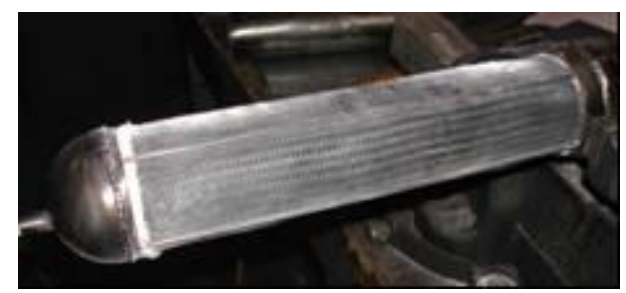

(a) internals after 650 hours
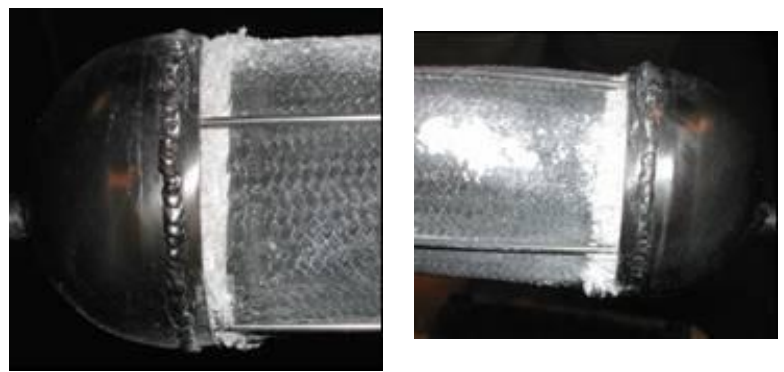

(b) exposed complex compound

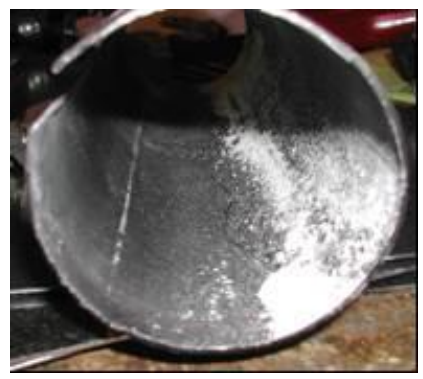

(c) complex compound observed outside of containment

Figure 185. Containment Test Sorber Destructive Evaluation

Two additional sorbers, shown in Figure 14, were assembled utilizing the tools developed in this project. These are multiple tube sorbers that were installed on the Task 5 field prototype. Both include complex compound discs die cut with the rolling die cutter. These were stacked manually. 


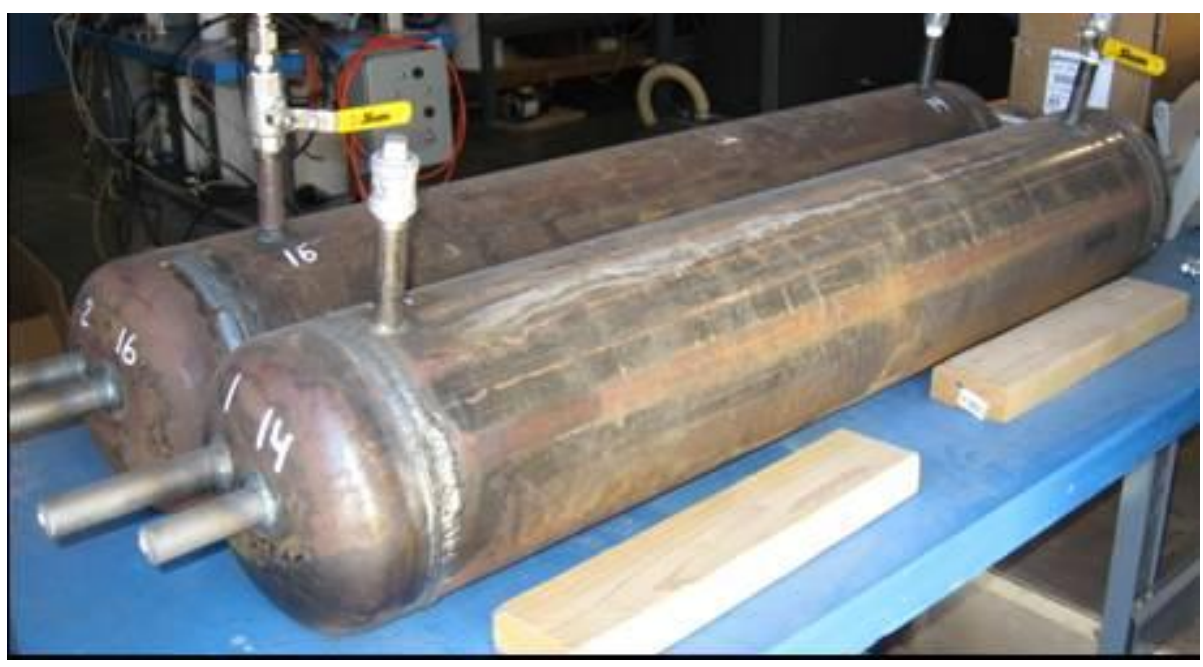

Figure 185. Multiple Tube Sorbers Assembled Using Impregnator and Rolling Die Cutter

\section{Conclusions}

Processes have been developed and tested over the course of this project to replace several manual processes in sorber fabrication and assembly. An impregnator increases the speed of impregnating substrate with complex compound and reduces the variation in complex compound loading density. The impregnator has been tested with several complex compounds and substrates.

The use of steel ruled dies and a rolling die cutter have enabled die cutting of single tube and multiple tube sorber discs. This capability has speeded the turnaround time in forming discs from substrate over past use of vendors. At production quantity levels, a high speed die cutter that utilizes a clicker press is recommended.

A prototype automated stacker has been assembled and tested to replace the labor intensive process of stacking the internals of a sorber. This equipment incorporates a SCARA robot, linear robot, vibratory bowl feeder, and vision system. The time to stack the internals reduces from at least six hours to less than twenty minutes. The automated stacker assembled is designed for a specific sorber design. However a design for other sorber configuration shows that modifying the concept for other automated stackers is possible.

Sorbers assembled from use of the automated equipment display a greater uniformity than ones manually assembled. In addition to increased quality of the assembled sorber, 
the time and labor needed to assemble a sorber are significantly less than what was required with manually assembled sorbers.

\section{Task 13. Evaluation of Energy Storage Systems Including Heat Activated Thermal} Energy Storage Systems (Aqua-Ammonia Absorption and Complex Compound Absorption Technology)

\section{Design, Fabrication and Laboratory Testing}

A meeting held with a telecommunications company to discuss loads and the use of a fuel fired aqua-ammonia chiller for cooling purposes during a power outage. Based on the results of this effort and a study commissioned by this company, it was decided to proceed with the construction of a low electric power consumption propane fired aquaammonia chiller to provide cooling for cell site installations during power outages.

Initial work focused on the fabrication of the components for the chiller, specifically the generator, absorber and rectifier. The generator used the improved configuration firetube with brazed fins. The generator was combined to with the absorber and rectifier and the associated interconnecting piping to form the GAR subassembly. This subsystem was then installed into the hydronic test apparatus for preliminary testing.

Figure 186 shows the GAR subsystem on test in the hydronic test chamber. The generator and absorber are shown with white insulation on them. The rectifier is the grey cylinder positioned between them near the top. The figure also shows the interconnecting tubing between the two components. 


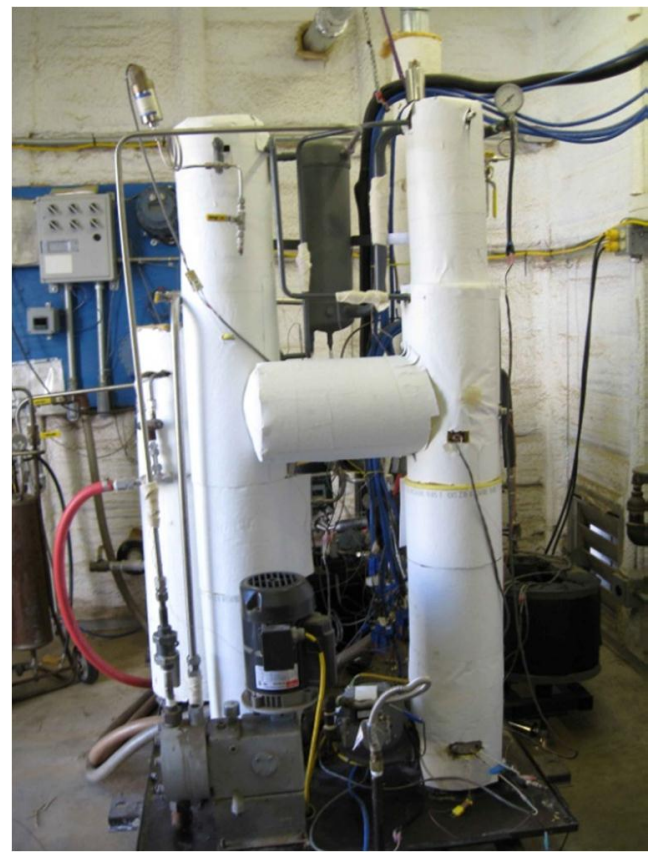

Figure 186. Generator, Absorber and Rectifier Subsystem Being Tested

Initial tests show excellent performance, with a COP of 0.719 and a capacity of 61,316 $\mathrm{Btu} / \mathrm{hr}$.

Subsequent to this initial component testing, the GAR subsystem was removed from the hydronic test stand and integrated into the chiller which was being assembled. Figure 187 is a photograph of the chiller during the assembly process. Shown are the GAR subsystem as well as the evaporator, subcooler, air coil on the base plate of the chiller. The solution pump is also installed, but is hidden in this photograph. 


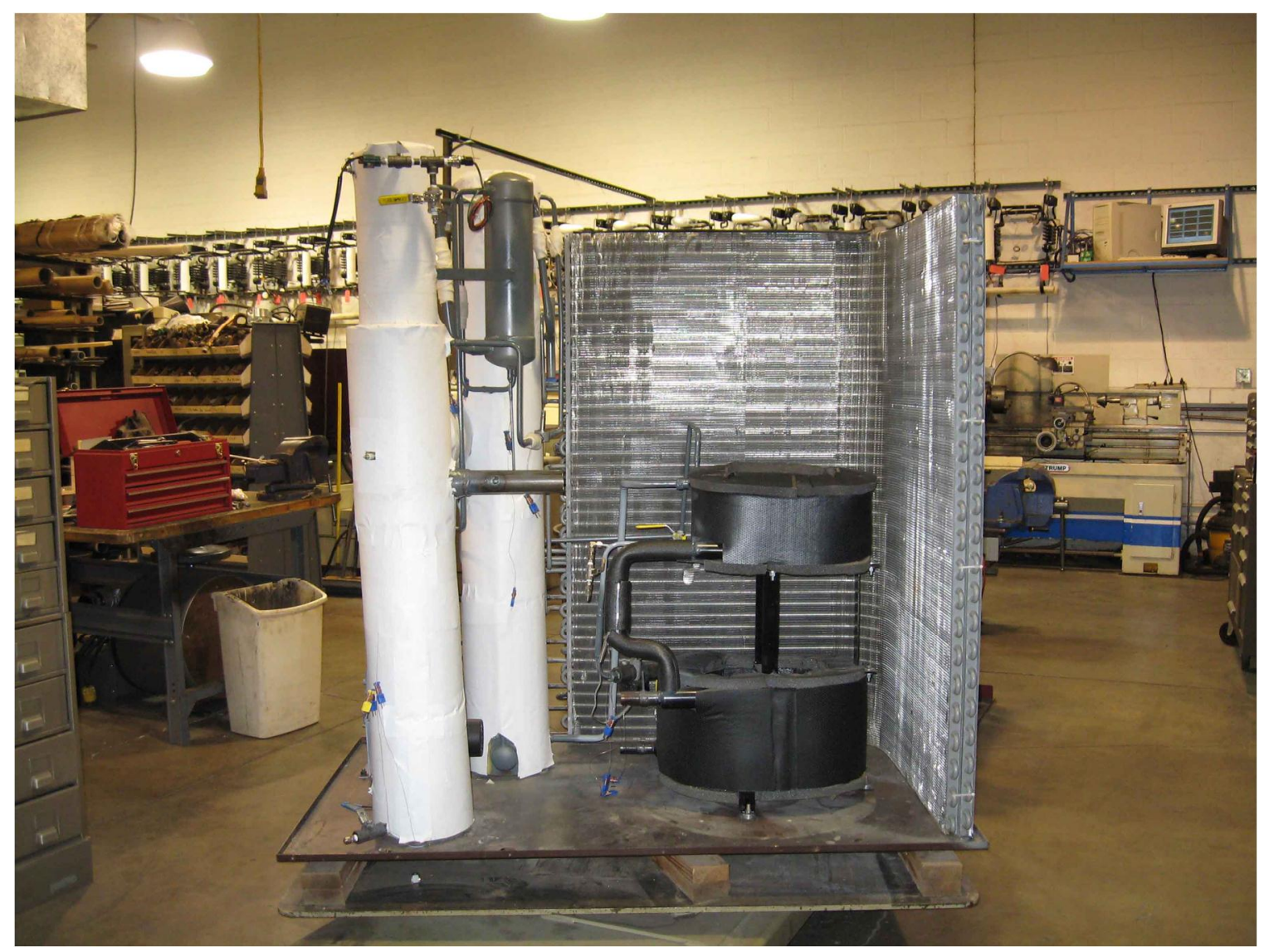

Figure 187. Partially Completed Chiller

The test chamber that simulates outdoor ambient conditions was modified to allow testing with propane. Three large propane tanks were added and the necessary purchased. Initial testing of the chiller was done with natural gas to establish baseline performance.

Controls for the chiller were tuned to operate the chiller near its desired (and derated) operating condition of approximately 40,000 Btu/hr output. Also, the fan speed was modulated to decrease fan power consumption dramatically. This increased the high side pressure somewhat over the nominal value at that firing rate.

Figure 188 show the results obtained during testing with natural gas. Figure 188 shows the capacity as a function of ambient temperature. Two different pump motors were used during this testing. One is a standard pump motor and one is a higher efficiency motor. It should be noted that the control strategy for this chiller is designed for minimized power consumption and therefore the cooling capacity does not increase significantly at lower ambient temperatures. 


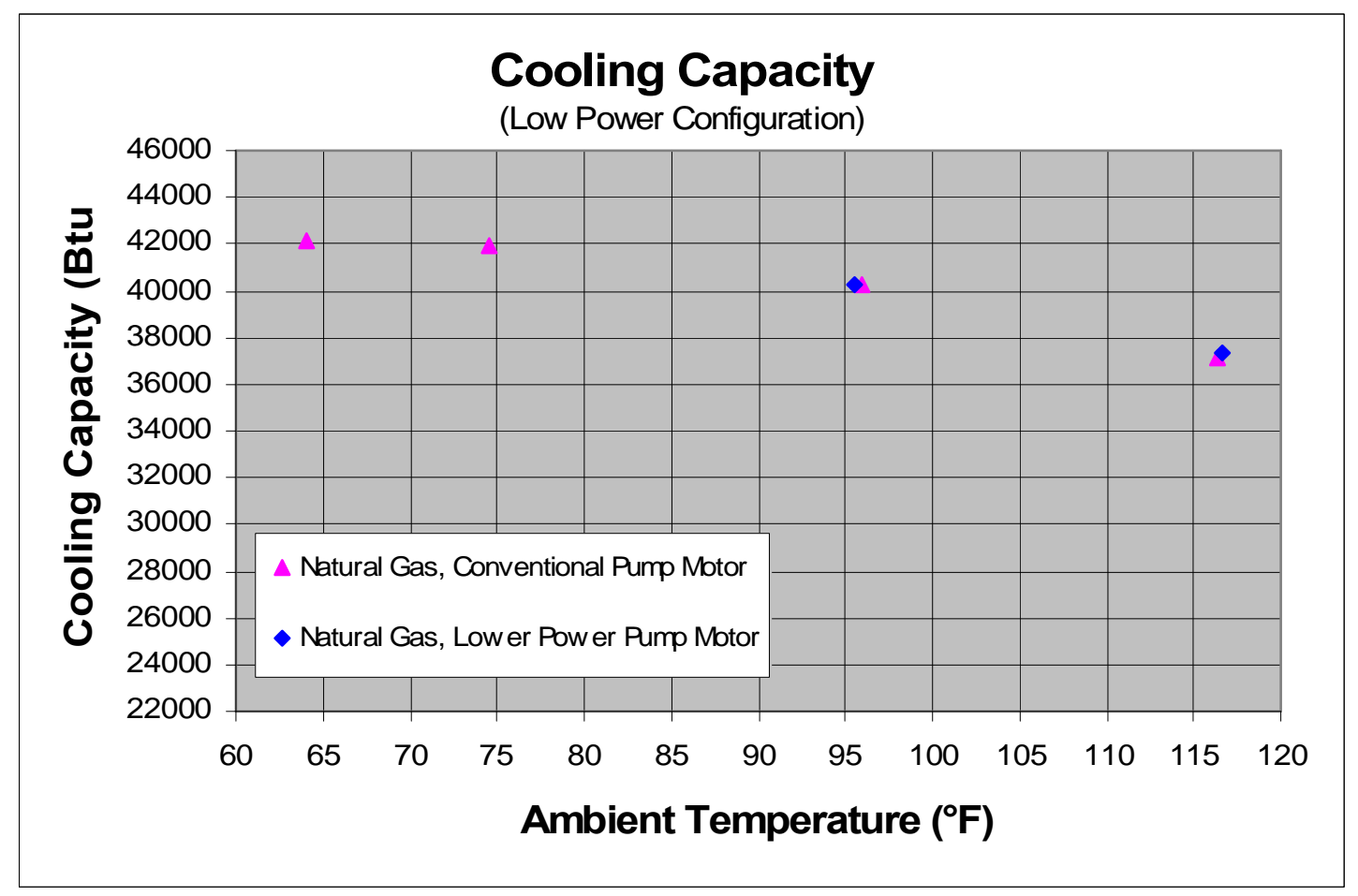

Figure 188. Capacity of Chiller Using Natural Gas

Testing of the chiller in the test chamber for the thermal storage application continued with a series of tests using stored propane gas for firing. The series of tests were conducted over a range of ambient temperatures, from $75^{\circ} \mathrm{F}$ to $116^{\circ} \mathrm{F}$ as well as a range of chilled water supply temperatures, from $50^{\circ} \mathrm{F}$ to $70^{\circ} \mathrm{F}$.

Figures 189 to 191 show the results of these tests. Figure 189 is the capacity as a function of ambient temperature for the three chilled water supply temperatures. As the figure shows (and would be expected), the capacity tends to decrease with increasing ambient temperature as well as decreasing chilled water supply temperature. 


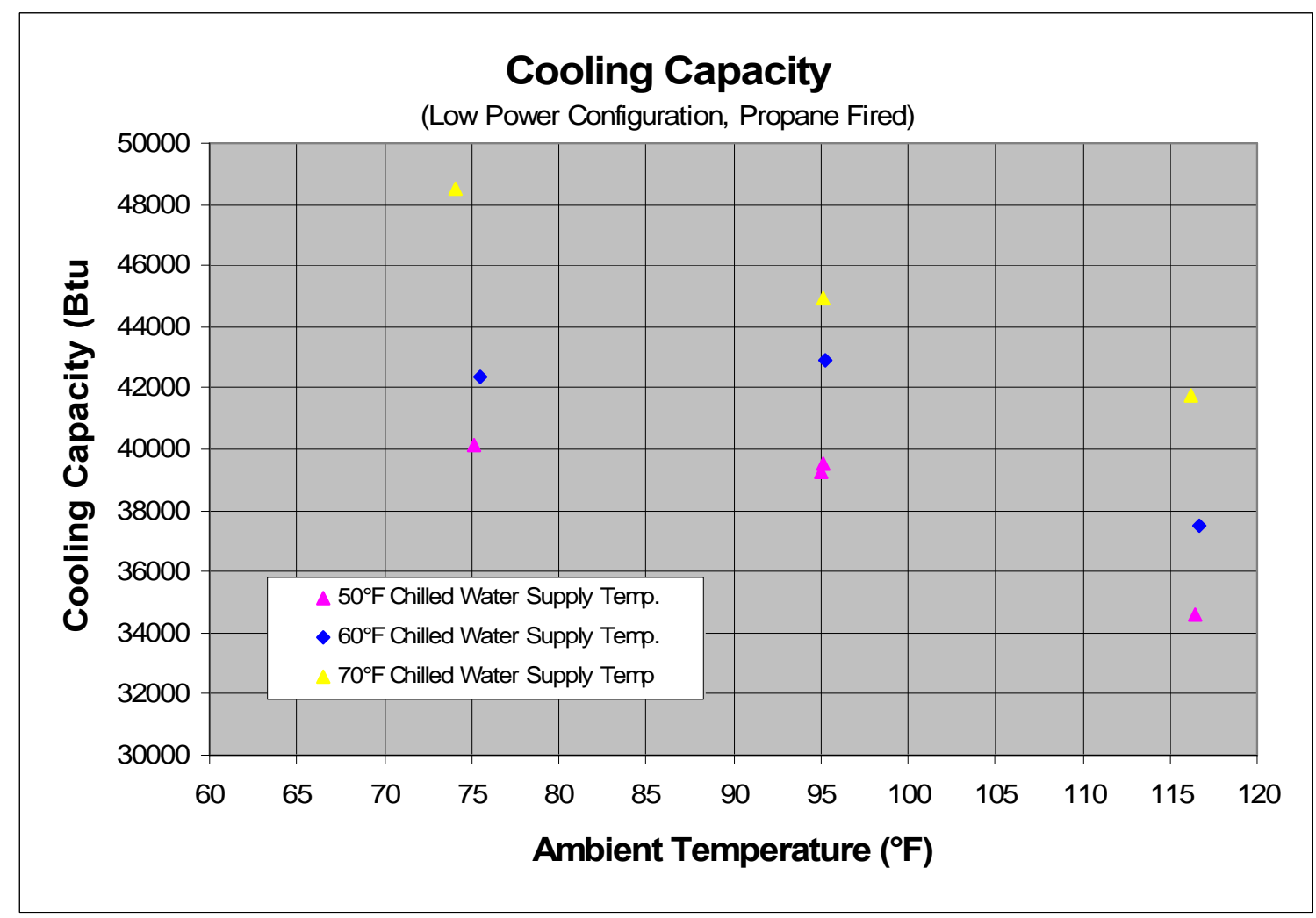

Figure 189. Capacity as a Function of Ambient Temperature and Supply Temperature

Figure 190 shows the associated COP also as a function of ambient temperature and chilled water supply temperature. The data shows decreasing COP with increasing ambient temperature and decreasing chilled water supply temperature. It should be noted that the chillerôs controller allows both the condenser fan and burner to modulate as needed to provide the desired chilled water temperature under each of the ambient conditions.

Figure 191 shows power consumption, again as a function of ambient temperature and chilled water supply temperature. As the figure shows, there is a dramatic decrease in power consumption with decreasing ambient temperature. However, even at the $95^{\circ} \mathrm{F}$ rating point, the power consumption for the chiller is only about $400 \mathrm{~W}$, which is very low. Also of interest is the fact that the power consumption is largely independent of chilled water temperature. This is an important result for a storage application since power will come from batteries and a lower chilled water temperature will allow lower indoor fan power for a given amount of heat transfer. 


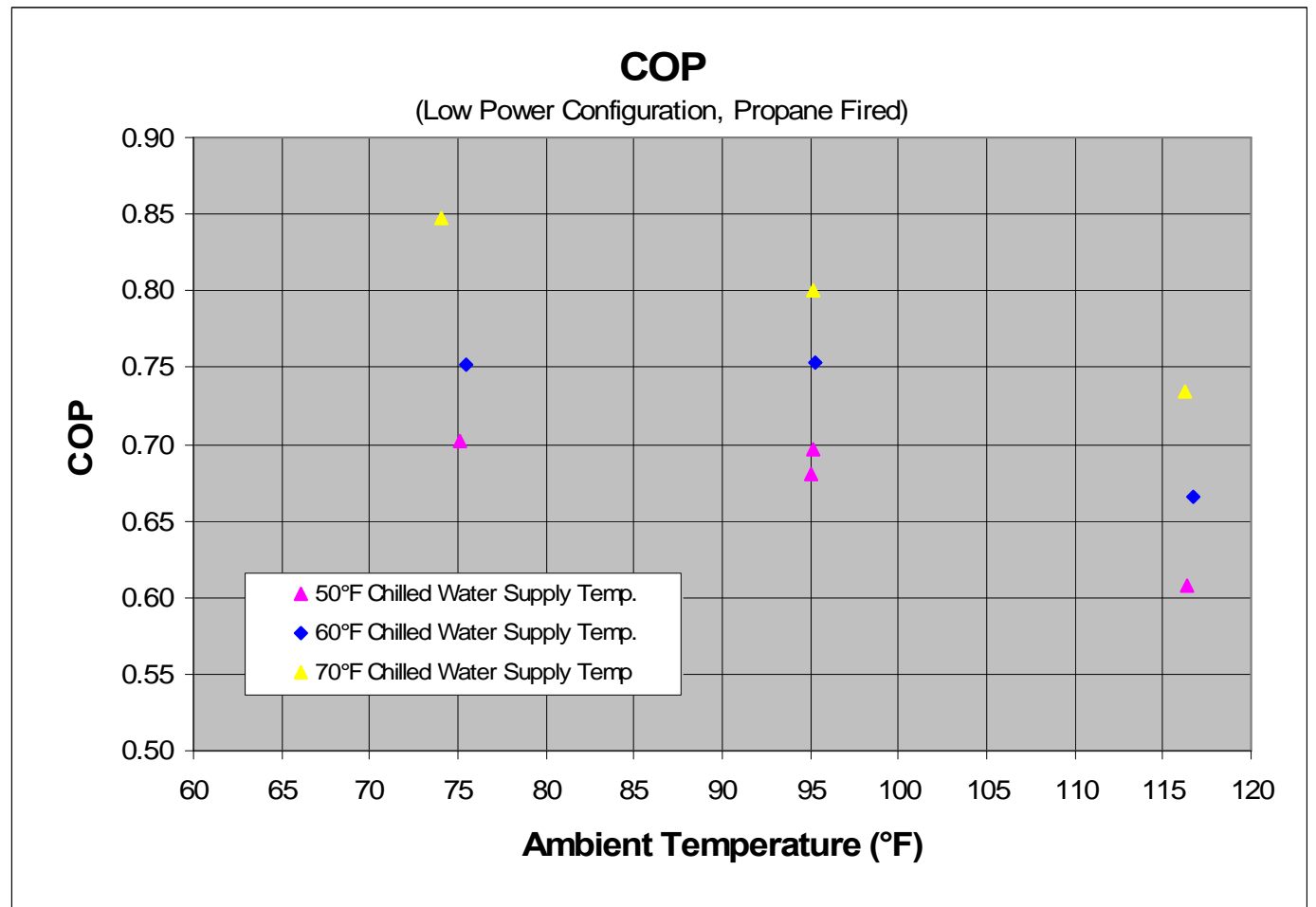

Figure 190. COP as a Function of Ambient Temperature and Supply Temperature

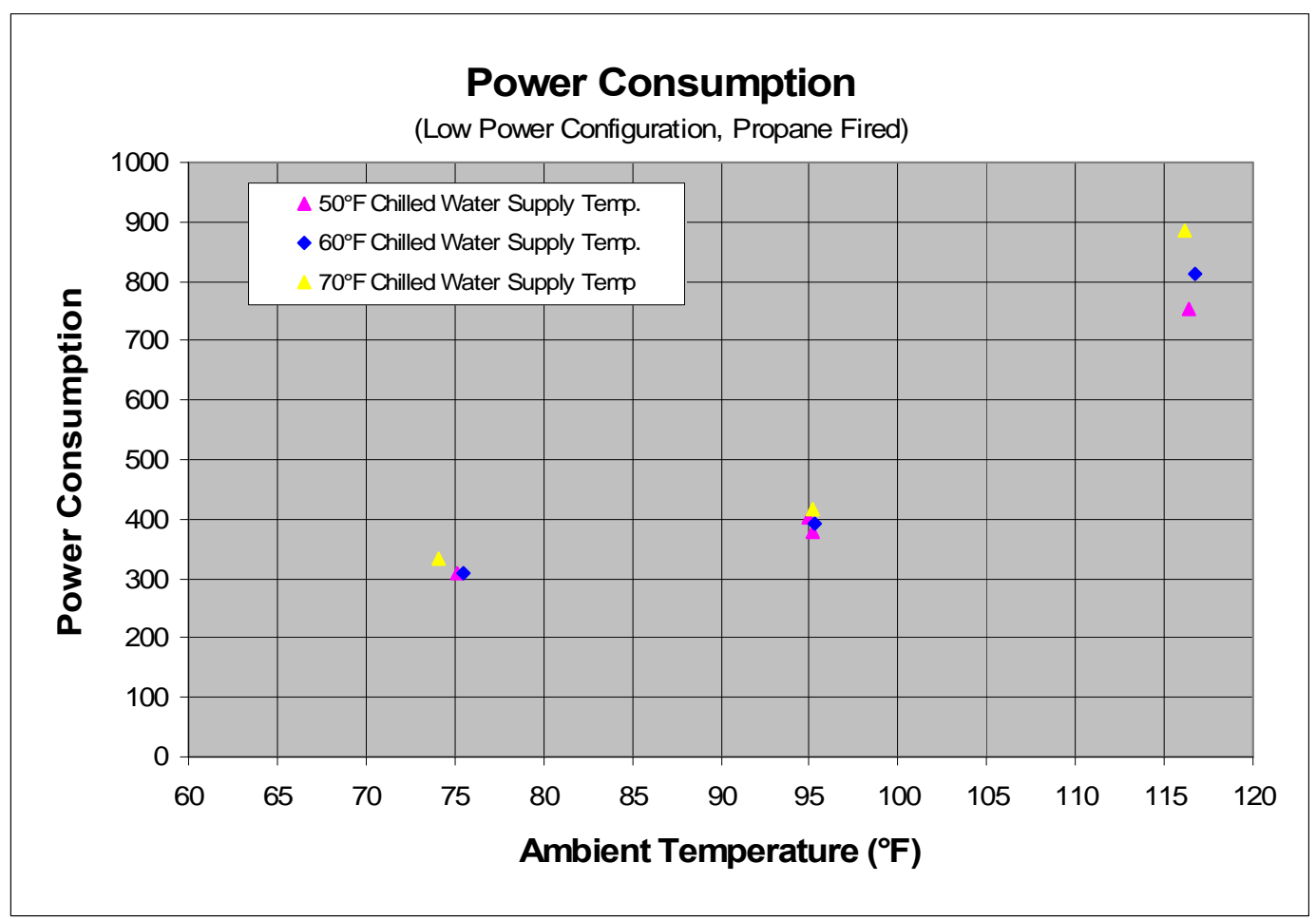

Figure 191. Power Consumption as a Function of Ambient Temperature and Supply Temperature 
Tests were conducted of the evaporator used in the chiller. The chiller was not operated at the time, since the only goal of the test was to determine pressure drop.

Figure 192 are the test results which show the pressure drop as a function of chilled water flow rate. All tests were conducted with pure water at temperatures in the range of $57^{\circ} \mathrm{F}$ to $62.4^{\circ} \mathrm{F}$. These results are readily scalable for different temperatures and concentrations of glycol/water solution. The data was curve fit with the following correlation derived from regression:

$$
\mathrm{dP}=0.06775 * \mathrm{Vol}+0.01082 * \mathrm{Vol}^{\wedge} 2
$$

Where:

$$
\begin{aligned}
& \mathrm{dP} \text { Ï pressure drop (psi) } \\
& \text { Vol Ï volumetric flow rate (gpm) }
\end{aligned}
$$

The $\mathrm{r}^{2}$ correlation coefficient for this curve was 0.99967 .

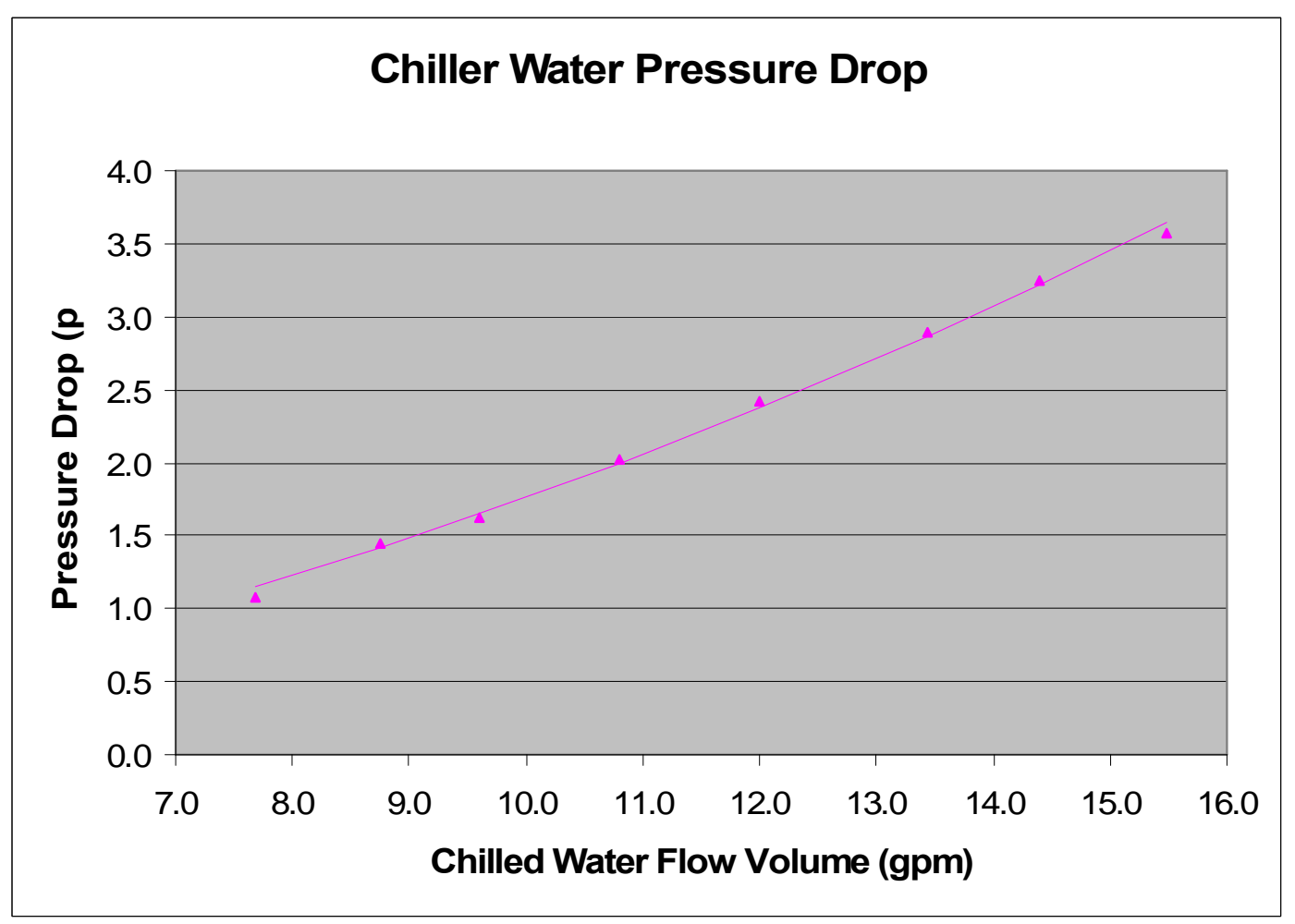

Figure 192. Evaporator Water Side Pressure Drop 


\section{Field Test Installation and Testing}

The chiller was delivered to a telecommunications station test site in Boulder City, NV and set in place. The goal of the installation was to determine performance of the chiller with propane firing as a means of providing the necessary cooling to the telecommunications station during times of power loss. This effort had corporate funding from the telecommunications company. Provisions for an indoor coil, instrumentation and power supply were made under the auspices of the operators of the host site.

Testing occurred in the August 2009 to October 2010 timeframe. The goal was to simulate a power outage with the subsequent air conditioning load in the shelter being taken care of by the then activated propane chiller. These tests assessed the performance of the low power consumption aqua-ammonia chiller driven by stored propane. The system also included a battery based power supply cabinet to produce electricity to run the electric power consumption components of the chiller.

Tests at the telecommunications shelter went exceedingly well. Shown on Table 12 is the data for only the day long tests that were conducted. Test durations ranged from $7.56 \mathrm{hr}$ to $9.17 \mathrm{hr}$ for these tests. With the modifications made to the chiller to allow for lower power consumption, the chiller and chilled water pump combined consumed only between 242 and 392 watts, the higher of which was during a hot August day in the Boulder City, NV (southern Nevada) location with an additional 5.6 KW of electric heaters added to the $2.4 \mathrm{~kW}$ load in the shelter, making this an extreme case load for such a shelter. It should be noted that the maximum ambient temperatures shown were in the location of the condenser coil, which was unfortunately impinged upon by the exhaust from the air conditioners of the adjacent telecommunications shelter, hence the extreme maximum ambient temperature of $140.9^{\circ} \mathrm{F}$ that was recorded for one of the data sets.

Long term propane consumption for the chiller was $1.66 \mathrm{lbm} / \mathrm{hr}$ at the baseline load for the shelter electronics and 2.17 and 2.18 with the addition of the $5.6 \mathrm{~kW}$ additional load in the shelter.

The system was capable of initiating reliably upon actuation by the thermostat and was able to control the shelter temperature without any threat of overheating the electronics, even in the most extreme temperatures tested. 


\begin{tabular}{|c|c|c|c|c|c|c|c|c|c|c|c|c|}
\hline \multicolumn{13}{|c|}{ Telecommunications Test Site Data Sets } \\
\hline & & & & & & & & & & & & \\
\hline & & & & & & & & & & & & Average \\
\hline & & & & & & \multicolumn{3}{|c|}{ Ambient Temperature -..... } & & & Chiller+Pump & Chiller+Pump \\
\hline \multirow[t]{3}{*}{ Date } & Description & Test Type & Load Information & Test & Test & $T \max$ & Tmin & Tavg & Propane & Avg Propane & Power & Power \\
\hline & & & & Duration & Duration & & & & Usage & Use Rate & Consumed & Rate \\
\hline & & & & $\min$ & $\mathrm{hr}$ & ${ }^{\circ} \mathrm{F}$ & ${ }^{\circ} \mathrm{F}$ & ${ }^{\circ} \mathrm{F}$ & $\mathrm{lbm}$ & $\mathrm{lbm} / \mathrm{hr}$ & W-hr & W \\
\hline $8 / 26 / 2009$ & Long time test, nominal electronics load & Day long & Baseline & 465.0 & 7.75 & 122.1 & 85.8 & 101.6 & 12.875 & 1.66 & 2153 & 277.8 \\
\hline $8 / 28 / 2009$ & Added load test, heaters turned on after unit fired (little consequence) & Day long & Added $5.6 \mathrm{~kW}$ to baseline & 453.5 & 7.56 & 140.9 & 85.9 & 101.9 & 16.45 & 2.18 & 2964 & 392.1 \\
\hline $10 / 7 / 2009$ & Long time test to determine performance with improved controls & Day long & Added $5.6 \mathrm{~kW}$ to baseline & 550.0 & 9.17 & 94.5 & 57.1 & 73.5 & 19.875 & 2.17 & 2221 & 242.3 \\
\hline
\end{tabular}

Table 12. Field Test Results for Day Long Tests 


\section{Ice Storage Using Aqua-Ammonia Chiller}

Efforts to evaluate the use of aqua-ammonia chiller technology to produce ice for thermal storage were initiated during the past month with the acquisition of a commercially available ice storage unit from Fafco under Rocky Research auspices.

Figures 193 and 194 show the tank which is installed beside the hydronic test chamber to allow good access for testing.

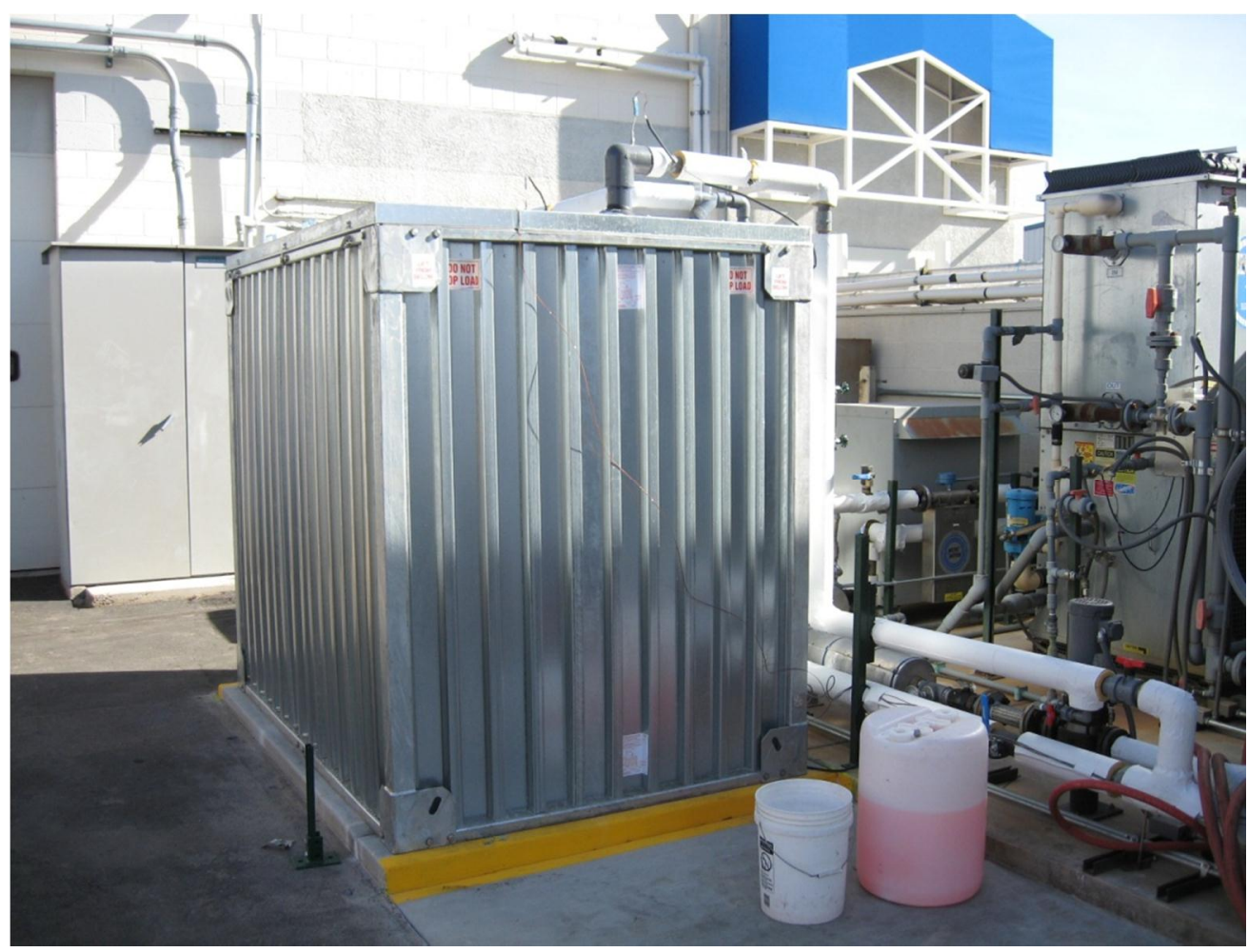

Figure 193. Photograph of Ice Storage Tank 


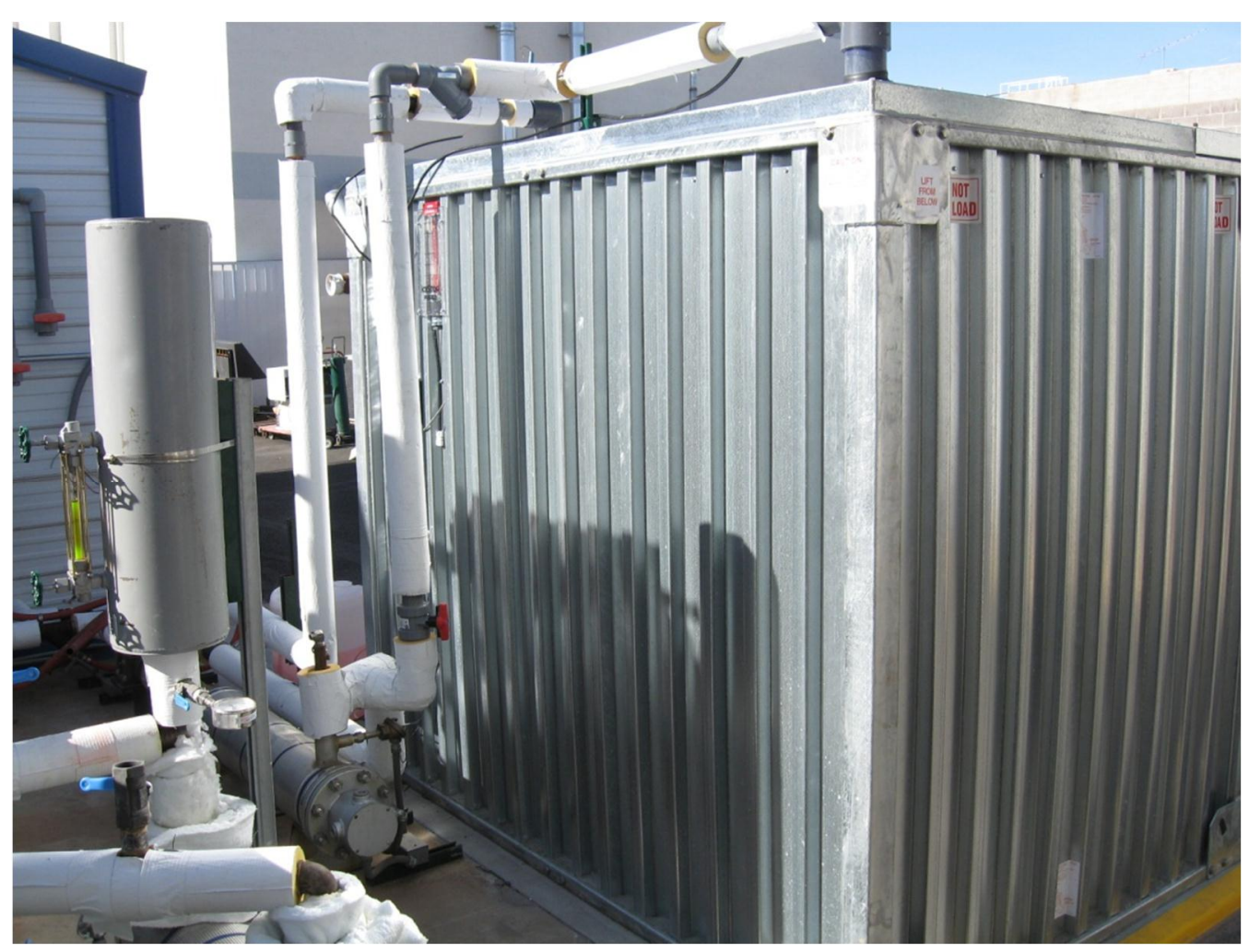

Figure 194. Photograph of Ice Storage Tank and Glycol/Water Piping

The tests were conducted to various levels of ice storage charge capacity to determine the chilled glycol temperature requirements as well as to determine chiller COP and capacity.

Preliminary results from these tests showed a capacity of approximately $42.5 \mathrm{kBtu} / \mathrm{hr}$ with a COP by gas of 0.49 . It should be noted that baseline tests with the generator used showed it to have lower than nominal performance so additional tests with a nominal generator would be required to better determine baseline performance.

A plot of performance of the system with an ice storage tank is shown in Figure 195. The figure shows a plot of inlet and outlet glycol temperature as a function of charge level in the storage tank. The cooling capacity of the test is less than the cooling capacity at the chiller due to a large chilled glycol pump which added heat to the loop. As the figure shows, even at charge levels of greater than $70 \%$, the glycol inlet temperature is well above $26^{\circ} \mathrm{F}$ and the outlet temperature is well above $30.5^{\circ} \mathrm{F}$. Also, there is only a decrease of approximately $1^{\circ} \mathrm{F}$ from the temperature observed at $10 \%$ charge level. Also of interest is the temperature depression required $\left(\sim 1^{\circ} \mathrm{F}\right)$ before ice starts to form on the surfaces. 


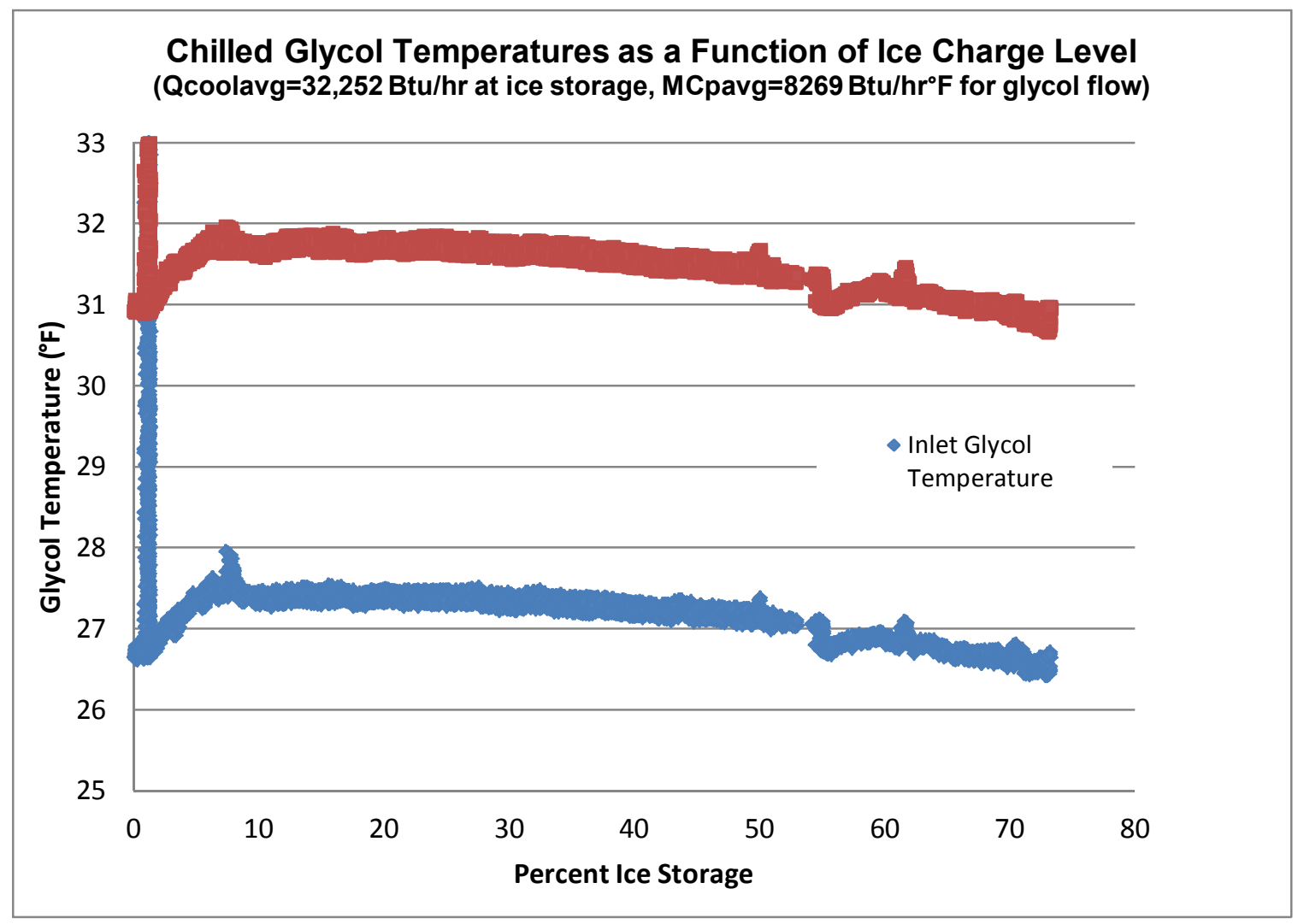

Figure 195. Chilled Glycol Temperature During Ice Storage Cycle

The results from this task show the aqua-ammonia technology to be compatible with two different modes of energy storage. Thermal energy storage, based on storable fuel (propane) was demonstrated in a laboratory setting as well as at a field test site. Thermal energy storage, in the form of ice, was shown to be possible by operating the chiller at low temperatures with a glycol loop to produce ice in an ice storage tank.

\section{References}

1. Andreone, Carl F. and S. Yokell, Tubular Heat Exchanger Inspection, Maintenance, and Repair, McGraw Hill, NY, 1998, pp 161-166.

2. MEGlobal Group, Ethylene Glycol Product Guide, 2005, p. 19. Retrieved from http://www.meglobal.biz/media/product_guides/MEGlobal_MEG.pdf on October 6, 2007. 